University of Tennessee Health Science Center UTHSC Digital Commons

\title{
8-2015
}

\section{Health-Related Quality of Life in Children with Cancer}

Tha'er Ghandi Almomani

University of Tennessee Health Science Center

Follow this and additional works at: https://dc.uthsc.edu/dissertations

Part of the Neoplasms Commons, and the Pediatric Nursing Commons

\section{Recommended Citation}

Almomani, Tha'er Ghandi , "Health-Related Quality of Life in Children with Cancer" (2015). Theses and Dissertations (ETD). Paper 12. http://dx.doi.org/10.21007/etd.cghs.2015.0010.

This Dissertation is brought to you for free and open access by the College of Graduate Health Sciences at UTHSC Digital Commons. It has been accepted for inclusion in Theses and Dissertations (ETD) by an authorized administrator of UTHSC Digital Commons. For more information, please contact jwelch30@uthsc.edu. 


\title{
Health-Related Quality of Life in Children with Cancer
}

\author{
Abstract \\ Health-related quality of life is an important phenomenon to measure in children undergoing treatment for \\ cancer. However, the effects of different treatment modalities and cancer related factors over the duration \\ of treatment have not been explored. To assess the effects of different child-, cancer-, and treatment- \\ related factors, we analyzed a large sample of children undergoing curative treatment for 5 different \\ childhood cancer diagnoses. These diagnostic groups were Hodgkin Lymphoma (HL), Acute \\ Lymphoblastic Leukemia (ALL), Acute Myeloid Leukemia (AML), Osteosarcoma (OS), and Melanoma. We \\ analyzed a sample of 710 patients across the five diagnostic groups over four time-points in treatment. \\ These time-points reflected significant clinical events that reflected change in the intensity or modality of \\ treatments. Our analysis identified significant changes across different diagnostic groups and over time \\ in HRQOL of children undergoing curative cancer treatments. Time in treatment was a significant \\ predictor of change in HRQOL, with children reporting higher HRQOL scores at the end of treatment in \\ comparison to the beginning of treatment. Demographic variables including age, gender, and race \\ predicted significant changes over time in children. Other treatment related variables including risk group \\ and surgery predicted change in HRQOL domains and cancerrelated symptoms in children undergoing \\ curative cancer treatment. Multiple cancer-related symptoms have been identified to significantly predict \\ HRQOL in children across the different diagnostic groups. These symptoms were also predicted by \\ different demographic, treatment, and cancer related factors. Some of these symptoms including pain \\ and hurt, and nausea did not regain the same level at the end of treatment in comparison to the beginning \\ of treatment, indicating residual effects of treatment on children with cancer even at the end of treatment. \\ Document Type \\ Dissertation \\ Degree Name \\ Doctor of Philosophy (PhD) \\ Program \\ Nursing Science \\ Research Advisor \\ Belinda N. Mandrell, PhD, RN. \\ Keywords \\ Health-Related Quality of Life, Longitudinal Studies, Pediatric Oncology \\ Subject Categories \\ Diseases | Medicine and Health Sciences | Neoplasms | Nursing | Pediatric Nursing
}

This dissertation is available at UTHSC Digital Commons: https://dc.uthsc.edu/dissertations/12 


\title{
Health-Related Quality of Life in Children with Cancer
}

\author{
A Dissertation \\ Presented for \\ The Graduate Studies Council \\ The University of Tennessee \\ Health Science Center
}

\begin{abstract}
In Partial Fulfillment
Of the Requirements for the Degree

Doctor of Philosophy

From The University of Tennessee
\end{abstract}

By

Tha'er Ghandi Almomani

August 2015 
Copyright $(\mathcal{C} 2015$ by Tha'er Ghandi Almomani. All rights reserved. 


\section{DEDICATION}

I dedicate this dissertation to the two women who made me reach this point in my life. To my mom, the one who inspired me and kept me on the right track for my $\mathrm{PhD}$, always supporting me and pushing me to achieve what she believed I could do. You're the reason I'm finally writing a dedication for my dissertation. For this, and for so much more and more, I'm grateful and thankful for the most wonderful mother a man can ever have.

To my wife Ban, who was always behind me in every step I took on this long road and supported me through the good and bad in these rough times. You helped me all the way handled the stresses I went through while still making my life as wonderful as it was. I love you. 


\section{ACKNOWLEDGEMENTS}

First and foremost, I would like to acknowledge the tremendous effort by my advisor, Belinda Mandrell. Your efforts and help have allowed me to reach this stage and to improve my abilities and skills as a researcher. I appreciate the continuous and honest feedback that allowed me to become a better researcher.

I would also like to acknowledge the continuous feedback and support from Dr. J. Carolyn Graff. You have been not just a mentor, but also my life couch for the last few years, and you have been doing a wonderful job at that.

Finally, I would like to acknowledge the tremendous support of the rest of my PhD committee members, Dr. Donna Hathaway, Dr. Patricia Cowan, Dr. Sheila Santacroce, and Dr. I-Chen Huang. 


\begin{abstract}
Health-related quality of life is an important phenomenon to measure in children undergoing treatment for cancer. However, the effects of different treatment modalities and cancer related factors over the duration of treatment have not been explored. To assess the effects of different child-, cancer-, and treatment-related factors, we analyzed a large sample of children undergoing curative treatment for 5 different childhood cancer diagnoses. These diagnostic groups were Hodgkin Lymphoma (HL), Acute Lymphoblastic Leukemia (ALL), Acute Myeloid Leukemia (AML), Osteosarcoma (OS ), and Melanoma. We analyzed a sample of 710 patients across the five diagnostic groups over four time-points in treatment. These time-points reflected significant clinical events that reflected change in the intensity or modality of treatments.
\end{abstract}

Our analysis identified significant changes across different diagnostic groups and over time in HRQOL of children undergoing curative cancer treatments. Time in treatment was a significant predictor of change in HRQOL, with children reporting higher HRQOL scores at the end of treatment in comparison to the beginning of treatment. Demographic variables including age, gender, and race predicted significant changes over time in children. Other treatment related variables including risk group and surgery predicted change in HRQOL domains and cancer-related symptoms in children undergoing curative cancer treatment.

Multiple cancer-related symptoms have been identified to significantly predict HRQOL in children across the different diagnostic groups. These symptoms were also predicted by different demographic, treatment, and cancer related factors. Some of these symptoms including pain and hurt, and nausea did not regain the same level at the end of treatment in comparison to the beginning of treatment, indicating residual effects of treatment on children with cancer even at the end of treatment. 


\section{TABLE OF CONTENTS}

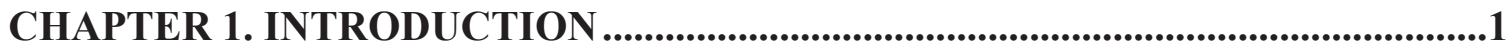

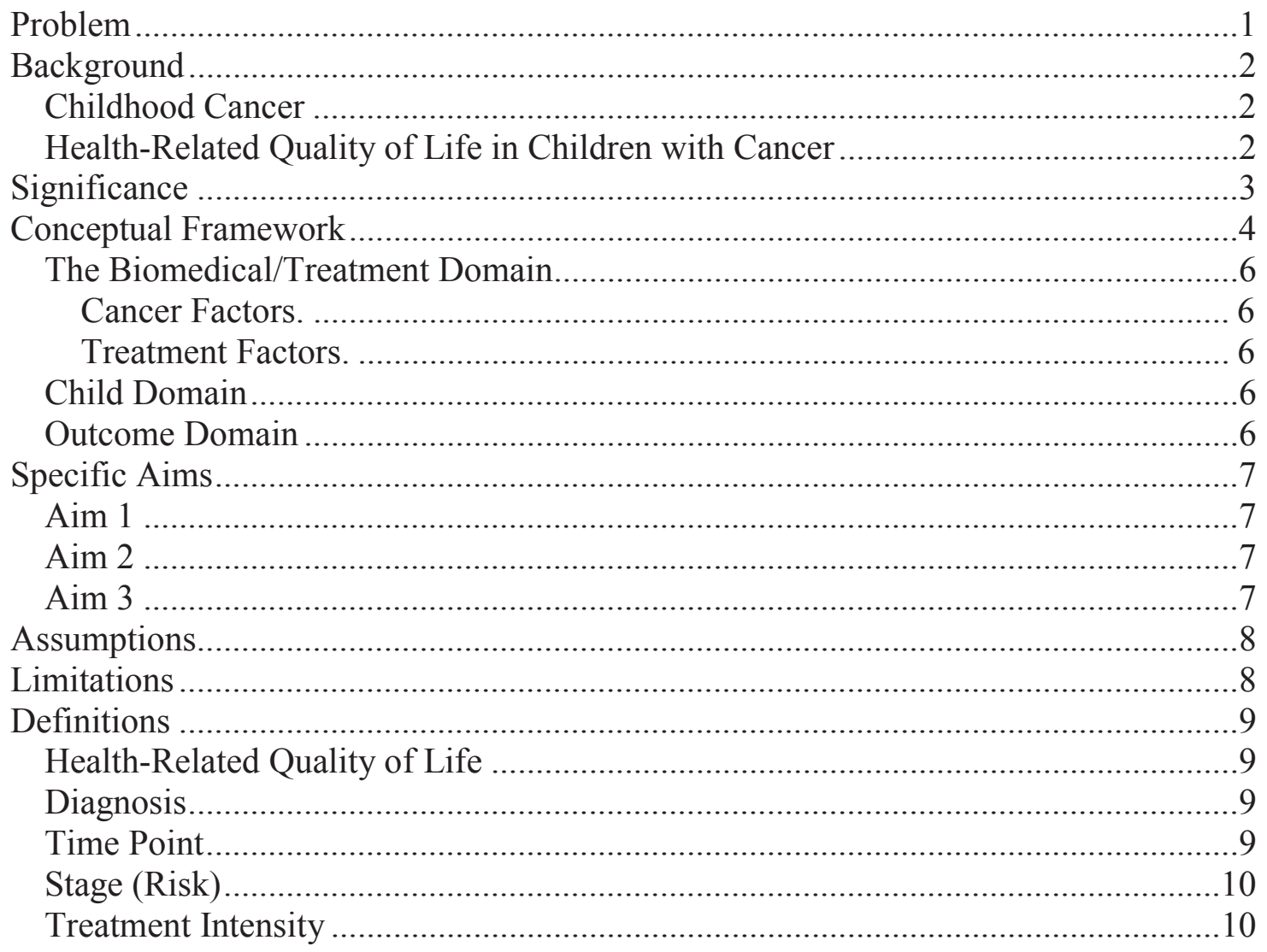

CHAPTER 2. REVIEW OF LITERATURE .................................................................11

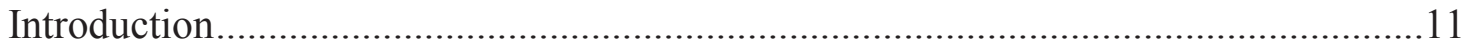

Quality of Life and Health-Related Quality of Life..................................................11

Factors, Measurement, and Conceptual Definition of HRQOL in Children with

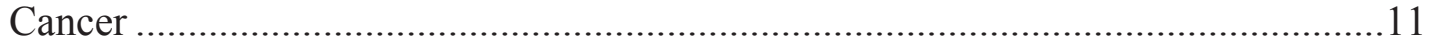

Types of Childhood Cancer Groups ....................................................................12

Acute Lymphoblastic Leukemia (ALL) ............................................................. 12

Acute Myeloid Leukemia (AML).................................................................. 12

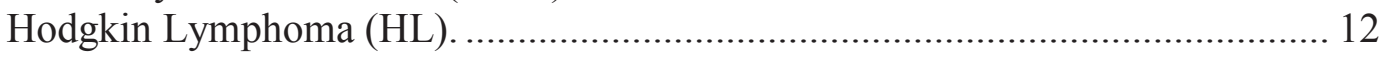

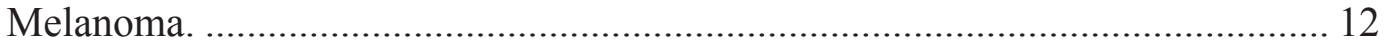

Osteosarcoma (OS) ....................................................................................... 14

Review of HRQOL Studies in Children under Cancer Treatment ................................15

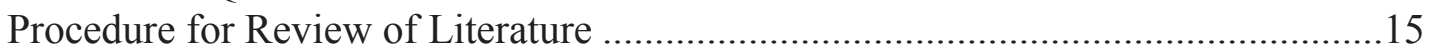

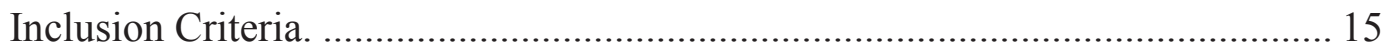

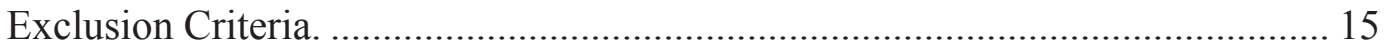

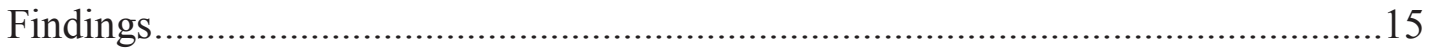

Cancer Factors Considered in the Systematic Review .............................................16

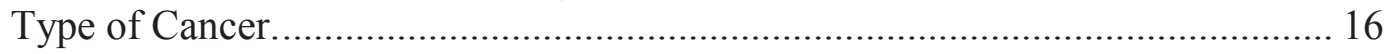




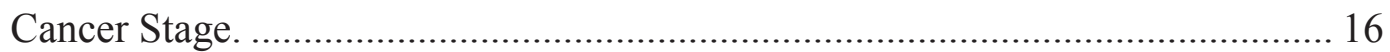

Treatment Factors Considered in the Systematic Review ......................................16

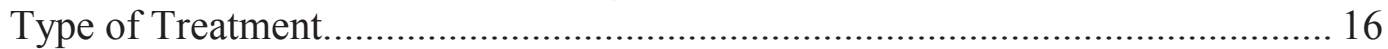

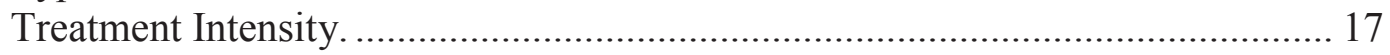

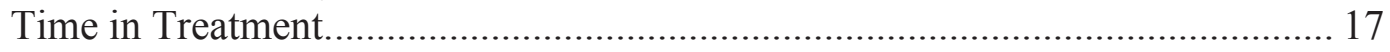

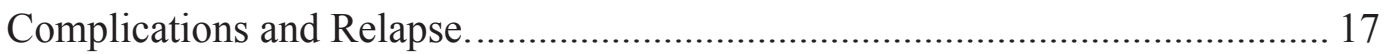

Child Factors Considered in the Systematic Review .......................................... 18

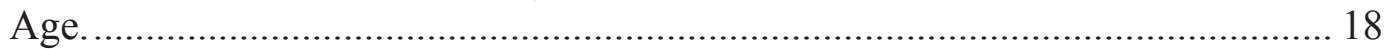

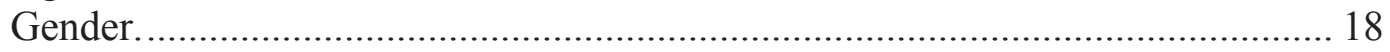

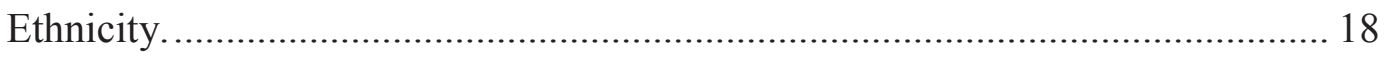

Family Factors Considered in the Systematic Review .........................................18

Community Factors Considered in the Systematic Review ....................................19

HRQOL Measurement Issues in Subject Studies ..................................................19

Conceptual Limitations of HRQOL Measurement ..................................................21

Conclusion from the Systematic Review of Literature ..........................................21

CHAPTER 3. METHODOLOGY ..........................................................................22

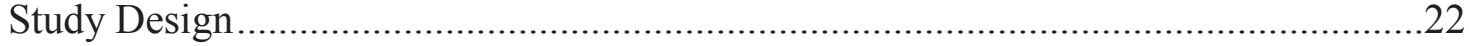

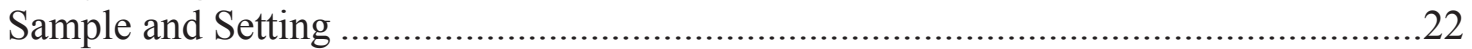

Acute Lymphoblastic Leukemia (ALL) ............................................................22

Acute Myeloid Leukemia (AML) .................................................................23

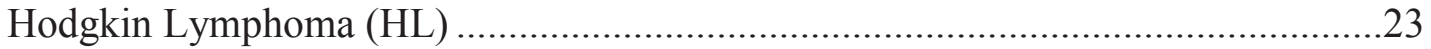

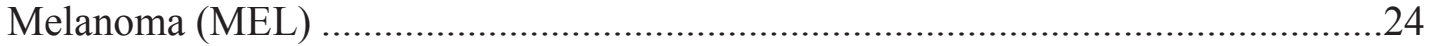

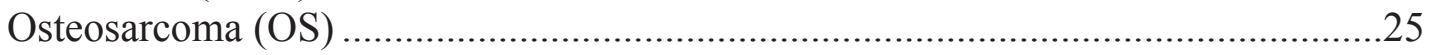

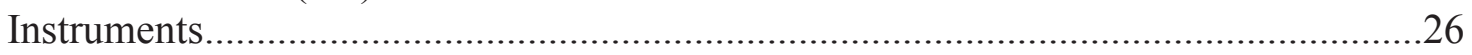

PedsQL Generic Core Scale (PedsQL-Generic) .................................................26

PedsQL Cancer Module (PedsQL-Cancer)............................................................27

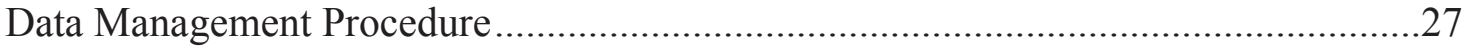

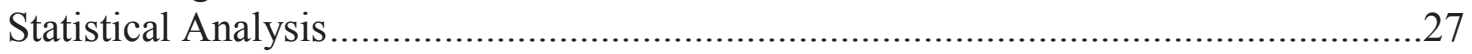

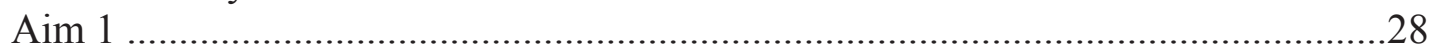

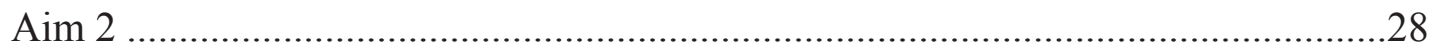

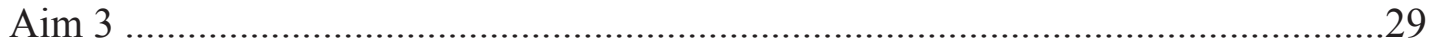

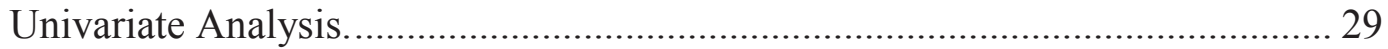

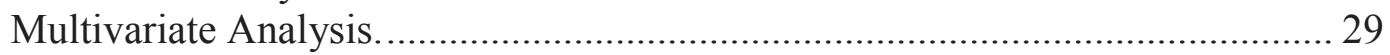

Human Studies Protection ...................................................................................... 30

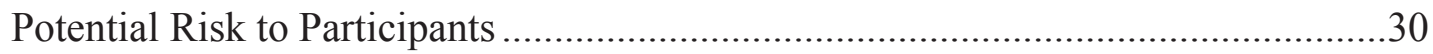

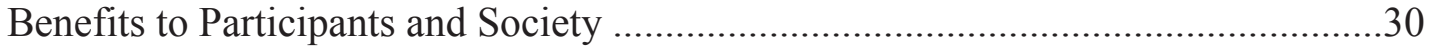

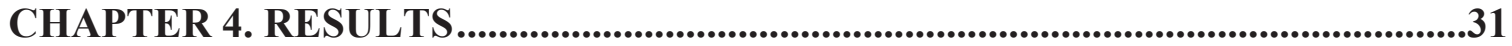

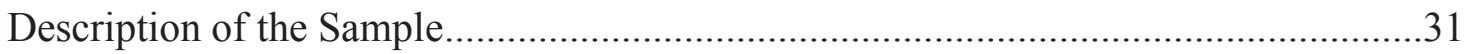

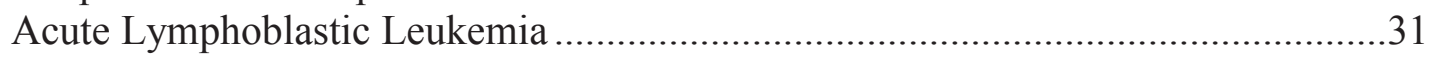

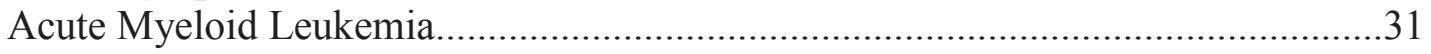

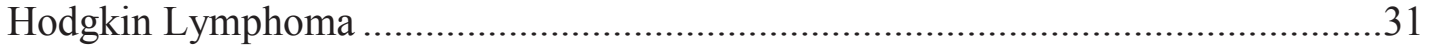

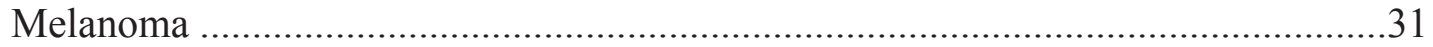

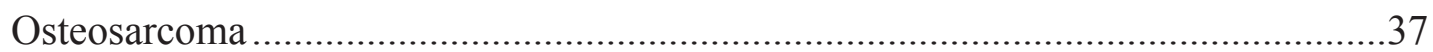

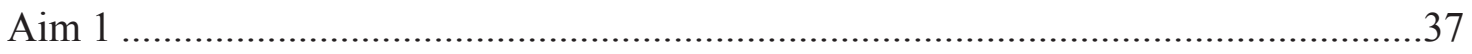




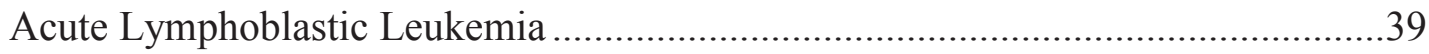

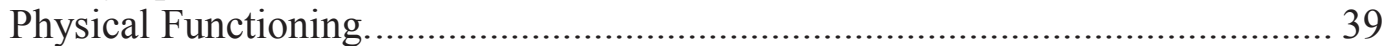

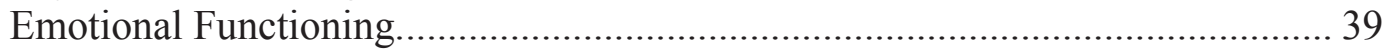

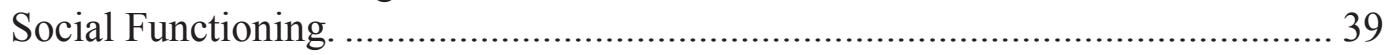

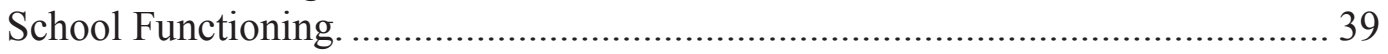

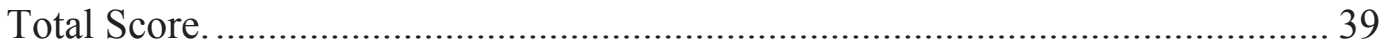

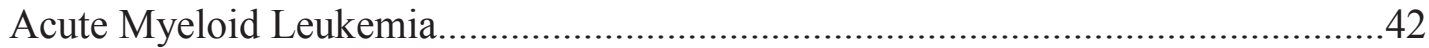

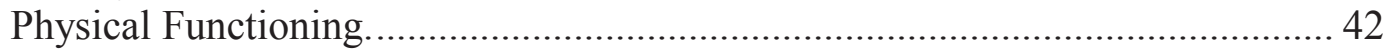

Emotional Functioning............................................................................. 42

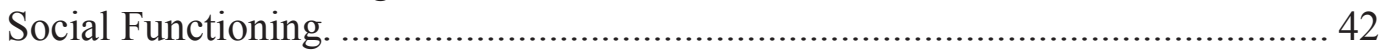

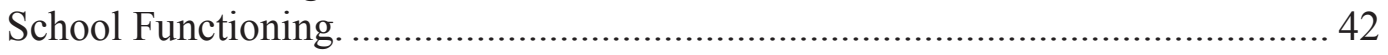

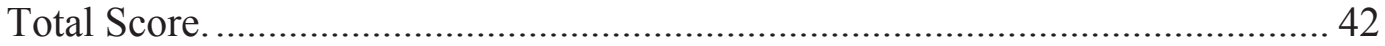

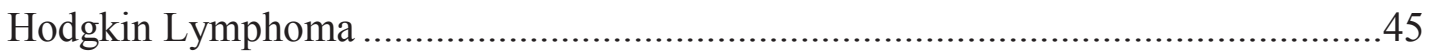

Physical Functioning ............................................................................. 45

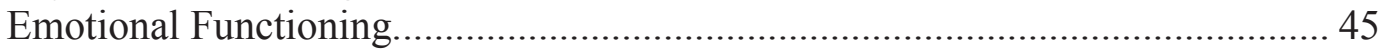

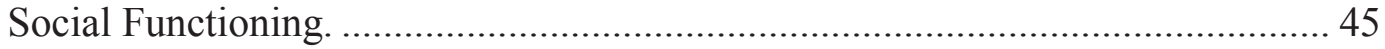

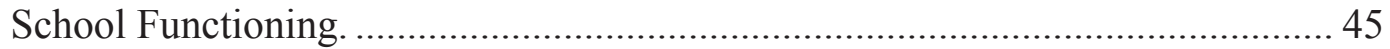

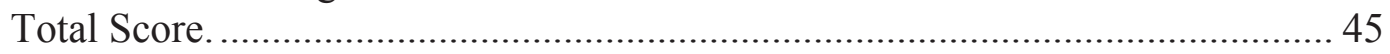

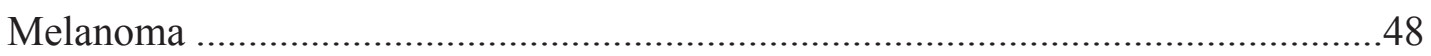

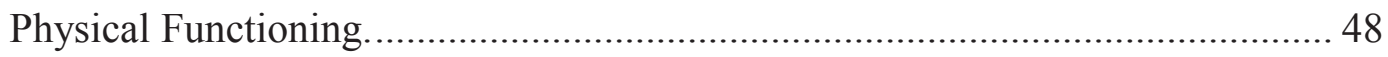

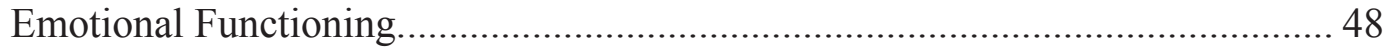

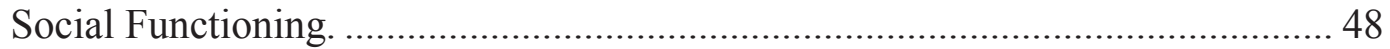

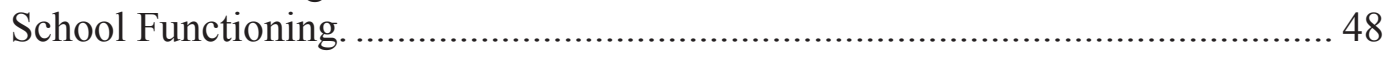

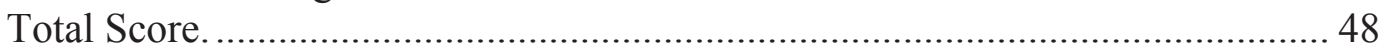

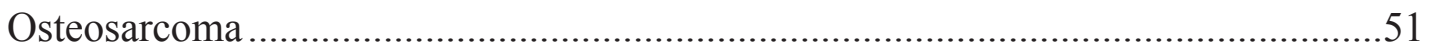

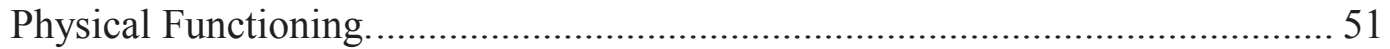

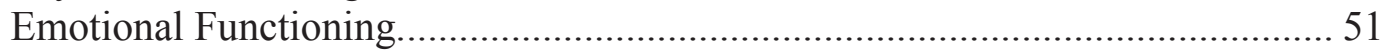

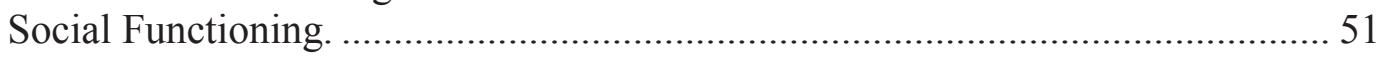

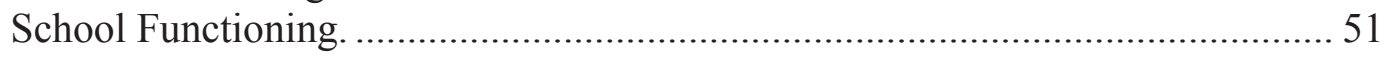

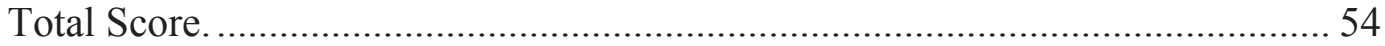

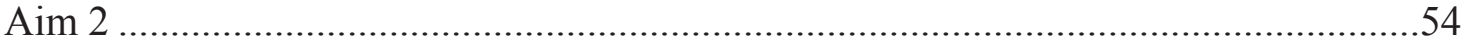

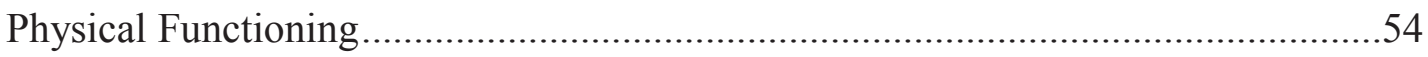

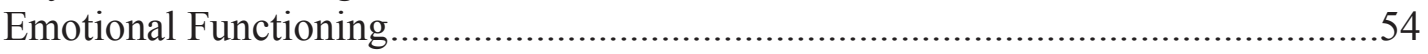

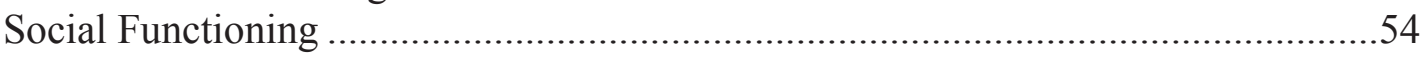

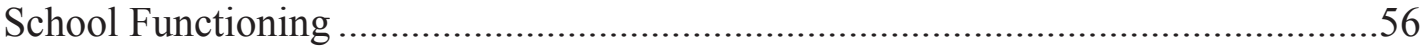

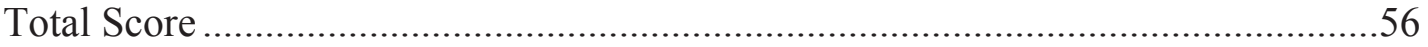

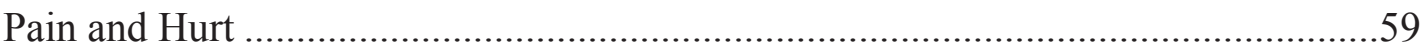

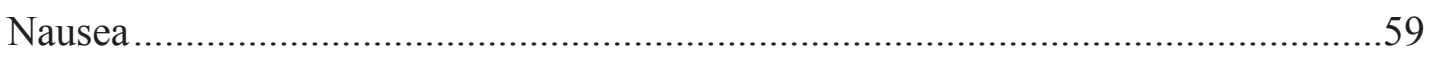

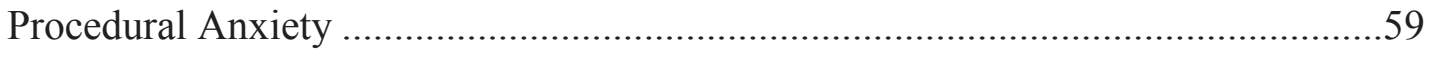

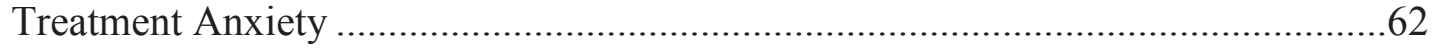

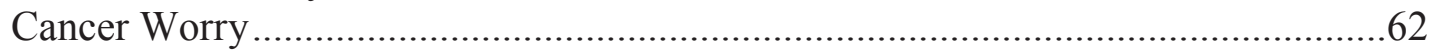

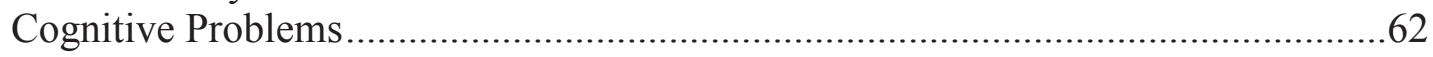

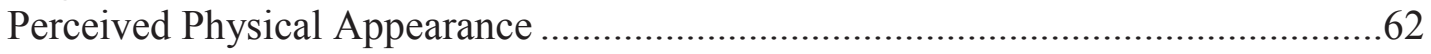

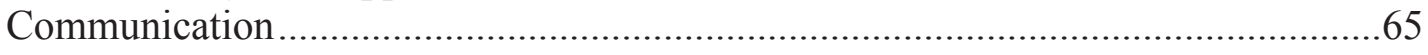

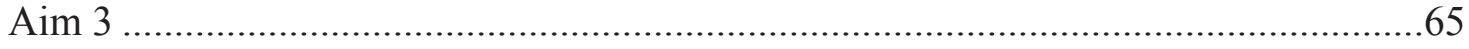

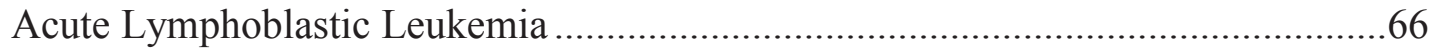




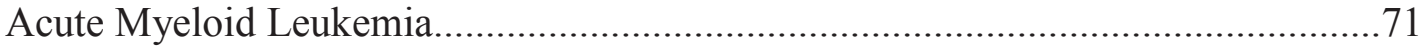

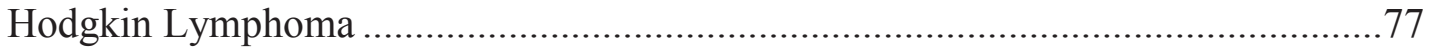

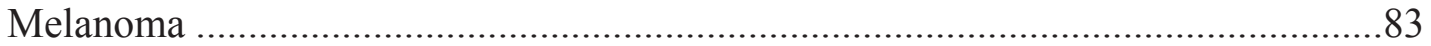

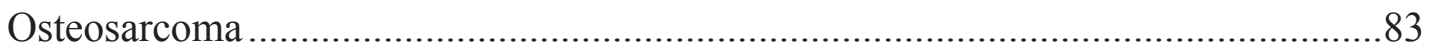

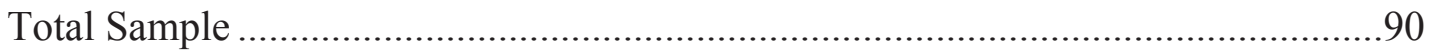

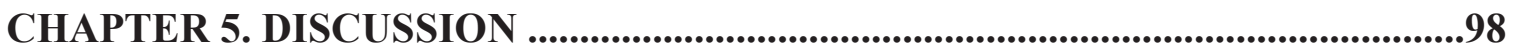

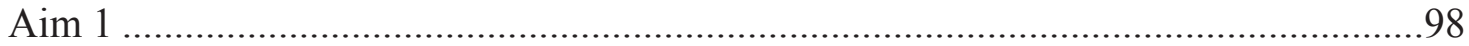

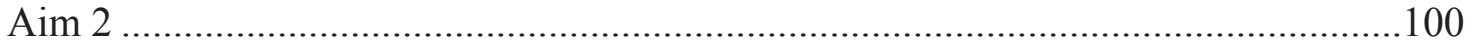

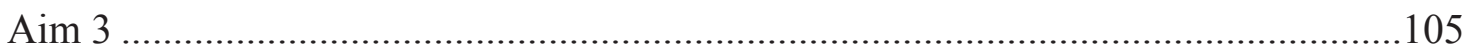

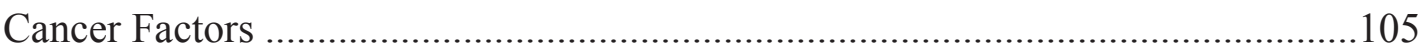

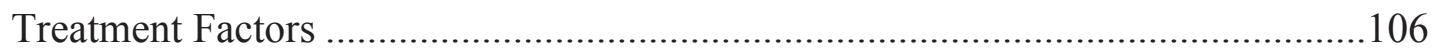

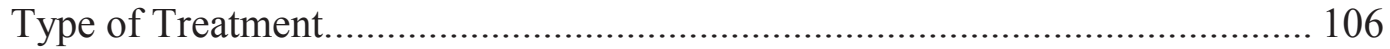

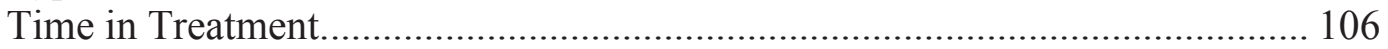

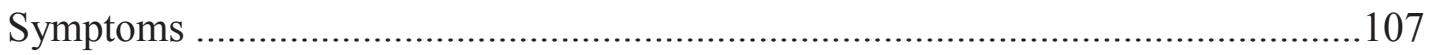

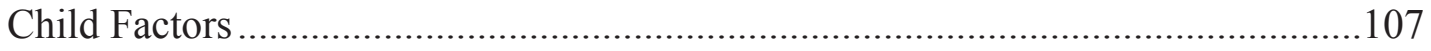

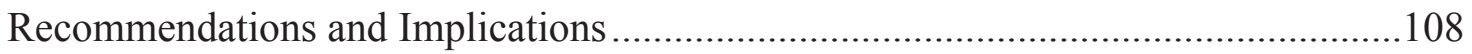

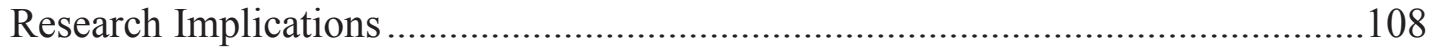

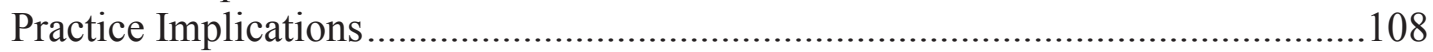

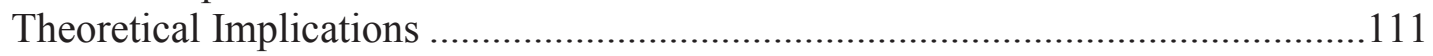

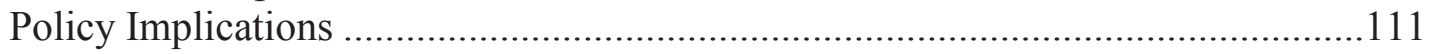

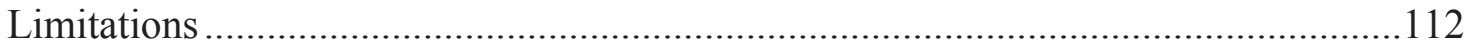

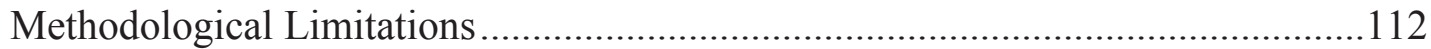

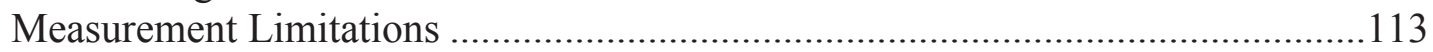

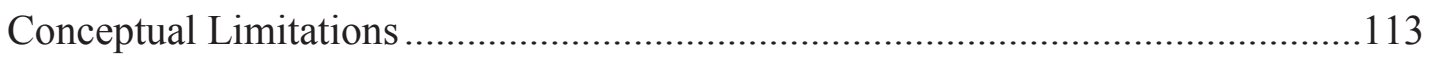

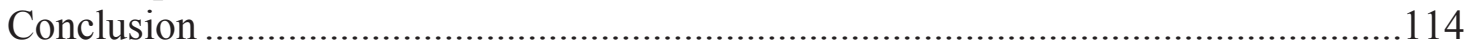

LIST OF REFERENCES .......................................................................................115

APPENDIX A. PEDSQL MODULES AND SCORING .........................................125

APPENDIX B. IRB APPROVALS...................................................................126

APPENDIX C. PEDSQL USER-AGREEMENT .........................................................128

VITA 


\section{LIST OF TABLES}

Table 4-1. Demographics of study participants by diagnostic group ..........................32

Table 4-2. Demographics of patients with acute lymphoblastic leukemia by risk

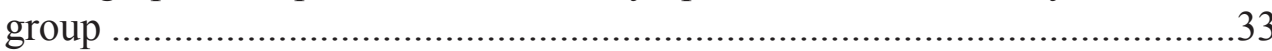

Table 4-3. Demographics of patients with acute myeloid leukemia by risk group........34

Table 4-4. Demographics of patients with Hodgkin lymphoma by risk group..............35

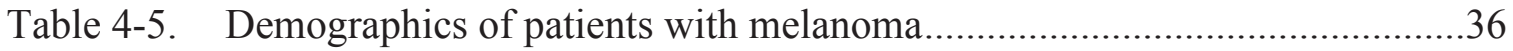

Table 4-6. Demographics of patients with osteosarcoma by study .............................38

Table 4-7. Domains and symptoms of HRQOL outcomes over time in ALL ..............40

Table 4-8. Domains and symptoms of HRQOL outcomes over time in AML .............43

Table 4-9. Domains and symptoms of HRQOL outcomes over time in HL.................46

Table 4-10. Domains and symptoms of HRQOL outcomes over time in melanoma ......49

Table 4-11. Domains and symptoms of HRQOL outcomes over time in OS .................52

Table 4-12. Physical HRQOL scores across diagnostic groups and over time ................55

Table 4-13. Emotional HRQOL scores across diagnostic scores and over time.............55

Table 4-14. Social HRQOL scores across diagnostic groups and over time ..................57

Table 4-15. School HRQOL scores across diagnostic groups and over time .................57

Table 4-16. Total HRQOL scores across diagnostic groups and over time ....................58

Table 4-17. Pain and hurt scores across diagnostic groups and over time .....................60

Table 4-18. Nausea scores across diagnostic groups and over time ...........................60

Table 4-19. Procedural anxiety scores across diagnostic groups and over time .............61

Table 4-20. Treatment anxiety scores across diagnostic groups and over time ..............63

Table 4-21. Cancer worry scores across diagnostic groups and over time ....................63

Table 4-22. Cognitive problems scores across diagnostic groups and over time............64 
Table 4-23. Perceived physical appearance scores across diagnostic groups and over time.

Table 4-24. Communication scores across diagnostic groups and over time .65

Table 4-25. Univariate model results investigating predictors of PedsQL-Generic

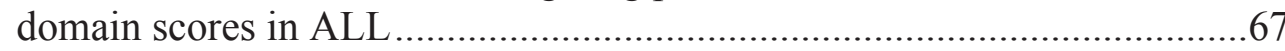

Table 4-26. Multivariate model results investigating predictors of PedsQL-Generic domain scores in ALL

Table 4-27. Univariate model results investigating predictors of PedsQL-Cancer domain scores in ALL

Table 4-28. Multivariate model results investigating predictors of PedsQL-Cancer

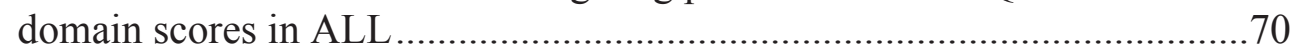

Table 4-29. Univariate model results investigating predictors of PedsQL-Generic domain scores in AML .72

Table 4-30. Multivariate model results investigating predictors of PedsQL-Generic domain scores in AML

Table 4-31. Univariate model results investigating predictors of PedsQL-Cancer domain scores in AML

Table 4-32. Multivariate model results investigating predictors of PedsQL-Cancer domain scores in AML .76

Table 4-33. Univariate model results investigating predictors of PedsQL-Generic domain scores in $\mathrm{HL}$

Table 4-34. Multivariable model results investigating predictors of PedsQL-Generic domain scores in HL

Table 4-35. Univariate model results investigating predictors of PedsQL-Cancer domain scores in HL .80

Table 4-36. Multivariate model results investigating predictors of PedsQL-Cancer domain scores in HL

Table 4-37. Univariate model results investigating predictors of PedsQL-Generic domain scores for melanoma

Table 4-38. Univariate model results investigating predictors of PedsQL-Cancer domain scores for melanoma .85

Table 4-39. Univariate model results investigating predictors of PedsQL-Generic domain scores in OS 
Table 4-40. Multivariate model results investigating predictors of PedsQL-Generic domain scores in OS

Table 4-41. Univariate model results investigating predictors of PedsQL-Cancer domain scores in OS

Table 4-42. Multivariate model results investigating predictors of PedsQL-Cancer domain scores in OS

Table 4-43. Univariate model results investigating predictors of PedsQL-Generic domain scores in the total sample

Table 4-44. Multivariate model results investigating predictors of PedsQL-Generic domain scores in the total sample

Table 4-45. Univariate model results investigating predictors of PedsQL-Cancer in the total sample

Table 4-46. Multivariate model results investigating predictors of PedsQL-Cancer scores in the total sample 95

Table 4-47. Model fit AIC values for PedsQL-Generic HRQOL domain scores .96

Table 4-48. Model fit AIC values for PedsQL-Cancer symptoms .97 


\section{LIST OF FIGURES}

Figure 1-1. Conceptual model of HRQOL in children with cancer ..............................5

Figure 2-1. Article selection process ........................................................................ 13

Figure 2-2. Generic HRQOL instruments used in the systematic review .....................20

Figure 2-3. Cancer-specific scales used in the systematic review ..............................20

Figure 4-1. HRQOL domain average scores across time on the PedsQL-Generic and the PedsQL-Cancer scales for the ALL group .........................................4

Figure 4-2. HRQOL domain average scores across time on the PedsQL-Generic and the PedsQL-Cancer scales for the AML group .......................................44

Figure 4-3. HRQOL domain average scores across time on the PedsQL-Generic and the PedsQL-Cancer scales for the HL group...........................................4

Figure 4-4. HRQOL domain average scores across time on the PedsQL-Generic and the PedsQL-Cancer scales for the melanoma group ..................................50

Figure 4-5. HRQOL domain average scores across time on the PedsQL-Generic and the PedsQL-Cancer scales for the OS group ...........................................53

Figure 4-6. HRQOL outcomes on PedsQL-Total domain across diagnostic groups ......58

Figure 5-1. Modified conceptual model of HRQOL in children with cancer ...............109 


\section{LIST OF ABBREVIATIONS}

AIC

ALL

AML

CNS

EFS

HDMTX

HL

HRQOL

MEL

PedsQL-Generic

PedsQL-Cancer

PI

QoL

SJCRH

T1

$\mathrm{T} 2, \mathrm{~T} 3$

$\mathrm{T} 4$
Akaike Information Criterion

Acute Lymphoblastic Leukemia

Acute Myeloid Leukemia

Central Nervous System

Event-Free Survival

High-Dose Methotrexate

Hodgkin Lymphoma

Health-Related Quality of Life

Melanoma

Pediatric Quality of Life - Generic core scale module

Pediatric Quality of Life - Cancer scale module

Principal Investigator

Quality of Life

St. Jude Children's Research Hospital

A time point representing the beginning of treatment

Time points representing significant clinical incidents that correspond with treatment changes

A time point at the end of treatment 


\section{CHAPTER 1. INTRODUCTION}

\section{Problem}

Health-related quality of life (HRQOL) is a complex phenomenon measuring domains of the person's general health and well-being. The aim of studying HRQOL is to specifically identify and quantify subjective aspects of social, emotional, physical, and psychological well-being. ${ }^{1}$ Measurement of HRQOL among patients during an illness experience is an important means of evaluating the quality and outcomes of healthcare. ${ }^{2-5}$ Since the introduction of the concept, researchers have defined, conceptualized, and measured HRQOL in various patient populations. Measurement of HRQOL has led to the identification of factors that impact the patient reported outcome (PRO) and HRQOL. However, progress in understanding and measuring HRQOL has been hindered by the ambiguous use of the term in describing the phenomena. HRQOL has been measured as a representation of an individual's health status, physical functioning, symptoms, psychosocial adjustment, well-being, life satisfaction, and happiness. In addition, measurement of HRQOL across diseases and treatment modalities make it difficult to draw comparisons between populations. As a result of disease and treatment variability, comparing HRQOL findings across studies or making implications to clinical practice is difficult. $^{6}$

The illness experience in children with cancer varies across cancer diagnoses due to different treatment modalities associated with disease risk and biology. Numerous factors have been identified as impacting HRQOL in children with cancer and include demographic, socio-economic status, cancer diagnosis, biology, treatment intensity and duration of treatment. Therefore, in assessing the illness experience of children undergoing curative cancer treatment, there is a need to consider aspects that extend beyond the measures of treatment response and survivorship. The modalities and intensity of treatment make it important to also measure the subjective experience of the child undergoing cancer treatment. This subjective cancer experience can best be measured through HRQOL measures. In addition, treatment modalities impact the patient's general well-being and health, both short term during curative treatment and long term into adult survivorship. Thus, children who undergo multiple or more intensive treatment modalities generally report decreased well-being and lower HRQOL. ${ }^{7-9}$

Time is an important variable that impacts HRQOL during treatment. Therefore, HRQOL should be measured over time, as children and adolescents progress in treatment and into survivorship. While evidence from childhood cancer survivors' studies describe stable HRQOL throughout the survivorship trajectory, ${ }^{10}$ results from HRQOL studies in children undergoing curative treatment describe variability by diagnosis and time. The association of HRQOL and time has been measured inconsistently, with studies measuring HRQOL at variable time points during and after the completion of treatment. Many HRQOL studies are limited to a cross-sectional design, only measuring HRQOL at a single time point in therapy within a specific cancer diagnostic group. These studies also included a limited number of factors that were measured with variable scales and 
instruments, leading to an incomplete and inconsistent understanding of the effect of time on the HRQOL experience.

Given the current state of knowledge, the overall aim of this study is to address some limitations of HRQOL research in children with cancer by measuring longitudinal trends of change in HRQOL within a large sample, across diagnoses and time, using a widely used and valid instrument. Through this study, we also aim to identify and quantify the factors affecting HRQOL across diagnoses and time.

\section{Background}

\section{Childhood Cancer}

Cancer is the leading cause of death from disease among children in developed countries. An estimated 12,060 new cases were expected to occur among children ages 0 to 14 in 2012. The most common childhood cancer is acute lymphoblastic leukemia (ALL), followed by cancers of the brain and central nervous system (CNS). Together, these cancers account for more than $50 \%$ of the new cases of childhood cancer in the US, with consistent trends in the European Union and most other countries. ${ }^{11}$

Over the last decades, there has been a marked improvement in the cure and survival rates, with mortality rates declining by $66 \%$ over the past four decades to a 2.2 per 100,000 in 2008. ${ }^{11}$ This decline in mortality is due to the development of highly specific diagnostic tests and improvement in treatment modalities and supportive care. However, children with cancer continue to develop severe side effects from intensive treatments including manifestation of physical, cognitive, emotional, psychological and social changes, either during treatment or later in life. ${ }^{12}$ More specifically symptoms within these domains may include nausea, vomiting, pain, fatigue, anxiety, cancer worry, and body image. Measuring these patient reported outcomes requires the use of selfreported measures in addition to the objective diagnostic indicators of tumor and treatment burden, thus allowing capture of the subjective and objective illness experience. Therefore, the utilization of HRQOL instruments to assess the subjective patient reported outcomes is important during the illness experience.

\section{Health-Related Quality of Life in Children with Cancer}

The measurement of HRQOL in children with cancer has evolved over several decades; from measurement of the patients' physical limitations to now include measures of physical, social, emotional, and psychological functioning.

However, the need to capture the child's self-reported firsthand experience remains the preferred method of HRQOL outcomes research. The utilization of reliable

and valid instruments for measuring HRQOL among age groups allows researchers to be 
confident that the concepts of interest are being consistently measured through the child's self-report of HRQOL during treatment, thus resulting in an improved understanding of factors that affect HRQOL during the illness experience across time. These factors include demographic, socio-economic status, diagnosis, treatment intensity and time in treatment. ${ }^{13-15}$ The identification of these factors allowed the development of interventions mediating these factors in children with cancer. ${ }^{1,14,16}$

Despite progress in improving HRQOL in children with cancer, most published studies provide incomplete information describing the impact of time and treatment. The majority of studies only assess single diagnostic groups of children with cancer, include small sample sizes, utilize a cross sectional design, measure a limited number of treatment factors, which limits the ability to report change in HRQOL over time. Most treatment regimens extend for months to years; however, the current HRQOL evidence does not describe the change in HRQOL through these treatments. The lack of evidence of factors impacting HRQOL over time leads to an incomplete understanding of the illness experience of children with cancer, and thus hinders the development of interventions that can address HRQOL mediating factors in real-time.

\section{Significance}

The assessment of HRQOL describes the subjective experience of the patient during an illness experience. HRQOL data have been shown to provide significant predictive power of survival in some patient groups and is comparable to the traditional indicators of tumor burden, tumor response, and other clinical factors. ${ }^{17,18}$ In a study of patients with advanced lung cancer, global HRQOL scores obtained immediately before diagnosis were the most significant predictors of the length of survival, even after adjusting for known prognostic factors. ${ }^{18,19}$

The measurement of HRQOL offers a unique perspective on the benefit-burden ratio from the patient's view. Successful treatments have led to the development of neuropsychological, physical, social, and emotional late effects that continue with survivors through their lives. ${ }^{20}$ In addition, research on HRQOL provides evidence to support policymakers allocation of health care resources and mandated reimbursement policies. ${ }^{4,21}$

The need for HRQOL assessment and measurement can also be recognized when two treatment regimens have equal outcomes. Such situations may lend weight to the treatment regimen that yields the higher HRQOL during treatment. ${ }^{17}$ This may be especially beneficial in children with cancer in which the overall survival is excellent and the differences in survival between treatment regimens are not significantly different. As a result, HRQOL information may add value when one treatment produces higher survival rates than another, but is more toxic, particularly when the average survival time is short. ${ }^{17}$ Furthermore, treatments that extend life while impairing HRQOL may not be worthwhile from the patient's perspective. Therefore, an important reason to assess HRQOL is to understand how an existing or novel treatment impacts an individual's 
functioning in the context of improvement in long-term survival. Similarly, if a new treatment is being compared with an existing standard of care (SOC), inclusion of a measure of HRQOL allows for comparison, especially if there is existing knowledge of the impact the SOC has on HRQOL. ${ }^{20}$

These findings reinforce the importance of collecting HRQOL data, and have led clinicians and researchers to consider HRQOL of patients with cancer as essential when measuring patients' response to treatments. The mounting evidence supporting the importance of collecting and measuring HRQOL in patients, along with a growing patient advocacy movement, led the National Cancer Institute (NCI) as well as other funding agencies to strongly recommend that outcome measures for cancer treatment include measuring HRQOL. ${ }^{22,23}$ The US Food and Drug Administration (FDA) has named patient-reported outcomes (PROs) including HRQOL as an important end point for approval of new anticancer drugs, which led most cooperative groups to integrate HRQOL research into hundreds of treatment protocols. The pharmaceutical industry has also started to include HRQOL end points in phase II to phase IV trials. ${ }^{20}$ These findings and recommendations support the call for enhanced utilization and collection of HRQOL information as an important end-point and outcome of treatment.

\section{Conceptual Framework}

An important limitation in HRQOL is the lack of consensus on a conceptual framework to guide the researchers' understanding and study of HRQOL in children. ${ }^{24}$ This limitation may explain the variation in items and domains measured in pediatric HRQOL instruments. To overcome these obstacles, literature from both adult oncology and the childhood epilepsy field was synthesized to develop the conceptual model for this HRQOL study in children undergoing cancer treatment. This model explains the relationship between factors that will be explored in this study. Figure 1-1 presents the inclusive HRQOL conceptual model that identifies all proposed factors affecting HRQOL in children under treatment. It also presents the abbreviated model that describes factors measured and included in this study. This study examined the biomedical/treatment factors as independent factors, and the child factors as mediating factors.

The inclusive conceptual model (Figure 1-1) identifies four domains that define HRQOL in children with cancer. These domains are a) the biomedical/treatment, b) environmental, c) child, and d) outcome. The biomedical/treatment domain is represented by two sets of factors, the cancer variable and the treatment variable. These factors represent the first insult to the child's HRQOL. The child's perception of change in HRQOL may be positively or negatively affected by the environmental domain which includes factors from the family and community. Depending on these variable characteristics, the child may find a strong support system of family and friends, or face uncertainty and stress due to lack of such support. The last domain is the child domain. This domain describes the understanding that children interact and perceive their illness in a unique and different perspective than their family or community and this perspective is influenced by the child's age, gender, and ethnicity. 


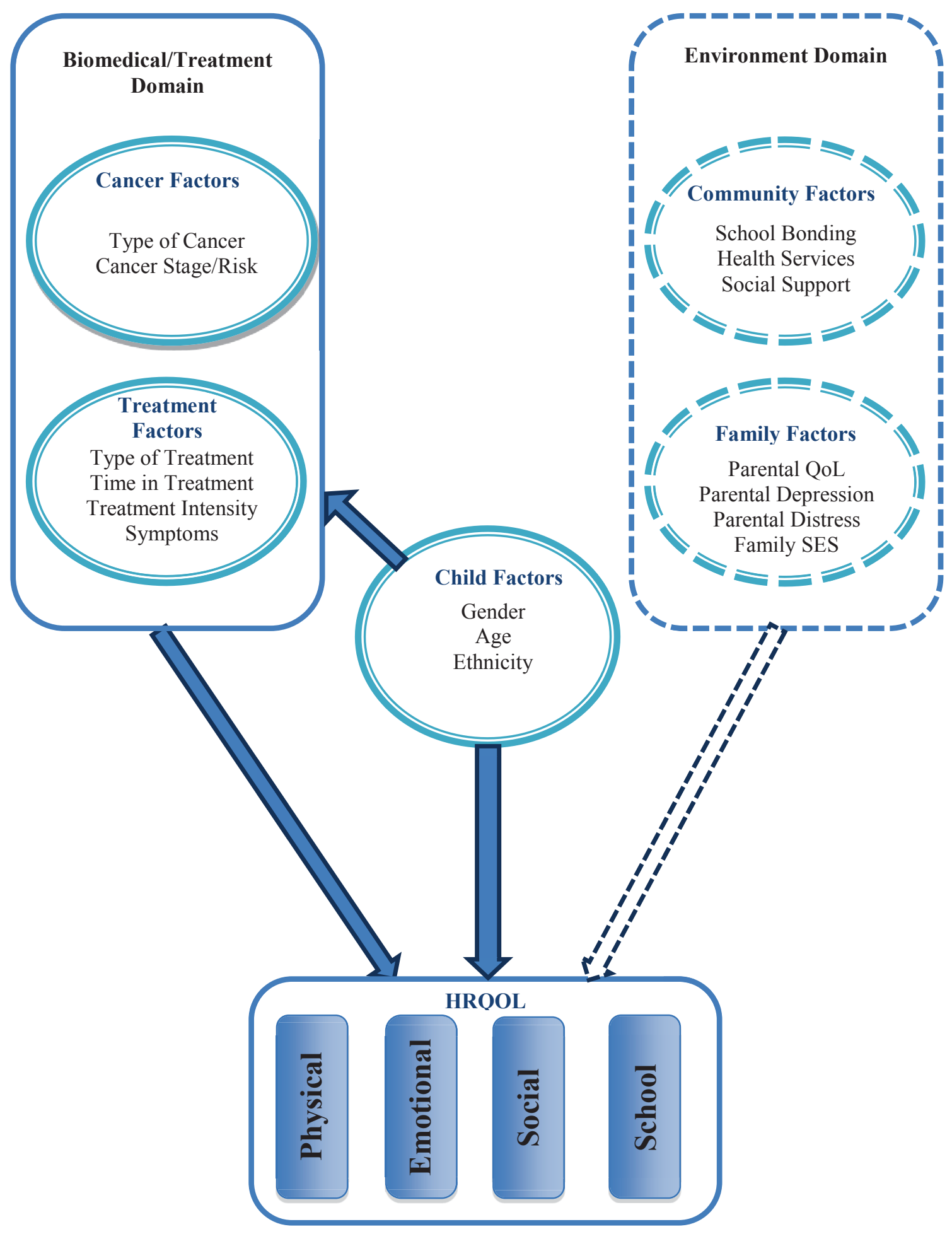

Figure 1-1. Conceptual model of HRQOL in children with cancer 
For this study, the final adapted model is depicted in solid lines. This model includes three domains: 1) biomedical treatment, 2) child, and 3) outcome. While the larger conceptual model identifies the importance of the environmental domain on HRQOL of children, our study did not include collection of data that would describe this domain.

\section{The Biomedical/Treatment Domain}

The factors within the biomedical/treatment domain impact the disease risk stage and define the modality of treatments used, thus impacting the child's HRQOL. This domain is further categorized into cancer and treatment factors.

Cancer Factors. Cancer factors in the proposed model include cancer diagnosis, and cancer stage or risk. Relapsed disease is not included within the model, as patients with relapse were taken off study.

Treatment Factors. Treatment factors include treatment side effects or cancerrelated symptoms, time in treatment, treatment intensity, and type of treatment. Time in treatment was measured at specific important treatment time points dictated by the treatment modality and length of treatment protocol. The data for this study were collected from patients over multiple time points (from the initiation of treatment through treatment and at the completion of treatment). In addition, the modality of treatments used (i.e., radiotherapy, chemotherapy, surgery, immunotherapy and stem cell transplantation) were identified for each diagnostic group.

\section{Child Domain}

The Child Domain included age, gender, and ethnicity. Age was measured as child age in years at the time of diagnosis. Ethnicity was self-reported and included Asian, Caucasian, Black, Hispanic, and Other. However, the categorization of ethnicity was divided to White versus other ethnicities due to the small sample size of ethnic groups outside of white. For descriptive purposes, Black ethnicity will be listed but will be included within the other ethnicities for analysis.

\section{Outcome Domain}

The outcome domain was assessed using the Pediatric Quality of Life ScaleGeneric core scale (PedsQL-Generic) and the Pediatric Quality of Life Scale-Cancer (PedsQL-Cancer) modules. These instruments measured three categories of HRQOL outcomes: physical, emotional, and social functioning. All three outcome categories were measured using content items within the instrument. 


\title{
Specific Aims
}

\begin{abstract}
Aim 1
To identify longitudinal trends in HRQOL change in diagnostic groups of children undergoing curative cancer treatment.
\end{abstract}

- $\quad$ Research Question 1-1: What is the self-reported HRQOL of children undergoing curative cancer treatment within each diagnostic group at each time point?

- $\quad$ Research Question 1-2: What is the difference in self-reported HRQOL of children undergoing curative cancer treatment at each time point within each diagnostic group?

\begin{abstract}
$\operatorname{Aim} 2$
To identify the differences in HRQOL among different diagnostic groups of children undergoing curative cancer treatment.

- $\quad$ Research Question 2-1: What is the difference in self-reported HRQOL of children undergoing curative cancer treatment between different diagnostic groups at each time point?
\end{abstract}

\section{$\operatorname{Aim} 3$}

To identify correlates with HRQOL of children undergoing curative cancer treatment over time within each diagnostic group.

- $\quad$ Research Question 3-1: Is there an association between cancer and treatment factors and self-reported HRQOL of children undergoing curative cancer treatment over time?

- $\quad$ Research Question 3-2: What is the combined effect of cancer and treatment factors on the self-reported HRQOL of children undergoing curative cancer treatment in each diagnostic group?

- $\quad$ Research Question 3-3: What are the associations between each variable and the change in self-reported HRQOL of children undergoing curative cancer treatment? 


\section{Assumptions}

Study assumptions are made regarding the sample and the efficacy of the collected data included:

1. Children are able to adequately and accurately provide an assessment of their HRQOL.

2. A child's self-report of their HRQOL is the most accurate report of their perceived HRQOL during an illness experience.

3. Other factors not included in the conceptual framework have a negligible effect on the child's HRQOL during treatment.

\section{Limitations}

Study limitations include:

1. The study was a retrospective analysis of existing data which leads to an inability to assess the integrity of the data collection and data entry methods. However, the team that collected the data was adequately trained in data collection and data storage. The data collection team was trained and prepared to identify and respond to potential questions and problems that may have risen through data collection.

2. The PI did not contribute to the study design nor data collection, thus limiting the PI's knowledge of potential problems that may have occurred with the data collection. The faculty advisor was part of the original study team.

3. Data collected and utilized in the current study did not include socio-demographic or socio-economic status information. This limitation impacts our ability to measure all these domains within our conceptual framework and prevents the consideration of these important factors. This poses a limitation in assessing the associated factors and the impact on HRQOL in children undergoing curative cancer treatment. However, this limitation does not affect the internal validity of the measures and the results reported from our sample.

4. Our sample included cancer diagnosis with varying treatment durations, modalities, and intensities, making comparison across diagnoses and time difficult.

5. HRQOL interviews for patients were administered using instrument modules based on the age at diagnosis, even if patients progressed in age through their treatment, each child continued to be interviewed using the same module at diagnosis. While this can assist with the statistical analysis, it does not consider 
the child's development as they progress in treatment. However, this limitation did not affect the content of questions that were asked to patients, the number of items or the validity of the responses.

6. Limitations in patient and treatment selection may have affected the final outcome of HRQOL. The study enrollment excluded children with relapsed or progressive disease. In addition, it is not known if patients who agreed to participate had a higher HRQOL than those that refused participation. Thus, the study was not able to determine how a relapse, progressive disease, or refusal to participate affected their HRQOL outcome compared to children who participated in the study. While the exclusion of relapsed patients reduced our understanding of HRQOL in those children, it allowed for higher validity of responses that adequately reflects HRQOL in our target population, children receiving curative treatment.

\section{Definitions}

\section{Health-Related Quality of Life}

Health-related quality of life was defined as a complex concept with multiple domains that are affected by the person's illness and health. These domains included: cognitive functioning, emotional functioning, psychological well-being, general health, physical functioning, physical symptoms and toxicity, role functioning, social well-being and functioning, and spiritual domains. Operationally, it was defined as the outcome measure of physical, emotional, psychosocial, and illness-related domains as determined by the PedsQL-Generic v4.0 and the PedsQL-Cancer v3.0.

\section{Diagnosis}

Diagnosis is defined as the cancer that was identified through examination of the patient history, signs, symptoms, and diagnostic data. The diagnosis was defined operationally as the identifying disease or illness as determined by entry onto a specific disease protocol.

\section{Time Point}

Time was defined as a particular instance or period of time covering a defined set of treatments for a patient under treatment in a certain diagnostic group. Operationally, it was defined as the time at which data were collected from each child during the treatment protocol as determined by the original study team. 


\section{Stage (Risk)}

Cancer stage was defined as the severity and subsequent side-effects experienced by the child during treatment. Operationally, it was defined as the treatment group for which each child was assigned based on disease-specific biological and diagnostic measures according to the treatment protocol and documented for each patient.

\section{Treatment Intensity}

Treatment intensity is defined as the extent of severity and subsequent side-effects experienced by the child during treatment. It was operationally defined as the sum of single or combined treatment modalities that included surgery, chemotherapy, immunotherapy, and radiotherapy. 


\section{CHAPTER 2. REVIEW OF LITERATURE}

\section{Introduction}

HRQOL is a dynamic concept that is affected by the changing image of self and numerous factors that impact the individual's perception of self. Programs of research continue to explore this dynamic phenomena, as well as factors that contribute to the continuous transformation of HRQOL within an illness experience. However, significant gaps remain in the pediatric oncology HRQOL literature, specifically related to factors that affect HRQOL during the treatment process, including the effect of time and duration of therapy. While multiple studies have successfully identified factors of HRQOL among selected diagnostic groups of childhood cancers, many of these studies have reported conflicting results that preclude the identification of other HRQOL factors in childhood cancer. ${ }^{14}$ Most studies have measured HRQOL at a single time point in treatment and included a single diagnostic group. ${ }^{1}$ Thus, it is difficult to draw conclusions on the HRQOL changes over time and across cancer diagnoses. Evidence is further hindered by the lack of studies measuring intensity or treatment factors and the impact on HRQOL during cancer treatment. ${ }^{25,26}$

This chapter includes a systematic review of the literature regarding the current status of HRQOL studies in children undergoing curative cancer treatment. This review focused in particular on factors examined by HRQOL studies in children undergoing curative cancer treatment. Additionally, these studies address concerns related to the HRQOL measurement and conceptual problems related to the definition and meaning of HRQOL.

\section{Quality of Life and Health-Related Quality of Life}

As the concept of health evolved to include a wider spectrum of psychological, social, and spiritual domains, so did the concept of quality of life (QoL). ${ }^{27}$ QoL was originally introduced as a measure of individual and community well-being. Thus, description of QoL among individuals during an illness experience required a new conceptual definition, health-related quality of life. Health-related quality of life was defined as an individual's impact by illness and health. Operationally, it was defined as the outcome measure of physical, emotional, psychosocial, and illness-related domains.

\section{Factors, Measurement, and Conceptual Definition of HRQOL in Children with Cancer}

Numerous studies have explored factors that affect the HRQOL among survivors of childhood cancer; however, few studies have explored factors and their impact on HRQOL in children during curative cancer treatment. In order to identify relevant studies that have described HRQOL and associated factors among children during curative 
cancer treatment, a structured review of the literature was performed to synthesize evidence and identify factors of interest. To achieve this goal, the conceptual model for this study (Figure 2-1) was used as a framework for categorizing and listing identified factors.

\section{Types of Childhood Cancer Groups}

This study aimed to measure HRQOL in five diagnostic groups of childhood cancer. The diagnostic groups included Acute Lymphoblastic Leukemia (ALL), Acute Myeloid Leukemia (AML), Hodgkin Lymphoma (HL), Osteosarcoma (OS), and Melanoma (MEL).

Acute Lymphoblastic Leukemia (ALL). ALL is a hematological cancer and is the most common pediatric cancer. In the United States, approximately 3,000 children are diagnosed with ALL annually. ALL affects slightly more boys than girls and more whites than blacks, with peak incidence 2 to 5 years of age. Siblings of children with cancer have a slightly higher risk of developing the disease; however, the incidence is relatively low. ALL is treated with combined rotational chemotherapy, with radiation reserved for those with a central nervous system relapse. Hematopoietic stem cell transplantation may be a treatment option for very high-risk cases or those who develop an early relapse. The intensity of ALL treatment varies over time and is dependent upon the patient risk group. ${ }^{28}$ About $98-99 \%$ of children with newly diagnosed ALL attain a complete remission in four to six weeks, with approximately $90 \%$ having event-free survival. $^{28,29}$

Acute Myeloid Leukemia (AML). Approximately 500 children are diagnosed with AML in the United States each year, comprising approximately $20 \%$ of the children diagnosed with leukemia. AML may occur as a secondary malignancy after the treatment of another malignancy. Although approximately $80-90 \%$ of children with AML attain remission, $70 \%$ will attain long-term remission with chemotherapy or stem cell transplantation. ${ }^{30}$

Hodgkin Lymphoma (HL). In the United States and northern Europe, HL is rare before five years of age, with increased incidence in adolescence with a peak in the second and fifth decade of life. Associated risk factors are male gender, having a sibling diagnosed with the disease, and Epstein-Barr virus. Chemotherapy alone or combined with low-dose radiation therapy is the standard treatment for young patients and patients with advanced disease; however, radiation significantly impairs the growth of bones and soft tissues in children and increases the risk of heart disease and secondary malignancies. Current event-free survival is $90 \%$.

Melanoma. Melanoma is the most common skin cancer in children. Of the estimated 55,000 cases of melanoma diagnosed in the United States each year, fewer than $5 \%$ occur in patients under 20 years of age and only $0.3 \%$ are younger than 11 years. Thus, melanoma accounts for only $1-2 \%$ of all pediatric cancers. ${ }^{31}$ 


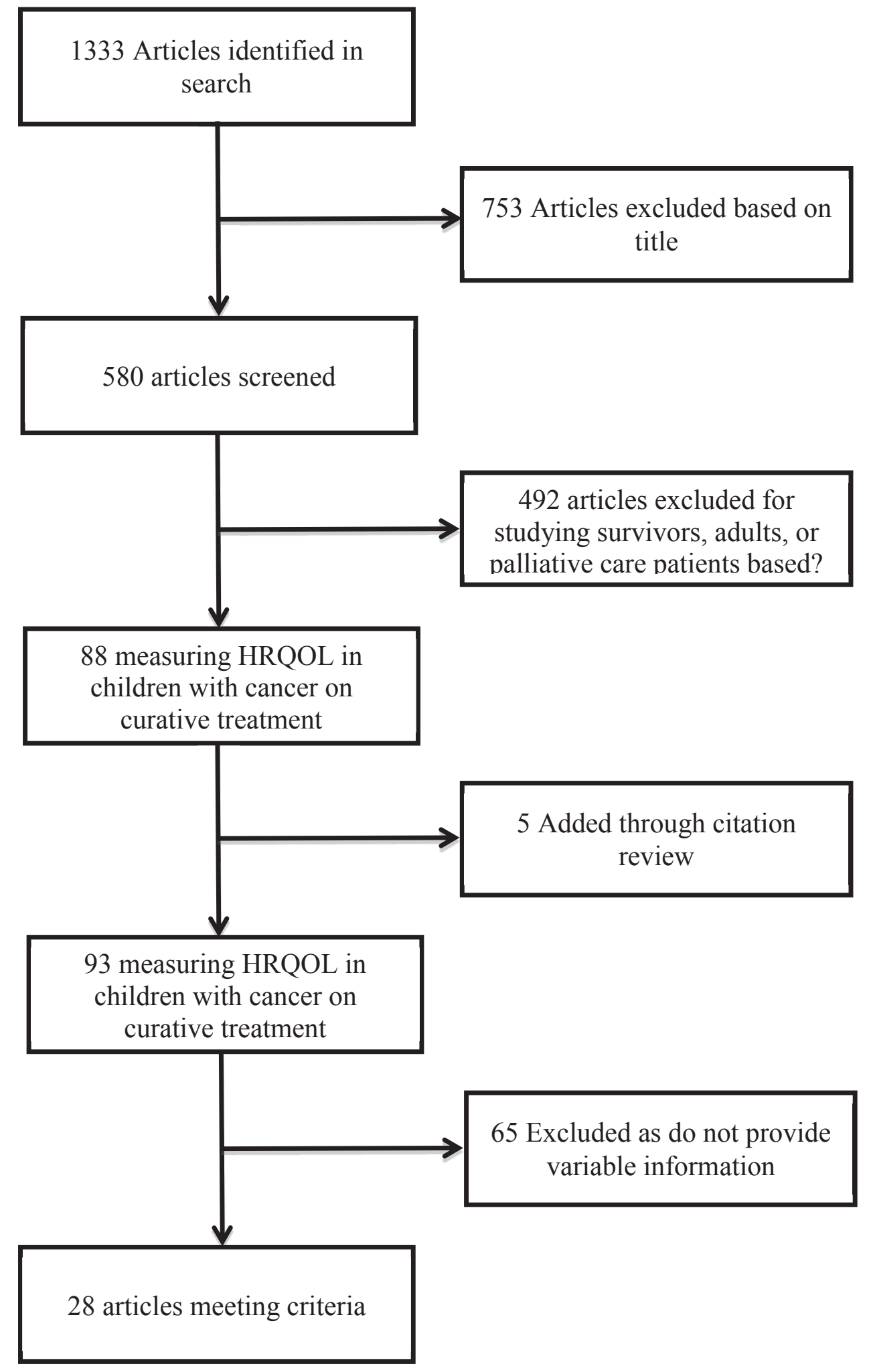

Figure 2-1. Article selection process 
Children with dysplastic nevus syndrome, giant congenital nevi, DNA repair disorders or immunodeficiency states have an increased risk of developing melanoma. The most common cause of skin cancer is exposure to the ultraviolet rays, but may also be secondary to cancer-causing chemicals and ionizing radiation. Individuals with a family history of melanoma are at increased risk. ${ }^{32}$

Thickness of a tumor has been shown to predict the likelihood of tumor spread (metastases) or recurrence. Optimal treatment for melanoma is complete surgical removal and is dependent upon the size, site, level of invasion into the skin and stage of the tumor. ${ }^{33}$ Prognosis for resected superficial melanomas is approximately $90 \%$, with patients surviving 10 years from diagnosis. Survival is decreased if the melanoma has spread to distant organs.

Osteosarcoma (OS). Osteosarcoma is the most common bone tumor in children and adolescents. The most common sites of this tumor are the femur, tibia, and humerus. It most commonly arises from the metaphysis of the bone. Each year in the United States, osteosarcoma is diagnosed in approximately 400 children and adolescents younger than 20 years of age. The peak incidence of osteosarcoma is in the second decade of life, during the adolescent growth spurt. It is extremely rare in children before the age of 5 years of age and is more frequent in the male gender and black race. ${ }^{34}$

Osteosarcoma may occur in long-term survivors of cancer who were treated with radiation therapy. The interval between radiation and the appearance of osteosarcoma ranges from 4 to 40 years (median, 12-16 years). Two suppressor genes, $p 53$ and $R b 1$ genes have major roles in tumor genesis in osteosarcoma, with approximately $3-4 \%$ of children with osteosarcoma having a germ line mutation in $p 53$. The majority of patients with germ line p53 mutations have a strong family history of cancer suggestive of the LiFraumeni syndrome (a familial cancer syndrome) or multiple cancers. ${ }^{35}$

Patients with osteosarcoma may present with pain, swelling, and sometimes decreased joint motion. Occasionally, a patient may present with a fracture at the tumor site. Symptoms are usually present for several months prior to diagnosis, with $15-20 \%$ of the patients having lung or bony metastatic disease at the time of diagnosis. Treatment of osteosarcoma includes surgery and chemotherapy. Surgical removal of all gross and microscopic tumors is required to prevent local tumor recurrence. The majority of patients $(95 \%)$ with localized osteosarcoma of the extremity are candidates for limbsalvage surgery. The use of multi-agent chemotherapy has markedly improved the outcome of patients with osteosarcoma. ${ }^{36-38}$

The over-all estimated 5-year survival for patients with osteosarcoma is $65 \%$, with the presence of metastasis at diagnosis having a significant impact on outcome. The estimated survival rate for patients with localized osteosarcoma is about $75 \%$ compared to $30 \%$ for patients with metastatic disease. ${ }^{36}$ 


\section{Review of HRQOL Studies in Children under Cancer Treatment}

To assess the current HRQOL literature in children undergoing curative cancer treatment, a systematic review of the literature was completed. The review identified relevant factors that significantly impact HRQOL in children as outlined by the conceptual model and instruments utilized in measuring HRQOL in children undergoing curative cancer treatment. In addition, we reviewed studies that identified issues in measuring and conceptualizing the definition of HRQOL.

\section{Procedure for Review of Literature}

A literature search of PubMed, CINAHL, and PsycINFO was performed using the terms "health-related quality of life" and "quality of life' as mesh terms. The term HRQOL was combined with a subject heading for cancer, and limited to children. Articles were initially scanned for eligibility based on title, followed by an abstract scan, and finally through a full text scan. Full text articles were also scanned for relevant literature that was not found during the literature search.

Inclusion Criteria. Study titles and abstracts were examined and screened for relevancy to the review. The remaining full text articles were screened using the following inclusion and exclusion criteria:

- $\quad$ Study subjects were limited to children under 18 years of age.

- $\quad$ Publication date was January 1st 2005, through March 1st 2013.

- $\quad$ Published in English.

- Study subjects were under curative cancer treatment with a curative intent.

- Study outcome or dependent factors were health-related quality of life or quality of life.

Exclusion Criteria. Studies were excluded from this report if they examined:

- Cancer survivors, or included cancer survivors with no separate analysis for groups under treatment and survivors.

- Children undergoing palliative care with no realistic chances of survival.

\section{Findings}

A total of 1333 articles were identified during the initial search and articles were scanned based on titles. Articles were excluded if the abstract included any of the exclusion criteria. The review resulted in the evaluation of 88 full-text articles, with 28 articles meeting the eligibility criteria for review.

The final 28 studies included in this review represented work conducted in 16 countries, with a majority of studies (17) occurring in the United States. Study sample 
size ranged from 8 to 411 . Using the conceptual framework, the factors were categorized into five categories: cancer, treatment, child, family, and community.

\section{Cancer Factors Considered in the Systematic Review}

Type of Cancer. The impact of cancer diagnosis has been found to alter HRQOL in children when compared to healthy norms. Most studies in our review were diagnosis specific, making it difficult to draw HRQOL comparisons between diagnostic groups. Studies that have assessed the impact of cancer diagnosis on HRQOL have conflicting results, with some studies showing a significant effect of diagnosis on HRQOL, and others reporting the cancer diagnosis as having little impact on HRQOL. ${ }^{7,8,13,15,16,39-47}$ Two studies found that children with ALL tend to report higher HRQOL than children with solid tumors or central nervous system (CNS) tumors, ${ }^{13,15,39}$ while another study reported that children with ALL experience a lower HRQOL than other groups. ${ }^{8}$ The poorest HRQOL was reported in children with AML and solid tumors, ${ }^{15,48}$ while other studies reported finding no correlation between the type of cancer and HRQOL of

children. ${ }^{7,13,16,39-42,46,49}$ Most of these studies measured HRQOL in a mixed sample of multiple, small diagnostic groups, thus proving difficult to interpret the effects of cancer type on the HRQOL outcome.

Cancer Stage. Only three studies in the review attempted to measure cancer stage or risk as a variable of HRQOL in children under curative treatment. ${ }^{9,49,50}$ Of those studies, only one could establish cancer stage as a significant variable. ${ }^{50}$ Thus, the influence of cancer stage or risk on HRQOL is not well understood.

\section{Treatment Factors Considered in the Systematic Review}

Type of Treatment. Treatment modality and treatment impact on HRQOL is frequently evaluated among diagnostic groups. Studies that explored the treatment modality as a variable affecting HRQOL found a significant decrease in HRQOL in children receiving radiotherapy, chemotherapy, or surgery. ${ }^{7,13,51,52}$ Radiotherapy was measured in a total of three studies; however, radiotherapy was not compared to other modalities and all of these studies measured HRQOL among patients with a brain tumor. $^{7,53}$ Two of the studies described HRQOL of children undergoing a new method of radiotherapy treatment (proton beam) without drawing any comparisons with other methods. ${ }^{7,53}$ These studies reported that children reported higher HRQOL scores after being treated with proton beam therapy in comparison to previous studies that reported on HRQOL in children receiving conventional radiotherapy treatment. ${ }^{7,53}$ Another study identified radiotherapy as a significant variable impacting HRQOL in children with brain tumors at the first year of diagnosis. ${ }^{49}$ As for chemotherapy, two out of three eligible studies identified chemotherapy as a significant predictor of lower HRQOL in children undergoing curative cancer treatment. ${ }^{7,49}$ One study found surgery to significantly lower HRQOL. ${ }^{13}$ Other studies in this review found no significant association between type of treatment and HRQOL in adolescents and children with cancer. ${ }^{13,40}$ 
Treatment Intensity. Treatment intensity is another variable that has been assessed as impacting HRQOL and was measured in five studies in our systematic review. ${ }^{7-9,13,40}$ Of those studies, three established a significant association between intensity of treatment and HRQOL in children receiving radiotherapy, ${ }^{7}$ and children with leukemia. ${ }^{8,9}$ No other studies could establish a significant association between intensity and type of treatment or other diagnostic group. ${ }^{13,40}$ Thus, this review supports the need to explore a possible association between treatment intensity and HRQOL in all diagnostic groups.

Time in Treatment. A generally low HRQOL was reported following diagnosis, and this trend continued during intensification or changes in treatment. ${ }^{13,15,46,49}$ Children with ALL receiving maintenance treatment reported significantly lower HRQOL as compared to children at the completion of treatment. ${ }^{54}$ However, there was a consensus among these studies that HRQOL steadily improved as children progressed in treatment, with highest HRQOL immediately after completion of treatment. ${ }^{41,49,53}$

Longitudinal HRQOL during cancer treatment was explored once in children with (ALL) receiving curative cancer treatment. 96 patients treated for ALL were followed over three time points during treatment in a study by Peeters et al. ${ }^{55}$ The child's HRQOL improved over time during treatment, especially in physical and mental functions. The study also noted a significant improvement in both patient and parent responses as time progressed. These findings were not correlated with age, and showed that HRQOL of children with ALL was lower than the general population of the same age.

Time is perhaps one of the least understood factors of HRQOL in children undergoing curative cancer treatment. Most studies assessing HRQOL in children undergoing curative cancer treatment use inconsistent time points across studies, making it difficult to infer HRQOL according to time in therapy. The cross-sectional designs of most studies further hinder understanding the change with time. For example, two reviewed studies assessed HRQOL at the time of diagnosis, ${ }^{15,16}$ while others chose a time point that was significant for the diagnostic group under study. ${ }^{46,50,56}$ The fact that each diagnostic group had variability in treatment modality, intensity and timing made it difficult to draw comparisons or make assumptions regarding HRQOL across diagnoses.

Complications and Relapse. A noticeable limitation in most studies was the exclusion of patients who were experiencing complications or relapse. ${ }^{15,40}$ Only one study measured complications, ${ }^{8}$ and one other study measured relapse status as factors of HRQOL. ${ }^{13}$ In general, children who progress under curative treatment were taken off curative study protocols and put on either palliative or experimental regimens. ${ }^{48}$ This explains the lack of studies that assess curative patients that relapse. Complications during treatment are not included as a HRQOL variable and may be attributed to difficulties in tracking and documenting complications during curative cancer treatment. Most patients who relapse or progress during treatment are removed from the curative treatment protocol and usually transferred to a hospice or palliative care setting in many occasions requiring a change of primary clinician and institute. 


\section{Child Factors Considered in the Systematic Review}

Age. Results from studies assessing age show limited evidence to support the role of age as a variable of HRQOL. Age was one of the frequently mentioned factors measured in children with cancer. ${ }^{7-9,13,16,39,40,42,44-47,49,50}$ However, of the 17 studies that measured age as a variable of HRQOL, only four identified age as having a significant impact on HRQOL during treatment. ${ }^{9,13,44,46}$ Young children generally reported lower procedural anxiety and treatment anxiety than adolescents, ${ }^{9}$ while older children reported better social HRQOL and communication that younger children. ${ }^{57}$ Overall, HRQOL has been found to improve with age, ${ }^{9,40}$ while another study found younger age to be associated with an improved HRQOL. ${ }^{21}$ Others reported no association between age and HRQOL in children. ${ }^{7,8,39,42,47,50,58}$ These studies reported that differences between parent proxy-reports and child self-reports of HRQOL were influenced by the child's age. ${ }^{7,25,40,49,59}$ Parsons et al. ${ }^{25}$ reported that the highest degree of difference between the child and parent report was seen in the physical functioning domain and the lowest for social functioning domain. This degree of difference was more evident in adolescents than in children with cancer. ${ }^{15,25}$

Gender. Gender is another frequently measured variable impacting HRQOL in children with cancer. However, of the 16 studies that examined gender as a variable of HRQOL, only four identified gender as a significant variable. In these studies, female gender was consistently associated with a lower HRQOL. ${ }^{8,13,44,45}$

Ethnicity. Few studies describe variations in HRQOL among ethnic groups and most of the studies were conducted among samples that included predominately white children. Only three studies examined ethnicity as a variable of HRQOL. ${ }^{7,39,45}$ Of these studies, Shankar et al. described the association of ethnicity on HRQOL of children undergoing curative cancer treatment, with non-white children reporting lower HRQOL than their white peers. ${ }^{45}$

\section{Family Factors Considered in the Systematic Review}

Few studies assessed the impact of family factors on the child's HRQOL during curative therapy; however, two studies found higher family functioning and involved parental care and bonding predicted higher physical HRQOL. ${ }^{40,49}$ Family resources were the strongest predictors of psychosocial HRQOL. ${ }^{40}$ Mothers with higher rated QoL were found to be predictive of the child's having higher HRQOL. ${ }^{16}$ In addition, parental overprotection was significantly related to a child's HRQOL $;^{40,42}$ higher parental overprotection and perceived child vulnerability were related to lower parent-proxy report of child HRQOL. ${ }^{40,42,46}$ Perceived child vulnerability mediated the effect of parental overprotection on children's HRQOL negatively. Higher family socio-economic status and annual income were also significant factors related to higher HRQOL in children with cancer. ${ }^{13,42}$ 


\section{Community Factors Considered in the Systematic Review}

A limited number of studies within our review addressed the association between community factors and HRQOL. Two studies attempted to measure the HRQOL difference in children treated in their home environment as opposed to being treated at a hospital. ${ }^{46,60}$ In these studies, both the child and parent reported a higher HRQOL when treated in a home environment as compared to a hospital environment. ${ }^{59}$ However, Stevens et al. ${ }^{60}$ described children as reporting more distress during treatment progression when at home. Tremolada et al. ${ }^{46}$ also found that when parents developed a trusting relationship with the hospital staff, the child reported a higher HRQOL.

\section{HRQOL Measurement Issues in Subject Studies}

Currently, there are numerous instruments that measure HRQOL in children. ${ }^{61}$ Additionally, there are disease-specific instruments that measure HRQOL in children with cancer, ${ }^{44,62}$ and instruments which measure HRQOL specific to the outcomes of a cancer diagnoses such as brain tumors. ${ }^{63}$ These instruments vary in the scope of domains measured, and the length and format of the questions. ${ }^{64}$ HRQOL instruments may be categorized as generic, disease-specific, and modular depending on their intended outcomes and disease population. ${ }^{65}$

The Pediatric Quality of life Scale (PedsQL) was found to be the most used generic module in the assessment of HRQOL in children with cancer (Figure 2-2). ${ }^{14,66}$ Other generic instruments by order of frequency include the Health Utility Index (HUI), and the Child Health Questionnaire (CHQ).

As for cancer-specific instruments, the PedsQL Cancer module was the most widely used cancer specific instrument in our review (Figure 2-3), followed by the Pediatric Oncology Quality of Life Scale (POQOLS). These findings were consistent with the systematic review based on Figure 2-1 and described earlier in this chapter.

Despite the reported variation of findings between studies using different instruments, most studies that utilized the PedsQL generic and cancer specific modules have reported similar findings. Studies that did not report consistent findings were more likely to have low sample size that impeded the power to reach conclusions with associated factors. ${ }^{41,49,50,67}$

These findings support the utilization of the most frequently used instruments in measuring HRQOL to identify and establish factors that significantly affect HRQOL of children with cancer. 


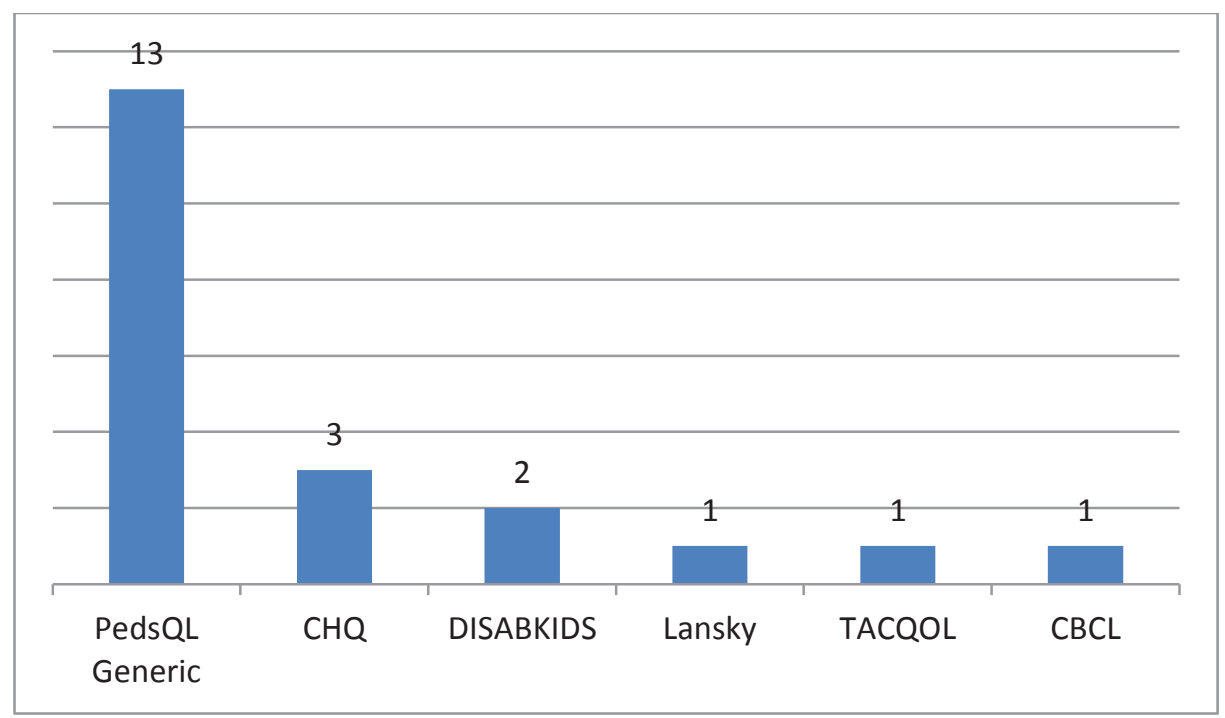

Figure 2-2. Generic HRQOL instruments used in the systematic review

PedsQL-Generic: Pediatric Quality of Life-Generic Scale; CHQ: Child Health Questionnaire; DISABKIDS: DISABKIDS instrument; Lansky: Lansky Performance Scale; TACQOL: TNO-AZL Child Quality of Life; CBCL: Child Behavior Checklist.

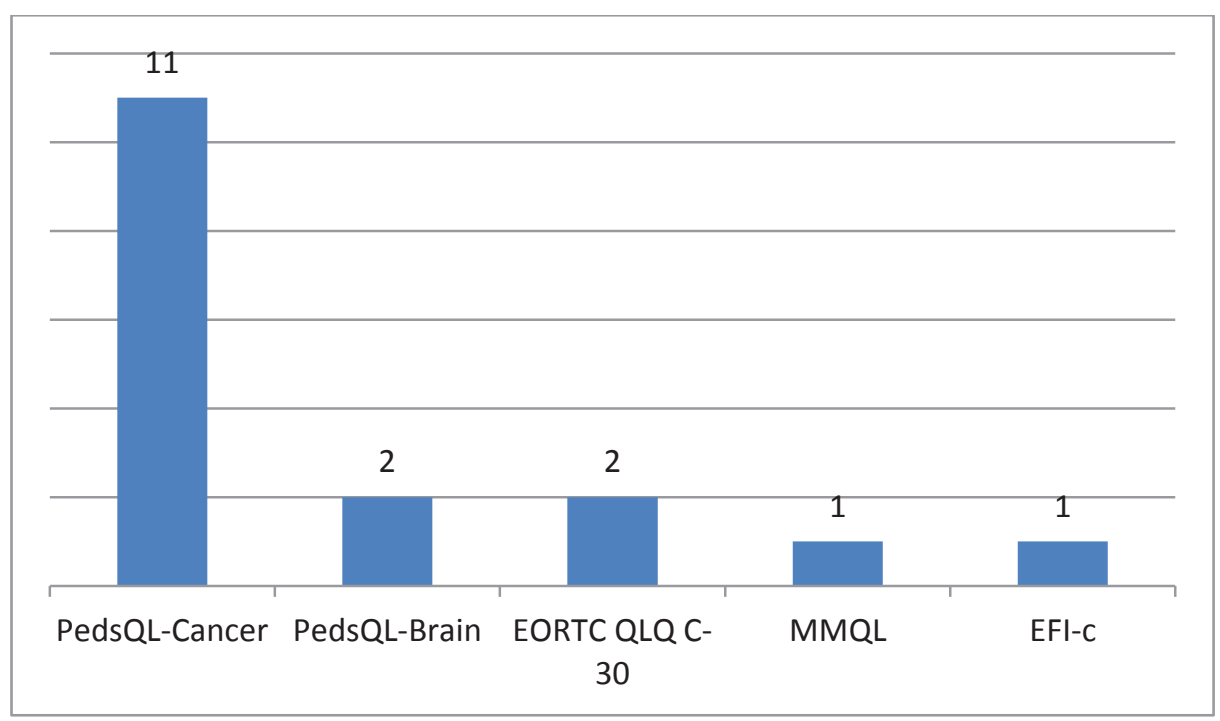

Figure 2-3. Cancer-specific scales used in the systematic review

PedsQL-Cancer: Pediatric Quality of Life - Cancer Module; EORTC QLQ C-30: European Organization for Research and Treatment of Cancer Quality of Life Questionnaire Cancer 30; MMQL: Minneapolis-Manchester Quality of Life; EFIc: Ecocultural Family Interview - cancer. 


\section{Conceptual Limitations of HRQOL Measurement}

Instruments measuring HRQOL in children with cancer have limitations due to lack of conceptual clarity in defining HRQOL. The concept of QoL was first introduced in the early 70's, as a means to measure the general satisfaction of healthy populations. ${ }^{20}$ Early in QoL research, the concept of QoL was viewed as an embodiment of change or interruption in health and well-being. At the time, health was widely viewed as a reflection of the physical aspects and domains of function. Thus, early HRQOL definitions corresponded with change and deterioration in physical health. This idea of limiting HRQOL definition to the functional domain is evident in earlier instruments that attempted to only measure aspects of functional physical activities. ${ }^{68}$ It is generally agreed, however, that the current scope of HRQOL measurement in children with cancer should include aspects of physical, social, emotional, psychological, and spiritual domains, ${ }^{1}$ most instruments fail to capture all these domains within their questions. ${ }^{66}$ Most notably, the domain of spiritual well-being is usually neglected due to the complex nature of this domain, exceeding the young children's cognitive development and ability to think abstractly. ${ }^{69,70}$

\section{Conclusion from the Systematic Review of Literature}

This review presents the current state of the science on the measurement and assessment of HRQOL in children undergoing curative cancer treatment. In addition to demographic and family factors, many treatment and cancer related factors significantly impact the HRQOL of children under curative cancer treatment. This review found time to be an important variable impacting HRQOL. Most studies of children under curative treatment were cross-sectional in nature and varied considerably in their sample size. Our review found limitations of the current research on HRQOL in children undergoing curative cancer treatment. These limitations can affect our understanding of the dynamic nature of HRQOL and the factors that impact the change in HRQOL over time.

The evidence from this review indicates a significant gap in comparing the impact of treatment types and treatment intensities on diagnostic groups. In addition, there is a lack of time-series studies that consider the dynamic change of HRQOL over time during curative cancer treatment. This review also points to wide variability in reporting and identifying factors impacting HRQOL in children with cancer. This variability can be explained by cross-sectional designs, small sample sizes, differences in instruments used to measure HRQOL as an outcome, and the dynamic nature of the HRQOL phenomenon. 


\section{CHAPTER 3. METHODOLOGY}

\section{Study Design}

This retrospective study analyzed HRQOL data collected from a convenience sample of children undergoing treatment for acute Lymphoblastic leukemia (ALL), acute myeloid leukemia (AML), Hodgkin's lymphoma (HL), osteosarcoma (OS), and melanoma (MEL). Data were collected from children and adolescents using two HRQOL instruments: The Pediatric Quality of Life Generic Core Scale version 4.0 (PedsQL Generic v4.0) and the Pediatric Quality of Life Cancer Module version 3.0 (PedsQL Cancer v3.0). The use of the same instruments in all groups allowed for comparisons between diagnostic groups. Reponses to these instruments were collected from patient self-report over multiple time points. These diagnostic groups varied in treatment modality, treatment intensity and treatment duration. In addition, diagnostic groups differed within groups according to stage of disease and treatment intensity. The overall aim of this study was to describe the HRQOL across time points within and between the diagnostic groups and to identify factors that impact the change in HRQOL over time.

\section{Sample and Setting}

Across the diagnostic groups, 720 patients were included in our HRQOL analyses. The sample included HRQOL data collected from children and adolescents treated on front-line (initial line of treatment) St. Jude Children's Research Hospital (SJCRH) protocols. SJCRH is a tertiary care hospital specialized in treating and caring for children with cancer and hematological disease. In addition to clinical care, the hospital has a research infrastructure that focuses on scientific advancement and improvement utilization of new treatment regimens for the treatment of childhood cancer. Patients at SJCRH are referred by an outside physician, and nearly all have a disease under clinical study, making them eligible for a research protocol. About 7,800 active patients are seen at SJCRH yearly; most are treated on a continuing outpatient basis as participants in ongoing research treatment protocols. The hospital has 78 hospital beds with admissions for chemotherapy or supportive care. Patients included in this study were between 5-18 years of age. Younger children were excluded as we could only obtain parent proxy reports of their HRQOL.

\section{Acute Lymphoblastic Leukemia (ALL)}

The SJCRH TOTALXV Protocol objective was to improve cure and health outcomes of children and adolescents diagnosed with acute lymphoblastic leukemia. The therapeutic aims of the protocol were to estimate the overall survival of children who were treated with a risk directed therapy and to monitor molecular remission induction rate. It also aimed to determine if CNS irradiation could be safely omitted in the context of the protocol's systematic therapy. In addition, it aimed to assess prognostic values of 
biological markers in childhood ALL. HRQOL data was collected from children and adolescents at designated time points during treatment. Protocol eligible patients were ages 1-18 years, diagnosed with precursor $\mathrm{B}$ cell or $\mathrm{T}$ cell leukemia and with no more than a week of prior therapy that is limited to glucocorticoids, vinca alkaloids, emergence radiation therapy and one dose of intrathecal chemotherapy.

At the time of diagnosis, patients were assigned to risk groups (low, standard, or high) according to genetic and molecular markers of their leukemia. Genetic and molecular markers predict treatment response and determine therapy intensity. Protocol Treatment for ALL consisted of three phases, Remission Induction (first 6-7 weeks), Consolidation (8weeks), and Continuation (120 weeks for girls and 146 weeks for boys).

HRQOL information was collected from patients on the treatment protocol at 4 time points in treatment: At day 40 of induction (T1), at week 7 of consolidation (T2), at week 48 of the treatment continuation phase (T3), and at the end of treatment. Since the treatment protocol differed in length based on gender, the end point of treatment (T4) was collected at week 120 for females, and week 146 for males which accounted for the end of treatment for each gender.

\section{Acute Myeloid Leukemia (AML)}

The AML02 was a frontline therapeutic protocol for the treatment of acute myeloid leukemia and aimed to compare immunologic and molecular remission induction rates in patients receiving two different induction therapy regimens. It also aimed to estimate the event-free survival (EFS) of AML patients who undergo risk-adapted and genotype-directed therapy, to assess the prognostic value of biological markers in childhood AML.

Patients were admitted to this treatment protocol if they had a confirmed diagnosis of AML, were less than 21 years, with no prior history of therapy for AML except for one dose of intrathecal chemotherapy. HRQOL data were collected from patients at baseline (T1), prior to induction II (T2), prior to consolidation III (T3), and at the completion of therapy (after count recovery following consolidation III) (T4). Patients enrolled in this protocol were categorized to 3 risk categories (low, standard, and high), based on cytogenetic and molecular characteristics, morphology, and response to therapy.

\section{Hodgkin Lymphoma (HL)}

Two protocols provided the HRQOL data for children and adolescents diagnosed with Hodgkin Lymphoma. Both HOD99 and HOD05 protocols utilized a risk adapted therapy approach to treat HL. The primary protocol objective was to estimate the event free survival distribution in intermediate risk Hodgkin's disease treated with Stanford V chemotherapy plus or minus low-dose, tailored-field radiation therapy. The protocols also aimed to determine patterns of treatment failure for children treated with or without 
tailored field radiation therapy and to describe patient quality of life during and after treatment from the patient and parent perspective. Eligible patients had histologically confirmed untreated Hodgkin's disease. Patients who were 21 years of age or younger, receiving limited emergent radiation therapy or steroid therapy because of cardiopulmonary decompensation or spinal cord compression were eligible for protocol enrollment.

Children and adolescents were assigned to one of three risk groups according to the extent of disease and biological subset. The risk groups were categorized as 1) Favorable; 2) Intermediate; and 3) Unfavorable groups. The groups varied in the intensity of chemotherapy and radiotherapy was delivered according to disease staging and response to treatment. Patients on the favorable risk arm did not receive radiotherapy. Therapy included 12 weeks of chemotherapy, followed by radiation therapy for intermediate and unfavorable risk groups. The dose to individual nodal sites was based on response after 8 weeks of chemotherapy: 15 Gy for patients achieving a complete response and 25.5 Gy achieving less than a complete response.

HRQOL data were obtained at baseline before the first treatment (T1); after 8 weeks of Stanford V (T2); after 12 weeks of chemotherapy and prior to or in the first few days of beginning radiation (T3); and at 3 to 6 months after completion of therapy follow-up evaluation (T4). The PedsQL-Cancer module was not required from patients at the beginning of treatment (T1). This step was taken as children who have not started treatment yet cannot give responses to many of the items on the PedsQL-Cancer module as they have not experienced the side-effects of cancer treatment.

\section{Melanoma (MEL)}

The primary treatment protocol aim for melanoma (MEL08) was to estimate the tumor response between two treatment arms assigned according to disease extent, in addition to identifying the impact of these therapies on patients' HRQOL. On this protocol, all patients with initial presentation of melanoma were treated with primary wide local excision with a minimum of $1 \mathrm{~cm}$ margin surrounding the primary lesion or biopsy scar. Patients with sentinel lymph node positive for disease underwent complete lymph node dissection of the involved nodal basin.

Patients were enrolled on MEL 08 if they had a histologic diagnosis of cutaneous malignant melanoma, were no more than 21 years of age, had adequate performance status and organ function, and did not receive any prior therapy for melanoma except for surgical resection of local and regional lymph nodes. Patients with localized disease must have undergone sentinel lymph node biopsy for positive disease. In cases of positive disease the patient had complete lymph node dissection of the involved nodal basin. Patients were excluded if they had prior therapy with dacarbazine or temozolomide, had a history of myocardial infarction, hypo or hyperthyroidism, diabetes mellitus, auto immune hepatitis, an uncontrolled infection, depression or other psychotic disorders, or were taking steroids. 
The MEL08 protocol required assignment to Stratum A or Stratum B. Patients assigned to Stratum A had a resected Stage IIC, IIIA and IIIB. Treatment included two phases of chemotherapy: Induction therapy over 4 weeks, receiving recombinant interferon $\alpha-2 b$ weekly. This was followed by Maintenance Therapy from week 5 to week 52. Patients enrolled on stratum B presented with Stage IIIC, Metastatic, Unresectable Stage III or Recurrent Disease and further divided into two groups based on the presence (Stratum B1) or absence (Stratum B2) of measurable disease. The dose and schedule of peginterferon $\alpha-2 b$ and temozolomide were the same for both groups. Patients receive 8 weekly doses of peginterferon $\alpha-2 b$ in combination with temozolomide daily for 6 weeks followed by a 2 week break. In the absence of recurrent disease or toxicity, patients in Stratum B2 received 7 courses of temozolomide in combination with peginterferon. Data were collected from children with melanoma at baseline before the start of treatment (T1); at week 4, the end of induction treatment (T2); at week 24 of treatment (T3); and at the end of treatment, at about 48 weeks from the beginning of treatment (T4).

\section{Osteosarcoma (OS)}

The aim of the Osteosarcoma protocol was to evaluate the feasibility of combining bevacizumab, a humanized monoclonal antibody against vascular endothelial growth factor with cisplatin, doxorubicin, and high-dose methotrexate (HDMTX) in patients with localized resectable osteosarcoma, and bevacizumab with cisplatin, doxorubicin, HDMTX, ifosfamide, and etoposide in patients with unresectable or metastatic osteosarcoma. The protocol also aimed to study the effect of adding bevacizumab to chemotherapy comprised of cisplatin, doxorubicin, and HDMTX on the event-free survival (EFS) in patients with localized resectable osteosarcoma compared to historical controls treated with cisplatin, doxorubicin, and HDMTX without bevacizumab. Thus, patients on this protocol were treated on one of two different arms according to the extent of tumor resection and metastatic status.

Patients were eligible for treatment if they: were younger than 30 years at diagnosis; had a newly diagnosed osteosarcoma; had adequate performance and organ function measures and had no previous chemotherapy or radiation therapy. Patients were excluded if they had a surgical procedure with serious or non-healing wounds, known bleeding disorders or coagulopathy, a deep vein thrombosis, cardiac disease or hypertension, proteinuria, central nervous system disease, or gastrointestinal perforation.

Children's and adolescents' disease was categorized according to the extent of tumor metastasis, i.e., localized, localized unresectable, or metastatic disease. Both treatment arms included chemotherapy, followed by radiotherapy, and additional chemotherapy after surgery recovery. The duration of treatment, however, differed between both groups; children with a resectable tumor were treated for a total of 31 weeks, while children with an unresectable tumor were treated for 39 weeks. 
HRQOL data was assessed for both arms of treatment at 4 time points: at diagnosis (T1), at week 8 and after cycle 2 of chemotherapy (T2), prior to radiation therapy or after cycle 4 of chemotherapy (T3), and at the end of radiation therapy (T4).

\section{Instruments}

This study measured HRQOL using the Pediatric Quality of Life Scale (PedsQL) Generic Core Scale v 4.0 $0^{71}$ and the PedsQL Cancer Module v 3.0 (Appendix A). ${ }^{72}$ These PedsQL scales are the most widely used quality of life scales in pediatric cancer research and include Generic and Cancer specific scales. ${ }^{14}$ The instruments have high reliability and validity and have been utilized extensively as outcome measures in research and clinical practice. $^{66,72-74}$

\section{PedsQL Generic Core Scale (PedsQL-Generic)}

The 23-item multidimensional PedsQL 4.0 Generic Core Scales includes four domains: physical functioning (8 items), emotional functioning (5 items), social functioning (5 items), and school functioning (5 items). Child self-report includes ages 57 years (young child), ages 8-12 years (child), and ages 13-18 years (adolescent). A 5point Likert response scale is utilized across child self-report for ages $8-18$ years. That is, $0=$ never a problem; $1=$ almost never a problem; $2=$ sometimes a problem; $3=$ often a problem; 4=almost always a problem.

To further increase the ease of use for the young child self-report (ages 5-7 years), the Likert scale is reworded and simplified to a 3 -point scale. That is, $0=$ not at all a problem; $2=$ sometimes a problem; $4=$ a lot of a problem; with each response choice anchored to a happy to sad faces scale. ${ }^{72}$ Items are reverse-scored and linearly transformed to a $0-100$ scale so that higher PedsQL 4.0 scores indicate better HRQOL (Appendix A). ${ }^{72}$ PedsQL v 4.0 Generic core scales have been heavily tested on different child population groups and have been shown to be valid and reliable. ${ }^{61,71}$

The PedsQL Generic scale internal consistency generally exceeds the standard of 0.70 for group comparisons. ${ }^{71}$ The Total Scale Score Cronbach alpha was 0.88 for child report, making the Total Scale Score suitable as a summary score for the primary analysis of HRQOL outcomes in clinical trials and other group comparisons.

The Physical Health $(\alpha=0.8)$ and Psychosocial Health $(\alpha=0.83)$ Summary Scores achieved high reliability scores as recommended for secondary analyses. The school functioning subscale for ages 5 to 7 was the only subscale that did not approach or exceed $0.70 .^{71}$ Considering that the physical health score is the same as physical summary score, and since the psychosocial summary score is a combination of emotional, social, and school scores, we reported in this study on 5 HRQOL domains: physical, emotional, social, and school domains, in addition to the total HRQOL summary score. 


\section{PedsQL Cancer Module (PedsQL-Cancer)}

The 27-item multidimensional PedsQL 3.0 Cancer Module Acute Version includes 8 domains: pain and hurt ( 2 items), nausea (5 items), procedural anxiety (3 items), treatment anxiety (3 items), worry (3 items), cognitive problems (5 items), perceived physical appearance ( 3 items), and communication ( 3 items). The format, instructions, Likert response scale, and scoring method are identical to the PedsQL 4.0 Generic Core Scales Acute Version, with higher scores indicating fewer problems and symptoms or better HRQOL. ${ }^{72}$ The PedsQL 3.0 Cancer Module Scales internal consistency reliabilities generally exceeded the recommended minimum alpha coefficient standard of 0.70 for group comparisons for child self-report ages $8-18$ years. $^{72}$

\section{Data Management Procedure}

Data for this study were previously collected as a secondary objective within each frontline treatment protocol at SJCRH. Approvals to conduct this retrospective analysis were obtained from both SJCRH and University of Tennessee Health Science Center Institutional Review Boards (Appendix B). Approval to use and collect the instruments was obtained (Appendix C).The primary investigator and faculty sponsor obtained necessary permission to access de-identified data for the purpose of this study.

Data were collected at specified time-points for each treatment protocol during face-to-face interviews. These data were collected by trained research nurses. The assigned research nurse followed the child's appointment and scheduled an interview at the designated time point for HRQOL data collection. The research nurse would remain with the family as they completed the questionnaires should the family or children have questions or concerns.

\section{Statistical Analysis}

Patient demographics were summarized for each diagnostic group by descriptive statistics (frequency and percent, mean and standard deviation, and median and range). HRQOL data were scored using the algorithm provided by the instrument manual. ${ }^{75}$ Internal consistency for each instrument domain was evaluated by Cronbach's alpha coefficients within each diagnostic group. The minimum standard of 0.70 for Cronbach's alpha coefficients was assumed for adequate internal reliability. ${ }^{72}$ HRQOL scores were summarized for each diagnostic group by domain at each time point in treatment using descriptive statistics (mean and standard deviation). HRQOL domains were scored using the instruction manual authored by James Varni (version 5: updated March 2014). Items were reverse scored and linearly transformed to a $0-100$ scale $(0=100,1=75,2=50,3=25$, $4=0$ ), so that higher scores indicate better HRQOL. Domain scores were computed as the sum of the items answered divided by the number of items answered. If more than $50 \%$ of the items in the domain are missing, then the domain score was not computed. ${ }^{75}$ Time at treatment was based on previously selected time points during data collection for each 
diagnostic group. For each diagnostic group, a time point representing the beginning of treatment (T1), two time points representing significant clinical incidents that correspond with treatment changes (T2, T3) and a time-point at the end of treatment (T4) were selected to represent changes over time in each diagnostic group, and to compare HRQOL between different diagnostic groups.

\section{Aim 1}

Aim 1 was to identify longitudinal trends in HRQOL change in diagnostic groups of children undergoing curative cancer treatment. The following research questions were related to this aim:

- $\quad$ Research Question 1-1: What is the self-reported HRQOL of children undergoing curative cancer treatment within each diagnostic group at each time point?

- $\quad$ Research Question 1-2: What is the difference in self-reported HRQOL of children undergoing curative cancer treatment at each time point within each diagnostic group?

To address these questions, HRQOL scores were summarized for each diagnostic group by domain at each time point using descriptive statistics (mean and standard deviation). Plots were also used to represent the data. The mixed effects linear model for repeated measures was used to assess change in HRQOL over time within each diagnostic group. An appropriate correlation structure was used to account for the correlation among repeated measurements made on the same patient.

\section{Aim 2}

Aim 2 was to identify the differences in HRQOL among different diagnostic groups of children undergoing curative cancer treatment. One question was related to this aim:

- $\quad$ Research Question 2-1: What is the difference in self-reported HRQOL of children undergoing curative cancer treatment between different diagnostic groups at each time point?

The mixed effects linear model for repeated measures was used to compare HRQOL over time between different diagnostic groups. An appropriate correlation structure was used to account for the correlation among repeated measurements made on the same patient. The model included the diagnostic group and time. 


\begin{abstract}
Aim 3
Aim 3 was to identify correlates with HRQOL of children undergoing curative cancer treatment over time within each diagnostic group. Three questions were related to this aim:
\end{abstract}

- $\quad$ Research Question 3-1: Is there an association between cancer and treatment factors and self-reported HRQOL of children undergoing curative cancer treatment over time?

- $\quad$ Research Question 3-2: What is the combined effect of cancer and treatment factors on the self-reported HRQOL of children undergoing curative cancer treatment in each diagnostic group?

- $\quad$ Research Question 3-3: What are the associations between each variable and the change in self-reported HRQOL of children undergoing curative cancer treatment?

To answer these three questions, the following statistical procedures were undertaken accordingly:

Univariate Analysis. The mixed effects linear model for repeated measures was used to examine the relationship of demographic variables and cancer and treatment factors to HRQOL. An appropriate correlation structure was used to account for the correlation among repeated measurements made on the same patient.

The following demographic and cancer and treatment factors were considered: gender, age at enrollment (child: age $<13$ years, teen: age $\geq 13$ years), race (white, other), time point in treatment, blocks of radiation received (none, 1 block, $>1$ block), and risk group (favorable, intermediate, unfavorable).

Multivariate Analysis. The criterion of $\mathrm{p}<0.1$ was used to select factors from the univariate model to include in the multivariable model. The mixed effects linear model for repeated measures was used to examine the effects of all selected factors on HRQOL.

An appropriate correlation structure was used to account for the correlation among repeated measurements made on the same patient. The multivariate model included main effects only (i.e., no interaction). A two-sided significance level of $p<0.05$ was used for all statistical tests unless otherwise stated. Statistical analyses were conducted using SAS 9.3 (SAS Institute, Cary, NC). 


\section{Human Studies Protection}

\section{Potential Risk to Participants}

Many concerns and consideration arise when conducting research in a vulnerable population such as children. These issues include the compromised state of the child's ability to process and consent to research. ${ }^{76}$ These issues are inherent in most research involving children and were addressed in this study. Data collection policies in this study dictated that in addition to parental consent to participate, the child was also asked to give assent. This question was asked verbally of any child who was developmentally capable of responding to the items on the questionnaires, and was required to be written at age 14 . Children were also given the option to answer the questionnaire at a later time, to choose not to respond at a later stage in their treatment trajectory, or to opt out of participation at any time they wanted. While this issue can compromise the completeness of the data, it ensures that no coercion was used to influence the child's and parent's participation in research.

Despite the minimally invasive approach in this study (responding to questionnaires), the use of questionnaire and interview questions can cause emotional discomfort and unpleasant feelings. ${ }^{77,78}$ In this case, the child could have decided not to answer such questions and would have been referred to a psychological service as instructed in the data collection protocol.

\section{Benefits to Participants and Society}

This study has potential benefit to children undergoing curative cancer treatment. Through the identification of treatment related factors that impact HRQOL change in children undergoing curative cancer treatment, interventions can be developed to specifically target diagnostic groups with lower HRQOL. The identification of domains of lower HRQOL allows researchers and clinicians to identify and intervene on these domains in an attempt to improve HRQOL and the illness experience of children undergoing curative cancer treatment. This allows for improved screening and management of symptoms that result in lower HRQOL in children and adolescents with cancer. Furthermore, identifying critical time points within diagnostic groups allows for targeting children at these time points with interventions that specifically address factors impacting HRQOL changes in children under curative cancer treatment. 


\section{CHAPTER 4. RESULTS}

\section{Description of the Sample}

The study sample included 710 participants across five diagnoses, including children and adolescents with Hodgkin lymphoma, acute lymphoblastic leukemia, acute myeloid leukemia, osteosarcoma, and melanoma. A study participant was defined as a child who had undergone and completed treatment at St. Jude Children's Research Hospital (SJCRH). The demographic data of the participants by diagnostic group are shown in Table 4-1.

Some of the demographic descriptions provided in the description tables are intended for thorough descriptive purposes. For statistical analysis purposes, age was categorized into two categories instead of three (Children ages 5-12 vs. Teenagers ages 13-18). Race was also categorized into White vs. Other races.

\section{Acute Lymphoblastic Leukemia}

The study included 234 participants with acute lymphoblastic leukemia (ALL).

Table 4-2 presents the demographics of the ALL participants by gender, age, and ethnicity across risk group. A greater percentage of this diagnostic group was male, and most of the sample was of white race.

\section{Acute Myeloid Leukemia}

The study included 86 participants with acute myeloid leukemia (AML). Table 4-3 presents the demographics of the AML participants by gender, age, and ethnicity across risk group.

\section{Hodgkin Lymphoma}

The study included 251 participants with HL. Table 4-4 presents the demographics of HL participants by gender, age, and ethnicity across risk group.

\section{Melanoma}

The study included 23 participants with Melanoma. The small sample size didn't allow for meaningful description of the effect of different variables on the HRQOL of the group, thus only a univariate analysis was performed on children with melanoma.

Table 4-5 presents the demographics of the Melanoma group. 
Table 4-1. Demographics of study participants by diagnostic group

\begin{tabular}{|c|c|c|c|c|c|c|c|c|c|c|c|c|}
\hline \multirow[b]{3}{*}{ Factor } & \multicolumn{10}{|c|}{ Diagnostic Group } & & \\
\hline & \multicolumn{2}{|c|}{$\operatorname{ALL}(n=234)$} & \multicolumn{2}{|c|}{ AML $(n=86)$} & \multicolumn{2}{|c|}{ HL $(n=251)$} & \multicolumn{2}{|c|}{$\begin{array}{c}\text { MEL } \\
(n=23)\end{array}$} & \multicolumn{2}{|c|}{$\operatorname{OS}(n=116)$} & \multicolumn{2}{|c|}{ Total $(N=710)$} \\
\hline & $\mathbf{n}$ & $\%$ & n & $\%$ & $n$ & $\%$ & $\mathbf{n}$ & $\%$ & $n$ & $\%$ & $\mathbf{N}$ & $\%$ \\
\hline Gender & & & & & & & & & & & & \\
\hline Female & 88 & 38 & 39 & 45 & 133 & 52 & 11 & 48 & 50 & 43 & 321 & 45 \\
\hline Male & 146 & 62 & 47 & 55 & 118 & 48 & 12 & 52 & 66 & 57 & 389 & 55 \\
\hline Age & & & & & & & & & & & & \\
\hline $\begin{array}{l}\text { Young child } \\
\text { (ages 5-7) }\end{array}$ & 84 & 36 & 10 & 11 & 8 & 3 & 3 & 13 & 9 & 8 & 114 & 16 \\
\hline $\begin{array}{l}\text { Child (ages 8- } \\
12 \text { ) }\end{array}$ & 84 & 36 & 33 & 38 & 46 & 18 & 5 & 22 & 39 & 34 & 207 & 29 \\
\hline $\begin{array}{l}\text { Teen(ages 13- } \\
18)\end{array}$ & 66 & 28 & 43 & 51 & 197 & 79 & 15 & 65 & 68 & 58 & 389 & 55 \\
\hline Ethnicity & & & & & & & & & & & & \\
\hline White & 188 & 80 & 57 & 68 & 192 & 76 & 16 & 70 & 76 & 66 & 529 & 75 \\
\hline Black & 37 & 16 & 19 & 24 & 49 & 20 & 2 & 9 & 28 & 24 & 135 & 19 \\
\hline Other & 9 & 4 & 10 & 8 & 10 & 4 & 5 & 21 & 12 & 10 & 46 & 6 \\
\hline
\end{tabular}

ALL: acute lymphoblastic leukemia; AML: acute myeloid leukemia; HL: Hodgkin lymphoma; MEL: melanoma; OS: osteosarcoma. 
Table 4-2. Demographics of patients with acute lymphoblastic leukemia by risk group

\begin{tabular}{|c|c|c|c|c|c|c|c|c|}
\hline \multirow[b]{3}{*}{ Factor } & \multicolumn{6}{|c|}{ Risk } & & \\
\hline & \multicolumn{2}{|c|}{$\begin{array}{c}\text { Low } \\
(n=94)\end{array}$} & \multicolumn{2}{|c|}{ Standard $(n=130)$} & \multicolumn{2}{|c|}{$\begin{array}{c}\text { High } \\
(n=10)\end{array}$} & \multicolumn{2}{|c|}{ All $(n=234)$} \\
\hline & $\mathbf{n}$ & $\%$ & $\mathbf{n}$ & $\%$ & $\mathbf{n}$ & $\%$ & $\mathbf{n}$ & $\%$ \\
\hline \multicolumn{9}{|l|}{ Gender } \\
\hline Female & 44 & 47 & 41 & 32 & 3 & 30 & 88 & 38 \\
\hline Male & 50 & 53 & 89 & 68 & 7 & 70 & 146 & 62 \\
\hline \multicolumn{9}{|c|}{ Age } \\
\hline \multicolumn{8}{|c|}{ Young child (ages 5- } & 36 \\
\hline Child (ages 8-12) & 32 & 34 & 49 & 38 & 3 & 30 & 84 & 36 \\
\hline Teen (ages 13-18) & 9 & 10 & 55 & 42 & 2 & 20 & 66 & 28 \\
\hline \multicolumn{9}{|l|}{ Ethnicity } \\
\hline White & 81 & 86 & 102 & 78 & 5 & 50 & 188 & 80 \\
\hline Black & 10 & 11 & 23 & 18 & 4 & 40 & 37 & 16 \\
\hline Other & 3 & 3 & 5 & 4 & 1 & 10 & 9 & 4 \\
\hline
\end{tabular}


Table 4-3. Demographics of patients with acute myeloid leukemia by risk group

\begin{tabular}{|c|c|c|c|c|c|c|c|c|}
\hline \multirow[b]{3}{*}{ Factor } & \multicolumn{6}{|c|}{ Risk Group } & & \\
\hline & \multicolumn{2}{|c|}{$\operatorname{Low}(n=29)$} & \multicolumn{2}{|c|}{ Standard $(n=25)$} & \multicolumn{2}{|c|}{ High $(n=32)$} & \multicolumn{2}{|c|}{ Total $(n=86)$} \\
\hline & $\mathbf{n}$ & $\%$ & $\mathbf{n}$ & $\%$ & $\mathbf{n}$ & $\%$ & $\mathbf{n}$ & $\%$ \\
\hline \multicolumn{9}{|l|}{ Gender } \\
\hline Female & 15 & 52 & 10 & 40 & 14 & 44 & 39 & 45 \\
\hline Male & 14 & 48 & 15 & 60 & 18 & 56 & 47 & 55 \\
\hline Age & & & & & & & & \\
\hline $\begin{array}{l}\text { Young child } \\
\text { (ages 5-7) }\end{array}$ & 3 & 10 & 1 & 4 & 6 & 19 & 10 & 12 \\
\hline $\begin{array}{l}\text { Child (ages 8- } \\
12 \text { ) }\end{array}$ & 13 & 45 & 10 & 40 & 10 & 31 & 33 & 38 \\
\hline $\begin{array}{l}\text { Teen (ages 13- } \\
18)\end{array}$ & 13 & 45 & 14 & 56 & 16 & 50 & 43 & 50 \\
\hline Ethnicity & & & & & & & & \\
\hline White & 19 & 65 & 16 & 64 & 22 & 68 & 57 & 66 \\
\hline Black & 8 & 28 & 6 & 24 & 5 & 16 & 19 & 22 \\
\hline Other & 2 & 7 & 3 & 12 & 5 & 16 & 10 & 12 \\
\hline
\end{tabular}


Table 4-4. Demographics of patients with Hodgkin lymphoma by risk group

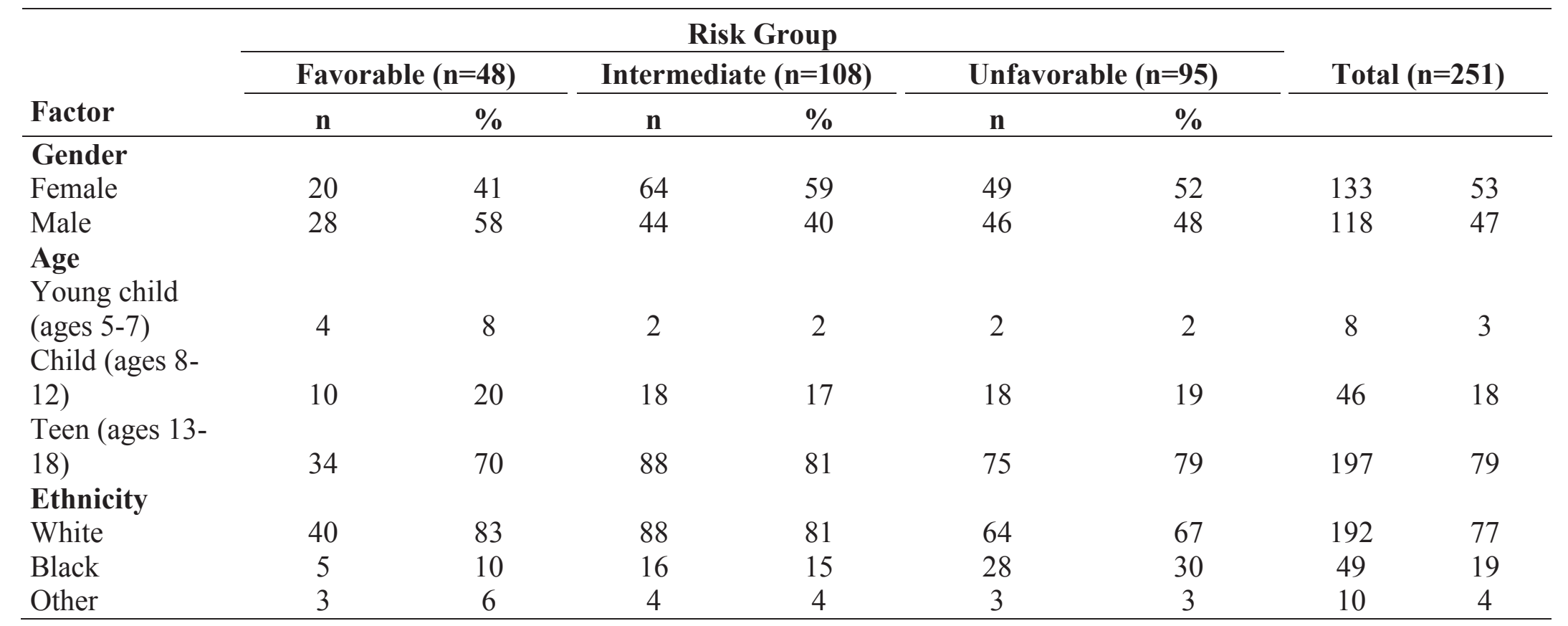


Table 4-5. Demographics of patients with melanoma

\begin{tabular}{lcc}
\hline & \multicolumn{2}{c}{ Total $(\mathbf{n}=\mathbf{2 3})$} \\
\cline { 2 - 3 } Factor & $\mathbf{n}$ & $\mathbf{\%}$ \\
\hline Gender & 11 & 48 \\
Female & 12 & 52 \\
Male & & \\
Age & 3 & 13 \\
Young child (ages 5-7) & 5 & 22 \\
Child (ages 8-12) & 15 & 65 \\
Teen (ages 13-18) & & 69 \\
Ethnicity & 16 & 9 \\
White & 2 & 22 \\
Black & 5 & \\
Other & & \\
\hline
\end{tabular}




\title{
Osteosarcoma
}

The study included 116 participants with Osteosarcoma (OS) treated across two protocols, OS99 and OS08. Table 4-6 presents the demographics of the OS participants by gender, age, and ethnicity across the two study groups.

\begin{abstract}
$\operatorname{Aim} 1$
Aim 1 was to identify longitudinal trends in HRQOL change in diagnostic groups of children undergoing curative cancer treatment. Two research questions were proposed to address this aim. The research questions to answer this aim were:

- $\quad$ Research Question 1-1: What is the self-reported HRQOL of children undergoing curative cancer treatment within each diagnostic group at each time point?

- $\quad$ Research Question 1-2: What is the difference in self-reported HRQOL of children undergoing curative cancer treatment at each time point within each diagnostic group?

To address these questions, HRQOL scores were summarized for each diagnostic group by domain at each time point using descriptive statistics (mean and standard deviation). The results are presented according to the domains of the PedsQL-Generic scale (physical, emotional, social, school), and the PedsQL-Cancer specific module (pain and hurt, nausea, procedural anxiety, treatment anxiety, cancer worry, cognitive problems, perceived physical appearance, communication).

For consistency, results in each diagnostic group are presented separately. Higher scores indicate fewer problems and symptoms or better HRQOL on the PedsQL-Generic and the PedsQL-Cancer modules. The results for each group are presented alphabetically in the same order they were presented in the demographic description section; acute lymphoblastic leukemia (ALL), acute myelocytic leukemia (AML), Hodgkin lymphoma (HL), melanoma, and osteosarcoma (OS).

Demographic descriptions are provided for each group in addition to the scores of each domain and cancer-related symptom in that particular group. In this section, a brief overview of the self-reported HRQOL in each group in addition to identifying differences in these self-reported HRQOL scores within each diagnostic group will be presented as well to give an overview of the longitudinal trends within each diagnostic group. These results pertain to each group separately and do not present comparisons with other diagnostic groups.
\end{abstract}


Table 4-6. Demographics of patients with osteosarcoma by study

\begin{tabular}{|c|c|c|c|c|c|c|}
\hline \multirow[b]{3}{*}{ Factor } & \multicolumn{4}{|c|}{ Study } & & \\
\hline & \multicolumn{2}{|c|}{ OS99 $(n=75)$} & \multicolumn{2}{|c|}{ OS08 $(n=41)$} & \multicolumn{2}{|c|}{ Total $(n=116)$} \\
\hline & $\mathbf{n}$ & $\%$ & $\mathbf{n}$ & $\%$ & $\mathbf{n}$ & $\%$ \\
\hline \multicolumn{7}{|l|}{ Gender } \\
\hline Female & 32 & 43 & 18 & 44 & 50 & 43 \\
\hline Male & 43 & 57 & 23 & 56 & 66 & 57 \\
\hline \multicolumn{7}{|l|}{ Age } \\
\hline $\begin{array}{l}\text { Young child } \\
\text { (ages 5-7) }\end{array}$ & 7 & 9 & 2 & 5 & 9 & 8 \\
\hline Child (ages 8-12) & 21 & 28 & 18 & 44 & 39 & 34 \\
\hline Teen (ages 13- & 47 & 63 & 21 & 51 & 68 & 58 \\
\hline Ethnicity & & & & & & \\
\hline White & 54 & 72 & 22 & 54 & 76 & 66 \\
\hline Black & 14 & 19 & 14 & 34 & 28 & 24 \\
\hline Other & 7 & 9 & 5 & 12 & 12 & 10 \\
\hline
\end{tabular}




\section{Acute Lymphoblastic Leukemia}

At day 40 of after the beginning of treatment (T1), participants with ALL had a mean HRQOL score of 68. This score steadily improved during treatment to an average score of 75 at the last time point (T4).All domains of HRQOL in children with ALL were less than 80 except for the social functioning domain at T2 (80.01) and T4 (82.21). Physical functioning was the lowest scoring domain at T1 (60.70); however, it improved at T2 through T4. The lowest domain across time was school, with the exception of T1, while social function was the highest scoring domain across all time-points.

As for cancer symptoms, all symptoms scored lower than 80 except for treatment anxiety. Procedural anxiety was the lowest scoring symptom, reflecting poorer HRQOL outcomes and more symptoms, at T1 (54.67), however, it improved over time reaching highest score at T4 (76.71). The lowest symptom scores at the end of treatment (T4) were for pain and hurt (70.57) and nausea (71.65). Procedural anxiety being the lowest domain at the initial time point. As treatment progressed, nausea became the lowest domain, with poorest outcomes, at both $\mathrm{T} 2$ and $\mathrm{T} 3$.

Physical Functioning. The physical functioning domain started as the lowest scoring domain in children with ALL, lower than all other domains. However, physical functioning improved at T2 and a stable score was maintained through treatment, achieving an increase from $\mathrm{T} 1$ to $\mathrm{T} 4$.

Emotional Functioning. Emotional functioning started at a mean score of 71 at $\mathrm{T} 1$, this score improved at $\mathrm{T} 2$, however, it dipped again at $\mathrm{T} 3$, and it eventually regained a higher score at $\mathrm{T} 4$ in comparison to $\mathrm{T} 1$.

Social Functioning. Social functioning was the highest mean score domain in children with ALL across all time points in treatment. It started at a mean score of 79.6 at T1, plateaued at T2 and T3, and reached a high score of 82.2 at T4.

School Functioning. School functioning maintained a steady score throughout treatment for children with ALL. School functioning was the lowest scoring domain at all time-points except for beginning of treatment (T1), where it was the second lowest domain after the physical functioning domain.

Total Score. Children with ALL reported an increase in their total HRQOL score at $\mathrm{T} 2$ in comparison to $\mathrm{T} 1$. The total score then decreased at T3, but increased again at the end of treatment (T4) to comparable levels of T2. In general, the total HRQOL score at the end of treatment (T4) is higher than at the beginning of treatment (T1).

Table 4-7 presents the HRQOL outcomes collected using the PedsQL-Generic and PedsQL-Cancer scales for the ALL group across all time points and domains.

Figure 4-1 presents the plotting of different HRQOL domain average scores across time on the PedsQL-Generic and the PedsQL-Cancer scales. Higher scores on the PedsQLGeneric and PedsQL-Cancer indicate fewer symptoms and better HRQOL. 
Table 4-7. Domains and symptoms of HRQOL outcomes over time in ALL

\begin{tabular}{|c|c|c|c|c|c|c|c|c|c|c|c|c|}
\hline \multirow[b]{2}{*}{ HRQOL } & \multicolumn{3}{|c|}{ T1 } & \multicolumn{3}{|c|}{$\mathrm{T} 2$} & \multicolumn{3}{|c|}{ T3 } & \multicolumn{3}{|c|}{ T4 } \\
\hline & $\mathbf{n}$ & Mean & StdDev & $\mathbf{n}$ & Mean & StdDev & $\mathbf{n}$ & Mean & StdDev & $\mathbf{n}$ & Mean & StdDev \\
\hline \multicolumn{13}{|l|}{ PedsQL-Generic Domains } \\
\hline Total Score & 209 & 68.66 & 17.19 & 203 & 75.14 & 16.04 & 169 & 73.55 & 14.75 & 158 & 75.70 & 14.35 \\
\hline Physical Functioning & 209 & 60.70 & 25.99 & 203 & 73.89 & 19.90 & 169 & 73.09 & 18.89 & 158 & 75.18 & 18.89 \\
\hline Emotional Functioning & 209 & 71.06 & 20.19 & 202 & 76.07 & 19.20 & 169 & 73.59 & 17.85 & 158 & 77.34 & 18.17 \\
\hline Social Functioning & 207 & 79.61 & 18.47 & 202 & 80.01 & 17.73 & 169 & 79.41 & 18.57 & 158 & 82.21 & 16.74 \\
\hline School Functioning & 156 & 67.27 & 23.22 & 167 & 70.10 & 22.16 & 156 & 68.17 & 19.60 & 150 & 68.10 & 18.81 \\
\hline \multicolumn{13}{|l|}{ PedsQL-Cancer Domains } \\
\hline Pain and Hurt & 206 & 67.17 & 27.80 & 200 & 79.38 & 22.62 & 168 & 68.75 & 25.81 & 158 & 70.57 & 28.92 \\
\hline Nausea & 206 & 72.96 & 19.55 & 200 & 63.44 & 20.19 & 167 & 68.77 & 18.27 & 158 & 71.65 & 17.36 \\
\hline Procedural Anxiety & 206 & 54.67 & 30.77 & 199 & 64.15 & 28.44 & 166 & 71.99 & 28.44 & 158 & 76.71 & 27.13 \\
\hline Treatment Anxiety & 205 & 82.87 & 23.02 & 200 & 86.42 & 19.86 & 167 & 89.97 & 16.90 & 157 & 91.03 & 16.89 \\
\hline Cancer Worry & 203 & 73.21 & 24.13 & 198 & 72.47 & 24.31 & 167 & 75.85 & 22.88 & 158 & 81.38 & 19.35 \\
\hline Cognitive Problems & 200 & 75.25 & 21.13 & 197 & 75.53 & 20.84 & 167 & 76.27 & 20.33 & 158 & 75.24 & 20.42 \\
\hline Perceived Physical Appearance & 206 & 78.64 & 23.65 & 200 & 78.96 & 24.34 & 167 & 75.85 & 24.61 & 159 & 80.45 & 23.19 \\
\hline Communication & 204 & 76.08 & 23.75 & 201 & 77.03 & 22.46 & 167 & 79.09 & 21.60 & 159 & 83.44 & 18.06 \\
\hline
\end{tabular}



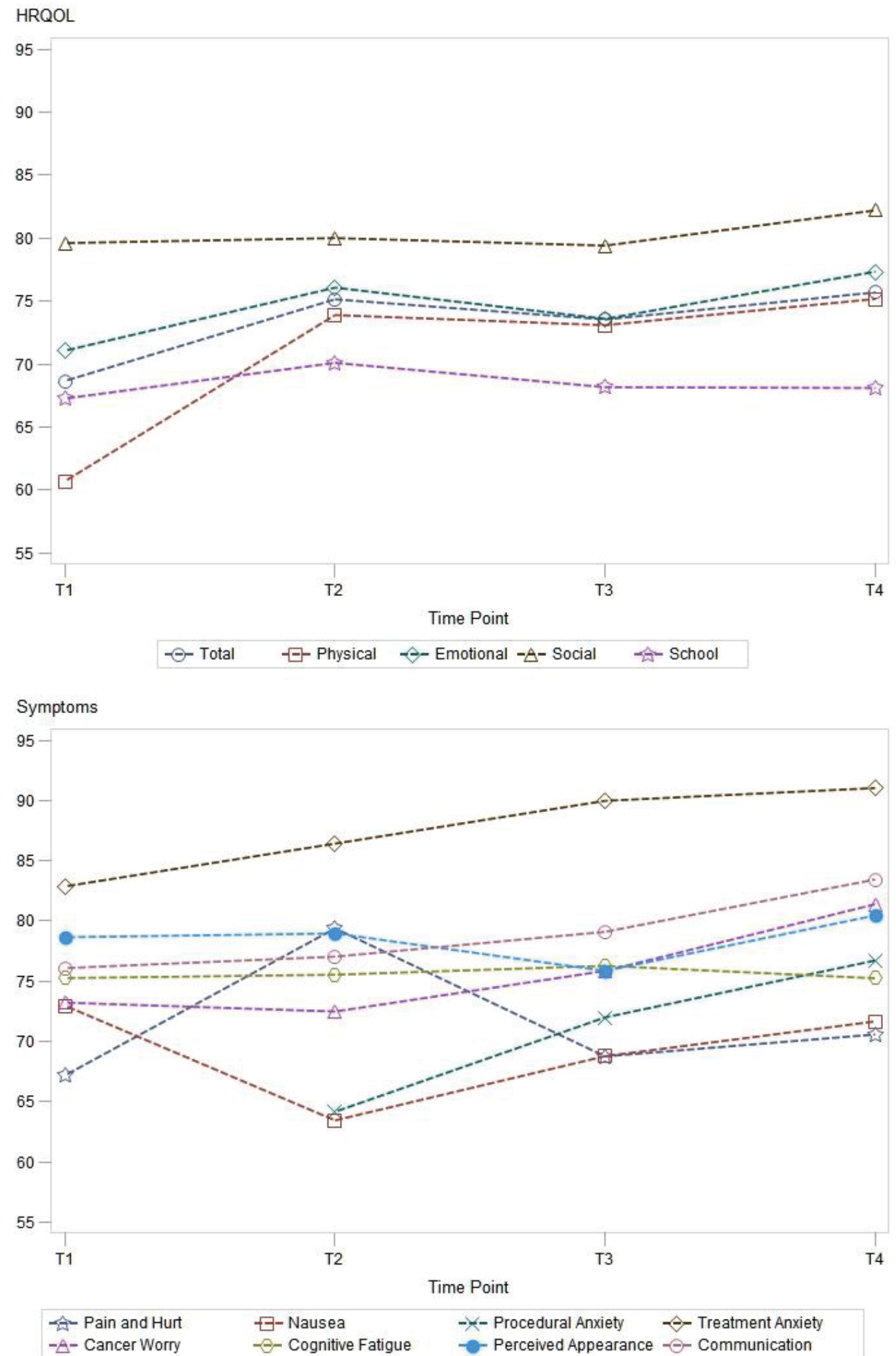

Figure 4-1. HRQOL domain average scores across time on the PedsQL-Generic and the PedsQL-Cancer scales for the ALL group 


\section{Acute Myeloid Leukemia}

All HRQOL domains in children with AML domains scored well below 80, except for the social functioning domain (85.56). The lowest scoring domains at T1 are the emotional functioning domain (65.07) and the physical functioning domain (65.41). During treatment at T2, the physical functioning domain experiences a significant drop (60.05), this trend is also experienced in the school functioning domain (67.51) and is reflected by a non-significant decrease in the total score (69.33). This trend is gradually resolved at T3, where all domains experience a gradual increase in their scores, and this trend carries over to the end of treatment (T4), where all domains are s higher than at the beginning of treatment (T1). Data related to cancer symptoms were not reported for children with AML at the beginning of treatment (T1). Throughout treatment (T2, T3), the lowest scoring cancer-related symptoms were nausea (T2, 59.86; T3, 65.33) and procedural anxiety $(\mathrm{T} 2,60.75 ; \mathrm{T} 3,66.76)$. Over time, children with AML report an improvement in all cancer-related symptom scores at the end of treatment (T4) in comparison to the beginning of treatment (T1).

Table 4-8 presents the HRQOL outcomes for the AML group across all time points and domains collected using the PedsQL-Generic and the PedsQL-Cancer scales. Higher scores on the scales indicate better HRQOL and fewer symptoms. Figure 4-2 presents the plotting of different HRQOL domain average scores across time on the PedsQL-Generic and the PedsQL-Cancer scales.

Physical Functioning. Physical functioning at T1 averaged at 65.41 for children with AML. This score dropped further at T2 to reach 60. However, it slowly improved at $\mathrm{T} 3$ and at T4 reaching a maximum score of 85 at the end of treatment (T4).

Emotional Functioning. Emotional functioning was the lowest scoring domain at the beginning of treatment at T1. However, emotional functioning was found to have trending improvement through treatment, reaching a mean score of 84.85 at T4.

Social Functioning. Social function was the highest mean score domain across all domain and time points in children with AML. The mean score for the social domain started at 85.6, reaching a high score of 92.5 at $\mathrm{T} 4$.

School Functioning. School functioning in children with AML experienced a decrease at T2 (67.4) in comparison to T1 (73.18); this decrease is corrected at T3 (72.36). At the end of treatment (T4), children with AML reported higher school functioning scores $(81.99)$ in comparisons to the beginning of treatment $(\mathrm{T} 1,73.18)$.

Total Score. As a reflection of the general trend in all HRQOL domains in children with AML, the total HRQOL score indicated a decrease at T2 (69.33), in comparison to the beginning of treatment $(\mathrm{T} 1,71.29)$. This trend is, however, reversed at T3 (74.90) and at T4 (86.57). The total HRQOL at the end of treatment (T4) is higher in comparison to the beginning of treatment (T1), indicating improved HRQOL. 
Table 4-8. Domains and symptoms of HRQOL outcomes over time in AML

\begin{tabular}{|c|c|c|c|c|c|c|c|c|c|c|c|c|}
\hline \multirow[b]{2}{*}{ HRQOL } & \multicolumn{3}{|c|}{$\mathrm{T} 1$} & \multicolumn{3}{|c|}{ T2 } & \multicolumn{3}{|c|}{ T3 } & \multicolumn{3}{|c|}{ T4 } \\
\hline & $\mathbf{n}$ & Mean & StdDev & $\mathbf{n}$ & Mean & StdDev & $\mathbf{n}$ & Mean & StdDev & $\mathbf{n}$ & Mean & StdDev \\
\hline \multicolumn{13}{|l|}{ PedsQL-Generic Domains } \\
\hline Total Score & 73 & 71.29 & 16.72 & 74 & 69.33 & 16.33 & 45 & 74.90 & 16.58 & 33 & 86.57 & 10.06 \\
\hline Emotional Functioning & 73 & 65.07 & 24.74 & 74 & 69.31 & 21.74 & 45 & 76.00 & 19.90 & 33 & 84.85 & 13.20 \\
\hline Social Functioning & 72 & 85.56 & 15.64 & 72 & 84.74 & 14.85 & 45 & 87.72 & 14.40 & 33 & 92.53 & 10.58 \\
\hline School Functioning & 67 & 73.18 & 19.11 & 59 & 67.51 & 23.03 & 36 & 72.36 & 17.50 & 28 & 81.99 & 16.58 \\
\hline \multicolumn{13}{|l|}{ PedsQL-Cancer Domains } \\
\hline Pain and Hurt & & & & 75 & 69.67 & 27.20 & 45 & 71.39 & 24.08 & 30 & 85.00 & 17.18 \\
\hline Nausea & & & & 75 & 59.86 & 21.94 & 45 & 65.33 & 20.10 & 30 & 82.67 & 17.31 \\
\hline Procedural Anxiety & & & & 74 & 60.75 & 32.26 & 45 & 66.76 & 31.31 & 30 & 74.17 & 25.37 \\
\hline Treatment Anxiety & & & & 75 & 82.50 & 24.34 & 45 & 91.67 & 16.95 & 30 & 93.61 & 13.43 \\
\hline Cancer Worry & & & & 74 & 67.62 & 24.43 & 45 & 70.56 & 23.48 & 30 & 80.00 & 23.53 \\
\hline Cognitive Problems & & & & 74 & 78.38 & 18.29 & 45 & 82.97 & 18.19 & 30 & 84.83 & 17.44 \\
\hline Perceived Physical Appearance & & & & 74 & 78.49 & 23.65 & 45 & 85.19 & 20.33 & 30 & 88.61 & 18.24 \\
\hline Communication & & & & 75 & 77.06 & 24.23 & 45 & 86.11 & 19.70 & 30 & 86.53 & 19.07 \\
\hline
\end{tabular}


HRQOL

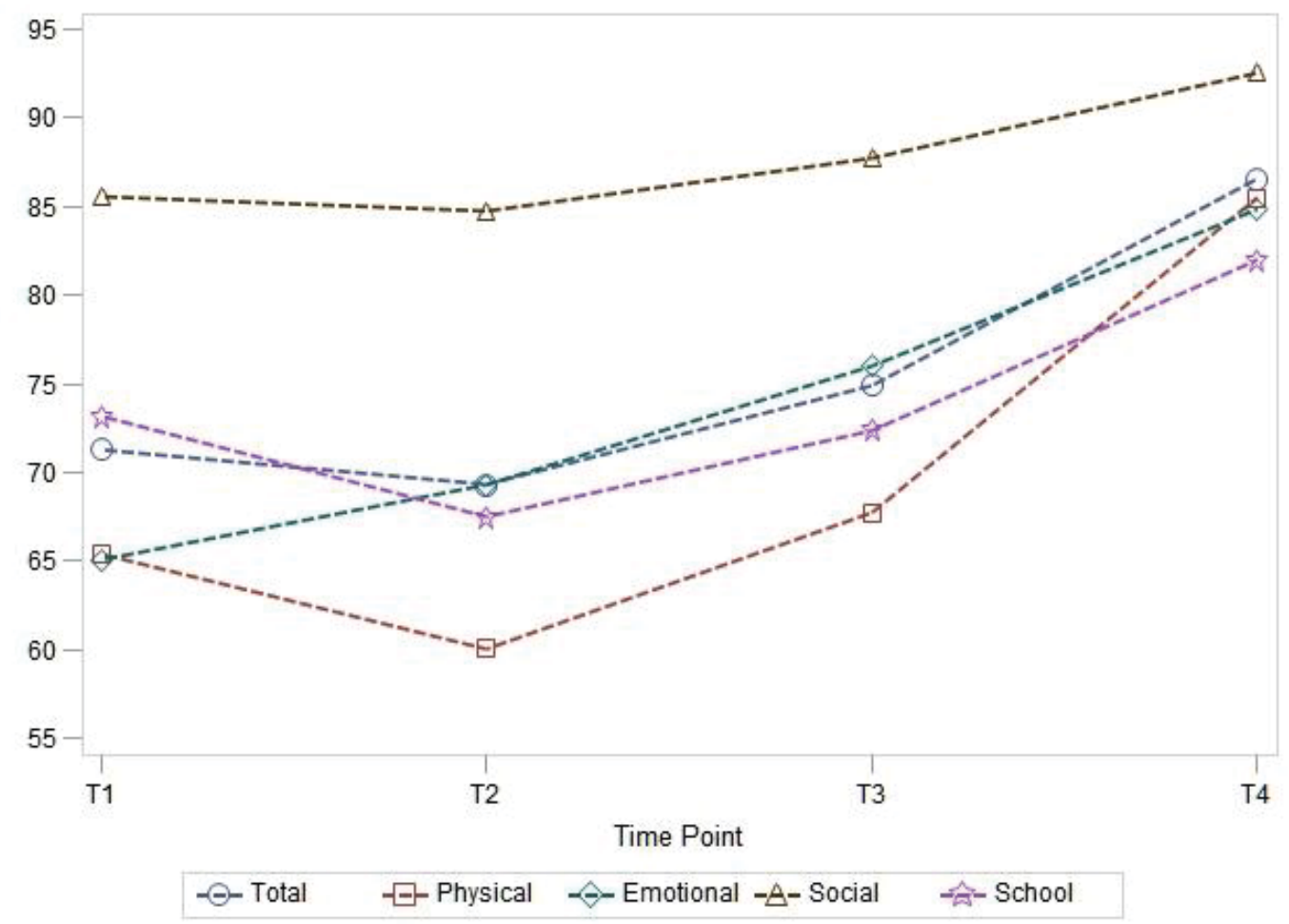

Symptoms

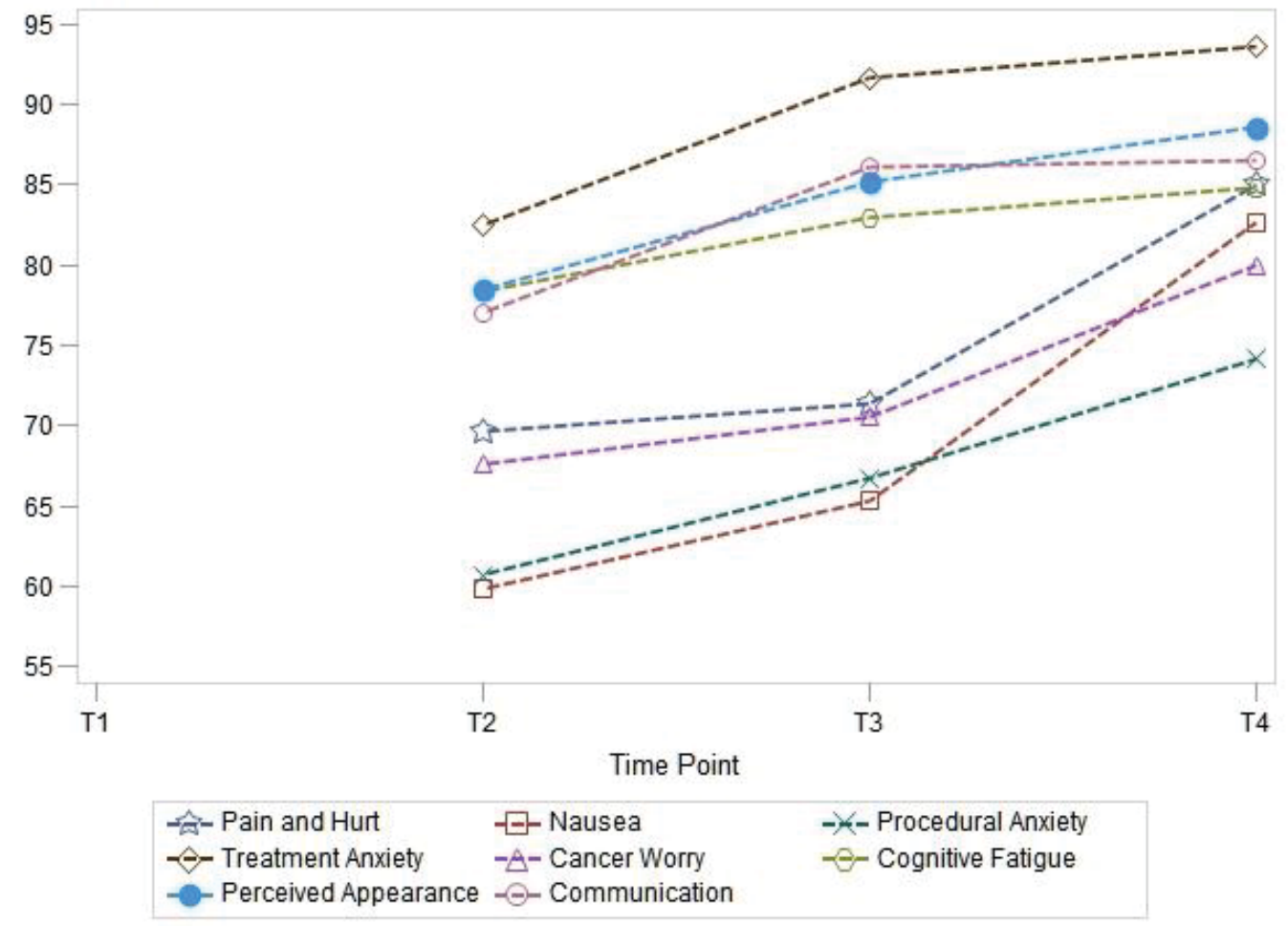

Figure 4-2. HRQOL domain average scores across time on the PedsQL-Generic and the PedsQL-Cancer scales for the AML group 


\section{Hodgkin Lymphoma}

At the initiation of therapy (T1) and during treatment (T2, T3), all HRQOL domains were less than 80 except social functioning (range 88.33-87.56). Emotional functioning (69.45) at the initiation of therapy was the lowest domain, followed by school functioning (70.76). During therapy (T2, T3) school functioning remained low (67.98, $70.67)$, followed by physical functioning $(70.82,72.63)$ and emotional functioning (71.54, 74.18). All HRQOL domains were 80 or higher at the completion of therapy time point, with social functioning remaining the highest (91.58). Symptom reports were only collected at T2, T3, and T4. During the two time points in treatment (T2, T3), nausea (T2, $60.70 ; \mathrm{T} 3,59.31)$ was reported as the lowest scoring symptom in children with HL. However, at the end of treatment (T4), cancer worry became the lowest scoring symptom in children with HL. Table 4-9 presents the HRQOL outcomes collected using the PedsQL-Generic and PedsQL-Cancer scales for the HL group across all time points and domains. The PedsQL Cancer scale was not collected at the beginning of treatment (T1). Figure 4-3 presents the plotting of different HRQOL domain average scores across time on the PedsQL-Generic and the PedsQL-Cancer scales.

Physical Functioning. The Physical functioning domain is relatively high at T1. However, at T2 and T3, the domain significantly dropped, becoming the lowest at T3 and the second lowest at T2. At T4, the physical domain improved at T4 from T3 and T1, achieving a higher score than at the beginning of treatment (T1).

Emotional Functioning. The emotional functioning domain is the lowest scoring domain for children with HL at the beginning of treatment, with a score of 69.5 at T1. However, this domain demonstrated a steady improvement during treatment and reaching a higher mean score of 80.16 at $\mathrm{T} 4$.

Social Functioning. The social functioning domains maintain the highest mean score across all time points in children with HL. This domain also show stable scores across all time points, starting with a mean score of 88.3 at $\mathrm{T} 1$ and ending with a mean score of 91.6 at $\mathrm{T} 4$.

School Functioning. Children with HL reported higher school functioning scores at the end of treatment (T4) in comparison to the beginning of treatment. This domain showed a decrease as children receive treatment at (T2, T3). School functioning was the lowest scoring domain during treatment (T2, T3) and the second lowest at the beginning of treatment $(\mathrm{T} 1,70.76)$ and end of treatment $(\mathrm{T} 4,80.20)$.

Total Score. As a reflection of the consistent trend of decreased HRQOL scores during treatment, the total HRQOL score indicated a decrease during treatment (T2, T3). However, the total HRQOL score for children with HL was higher at the end of treatment (T4) in comparison to the beginning of treatment (T1). 
Table 4-9. Domains and symptoms of HRQOL outcomes over time in HL

\begin{tabular}{|c|c|c|c|c|c|c|c|c|c|c|c|c|}
\hline \multirow[b]{2}{*}{ HRQOL } & \multicolumn{3}{|c|}{$\mathrm{T} 1$} & \multicolumn{3}{|c|}{ T2 } & \multicolumn{3}{|c|}{ T3 } & \multicolumn{3}{|c|}{ T4 } \\
\hline & $\mathbf{n}$ & Mean & StdDev & $\mathbf{n}$ & Mean & StdDev & $\mathbf{n}$ & Mean & StdDev & $\mathbf{n}$ & Mean & StdDev \\
\hline \multicolumn{13}{|l|}{ PedsQL-Generic Domains } \\
\hline Total Score & 197 & 77.21 & 14.72 & 194 & 74.04 & 15.54 & 181 & 76.51 & 15.95 & 164 & 84.47 & 14.31 \\
\hline Physical Functioning & 217 & 78.38 & 21.22 & 216 & 70.82 & 21.44 & 204 & 72.63 & 22.48 & 177 & 84.79 & 15.90 \\
\hline Emotional Functioning & 217 & 69.45 & 18.04 & 216 & 71.54 & 20.20 & 204 & 74.18 & 20.80 & 177 & 80.16 & 22.07 \\
\hline Social Functioning & 218 & 88.33 & 14.73 & 216 & 87.56 & 14.04 & 204 & 87.72 & 14.16 & 177 & 91.58 & 13.01 \\
\hline School Functioning & 199 & 70.76 & 18.08 & 194 & 67.98 & 20.82 & 181 & 70.67 & 21.74 & 164 & 80.20 & 18.81 \\
\hline \multicolumn{13}{|l|}{ PedsQL-Cancer Domains } \\
\hline Pain and Hurt & & & & 212 & 65.92 & 25.56 & 196 & 69.39 & 26.04 & 174 & 84.91 & 21.43 \\
\hline Nausea & & & & 212 & 60.70 & 23.05 & 196 & 59.31 & 24.47 & 170 & 77.92 & 22.45 \\
\hline Procedural Anxiety & & & & 211 & 71.05 & 27.93 & 195 & 72.39 & 29.08 & 174 & 78.35 & 25.66 \\
\hline Treatment Anxiety & & & & 212 & 85.36 & 19.16 & 196 & 82.57 & 22.55 & 174 & 84.77 & 21.31 \\
\hline Cancer Worry & & & & 211 & 65.92 & 24.12 & 196 & 66.50 & 24.79 & 170 & 69.88 & 26.97 \\
\hline Cognitive Problems & & & & 211 & 77.42 & 19.24 & 194 & 78.85 & 20.37 & 174 & 80.77 & 20.95 \\
\hline Perceived Physical Appearance & & & & 212 & 77.00 & 22.95 & 196 & 78.23 & 23.19 & 172 & 80.81 & 23.90 \\
\hline Communication & & & & 212 & 78.89 & 19.68 & 196 & 81.63 & 20.71 & 172 & 85.56 & 19.28 \\
\hline
\end{tabular}


HRQOL

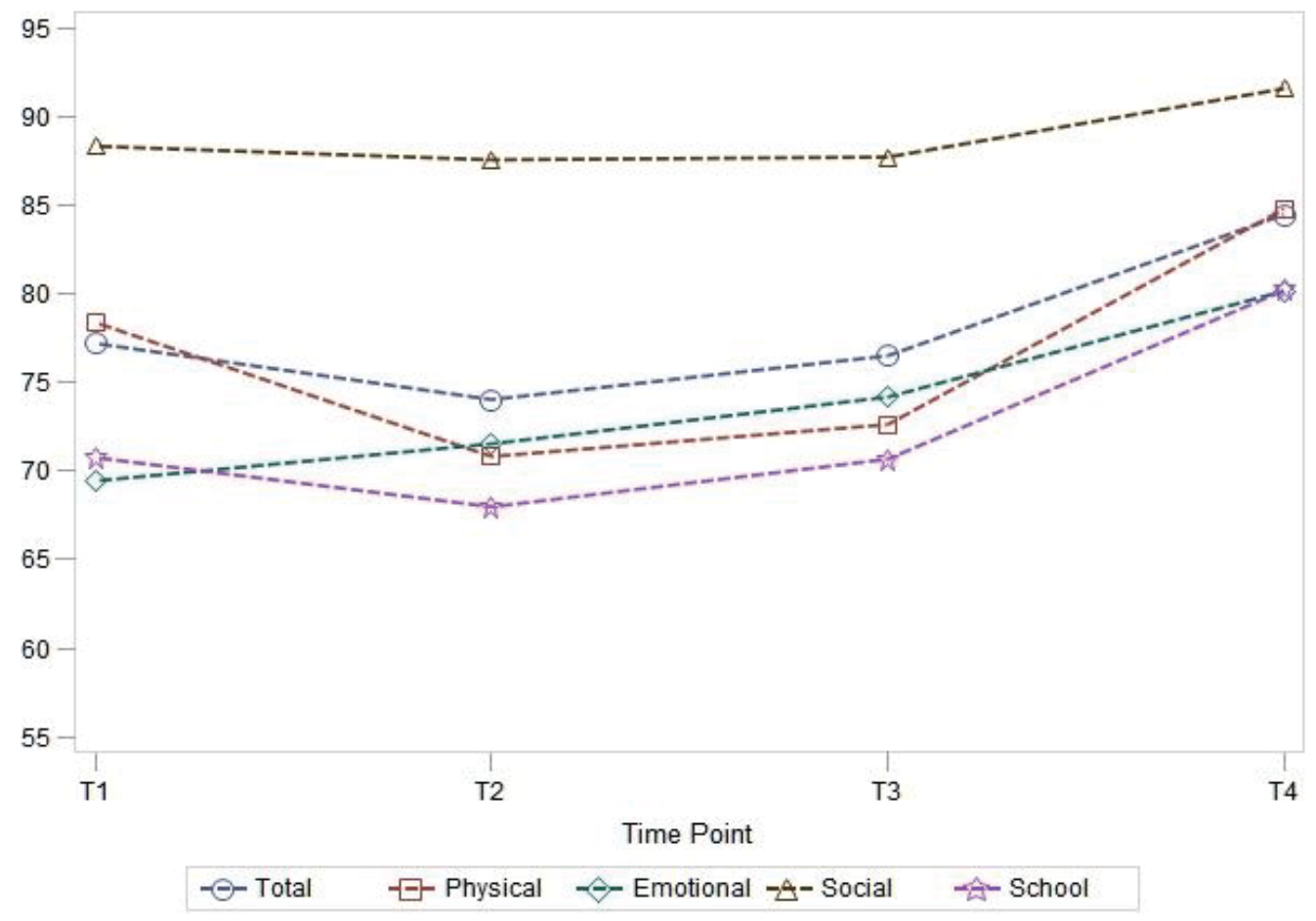

Symptoms

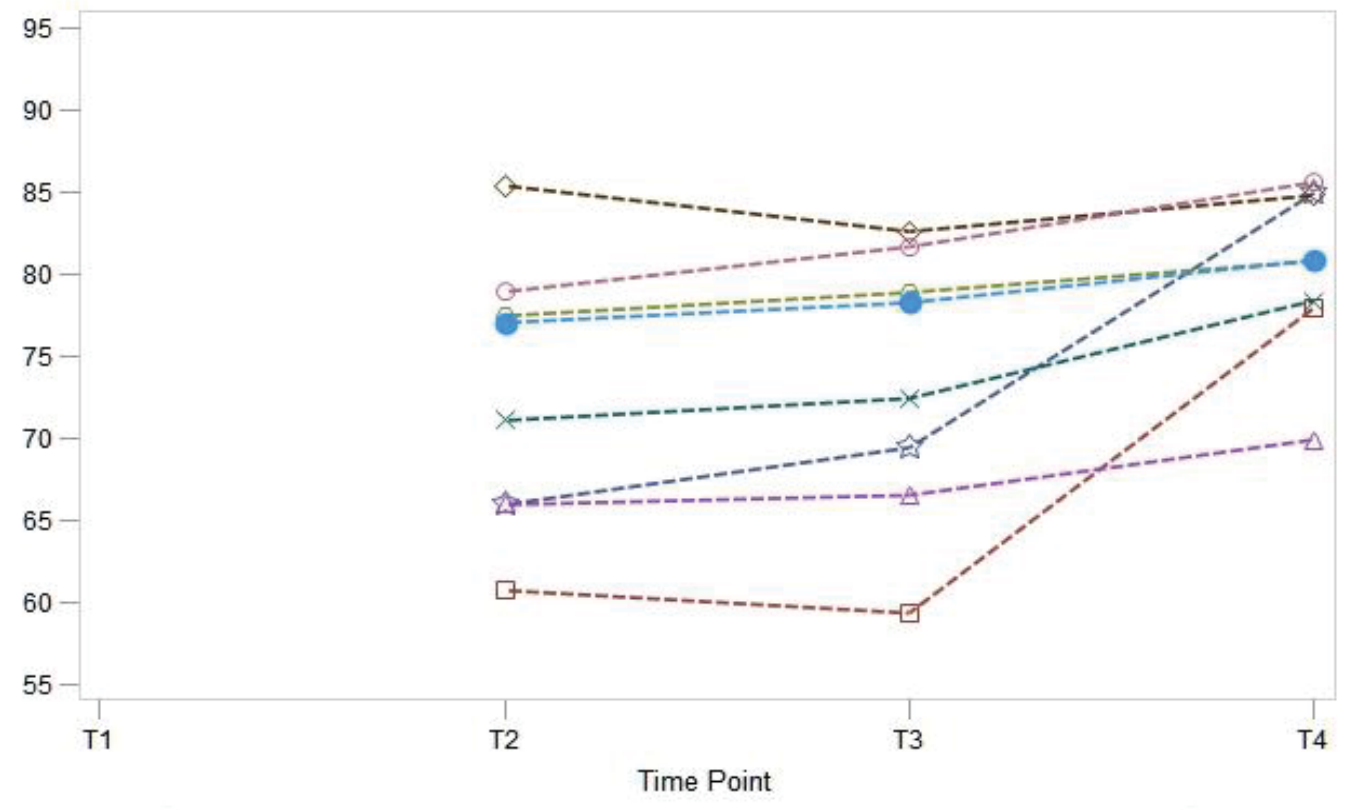

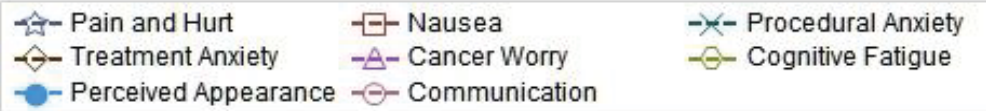

Figure 4-3. HRQOL domain average scores across time on the PedsQL-Generic and the PedsQL-Cancer scales for the HL group 


\section{Melanoma}

The melanoma group experienced HRQOL scores that were below or around 80 . School functioning was the lowest scoring domain in children with melanoma across all time points in treatment. The highest scoring HRQOL domain at the beginning of treatment (T1) in children with Melanoma was the social functioning domain (82.95). However, at the end of treatment (T4), the highest scoring HRQOL domain was the physical functioning domain (83.53) followed closely by the social functioning domain (83.13).As for cancer-related symptoms, the highest scoring symptom across all time points was treatment anxiety, while the lowest scoring symptom across all time points was the procedural anxiety. Nausea improved gradually over time in children with melanoma from T1 (73.48) to the second highest domain at the end of treatment (T4, 87.50).Table 4-10 presents the HRQOL outcomes for the melanoma group across all time points and domains collected using the PedsQL-Generic and the PedsQL-Cancer scales. Figure 4-4 presents the plotting of different HRQOL domain average scores across time on the PedsQL-Generic and the PedsQL-Cancer scales.

Physical Functioning. Children with melanoma reported a high physical score at beginning of treatment $(\mathrm{T} 1,79.39)$. This score slightly declined at T2 (77.19), but improved gradually to a mean physical functioning score of 83.5 at the end of treatment (T4). At the end of treatment (T4) physical functioning was the highest mean domain score in children with melanoma.

Emotional Functioning. Emotional functioning was the second lowest domain in children with melanoma, with a mean score of 73.5 at T1. This domain gradually increased throughout treatment $(\mathrm{T} 2,83.26 ; \mathrm{T} 3,82.06)$, but decreased at the end of treatment $(\mathrm{T} 4,78.4)$.

Social Functioning. Social functioning was the highest mean scoring domain across all time points except at the end of treatment (T4) in children with melanoma and remained relatively stable over time. Children with melanoma reported a mean social score of 82.9 at T1. This score was the same at T2, increased to 87 at T3, and decreased to the same level at $\mathrm{T} 4$, reaching a mean score of 83.1 at $\mathrm{T} 4$.

School Functioning. School functioning was the lowest scoring domain at all time-points in children with melanoma. However, it showed improvement during treatment $(\mathrm{T} 2,72.00 ; \mathrm{T} 3,74.71)$ in comparison to the beginning of treatment $(\mathrm{T} 1,68.82)$. At the end of treatment (T4), school functioning decreased again (69.64).

Total Score. The total HRQOL score at the beginning of treatment (T1, 76.56) experienced a trend of increase throughout treatment points. During treatment, (T2, T3), the total score increased $(78.99,81.33)$ in comparison to at the beginning of treatment (T1, 76.56). However, at the end of treatment (T4, 79.59), the total HRQOL score is lower than in comparison to the previous time point (T3). The total HRQOL score at the end of treatment (T4) remains higher than at the beginning of treatment (T1). 
Table 4-10. Domains and symptoms of HRQOL outcomes over time in melanoma

\begin{tabular}{|c|c|c|c|c|c|c|c|c|c|c|c|c|}
\hline \multirow[b]{2}{*}{ HRQOL } & \multicolumn{3}{|c|}{ T1 } & \multicolumn{3}{|c|}{ T2 } & \multicolumn{3}{|c|}{ T3 } & \multicolumn{3}{|c|}{ T4 } \\
\hline & $\mathbf{n}$ & Mean & StdDev & $\mathbf{N}$ & Mean & StdDev & $\mathbf{n}$ & Mean & StdDev & $\mathbf{n}$ & Mean & StdDev \\
\hline \multicolumn{13}{|l|}{ PedsQL-Generic Domains } \\
\hline Total Score & 23 & 76.56 & 18.02 & 23 & 78.99 & 15.63 & 17 & 81.33 & 16.00 & 16 & 79.59 & 16.06 \\
\hline Physical Functioning & 23 & 79.39 & 20.82 & 23 & 77.19 & 18.21 & 17 & 81.43 & 17.42 & 16 & 83.53 & 14.11 \\
\hline Emotional Functioning & 23 & 73.53 & 21.73 & 23 & 83.26 & 16.96 & 17 & 82.06 & 21.51 & 16 & 78.44 & 20.71 \\
\hline Social Functioning & 22 & 82.95 & 24.04 & 23 & 83.91 & 24.86 & 17 & 87.06 & 24.75 & 16 & 83.13 & 24.55 \\
\hline School Functioning & 17 & 68.82 & 25.16 & 20 & 72.00 & 34.12 & 17 & 74.71 & 23.55 & 14 & 69.64 & 18.65 \\
\hline Pain and Hurt & & & & 23 & 79.35 & 21.52 & 16 & 83.59 & 19.75 & 14 & 80.36 & 21.21 \\
\hline Nausea & & & & 23 & 73.48 & 23.86 & 16 & 81.25 & 17.94 & 16 & 87.50 & 14.49 \\
\hline Procedural Anxiety & & & & 23 & 72.10 & 28.82 & 16 & 67.19 & 33.12 & 16 & 68.75 & 31.70 \\
\hline Treatment Anxiety & & & & 23 & 90.22 & 16.60 & 16 & 89.06 & 15.13 & 16 & 91.67 & 14.91 \\
\hline Cancer Worry & & & & 23 & 77.17 & 21.35 & 16 & 77.60 & 27.17 & 16 & 79.17 & 28.22 \\
\hline Cognitive Problems & & & & 23 & 82.07 & 25.51 & 16 & 80.94 & 24.17 & 16 & 80.00 & 17.77 \\
\hline Perceived Physical Appearance & & & & 23 & 80.43 & 27.02 & 16 & 74.48 & 30.35 & 16 & 72.92 & 30.81 \\
\hline Communication & & & & 23 & 82.61 & 25.49 & 16 & 82.81 & 20.06 & 16 & 77.08 & 28.79 \\
\hline
\end{tabular}



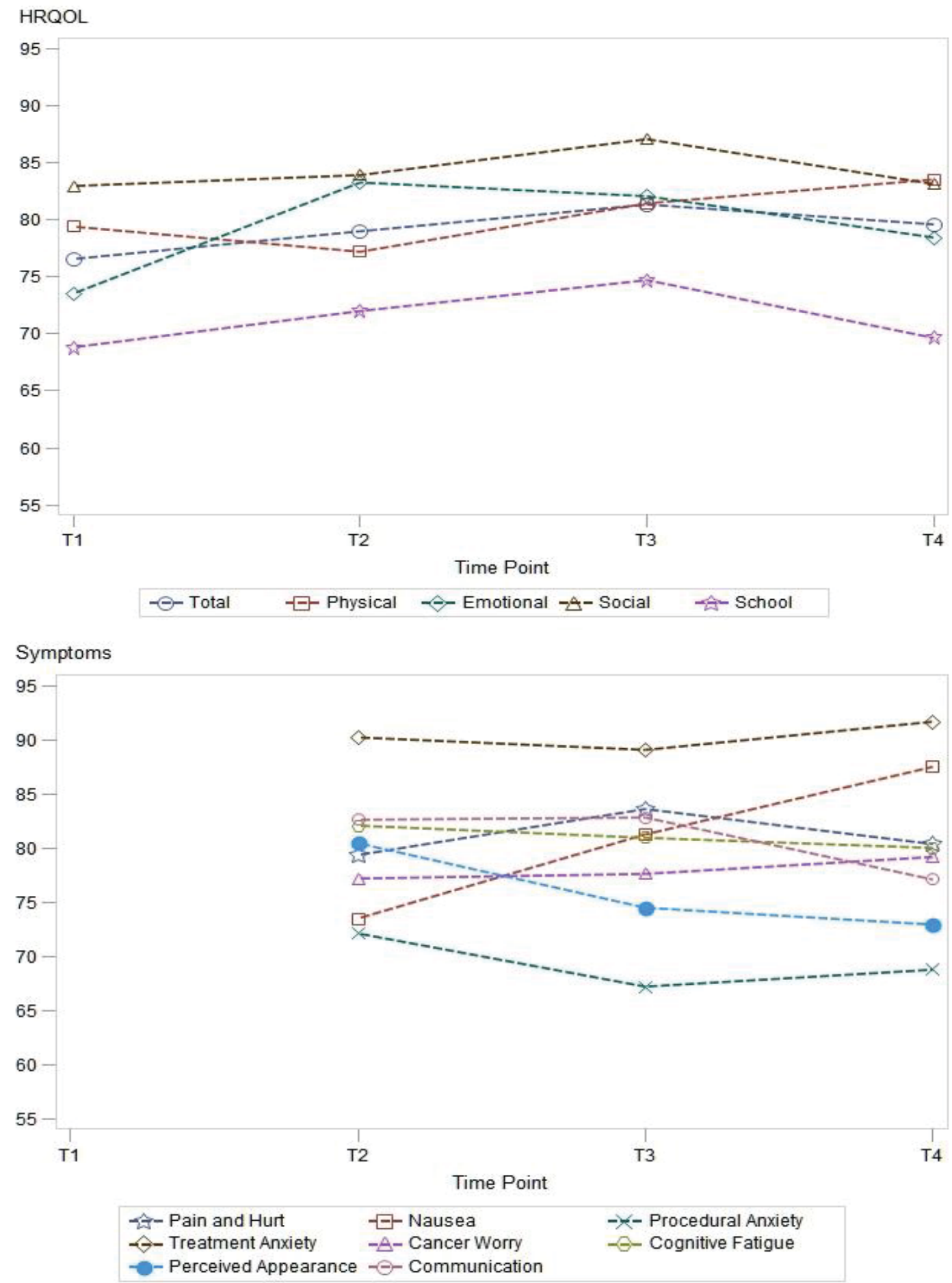

Figure 4-4. HRQOL domain average scores across time on the PedsQL-Generic and the PedsQL-Cancer scales for the melanoma group 


\section{Osteosarcoma}

The OS group reported HRQOL domain scores well below 80 at all HRQOL domains. The physical functioning domain (46.81) was the lowest scoring domain at the beginning of treatment (T1) and throughout the other time points (T2, T3); it also was the lowest scoring domain at the end of treatment (T4, 62.46). The highest scoring domain at the beginning of treatment (T1) was the social functioning domain (77.35). The social functioning domain was the only domain that scored lower at the end of treatment (T4) in comparison to the beginning of treatment. All the remaining domains reported an increase over time and reported highest scores at the end of treatment (T4). However, at the end of treatment (T4), the highest scoring domain was the social functioning domain (76.55).

As for cancer-related symptoms in the OS group, the lowest scoring symptom, indicating more problems, at the beginning of treatment (T1) was cancer worry (52.18) followed closely by pain and hurt (52.55). Cancer worry improved gradually over time in treatment to a highest score (69.82) at the end of treatment (T4). The highest scoring symptom across all time points was treatment anxiety. At the beginning of treatment the nausea score was 67.29, however, during treatment (T2, T3), nausea scores decreased to become the lowest scoring symptom reported by the OS group (T2, 50.73; T3, 48.54). Nausea improved again at the end of treatment (T4) to achieve a higher mean score than at the start of treatment (T1).Table 4-11 presents the HRQOL outcomes for the OS group across all time points and domains collected using the PedsQL-Generic and the PedsQLCancer scales. Figure 4-5 presents the plotting of different HRQOL domain average scores across time on the PedsQL-Generic and the PedsQL-Cancer scales.

Physical Functioning. Children with OS started with a considerably low physical functioning score, with a mean score of 46.81. This score only slightly improved during treatment and reached the highest score of 62.46 at $\mathrm{T} 4$.

Emotional Functioning. Children with OS reported the lowest emotional mean score at T1 compared to the other groups. The mean emotional score at T1 was 60.66. This domain, however, showed gradual improvements, reaching a highest score (76.10) at T4.

Social Functioning. Social functioning domain started as the highest scoring domain at the first three time points in children with OS; however, children with OS were the only diagnostic group who reported lower social mean scores at the end of treatment $\mathrm{T} 4$ in comparison to baseline $\mathrm{T} 1$.

School Functioning. School functioning in children with OS reflected a trend of gradual improvement over time. At the beginning of treatment (T1), children with OS reported the lowest school functioning score (63.80), this score improved at T2 (68.64) and maintained a relatively stable score at T3 (67.54). At the end of treatment (T4), children with OS reported a higher school functioning score (74.31) than all previous time points. 
Table 4-11. Domains and symptoms of HRQOL outcomes over time in OS

\begin{tabular}{|c|c|c|c|c|c|c|c|c|c|c|c|c|}
\hline \multirow[b]{2}{*}{ HRQOL } & \multicolumn{3}{|c|}{ T1 } & \multicolumn{3}{|c|}{$\mathbf{T 2}$} & \multicolumn{3}{|c|}{ T3 } & \multicolumn{3}{|c|}{ T4 } \\
\hline & $\mathbf{n}$ & Mean & StdDev & $\mathbf{n}$ & Mean & StdDev & $\mathbf{n}$ & Mean & StdDev & $\mathbf{n}$ & Mean & StdDev \\
\hline \multicolumn{13}{|l|}{ PedsQL-Generic Domains } \\
\hline Total Score & 110 & 59.91 & 17.91 & 100 & 63.82 & 17.12 & 89 & 62.86 & 16.14 & 84 & 70.69 & 17.04 \\
\hline Physical Functioning & 110 & 46.81 & 27.98 & 100 & 51.75 & 24.80 & 89 & 48.77 & 21.59 & 84 & 62.46 & 21.83 \\
\hline Emotional Functioning & 110 & 60.66 & 22.75 & 100 & 66.40 & 22.10 & 89 & 69.66 & 22.64 & 82 & 76.10 & 18.84 \\
\hline Social Functioning & 110 & 77.35 & 18.18 & 99 & 79.39 & 15.52 & 89 & 74.94 & 17.83 & 82 & 76.55 & 17.14 \\
\hline School Functioning & 98 & 63.80 & 22.70 & 77 & 68.64 & 24.03 & 77 & 67.54 & 23.80 & 74 & 74.31 & 19.16 \\
\hline \multicolumn{13}{|l|}{ PedsQL-Cancer Domains } \\
\hline Nausea & 107 & 67.29 & 26.25 & 101 & 50.73 & 23.49 & 89 & 48.54 & 22.83 & 80 & 73.88 & 22.09 \\
\hline Procedural Anxiety & 108 & 59.57 & 34.50 & 100 & 72.71 & 28.74 & 89 & 73.69 & 28.48 & 81 & 76.23 & 30.19 \\
\hline Treatment Anxiety & 107 & 74.57 & 28.33 & 101 & 86.30 & 19.31 & 88 & 89.30 & 17.73 & 82 & 88.92 & 19.42 \\
\hline Cancer Worry & 105 & 52.18 & 32.18 & 100 & 58.17 & 30.95 & 89 & 64.98 & 28.18 & 82 & 69.82 & 25.41 \\
\hline Cognitive Problems & 107 & 74.57 & 20.81 & 101 & 75.86 & 18.81 & 89 & 77.75 & 17.44 & 82 & 79.92 & 17.49 \\
\hline Perceived Physical Appearance & 108 & 75.00 & 25.39 & 100 & 76.29 & 24.01 & 89 & 79.87 & 20.83 & 82 & 81.30 & 21.38 \\
\hline Communication & 107 & 73.01 & 24.38 & 99 & 76.26 & 25.35 & 89 & 81.09 & 20.44 & 81 & 82.92 & 20.54 \\
\hline
\end{tabular}



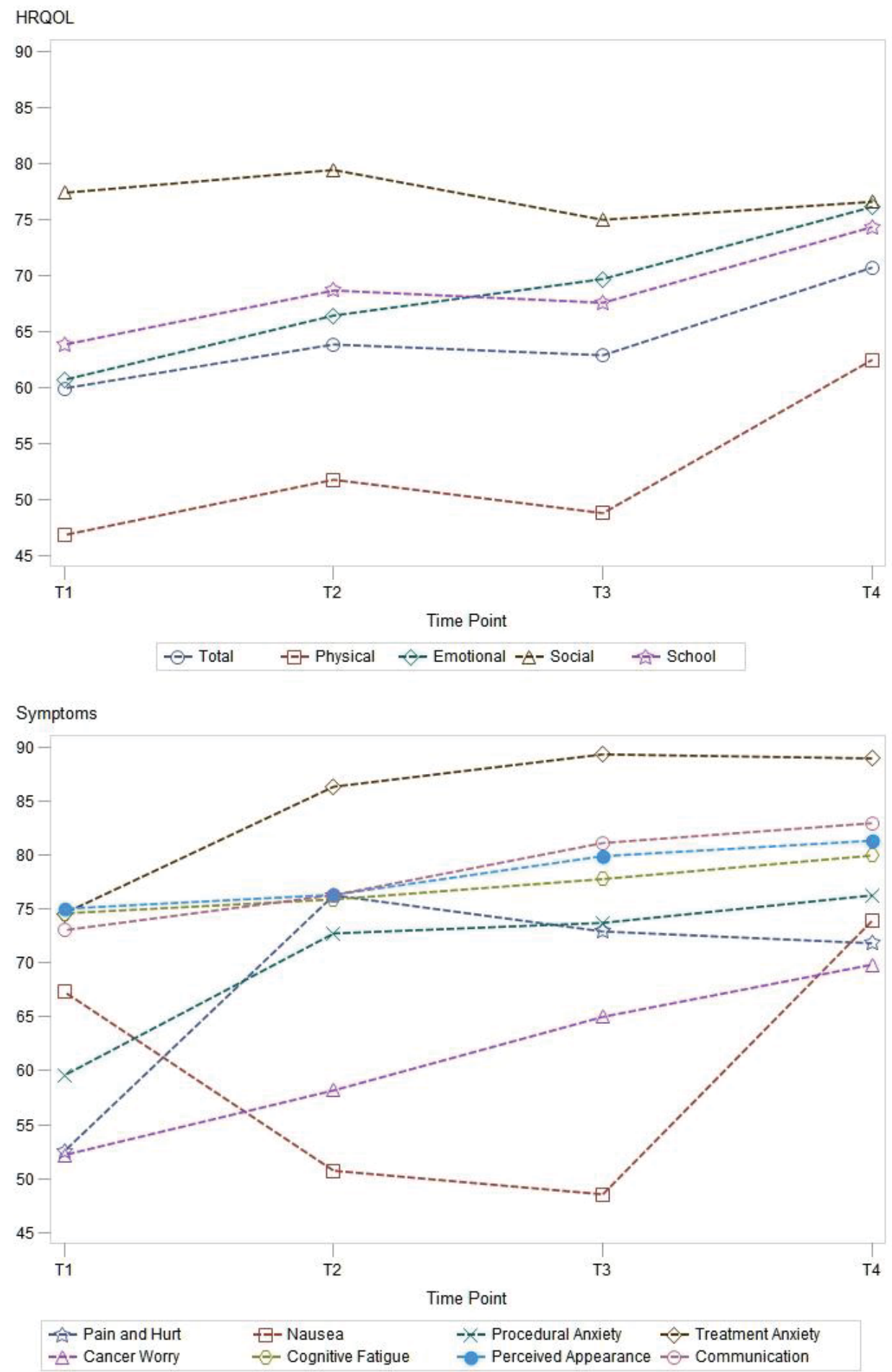

Figure 4-5. HRQOL domain average scores across time on the PedsQL-Generic and the PedsQL-Cancer scales for the OS group 
Total Score. The total score corresponded with the trend of the previous domains. The total HRQL score is lower at the beginning of treatment (T1, 59.91). HRQOL total score then increased gradually at T2 (63.82) and T3 (74.9). The Total score at the end of treatment $(\mathrm{T} 4,70.69)$ was higher than the previous time point during treatment (T3), or at the beginning of treatment (T1).

\begin{abstract}
$\operatorname{Aim} 2$
Aim 2 was to identify the differences in HRQOL among different diagnostic groups of children undergoing curative cancer treatment.

- $\quad$ Research Question 2-1: What is the difference in child self-reported HRQOL of children undergoing curative cancer treatment between different diagnostic groups at each time point?
\end{abstract}

\title{
Physical Functioning
}

Physical Functioning scores were lowest in the OS group across all time points and highest for the melanoma groups across all time points except at T4 where the AML group scored the highest on the physical functioning domain $(\mathrm{M}=85.51)$. All diagnostic groups reported a significantly higher physical domain score at the end of treatment at T4 in comparison to T1 $(\mathrm{p}<.0001)$ except for the melanoma group which reported higher, but not significant, increase in the physical domain score $(\mathrm{p}=.3278)$. Table 4-12 presents the mean physical functioning scores over time in each diagnostic group.

\section{Emotional Functioning}

Emotional functioning scores were lowest in children with OS (M=60.66), and highest in children with melanoma $(\mathrm{M}=73.53)$ at $\mathrm{T} 1$. The emotional functioning domain shows consistent increase over time in all diagnostic groups except for the melanoma group where emotional function reaches high levels during treatment at T2 $(\mathrm{M}=83.26)$ and T3(M=82.06) but lower scores at T4 $(\mathrm{M}=78.44)$. At $\mathrm{T} 4$, the highest emotional domain score across groups is for the AML group $(\mathrm{M}=84.85)$, followed closely by the HL group ( $\mathrm{M}=80.38)$. All diagnostic group showed significant increases in emotional functioning at T4 in comparison to T1 $(\mathrm{p}<.0001)$ except for the melanoma group which achieves non-significant increase in the emotional score domain $(p=.3064)$. Table 4-13 presents the mean emotional functioning score over time in each diagnostic group.

\section{Social Functioning}

The social functioning domain scores were generally higher than most other domains across all diagnostic groups. The OS group scored the lowest social functioning 
Table 4-12. Physical HRQOL scores across diagnostic groups and over time

\begin{tabular}{|c|c|c|c|c|c|c|c|c|}
\hline \multirow[b]{3}{*}{ Diagnosis } & \multicolumn{8}{|c|}{ Time Point } \\
\hline & \multicolumn{2}{|c|}{ T1 } & \multicolumn{2}{|c|}{$\mathbf{T 2}$} & \multicolumn{2}{|c|}{ T3 } & \multicolumn{2}{|c|}{ T4 } \\
\hline & $\mathbf{n}$ & Mean & $\mathbf{n}$ & Mean & n & Mean & n & Mean \\
\hline$\overline{\text { ALL }}$ & 209 & 60.70 & 203 & $73.89^{\wedge}$ & 169 & $73.09^{\wedge}$ & 158 & $75.18^{\wedge}$ \\
\hline AML & 73 & 65.41 & 74 & 60.05 & 45 & 67.74 & 33 & $85.51^{\wedge}$ \\
\hline HL* & 218 & 78.30 & 216 & $70.82^{\wedge}$ & 205 & $72.53^{\wedge}$ & 177 & $84.85^{\wedge}$ \\
\hline MEL & 23 & 79.39 & 23 & 77.19 & 17 & 81.43 & 16 & 83.53 \\
\hline OS & 110 & 46.81 & 100 & 51.75 & 89 & 48.77 & 84 & $62.46^{\wedge}$ \\
\hline
\end{tabular}

ALL: acute lymphoblastic leukemia, AML: acute myeloid leukemia; HL: Hodgkin lymphoma; MEL: melanoma; OS: osteosarcoma.

$*: p<0.05$ between diagnostic groups in comparison to acute lymphoblastic leukemia; $\wedge: p<0.05$ within group over time in comparison to first time point of measurement.

Table 4-13. Emotional HRQOL scores across diagnostic scores and over time

\begin{tabular}{|c|c|c|c|c|c|c|c|c|}
\hline \multirow[b]{3}{*}{ Diagnosis } & \multicolumn{8}{|c|}{ Time Point } \\
\hline & \multicolumn{2}{|c|}{ T1 } & \multicolumn{2}{|c|}{ T2 } & \multicolumn{2}{|c|}{ T3 } & \multicolumn{2}{|c|}{ T4 } \\
\hline & $\mathbf{n}$ & Mean & $\mathbf{n}$ & Mean & $\mathbf{n}$ & Mean & $\mathbf{n}$ & Mean \\
\hline$\overline{\text { ALL }}$ & 209 & 71.06 & 202 & $76.07^{\wedge}$ & 169 & 73.59 & 158 & $\overline{77.34^{\wedge}}$ \\
\hline AML & 73 & 65.07 & 74 & 69.31 & 45 & $76.00^{\wedge}$ & 33 & $84.85^{\wedge}$ \\
\hline HL & 218 & 69.40 & 216 & 71.66 & 205 & $74.26^{\wedge}$ & 177 & $80.38^{\wedge}$ \\
\hline MEL & 23 & 73.53 & 23 & 83.26 & 17 & 82.06 & 16 & 78.44 \\
\hline OS & 110 & 60.66 & 100 & $66.40^{\wedge}$ & 89 & $69.66^{\wedge}$ & 82 & $76.10^{\wedge}$ \\
\hline
\end{tabular}

ALL: acute lymphoblastic leukemia; AML: acute myeloid leukemia; HL; Hodgkin lymphoma; MEL: melanoma; OS: osteosarcoma.

$*: p<0.05$ between diagnostic groups in comparison to acute lymphoblastic leukemia; $\wedge: p<0.05$ within group over time in comparison to first time point of measurement. 
score among all other groups across all time points (T1, M=77.35; T2, M=79.39; T3, $\mathrm{M}=74.94 ; \mathrm{T} 4, \mathrm{M}=76.55)$. The OS group was also the only group that reported a lower social functioning at T4 in comparison to T1 $(p=.8874)$, while all other groups reported an increase. The HL and AML were the highest scoring diagnostic groups, with the HL group scoring highest at T1 $(\mathrm{M}=88.14), \mathrm{T} 2(87.42)$, and T3 (87.49), and the AML group scoring the highest average social functioning score at T4 (92.53). All diagnostic groups except for the OS group reported higher, but not significant increases in social functioning at T4 in comparison to T1. Table 4-14 describes the change in social functioning scores over time in each diagnostic group.

\section{School Functioning}

School functioning maintained a relatively stable outcome over time. The lowest school functioning score at the beginning of treatment (T1) was for the OS group $(M=63.80)$, indicating poorer outcomes. However, at the end of treatment (T4), children with ALL $(\mathrm{M}=68.10)$ reported the lowest school functioning among all groups.

There was also a noticeable different between school functioning at the end of treatment (T4) in children with AML (81.99) and HL (80.21), and the OS (74.31), melanoma (69.64), and ALL (68.1) groups. Children with HL and OS reported significantly higher school functioning scores $(p<0.0001)$ at the end of treatment $(\mathrm{T} 4)$ in comparison to the beginning of treatment (T1). Table 4-15 describes the change in school functioning scores over time in each diagnostic group.

\section{Total Score}

With the exception of children with melanoma, all other diagnostic groups reported significant increases $(\mathrm{p}<.0001)$ in total HRQOL scores at the end of treatment (T4) in comparison to the beginning of treatment (T1). The HRQOL total score was lowest for the OS group over all time points.

The highest mean HRQOL total scores at T1 were 77.00 for the HL and 76.56 for the melanoma diagnostic groups. The melanoma group maintained the highest total score through treatment at $\mathrm{T} 2(\mathrm{M}=78.99)$ and $\mathrm{T} 3(\mathrm{M}=81.33)$. However, at $\mathrm{T} 4$, the highest total HRQOL score was for the AML (86.57) group which experienced the most significant change in HRQOL total score from T1 to T4 $(\mathrm{p}<.0001)$.

Table 4-16 presents the change in total HRQOL scores diagnostic groups and over time. Figure 4-6 presents the plotting of total HRQOL scores over time in each diagnostic group. It demonstrates the variation within different diagnostic groups across time. 
Table 4-14. Social HRQOL scores across diagnostic groups and over time

\begin{tabular}{|c|c|c|c|c|c|c|c|c|}
\hline \multirow[b]{3}{*}{ Diagnosis } & \multicolumn{8}{|c|}{ Time Point } \\
\hline & \multicolumn{2}{|c|}{ T1 } & \multicolumn{2}{|c|}{ T2 } & \multicolumn{2}{|c|}{ T3 } & \multicolumn{2}{|c|}{ T4 } \\
\hline & $\mathbf{n}$ & Mean & $\mathbf{n}$ & Mean & $\mathbf{n}$ & Mean & n & Mean \\
\hline ALL & 207 & 79.61 & 202 & 80.01 & 169 & 79.41 & 158 & 82.21 \\
\hline AML* & 72 & 85.56 & 72 & 84.74 & 45 & 87.72 & 33 & 92.53 \\
\hline HL* & 218 & 88.14 & 216 & 87.42 & 205 & 87.49 & 177 & $91.58^{\wedge}$ \\
\hline MEL & 22 & 82.95 & 23 & 83.91 & 17 & 87.06 & 16 & 83.13 \\
\hline OS & 110 & 77.35 & 99 & 79.39 & 89 & 74.94 & 82 & 76.55 \\
\hline
\end{tabular}

ALL: acute lymphoblastic leukemia, AML: acute myeloid leukemia; HL: Hodgkin lymphoma; MEL: melanoma; OS: osteosarcoma.

$*: p<0.05$ between diagnostic groups in comparison to acute lymphoblastic leukemia; $\wedge: p<0.05$ within group over time in comparison to first time point of measurement.

Table 4-15. School HRQOL scores across diagnostic groups and over time

\begin{tabular}{|c|c|c|c|c|c|c|c|c|}
\hline \multirow[b]{3}{*}{ Diagnosis } & \multicolumn{8}{|c|}{ Time Point } \\
\hline & \multicolumn{2}{|c|}{ T1 } & \multicolumn{2}{|r|}{ T2 } & \multicolumn{2}{|c|}{ T3 } & \multicolumn{2}{|r|}{ T4 } \\
\hline & n & Mean & n & Mean & $\mathbf{n}$ & Mean & $\mathbf{n}$ & Mean \\
\hline$\overline{A L L}$ & 156 & 67.27 & 167 & 70.10 & 156 & 68.17 & 150 & 68.10 \\
\hline AML & 67 & 73.18 & 59 & 67.51 & 36 & 72.36 & 28 & 81.99 \\
\hline HL & 202 & 70.41 & 197 & 68.14 & 182 & 70.76 & 165 & $80.21^{\wedge}$ \\
\hline MEL & 17 & 68.82 & 20 & 72.00 & 17 & 74.71 & 14 & 69.64 \\
\hline OS & 98 & 63.80 & 77 & $68.64^{\wedge}$ & 77 & 67.54 & 74 & $74.31^{\wedge}$ \\
\hline
\end{tabular}

ALL: acute lymphoblastic leukemia, AML: acute myeloid leukemia; HL: Hodgkin lymphoma; MEL: melanoma; OS: osteosarcoma.

$*: p<0.05$ between diagnostic groups in comparison to acute lymphoblastic leukemia; $\wedge: p<0.05$ within group over time in comparison to first time point of measurement. 
Table 4-16. Total HRQOL scores across diagnostic groups and over time

\begin{tabular}{|c|c|c|c|c|c|c|c|c|}
\hline \multirow[b]{3}{*}{ Diagnosis } & \multicolumn{8}{|c|}{ Time Point } \\
\hline & \multicolumn{2}{|c|}{ T1 } & \multicolumn{2}{|c|}{ T2 } & \multicolumn{2}{|c|}{ T3 } & \multicolumn{2}{|c|}{ T4 } \\
\hline & n & Mean & $\mathbf{n}$ & Mean & $\mathbf{n}$ & Mean & $\mathbf{n}$ & Mean \\
\hline$\overline{\text { ALL }}$ & 209 & 68.66 & 203 & $75.14^{\wedge}$ & 169 & $73.55^{\wedge}$ & 158 & $75.70^{\wedge}$ \\
\hline AML & 73 & 71.29 & 74 & 69.33 & 45 & 74.90 & 33 & $86.57^{\wedge}$ \\
\hline HL & 218 & 77.00 & 216 & $74.15^{\wedge}$ & 205 & 75.77 & 177 & $84.35^{\wedge}$ \\
\hline MEL & 23 & 76.56 & 23 & 78.99 & 17 & 81.33 & 16 & 79.59 \\
\hline OS & 110 & 59.91 & 100 & $63.82^{\wedge}$ & 89 & 62.86 & 84 & $70.69^{\wedge}$ \\
\hline
\end{tabular}

ALL: acute lymphoblastic leukemia, AML: acute myeloid leukemia; HL: Hodgkin lymphoma; MEL: melanoma; OS: osteosarcoma.

$*: p<0.05$ between diagnostic groups in comparison to acute lymphoblastic leukemia; $\wedge: p<0.05$ within group over time in comparison to first time point of measurement.

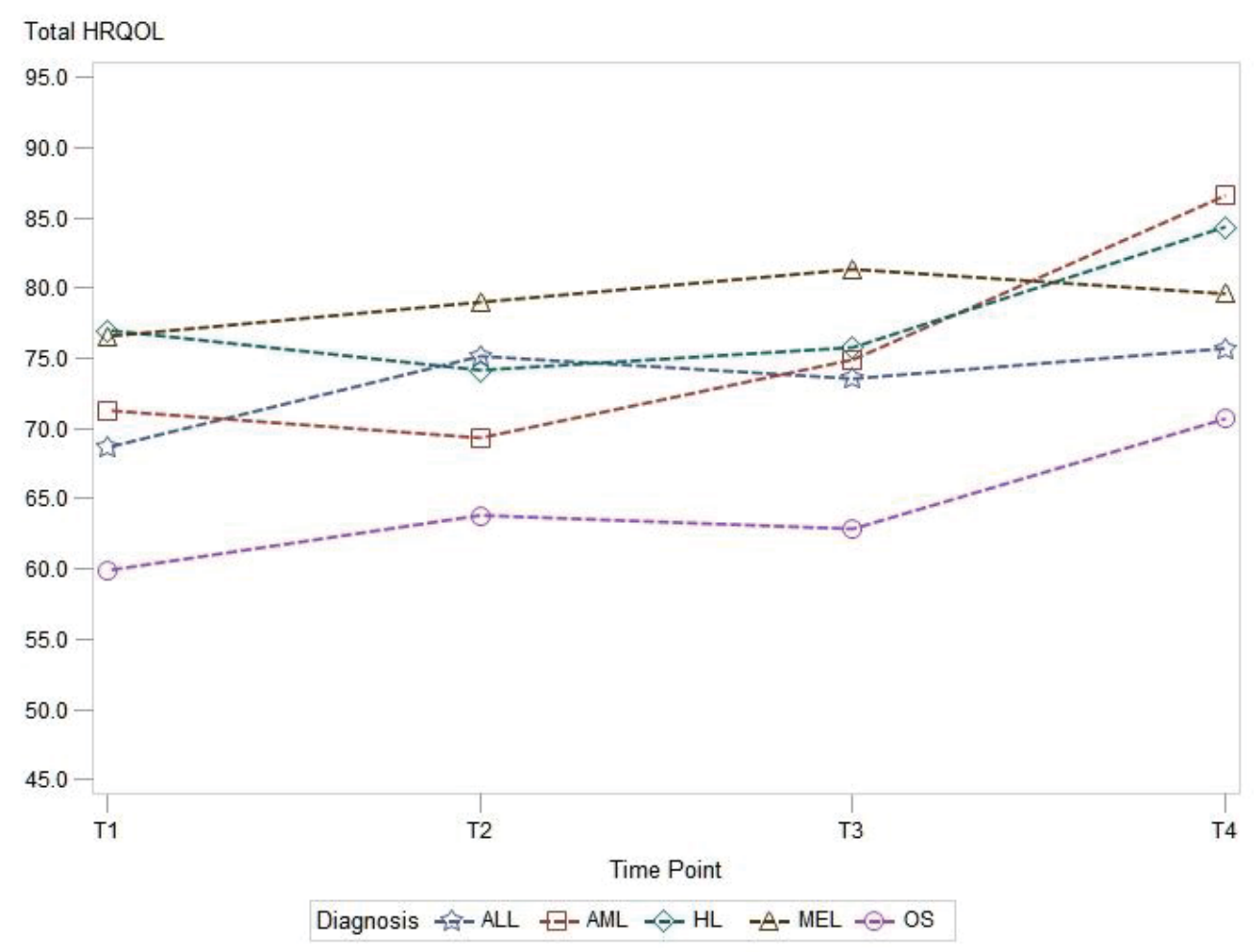

Figure 4-6. HRQOL outcomes on PedsQL-Total domain across diagnostic groups

ALL: acute lymphoblastic leukemia, AML: acute myeloid leukemia; HL: Hodgkin lymphoma; MEL: melanoma; OS: osteosarcoma. 


\section{Pain and Hurt}

No information were collected on Pain and hurt at T1 for the AML, HL, and melanoma groups as patients did not experience cancer-related symptoms before beginning treatment. At the 3 time points following T1, two groups could be identified by the differences in pain and hurt scores. Children with AML $(p=.7586)$ and HL $(p=.5031)$ experienced lower but not significantly different pain and hurt scores in comparison to children with ALL. Children with melanoma reported significantly better pain and hurt scores $(p=.0371)$, and children with OS reported a significantly lower pain and hurt scores $(p=.0741)$, in comparison to the ALL group.

In general, diagnosis was a significant predictor of change in pain and hurt scores $(\mathrm{p}=.033)$. Overall, pain and hurt symptoms improved significantly between the beginning of treatment (T1) and the end of treatment (T4) in children with AML, HL, and OS, but not in children with ALL and melanoma, where pain and hurt scores improved but not significantly. Table 4-17 presents the change in Pain and hurt scores over time and across the different diagnostic groups.

\section{Nausea}

Nausea symptoms were significantly predicted by diagnosis. All groups reported significantly lower nausea scores $(\mathrm{p}<.1)$ in comparison to the ALL group, except for the melanoma group, which reported significantly higher scores $(\mathrm{p}<.0045)$ in comparison to the ALL group. Over time, nausea scores significantly improved in the overall sample $(p<.005)$. However, by examining each group separately, we found that all groups reported significantly improved nausea scores $(\mathrm{p}<.05)$ at the end of treatment $(\mathrm{T} 4)$ in comparison to the beginning of treatment (T1), except for the ALL group $(p=.4048)$. Table 4-18 presents the change in nausea scores over time and across the different diagnostic groups in the study.

\section{Procedural Anxiety}

Across diagnostic groups and over time, children with ALL reported the lowest procedural anxiety scores at $\mathrm{T} 1(\mathrm{M}=54.67)$, indicating high burden of symptom. At the end of treatment (T4), children with HL reported the highest procedural anxiety scores, indicating less symptom burden.

Over time, children reported a significantly improved procedural anxiety scores $(\mathrm{p}<.05)$ at the end of treatment in comparison to the beginning of treatment $(\mathrm{T} 1)$, except for children with melanoma, where procedural anxiety scores improved but not significantly $(p=.7634)$. Table 4-19 presents the change in procedural anxiety scores over time and across the different diagnostic groups. 
Table 4-17. Pain and hurt scores across diagnostic groups and over time

\begin{tabular}{|c|c|c|c|c|c|c|c|c|}
\hline \multirow[b]{3}{*}{ Diagnosis } & \multicolumn{8}{|c|}{ Time Point } \\
\hline & \multicolumn{2}{|c|}{ T1 } & \multicolumn{2}{|c|}{$\mathrm{T} 2$} & \multicolumn{2}{|c|}{ T3 } & \multicolumn{2}{|c|}{ T4 } \\
\hline & n & Mean & $\mathbf{n}$ & Mean & $\mathbf{n}$ & Mean & n & Mean \\
\hline$\overline{A L L}$ & 206 & 67.17 & 200 & $79.38^{\wedge}$ & 168 & 68.75 & 158 & 70.57 \\
\hline AML & . & . & 75 & 69.67 & 45 & 71.39 & 30 & $85.00^{\wedge}$ \\
\hline HL & . & . & 212 & 65.92 & 196 & 69.39 & 174 & $84.91^{\wedge}$ \\
\hline MEL* & . & . & 23 & 79.35 & 16 & 83.59 & 14 & 80.36 \\
\hline OS & 108 & 52.55 & 101 & $76.24^{\wedge}$ & 89 & 72.89 & 82 & $71.80^{\wedge}$ \\
\hline
\end{tabular}

ALL: acute lymphoblastic leukemia, AML: acute myeloid leukemia; HL: Hodgkin lymphoma; MEL: melanoma; OS: osteosarcoma.

$*: p<0.05$ between diagnostic groups in comparison to acute lymphoblastic leukemia; $\wedge: p<0.05$ within group over time in comparison to first time point of measurement.

Table 4-18. Nausea scores across diagnostic groups and over time

\begin{tabular}{|c|c|c|c|c|c|c|c|c|}
\hline \multirow[b]{3}{*}{ Diagnosis } & \multicolumn{8}{|c|}{ Time Point } \\
\hline & \multicolumn{2}{|c|}{ T1 } & \multicolumn{2}{|c|}{ T2 } & \multicolumn{2}{|c|}{ T3 } & \multicolumn{2}{|c|}{ T4 } \\
\hline & $\mathrm{n}$ & Mean & $\mathrm{n}$ & Mean & $\mathbf{n}$ & Mean & $\mathbf{n}$ & Mean \\
\hline$\overline{\text { ALL }}$ & 206 & 72.96 & 200 & $63.44^{\wedge}$ & 167 & 68.77 & 158 & 71.65 \\
\hline AML & . & . & 75 & 59.86 & 45 & 65.33 & 30 & $82.67^{\wedge}$ \\
\hline HL & . & . & 212 & 60.70 & 196 & 59.31 & 170 & $77.92^{\wedge}$ \\
\hline MEL* & & & 23 & 73.48 & 16 & 81.25 & 16 & $87.50^{\wedge}$ \\
\hline OS & 107 & 67.29 & 101 & $50.73^{\wedge}$ & 89 & $48.54^{\wedge}$ & 80 & $73.88^{\wedge}$ \\
\hline
\end{tabular}

ALL: acute lymphoblastic leukemia, AML: acute myeloid leukemia; HL: Hodgkin lymphoma; MEL: melanoma; OS: osteosarcoma.

$*: p<0.05$ between diagnostic groups in comparison to acute lymphoblastic leukemia; $\wedge: p<0.05$ within group over time in comparison to first time point of measurement. 
Table 4-19. Procedural anxiety scores across diagnostic groups and over time

\begin{tabular}{|c|c|c|c|c|c|c|c|c|}
\hline \multirow[b]{3}{*}{ Diagnosis } & \multicolumn{8}{|c|}{ Time Point } \\
\hline & \multicolumn{2}{|c|}{ T1 } & \multicolumn{2}{|c|}{$\mathbf{T 2}$} & \multicolumn{2}{|c|}{ T3 } & \multicolumn{2}{|r|}{ T4 } \\
\hline & $\mathbf{n}$ & Mean & n & Mean & n & Mean & n & Mean \\
\hline$\overline{A L L}$ & 206 & 54.67 & 199 & $64.15^{\wedge}$ & 166 & $71.99^{\wedge}$ & 158 & $76.71^{\wedge}$ \\
\hline AML & . & . & 74 & 60.75 & 45 & 66.76 & 30 & $74.17^{\wedge}$ \\
\hline HL & . & . & 211 & 71.05 & 195 & 72.39 & 174 & $78.35^{\wedge}$ \\
\hline MEL & . & . & 23 & 72.10 & 16 & 67.19 & 16 & 68.75 \\
\hline OS & 108 & 59.57 & 100 & $72.71^{\wedge}$ & 89 & $73.69^{\wedge}$ & 81 & $76.23^{\wedge}$ \\
\hline
\end{tabular}

ALL: acute lymphoblastic leukemia, AML: acute myeloid leukemia; HL: Hodgkin lymphoma; MEL: melanoma; OS: osteosarcoma.

$*: p<0.05$ between diagnostic groups in comparison to acute lymphoblastic leukemia; $\wedge: p<0.05$ within group over time in comparison to first time point of measurement. 


\section{Treatment Anxiety}

Treatment anxiety was generally not predicted by the different diagnoses in the overall sample. Table 4-20 presents the change in treatment anxiety scores over time and across the different diagnostic groups. Children with HL reported significantly lower treatment anxiety scores, indicating higher symptom burden in comparison to children with ALL $(\mathrm{p}<.0432)$. Over time in the overall sample, children reported higher treatment anxiety scores, indicating better outcomes, at the end of treatment (T4) in comparison to T1 $(p<.0001)$. This trend was not significant, however, in children with HL $(p=.8591)$, and melanoma $(\mathrm{p}=.5752)$.

\section{Cancer Worry}

Table 4-21 presents the change in cancer worry scores across different diagnostic groups and over time. The lowest cancer worry score at the beginning of treatment was for the OS groups $(\mathrm{M}=74.57)$. At the end of treatment (T4), children with AML reported the highest cancer worry score. Symptoms of cancer worry were significantly predicted by diagnosis and time in treatment in the overall sample $(\mathrm{p}<.0001)$. There were no significant differences in cancer worry scores among different diagnostic groups over time in our sample.

\section{Cognitive Problems}

Cognitive problems scores maintained relatively stable scores over time. The group with the lowest cognitive fatigue scores was the OS group at T1 ( $M=74.57)$. Overall in the general sample, cognitive fatigue scores improved significantly at the end of treatment (T4) in comparison to the beginning of treatment $(\mathrm{T} 1, \mathrm{p}=.002)$. This trend, however, was not observed in all diagnostic groups, only children with HL $(\mathrm{p}<.0123)$ and OS ( $p<.0023)$ reported significant improvement in cognitive problems at T4 in comparison to $\mathrm{T} 1$. There were no significant differences between diagnostic groups over time in our sample. Table 4-22 presents the change in cognitive problems' scores across different diagnostic groups and over time.

\section{Perceived Physical Appearance}

Perceived physical appearance was a relatively stable symptom that significantly improved over time in children within our overall sample. Children reported significantly higher perceived physical appearance scores $(p<.0089)$ at the end of treatment (T4) in comparison to the beginning of treatment (T1). However, the trend of improvement over time was not significant in all diagnostic groups. Diagnosis was not a predictor of perceived physical appearance scores, indicating that children across all diagnostic groups experienced similar effects. Table 4-23 presents the change in perceived physical appearance scores across different diagnostic groups and over time. 
Table 4-20. Treatment anxiety scores across diagnostic groups and over time

\begin{tabular}{|c|c|c|c|c|c|c|c|c|}
\hline \multirow[b]{3}{*}{ Diagnosis } & \multicolumn{8}{|c|}{ Time Point } \\
\hline & \multicolumn{2}{|c|}{ T1 } & \multicolumn{2}{|c|}{$\mathbf{T} 2$} & \multicolumn{2}{|r|}{ T3 } & \multicolumn{2}{|r|}{ T4 } \\
\hline & $\mathbf{n}$ & Mean & n & Mean & $\mathbf{n}$ & Mean & $\mathbf{n}$ & Mean \\
\hline$\overline{A L L}$ & 205 & 82.87 & 200 & $86.42^{\wedge}$ & 167 & $89.97^{\wedge}$ & 157 & $91.03^{\wedge}$ \\
\hline AML & . & . & 75 & 82.50 & 45 & 91.67 & 30 & 93.61 \\
\hline HL* & . & . & 212 & 85.36 & 196 & 82.57 & 174 & 84.77 \\
\hline MEL & . & . & 23 & 90.22 & 16 & 89.06 & 16 & 91.67 \\
\hline OS & 107 & 74.57 & 101 & $86.30^{\wedge}$ & 88 & $89.30^{\wedge}$ & 82 & $88.92^{\wedge}$ \\
\hline
\end{tabular}

ALL: acute lymphoblastic leukemia, AML: acute myeloid leukemia; HL: Hodgkin lymphoma; MEL: melanoma; OS: osteosarcoma.

$*: p<0.05$ between diagnostic groups in comparison to acute lymphoblastic leukemia; $\wedge: p<0.05$ within group over time in comparison to first time point of measurement.

Table 4-21. Cancer worry scores across diagnostic groups and over time

\begin{tabular}{|c|c|c|c|c|c|c|c|c|}
\hline \multirow[b]{3}{*}{ Diagnosis } & \multicolumn{8}{|c|}{ Time Point } \\
\hline & \multicolumn{2}{|c|}{ T1 } & \multicolumn{2}{|c|}{$\mathbf{T} 2$} & \multicolumn{2}{|c|}{ T3 } & \multicolumn{2}{|c|}{ T4 } \\
\hline & $\mathbf{n}$ & Mean & $\mathbf{n}$ & Mean & n & Mean & n & Mean \\
\hline$\overline{A L L}$ & 205 & 82.87 & 200 & 86.42 & 167 & 89.97 & 157 & $91.03^{\wedge}$ \\
\hline AML & . & . & 75 & 82.50 & 45 & 91.67 & 30 & 93.61 \\
\hline HL & . & . & 212 & 85.36 & 196 & 82.57 & 174 & $84.77^{\wedge}$ \\
\hline MEL & . & . & 23 & 90.22 & 16 & 89.06 & 16 & 91.67 \\
\hline OS & 107 & 74.57 & 101 & $86.30^{\wedge}$ & 88 & $89.30^{\wedge}$ & 82 & $88.92^{\wedge}$ \\
\hline
\end{tabular}

ALL: acute lymphoblastic leukemia, AML: acute myeloid leukemia; HL: Hodgkin lymphoma; MEL: melanoma; OS: osteosarcoma.

$*: p<0.05$ between diagnostic groups in comparison to acute lymphoblastic leukemia; $\wedge: p<0.05$ within group over time in comparison to first time point of measurement. 
Table 4-22. Cognitive problems scores across diagnostic groups and over time

\begin{tabular}{|c|c|c|c|c|c|c|c|c|}
\hline \multirow[b]{3}{*}{ Diagnosis } & \multicolumn{8}{|c|}{ Time Point } \\
\hline & \multicolumn{2}{|c|}{ T1 } & \multicolumn{2}{|c|}{ T2 } & \multicolumn{2}{|c|}{ T3 } & \multicolumn{2}{|r|}{ T4 } \\
\hline & $\mathbf{n}$ & Mean & $\mathbf{n}$ & Mean & $\mathbf{n}$ & Mean & $\mathbf{n}$ & Mean \\
\hline ALL & 200 & 75.25 & 197 & 75.53 & 167 & 76.27 & 158 & 75.24 \\
\hline AML & & & 74 & 78.38 & 45 & 82.97 & 30 & 84.83 \\
\hline HL & & & 211 & 77.42 & 194 & 78.85 & 174 & $80.77^{\wedge}$ \\
\hline MEL & & & 23 & 82.07 & 16 & 80.94 & 16 & 80.00 \\
\hline OS & 107 & 74.57 & 101 & 75.86 & 89 & $77.75^{\wedge}$ & 82 & $79.92^{\wedge}$ \\
\hline
\end{tabular}

ALL: acute lymphoblastic leukemia, AML: acute myeloid leukemia; HL: Hodgkin lymphoma; MEL: melanoma; OS: osteosarcoma.

$*: p<0.05$ between diagnostic groups in comparison to acute lymphoblastic leukemia; $\wedge: p<0.05$ within group over time in comparison to first time point of measurement.

Table 4-23. Perceived physical appearance scores across diagnostic groups and over time

\begin{tabular}{|c|c|c|c|c|c|c|c|c|}
\hline \multirow[b]{3}{*}{ Diagnosis } & \multicolumn{8}{|c|}{ Time Point } \\
\hline & \multicolumn{2}{|c|}{ T1 } & \multicolumn{2}{|c|}{ T2 } & \multicolumn{2}{|c|}{ T3 } & \multicolumn{2}{|c|}{ T4 } \\
\hline & $\mathbf{n}$ & Mean & $\mathbf{n}$ & Mean & $\mathbf{n}$ & Mean & $\mathbf{n}$ & Mean \\
\hline$\overline{\text { ALL }}$ & 206 & 78.64 & 200 & 78.96 & 167 & 75.85 & 159 & 80.45 \\
\hline AML & & . & 74 & 78.49 & 45 & 85.19 & 30 & 88.61 \\
\hline HL & & . & 212 & 77.00 & 196 & 78.23 & 172 & $80.81^{\wedge}$ \\
\hline MEL & & & 23 & 80.43 & 16 & 74.48 & 16 & 72.92 \\
\hline OS & 108 & 75.00 & 100 & 76.29 & 89 & 79.87 & 82 & $81.30^{\wedge}$ \\
\hline
\end{tabular}

ALL: acute lymphoblastic leukemia, AML: acute myeloid leukemia; HL: Hodgkin lymphoma; MEL: melanoma; OS: osteosarcoma.

$*: p<0.05$ between diagnostic groups in comparison to acute lymphoblastic leukemia; $\wedge: p<0.05$ within group over time in comparison to first time point of measurement. 


\section{Communication}

Communication scores generally improved over time in the overall sample.

Table 4-24 presents the change in communication scores across different diagnostic groups and over time. The lowest communication score was for the OS group at the beginning of treatment ( $\mathrm{T} 1, \mathrm{M}=73.01)$. Examining each diagnostic group separately, only children with ALL $(\mathrm{p}=.0003)$, HL $(\mathrm{p}<.0001)$, and OS $(\mathrm{p}<.0001)$ experienced a significant increase in their communication scores at the end of treatment (T4) in comparison to the beginning of treatment (T1). In the overall sample, diagnosis was not a predictor of communication scores $(\mathrm{p}=.2209)$.

\section{Aim 3}

Aim 3 was to identify correlates with HRQOL of children undergoing curative cancer treatment over time within each diagnostic group.

- $\quad$ Research Question 3-1: Is there an association between cancer and treatment factors and self-reported HRQOL of children undergoing curative cancer treatment over time?

- $\quad$ Research Question 3-3: What are the associations between each variable and the change in self-reported HRQOL of children undergoing curative cancer treatment?

Table 4-24. Communication scores across diagnostic groups and over time

\section{Time Point}

\begin{tabular}{|c|c|c|c|c|c|c|c|c|}
\hline \multirow[b]{2}{*}{ Diagnosis } & \multicolumn{2}{|c|}{ T1 } & \multicolumn{2}{|c|}{$\mathbf{T 2}$} & \multicolumn{2}{|c|}{ T3 } & \multicolumn{2}{|c|}{ T4 } \\
\hline & $\mathbf{n}$ & Mean & $\mathbf{n}$ & Mean & $\mathbf{n}$ & Mean & $\mathbf{n}$ & Mean \\
\hline ALL & 204 & 76.08 & 201 & 77.03 & 167 & 79.09 & 159 & $83.44^{\wedge}$ \\
\hline AML & . & . & 75 & 77.06 & 45 & 86.11 & 30 & 86.53 \\
\hline HL & . & . & 212 & 78.89 & 196 & 81.63 & 172 & $85.56^{\wedge}$ \\
\hline MEL & . & . & 23 & 82.61 & 16 & 82.81 & 16 & 77.08 \\
\hline OS & 107 & 73.01 & 99 & $76.26^{\wedge}$ & 89 & 81.09 & 81 & $82.92^{\wedge}$ \\
\hline
\end{tabular}

ALL: acute lymphoblastic leukemia, AML: acute myeloid leukemia; HL: Hodgkin lymphoma; MEL: melanoma; OS: osteosarcoma.

$*: p<0.05$ between diagnostic groups in comparison to acute lymphoblastic leukemia; $\wedge: p<0.05$ within group over time in comparison to first time point of measurement. 


\section{Acute Lymphoblastic Leukemia}

A univariate model to identify predictors of the PedsQL-Generic domain scores identified age, gender, race, risk group, and time as significant predictors of HRQOL domains on the PedsQL-Generic scale (Table 4-25). A multivariate analysis of the PedsQL-Generic domain scores which included the significant factors from the univariate analysis for each domain identified age, gender, race, risk group, and time as significant predictors of the physical, emotional and total HRQOL scores. No included factors were identified to predict the social functioning and school functioning domains on the multivariate analysis (Table 4-26).On the PedsQL-Cancer module, age, gender, race, risk group and time were also significant predictors of different cancer-related symptoms in children with ALL (Table 4-27). A multivariate analysis of the PedsQL-Cancer symptom scores which included the significant factors from the univariate analysis for each symptom identified age, gender, race, risk group, and time as significant predictors of the cancer-related symptoms (Table 4-28).

In multivariate models, age was a significant predictor of HRQOL in children with ALL only on the physical domain score $(\mathrm{p}<.0001)$. Children $(5-12$ years) reported significantly better physical functioning score. Age was also a predictor of cancer-related symptoms, including pain and hurt, nausea, procedural anxiety, and communication. Children (ages 5-12 years) reported significantly better pain and hurt ( $\mathrm{p}=.0003)$, and nausea $(\mathrm{p}=.0003)$ scores, and reported significantly lower, indicating worse outcomes, procedural anxiety $(\mathrm{p}<.0001)$ and communication $(\mathrm{p}=.0009)$ scores than adolescents.

Gender was a significant predictor of physical $(\mathrm{p}=.0003)$, emotional $(\mathrm{p}<.0001)$, and total $(p=.0005)$ scores of HRQOL. In all these domains, being female was associated with a significantly lower HRQOL. Female gender was also associated with lower pain and hurt $(\mathrm{p}=.0104)$, nausea $(\mathrm{p}=.0104)$, procedural anxiety $(\mathrm{p}=.0074)$, cancer worry $(p<.0001)$, and perceived physical appearance scores $(p=.0002)$.

Ethnicity was also a predictor of HRQOL in children with ALL, non-white children reported significantly lower physical functioning $(\mathrm{p}<.0001)$, and total HRQOL $(p=.0016)$ scores. Non-white race was also a predictor of lower, and worse pain and hurt $(\mathrm{p}=.0002)$, nausea $(\mathrm{p}=.0002)$, and treatment anxiety $(\mathrm{p}=.0184)$ scores.

Time predicted higher physical, emotional, and total HRQOL scores. Children reported significantly higher $(\mathrm{p}<.0001)$ HRQOL scores on these domains at the end of treatment (T4) in comparison to the beginning of treatment (T1). This significance was also reported for procedural anxiety, treatment anxiety, and cancer worry $(\mathrm{p}<.0001)$.

Risk predicted HRQOL domains and cancer symptoms in children with ALL. Children on the Low risk arm of therapy reported higher physical $(p=.01)$, emotional $(p=.0253)$ and total $(p=.01)$ HRQOL scores than children on the Standard/High risk group. Children on the Standard/High risk arm also reported lower pain and hurt $(p=.0102)$, nausea $(p=.0102)$, cancer worry $(p=.0239)$, and cognitive problems $(p=.0081)$ scores, indicating higher symptom burden. 
Table 4-25. Univariate model results investigating predictors of PedsQL-Generic domain scores in ALL

\begin{tabular}{|c|c|c|c|c|c|c|c|c|c|c|}
\hline \multirow[b]{2}{*}{ Factor } & \multicolumn{2}{|c|}{ Physical Functioning } & \multicolumn{2}{|c|}{$\begin{array}{c}\text { Emotional } \\
\text { Functioning }\end{array}$} & \multicolumn{2}{|c|}{ Social Functioning } & \multicolumn{2}{|c|}{ School Functioning } & \multicolumn{2}{|c|}{ Total Score } \\
\hline & B (SE) & $\mathbf{P}$ & B (SE) & $\mathbf{P}$ & B (SE) & $\mathbf{P}$ & B (SE) & $\mathbf{P}$ & B (SE) & $\mathbf{P}$ \\
\hline $\begin{array}{l}\text { Age (Child vs. } \\
\text { Teen) }\end{array}$ & $\begin{array}{l}12.78 \\
(2.41)\end{array}$ & $<.0001$ & $1.26(2.14)$ & 0.5566 & $-2.5(1.92)$ & 0.1937 & $4.66(2.33)$ & 0.0465 & $5.06(1.85)$ & 0.0063 \\
\hline $\begin{array}{l}\text { Gender (Male vs. } \\
\text { Female) }\end{array}$ & $6.4(2.36)$ & 0.0068 & $7.77(1.93)$ & $<.0001$ & $2.61(1.79)$ & 0.1463 & $2.13(2.17)$ & 0.3282 & $4.95(1.72)$ & 0.0042 \\
\hline $\begin{array}{l}\text { Ethnicity (Other } \\
\text { vs. White) }\end{array}$ & $\begin{array}{c}-10.54 \\
(2.9)\end{array}$ & 0.0003 & $\begin{array}{l}-3.53 \\
(2.49)\end{array}$ & 0.1565 & $\begin{array}{l}-3.58 \\
(2.23)\end{array}$ & 0.1087 & $\begin{array}{l}-3.54 \\
(2.72)\end{array}$ & 0.1935 & $\begin{array}{l}-5.94 \\
(2.15)\end{array}$ & 0.0059 \\
\hline $\begin{array}{l}\text { Risk Group (Low } \\
\text { vs. Standard/High) }\end{array}$ & $7.66(2.3)$ & 0.0010 & $3.26(1.97)$ & 0.0983 & $1.69(1.77)$ & 0.3406 & $4.01(2.11)$ & 0.0585 & $4.43(1.71)$ & 0.0097 \\
\hline Time & & $<.0001$ & & 0.0003 & & 0.3331 & & 0.4867 & & $<.0001$ \\
\hline T1 vs. T2 & $\begin{array}{l}-13.35 \\
(1.58)\end{array}$ & $<.0001$ & $-5.12(1.5)$ & 0.0007 & $\begin{array}{l}-0.74 \\
(1.49)\end{array}$ & 0.6183 & $\begin{array}{l}-3.08 \\
(2.07)\end{array}$ & 0.1373 & $\begin{array}{l}-6.66 \\
(1.16)\end{array}$ & $<.0001$ \\
\hline T1 vs. T3 & $\begin{array}{l}-12.44 \\
(1.67)\end{array}$ & $<.0001$ & $\begin{array}{l}-2.82 \\
(1.58)\end{array}$ & 0.0749 & $0.06(1.58)$ & 0.9682 & $\begin{array}{l}-0.99 \\
(2.11)\end{array}$ & 0.6405 & $\begin{array}{l}-5.09 \\
(1.23)\end{array}$ & $<.0001$ \\
\hline T1 vs. T4 & $\begin{array}{r}-14.07 \\
(1.71)\end{array}$ & $<.0001$ & $\begin{array}{l}-6.42 \\
(1.61)\end{array}$ & $<.0001$ & $\begin{array}{l}-2.62 \\
(1.61)\end{array}$ & 0.1035 & $\begin{array}{l}-0.83 \\
(2.14)\end{array}$ & 0.6994 & $\begin{array}{l}-6.94 \\
(1.25)\end{array}$ & $<.0001$ \\
\hline
\end{tabular}


Table 4-26. Multivariate model results investigating predictors of PedsQL-Generic domain scores in ALL

\begin{tabular}{|c|c|c|c|c|c|c|c|c|}
\hline \multirow[b]{2}{*}{ Factor } & \multicolumn{2}{|c|}{ Physical Functioning } & \multicolumn{2}{|c|}{ Emotional Functioning } & \multicolumn{2}{|c|}{ School Functioning } & \multicolumn{2}{|c|}{ Total Score } \\
\hline & B (SE) & $\mathbf{P}$ & B (SE) & $\mathbf{P}$ & B (SE) & $\mathbf{P}$ & B (SE) & $\mathbf{P}$ \\
\hline $\begin{array}{l}\text { Age (Child vs. } \\
\text { Teen) }\end{array}$ & $10.48(2.41)$ & $<.0001$ & & . & $3.54(2.49)$ & 0.1553 & $3.38(1.88)$ & 0.0732 \\
\hline $\begin{array}{l}\text { Gender (Male vs. } \\
\text { Female) }\end{array}$ & $7.79(2.13)$ & 0.0003 & $8.5(1.94)$ & $<.0001$ & & . & $5.81(1.67)$ & 0.0005 \\
\hline $\begin{array}{l}\text { Ethnicity (Other } \\
\text { vs. White) }\end{array}$ & $-11.24(2.65)$ & $<.0001$ & & . & & . & $-6.56(2.07)$ & 0.0016 \\
\hline $\begin{array}{l}\text { Risk Group (Low } \\
\text { vs. } \\
\text { Standard/High) }\end{array}$ & $5.87(2.27)$ & 0.0100 & $4.3(1.92)$ & 0.0253 & $2.88(2.26)$ & 0.2016 & $4.59(1.77)$ & 0.0100 \\
\hline Time & & . & & . & & . & & . \\
\hline T1 vs. T2 & $-13.39(1.57)$ & $<.0001$ & $-5.15(1.49)$ & 0.0006 & & . & $-6.67(1.16)$ & $<.0001$ \\
\hline T1 vs. T3 & $-12.38(1.67)$ & $<.0001$ & $-2.7(1.58)$ & 0.0885 & & . & $-5.03(1.23)$ & $<.0001$ \\
\hline T1 vs. T4 & $-13.92(1.7)$ & $<.0001$ & $-6.26(1.61)$ & 0.0001 & & . & $-6.82(1.25)$ & $<.0001$ \\
\hline
\end{tabular}


Table 4-27. Univariate model results investigating predictors of PedsQL-Cancer domain scores in ALL

\begin{tabular}{|c|c|c|c|c|c|c|c|c|c|c|c|c|c|c|c|c|}
\hline \multirow[b]{2}{*}{ Factor } & \multicolumn{2}{|c|}{ Pain and Hurt } & \multicolumn{2}{|c|}{ Nausea } & \multicolumn{2}{|c|}{$\begin{array}{c}\text { Procedural } \\
\text { Anxiety }\end{array}$} & \multicolumn{2}{|c|}{$\begin{array}{c}\text { Treatment } \\
\text { Anxiety }\end{array}$} & \multicolumn{2}{|c|}{ Cancer Worry } & \multicolumn{2}{|c|}{$\begin{array}{l}\text { Cognitive } \\
\text { Problems } \\
\end{array}$} & \multicolumn{2}{|c|}{$\begin{array}{c}\text { Perceived } \\
\text { Physical } \\
\text { Appearance } \\
\end{array}$} & \multicolumn{2}{|c|}{$\begin{array}{c}\text { Communica- } \\
\text { tion }\end{array}$} \\
\hline & $\begin{array}{c}\text { B } \\
(\mathrm{SE})\end{array}$ & $\mathbf{P}$ & $\begin{array}{c}\text { B } \\
(\mathrm{SE})\end{array}$ & $\mathbf{P}$ & $\begin{array}{c}\text { B } \\
(\mathrm{SE})\end{array}$ & $\mathbf{P}$ & $\begin{array}{c}\text { B } \\
(\mathrm{SE})\end{array}$ & $\mathbf{P}$ & $\begin{array}{c}\text { B } \\
(\mathrm{SE})\end{array}$ & $\mathbf{P}$ & $\begin{array}{c}\text { B } \\
(\mathrm{SE})\end{array}$ & $\mathbf{P}$ & $\begin{array}{c}\text { B } \\
(\mathrm{SE})\end{array}$ & $\mathbf{P}$ & $\begin{array}{c}\text { B } \\
(\mathrm{SE})\end{array}$ & $\mathbf{P}$ \\
\hline $\begin{array}{l}\text { Age (Child } \\
\text { vs. Teen) }\end{array}$ & $\begin{array}{l}12.99 \\
(2.76)\end{array}$ & $\begin{array}{c}<.000 \\
1\end{array}$ & $\begin{array}{c}2.11 \\
(2.08)\end{array}$ & 0.3102 & $\begin{array}{l}-16.64 \\
(3.28)\end{array}$ & $\begin{array}{c}<.000 \\
1\end{array}$ & $\begin{array}{l}-3.95 \\
(2.23)\end{array}$ & 0.0772 & $\begin{array}{c}2.23 \\
(2.63)\end{array}$ & 0.3964 & $\begin{array}{l}5.33 \\
(2.37)\end{array}$ & 0.0249 & $\begin{array}{c}2.27 \\
(2.69)\end{array}$ & 0.3997 & $\begin{array}{l}-7.02 \\
(2.18)\end{array}$ & $\begin{array}{c}0.001 \\
4\end{array}$ \\
\hline $\begin{array}{l}\text { Gender } \\
\text { (Male vs. } \\
\text { Female) }\end{array}$ & $\begin{array}{c}5.03 \\
(2.69)\end{array}$ & 0.0617 & $\begin{array}{l}5.15 \\
(1.92)\end{array}$ & 0.0076 & $\begin{array}{l}8.68 \\
(3.18)\end{array}$ & 0.0066 & $\begin{array}{l}2.66 \\
(2.1)\end{array}$ & 0.2058 & $\begin{array}{l}9.43 \\
(2.39)\end{array}$ & $\begin{array}{c}<.000 \\
1\end{array}$ & $\begin{array}{c}0.27 \\
(2.25)\end{array}$ & 0.9037 & $\begin{array}{c}9.32 \\
(2.45)\end{array}$ & 0.0002 & $\begin{array}{c}3.37 \\
(2.06)\end{array}$ & $\begin{array}{c}0.102 \\
8\end{array}$ \\
\hline $\begin{array}{l}\text { Ethnicity } \\
\text { (Other vs. } \\
\text { White) }\end{array}$ & $\begin{array}{l}-10.81 \\
(3.23)\end{array}$ & 0.0009 & $\begin{array}{l}-4.93 \\
(2.35)\end{array}$ & 0.0365 & $\begin{array}{l}-2.71 \\
(3.94)\end{array}$ & 0.4913 & $\begin{array}{l}-5.41 \\
(2.54)\end{array}$ & 0.0336 & $\begin{array}{c}0.05 \\
(3.01)\end{array}$ & 0.9865 & $\begin{array}{l}-2.23 \\
(2.74)\end{array}$ & 0.4146 & $\begin{array}{l}-1.75 \\
(3.07)\end{array}$ & 0.5703 & $\begin{array}{l}-2.46 \\
(2.54)\end{array}$ & $\begin{array}{c}0.332 \\
8\end{array}$ \\
\hline $\begin{array}{l}\text { Risk Group } \\
\text { (Low vs. } \\
\text { Standard/ } \\
\text { High) }\end{array}$ & $\begin{array}{c}7.9 \\
(2.59)\end{array}$ & 0.0025 & $\begin{array}{l}2.18 \\
(1.9)\end{array}$ & 0.2529 & $\begin{array}{l}-3.83 \\
(3.16)\end{array}$ & 0.2271 & $\begin{array}{c}0.44 \\
(2.06)\end{array}$ & 0.8325 & $\begin{array}{c}4.6 \\
(2.4)\end{array}$ & 0.0564 & $\begin{array}{l}7.11 \\
(2.15)\end{array}$ & 0.0010 & $\begin{array}{c}3.72 \\
(2.46)\end{array}$ & 0.1318 & $\begin{array}{c}0.6 \\
(2.04)\end{array}$ & $\begin{array}{c}0.768 \\
9\end{array}$ \\
\hline Time & & $\begin{array}{c}<.000 \\
1\end{array}$ & & $\begin{array}{c}<.000 \\
1\end{array}$ & & $\begin{array}{c}<.000 \\
1\end{array}$ & & $\begin{array}{c}<.000 \\
1\end{array}$ & & $\begin{array}{c}<.000 \\
1\end{array}$ & & 0.9325 & & 0.2502 & & $\begin{array}{c}0.002 \\
1\end{array}$ \\
\hline T1 vs. T2 & $\begin{array}{l}-12.19 \\
(2.17)\end{array}$ & $\begin{array}{c}<.000 \\
1\end{array}$ & $\begin{array}{c}9.73 \\
(1.57)\end{array}$ & $\begin{array}{c}<.000 \\
1\end{array}$ & $\begin{array}{c}-10.25 \\
(2.1)\end{array}$ & $\begin{array}{c}<.000 \\
1\end{array}$ & $\begin{array}{l}-3.75 \\
(1.53)\end{array}$ & 0.0148 & $\begin{array}{c}0.53 \\
(1.81)\end{array}$ & 0.7706 & $\begin{array}{c}-0.71 \\
(1.61)\end{array}$ & 0.6623 & $\begin{array}{l}-0.46 \\
(1.92)\end{array}$ & 0.8102 & $\begin{array}{l}-1.03 \\
(1.93)\end{array}$ & $\begin{array}{c}0.592 \\
5\end{array}$ \\
\hline T1 vs. T3 & $\begin{array}{l}-1.84 \\
(2.29)\end{array}$ & 0.4221 & $\begin{array}{c}3.97 \\
(1.67)\end{array}$ & 0.0175 & $\begin{array}{r}-18.57 \\
(2.23)\end{array}$ & $\begin{array}{c}<.000 \\
1\end{array}$ & $\begin{array}{l}-7.26 \\
(1.62)\end{array}$ & $\begin{array}{c}<.000 \\
1\end{array}$ & $\begin{array}{c}-2.9 \\
(1.91)\end{array}$ & 0.1291 & $\begin{array}{r}-1.05 \\
(1.7)\end{array}$ & 0.5387 & $\begin{array}{c}2.47 \\
(2.03)\end{array}$ & 0.2247 & $\begin{array}{l}-3.14 \\
(2.04)\end{array}$ & $\begin{array}{c}0.123 \\
6\end{array}$ \\
\hline T1 vs. T4 & $\begin{array}{l}-3.25 \\
(2.33)\end{array}$ & 0.1643 & $\begin{array}{c}1.41 \\
(1.69)\end{array}$ & 0.4048 & $\begin{array}{l}-23.37 \\
(2.26)\end{array}$ & $\begin{array}{c}<.000 \\
1\end{array}$ & $\begin{array}{l}-8.51 \\
(1.65)\end{array}$ & $\begin{array}{c}<.000 \\
1\end{array}$ & $\begin{array}{c}-8.2 \\
(1.94)\end{array}$ & $\begin{array}{c}<.000 \\
1\end{array}$ & $\begin{array}{l}-0.32 \\
(1.73)\end{array}$ & 0.8544 & $\begin{array}{l}-1.73 \\
(2.06)\end{array}$ & 0.4016 & $\begin{array}{c}-7.5 \\
(2.07)\end{array}$ & $\begin{array}{c}0.000 \\
3\end{array}$ \\
\hline
\end{tabular}


Table 4-28. Multivariate model results investigating predictors of PedsQL-Cancer domain scores in ALL

\begin{tabular}{|c|c|c|c|c|c|c|c|c|c|c|c|c|c|c|c|c|}
\hline \multirow[b]{2}{*}{ Factor } & \multicolumn{2}{|c|}{ Pain and Hurt } & \multicolumn{2}{|c|}{ Nausea } & \multicolumn{2}{|c|}{$\begin{array}{c}\text { Procedural } \\
\text { Anxiety } \\
\end{array}$} & \multicolumn{2}{|c|}{$\begin{array}{c}\text { Treatment } \\
\text { Anxiety }\end{array}$} & \multicolumn{2}{|c|}{ Cancer Worry } & \multicolumn{2}{|c|}{$\begin{array}{l}\text { Cognitive } \\
\text { Problems } \\
\end{array}$} & \multicolumn{2}{|c|}{$\begin{array}{c}\text { Perceived } \\
\text { Physical } \\
\text { Appearance } \\
\end{array}$} & \multicolumn{2}{|c|}{$\begin{array}{c}\text { Communica- } \\
\text { tion }\end{array}$} \\
\hline & $\begin{array}{c}\text { B } \\
(\mathrm{SE})\end{array}$ & $\mathbf{P}$ & $\begin{array}{c}\text { B } \\
(\mathrm{SE})\end{array}$ & $\mathbf{P}$ & $\begin{array}{c}\text { B } \\
(\mathrm{SE})\end{array}$ & $\mathbf{P}$ & $\begin{array}{c}\text { B } \\
(\mathrm{SE})\end{array}$ & $\mathbf{P}$ & $\begin{array}{c}\text { B } \\
(\mathrm{SE})\end{array}$ & $\mathbf{P}$ & $\begin{array}{c}\text { B } \\
(\mathrm{SE})\end{array}$ & $\mathbf{P}$ & $\begin{array}{c}\text { B } \\
(\mathrm{SE})\end{array}$ & $\mathbf{P}$ & $\begin{array}{c}\text { B } \\
(\mathrm{SE})\end{array}$ & $\mathbf{P}$ \\
\hline $\begin{array}{l}\text { Age (Child } \\
\text { vs. Teen) }\end{array}$ & $\begin{array}{l}10.39 \\
(2.86)\end{array}$ & 0.0003 & $\begin{array}{l}10.39 \\
(2.86)\end{array}$ & 0.0003 & $\begin{array}{l}-17.6 \\
(3.24)\end{array}$ & $\begin{array}{c}<.000 \\
1\end{array}$ & $\begin{array}{l}-4.27 \\
(2.21)\end{array}$ & 0.0538 & & . & $\begin{array}{c}2.94 \\
(2.51)\end{array}$ & 0.2419 & & . & $\begin{array}{l}-7.25 \\
(2.18)\end{array}$ & 0.0009 \\
\hline $\begin{array}{l}\text { Gender } \\
\text { (Male vs. } \\
\text { Female) }\end{array}$ & $\begin{array}{l}6.42 \\
(2.5)\end{array}$ & 0.0104 & $\begin{array}{l}6.42 \\
(2.5)\end{array}$ & 0.0104 & $\begin{array}{c}8.14 \\
(3.03)\end{array}$ & 0.0074 & & . & $\begin{array}{l}10.32 \\
(2.4)\end{array}$ & $\begin{array}{c}<.000 \\
1\end{array}$ & & . & $\begin{array}{l}9.32 \\
(2.45)\end{array}$ & 0.0002 & & . \\
\hline $\begin{array}{l}\text { Ethnicity } \\
\text { (Other vs. } \\
\text { White) }\end{array}$ & $\begin{array}{c}-11.47 \\
(3.1)\end{array}$ & 0.0002 & $\begin{array}{c}-11.47 \\
(3.1)\end{array}$ & 0.0002 & & . & $\begin{array}{l}-5.96 \\
(2.52)\end{array}$ & 0.0184 & & . & & & & & & \\
\hline $\begin{array}{l}\text { Risk Group } \\
\text { (Low vs. } \\
\text { Standard/H } \\
\text { igh) }\end{array}$ & $\begin{array}{l}6.88 \\
(2.67)\end{array}$ & 0.0102 & $\begin{array}{l}6.88 \\
(2.67)\end{array}$ & 0.0102 & & . & & . & $\begin{array}{c}5.37 \\
(2.37)\end{array}$ & 0.0239 & $\begin{array}{c}6.13 \\
(2.31)\end{array}$ & 0.0081 & & . & & . \\
\hline Time & & . & & . & & . & & . & & . & & . & & . & & . \\
\hline T1 vs. T2 & $\begin{array}{l}-12.35 \\
(2.17)\end{array}$ & $\begin{array}{c}<.000 \\
1\end{array}$ & $\begin{array}{l}-12.35 \\
(2.17)\end{array}$ & $\begin{array}{c}<.000 \\
1\end{array}$ & $\begin{array}{l}-10.36 \\
(2.1)\end{array}$ & $\begin{array}{c}<.000 \\
1\end{array}$ & $\begin{array}{l}-3.74 \\
(1.53)\end{array}$ & 0.0149 & & . & & . & & . & $\begin{array}{l}-7.63 \\
(2.06)\end{array}$ & 0.0002 \\
\hline T1 vs. T3 & & . & & . & $\begin{array}{l}-18.7 \\
(2.22)\end{array}$ & $\begin{array}{c}<.000 \\
1\end{array}$ & $\begin{array}{l}-7.39 \\
(1.62)\end{array}$ & $\begin{array}{c}<.000 \\
1\end{array}$ & & . & & & & & & \\
\hline T1 vs. T4 & & . & & . & $\begin{array}{l}-23.83 \\
(2.26)\end{array}$ & $\begin{array}{c}<.000 \\
1\end{array}$ & $\begin{array}{l}-8.65 \\
(1.65)\end{array}$ & $\begin{array}{c}<.000 \\
1\end{array}$ & $\begin{array}{l}-8.08 \\
(1.94)\end{array}$ & $\begin{array}{c}<.000 \\
1\end{array}$ & & & & & & \\
\hline
\end{tabular}




\section{Acute Myeloid Leukemia}

A univariate model to identify predictors of the PedsQL-Generic domain scores identified age, risk group, and time as significant predictors of HRQOL on the PedsQLGeneric scale (Table 4-29). A multivariate analysis of the PedsQL-Generic domain scores which included the significant factors from the univariate analysis for each domain identified risk group and time as the only significant predictors of the physical functioning domain, emotional functioning domain and total HRQOL scores

(Table 4-30). None of the factors that have been included in our analysis were significant predictors of the social functioning domain or the school functioning domain in children with AML.

On the PedsQL-Cancer module, age, risk group and time were also significant predictors of HRQOL in children with AML (Table 4-31). A multivariate analysis of the PedsQL-Cancer symptom scores which included the significant factors from the univariate analysis for each domain identified age and time as the only significant predictors of cancer-related symptoms (Table 4-32).

Most cancer-related symptoms in children with AML, including treatment anxiety, cancer worry, cognitive problems, perceived physical appearance, and communication were not significantly correlated with any of the factors included in our study.

Fewer predictor factors were identified in children with AML. Time in treatment was the only significant predictor of HRQOL in children with AML on our PedsQLGeneric multivariate linear model. Children reported significantly higher $(p=.0001)$ on the physical, emotional, and total HRQOL scores at the end of treatment (T4) in comparison to the beginning of treatment (T1). Other factors considered in our analysis, including ethnicity and risk had no significant effect on HRQOL in our sample of children with AML.

The remaining cancer-related symptoms of pain and hurt, nausea, and procedural anxiety were correlated with time in treatment, while procedural anxiety was the only symptom correlated with age. Children with AML reported improved pain and hurt $(p=.0077)$, nausea $(p<.0001)$, and procedural anxiety $(p=.0247)$ at the end of their treatment (T4) in comparison to the first point where cancer-related symptoms were collected at T2. Age was not a significant predictor of HRQOL domains. However, it was a significant predictor of cancer-related symptoms. Children (ages 5-12 years) reported significantly more issues related to procedural anxiety $(p=.018)$ than adolescents (ages 13-18 years). Ethnicity, risk, and gender were not correlated with any of the HRQOL domain scores on the PedsQL-Generic scale and were also not correlated with any of the cancer-related symptoms on the PedsQL-Cancer scale. 
Table 4-29. Univariate model results investigating predictors of PedsQL-Generic domain scores in AML

\begin{tabular}{|c|c|c|c|c|c|c|c|c|c|c|}
\hline \multirow[b]{2}{*}{ Factor } & \multicolumn{2}{|c|}{ Physical Functioning } & \multicolumn{2}{|c|}{ Emotional Functioning } & \multicolumn{2}{|c|}{ Social Functioning } & \multicolumn{2}{|c|}{ School Functioning } & \multicolumn{2}{|c|}{ Total Score } \\
\hline & B (SE) & $\mathbf{P}$ & B (SE) & $\mathbf{P}$ & B (SE) & $\mathbf{P}$ & B (SE) & $\mathbf{P}$ & B (SE) & $\mathbf{P}$ \\
\hline $\begin{array}{l}\text { Age (Child } \\
\text { vs. Teen) }\end{array}$ & $8.63(4.64)$ & 0.0649 & $-1.64(4.15)$ & 0.6936 & $-4.36(2.65)$ & 0.1022 & $0.08(3.92)$ & 0.9836 & $1.83(3.18)$ & 0.5661 \\
\hline $\begin{array}{l}\text { Gender } \\
\text { (Male vs. } \\
\text { Female) }\end{array}$ & $-1.53(4.8)$ & 0.7503 & $3.12(4.15)$ & 0.4528 & $-0.51(2.71)$ & 0.8498 & $-4.46(3.95)$ & 0.2619 & $-0.46(3.21)$ & 0.8869 \\
\hline $\begin{array}{l}\text { Ethnicity } \\
\text { (Other vs. } \\
\text { White) }\end{array}$ & $-0.08(5.06)$ & 0.9882 & $-3.01(4.39)$ & 0.4943 & $0.33(2.85)$ & 0.9074 & $5.8(4.11)$ & 0.1610 & $0.08(3.38)$ & 0.9820 \\
\hline Risk Group & & 0.2886 & & 0.0292 & & 0.0529 & & 0.0378 & & 0.0586 \\
\hline High vs. Low & $-8.79(5.61)$ & 0.1193 & $-8.46(4.77)$ & 0.0782 & $-6.73(3.13)$ & 0.0337 & $-8.71(4.45)$ & 0.0530 & $-7.95(3.68)$ & 0.0324 \\
\hline $\begin{array}{l}\text { High vs. } \\
\text { Standard }\end{array}$ & $-3.29(5.89)$ & 0.5777 & $-13.18(5.01)$ & 0.0095 & $-6.84(3.28)$ & 0.0391 & $-11.67(4.78)$ & 0.0162 & $-7.61(3.87)$ & 0.0511 \\
\hline Time & & $<.0001$ & & 0.0001 & & 0.0883 & & 0.0185 & & $<.0001$ \\
\hline T1 vs. T2 & 3.78 (2.99) & 0.2089 & $-5.09(2.66)$ & 0.0581 & $0.46(1.95)$ & 0.8149 & $4.87(2.74)$ & 0.0783 & $0.73(1.87)$ & 0.6953 \\
\hline T1 vs. T3 & $-0.02(3.54)$ & 0.9947 & $-8.41(3.15)$ & 0.0085 & $-0.75(2.27)$ & 0.7423 & $2.59(3.27)$ & 0.4294 & $-1.28(2.22)$ & 0.5634 \\
\hline T1 vs. T4 & $-16.12(3.98)$ & $<.0001$ & $-16.38(3.54)$ & $<.0001$ & $-5.79(2.55)$ & 0.0247 & $-6.42(3.6)$ & 0.0777 & $-12.21(2.49)$ & $<.0001$ \\
\hline
\end{tabular}


Table 4-30. Multivariate model results investigating predictors of PedsQL-Generic domain scores in AML

\begin{tabular}{|c|c|c|c|c|c|c|c|c|c|c|}
\hline \multirow[b]{2}{*}{ Factor } & \multicolumn{2}{|c|}{ Physical Functioning } & \multicolumn{2}{|c|}{ Emotional Functioning } & \multicolumn{2}{|c|}{ Social Functioning } & \multicolumn{2}{|c|}{ School Functioning } & \multicolumn{2}{|c|}{ Total Score } \\
\hline & B (SE) & $\mathbf{P}$ & B (SE) & $\mathbf{P}$ & B (SE) & $\mathbf{P}$ & B (SE) & $\mathbf{P}$ & B (SE) & $\mathbf{P}$ \\
\hline $\begin{array}{l}\text { Age (Child } \\
\text { vs. Teen) }\end{array}$ & $7.86(4.46)$ & 0.0800 & & . & & . & & . & & . \\
\hline Time & & . & & . & & . & & . & & . \\
\hline T1 vs. T4 & $-15.82(3.99)$ & 0.0001 & $-15.66(3.56)$ & $<.0001$ & $-5.05(2.56)$ & 0.0505 & $-5.48(3.62)$ & 0.1336 & $-11.65(2.51)$ & $<.0001$ \\
\hline T1 vs. T2 & & . & $-4.96(2.66)$ & 0.0639 & & . & $4.74(2.73)$ & 0.0852 & & . \\
\hline T1 vs. T3 & & . & $-7.68(3.17)$ & 0.0169 & & . & & . & & . \\
\hline
\end{tabular}


Table 4-31. Univariate model results investigating predictors of PedsQL-Cancer domain scores in AML

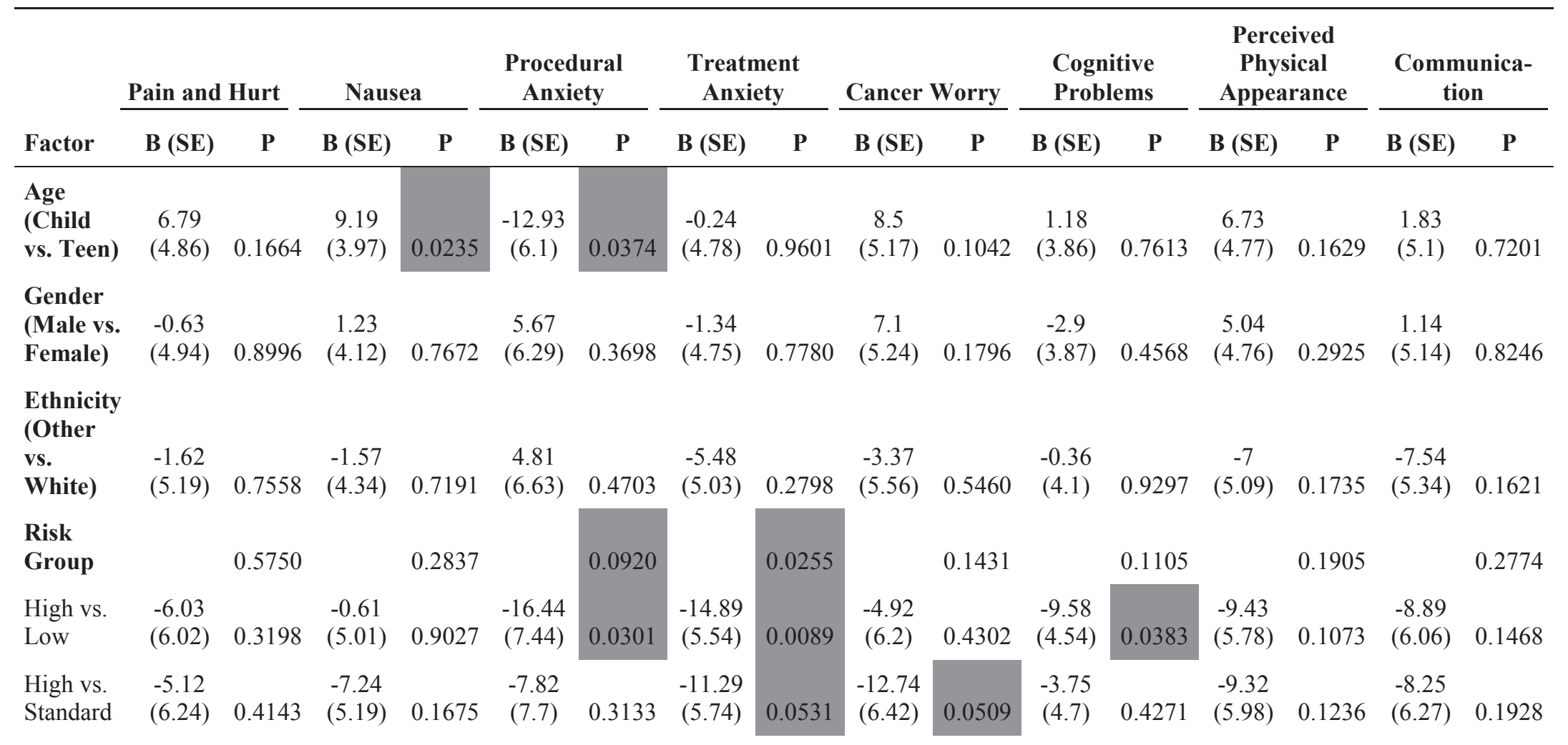




\section{Table 4-31. (Continued)}

\begin{tabular}{|c|c|c|c|c|c|c|c|c|c|c|c|c|c|c|c|c|}
\hline \multirow[b]{2}{*}{ Factor } & \multicolumn{2}{|c|}{ Pain and Hurt } & \multicolumn{2}{|c|}{ Nausea } & \multicolumn{2}{|c|}{$\begin{array}{c}\text { Procedural } \\
\text { Anxiety }\end{array}$} & \multicolumn{2}{|c|}{$\begin{array}{c}\text { Treatment } \\
\text { Anxiety }\end{array}$} & \multicolumn{2}{|c|}{ Cancer Worry } & \multicolumn{2}{|c|}{$\begin{array}{l}\text { Cognitive } \\
\text { Problems } \\
\end{array}$} & \multicolumn{2}{|c|}{$\begin{array}{c}\text { Perceived } \\
\text { Physical } \\
\text { Appearance }\end{array}$} & \multicolumn{2}{|c|}{$\begin{array}{c}\text { Communica- } \\
\text { tion }\end{array}$} \\
\hline & $\mathrm{B}(\mathrm{SE})$ & $\mathbf{P}$ & $\mathrm{B}$ (SE) & $\mathbf{P}$ & B (SE) & $\mathbf{P}$ & $\mathrm{B}(\mathrm{SE})$ & $\mathbf{P}$ & B (SE) & $\mathbf{P}$ & $\mathrm{B}(\mathrm{SE})$ & $\mathbf{P}$ & B (SE) & $\mathbf{P}$ & B (SE) & $\mathbf{P}$ \\
\hline Time & & 0.0192 & & $<.0001$ & & 0.0564 & & 0.0817 & & 0.1634 & & 0.4523 & & 0.0967 & & 0.2791 \\
\hline T2 vs. T3 & $\begin{array}{l}-0.52 \\
(4.1)\end{array}$ & 0.8989 & $\begin{array}{l}-4.77 \\
(3.53)\end{array}$ & 0.1812 & $\begin{array}{l}-4.34 \\
(4.66)\end{array}$ & 0.3543 & $\begin{array}{l}-5.43 \\
(2.91)\end{array}$ & 0.0663 & $\begin{array}{l}-0.03 \\
(3.06)\end{array}$ & 0.9924 & $\begin{array}{l}-1.84 \\
(2.28)\end{array}$ & 0.4228 & $\begin{array}{l}-5.33 \\
(2.87)\end{array}$ & 0.0674 & $\begin{array}{l}-4.19 \\
(2.77)\end{array}$ & 0.1353 \\
\hline T2 vs. T4 & $\begin{array}{r}-13.08 \\
(4.77)\end{array}$ & 0.0077 & $\begin{array}{c}-21.39 \\
(4.1)\end{array}$ & $<.0001$ & $\begin{array}{l}-13.28 \\
(5.43)\end{array}$ & 0.0169 & $\begin{array}{l}-6.56 \\
(3.4)\end{array}$ & 0.0578 & $\begin{array}{l}-6.33 \\
(3.57)\end{array}$ & 0.0810 & $\begin{array}{l}-3.25 \\
(2.67)\end{array}$ & 0.2272 & $\begin{array}{c}-6.1 \\
(3.35)\end{array}$ & 0.0731 & $\begin{array}{l}-3.61 \\
(3.24)\end{array}$ & 0.2681 \\
\hline
\end{tabular}


Table 4-32. Multivariate model results investigating predictors of PedsQL-Cancer domain scores in AML

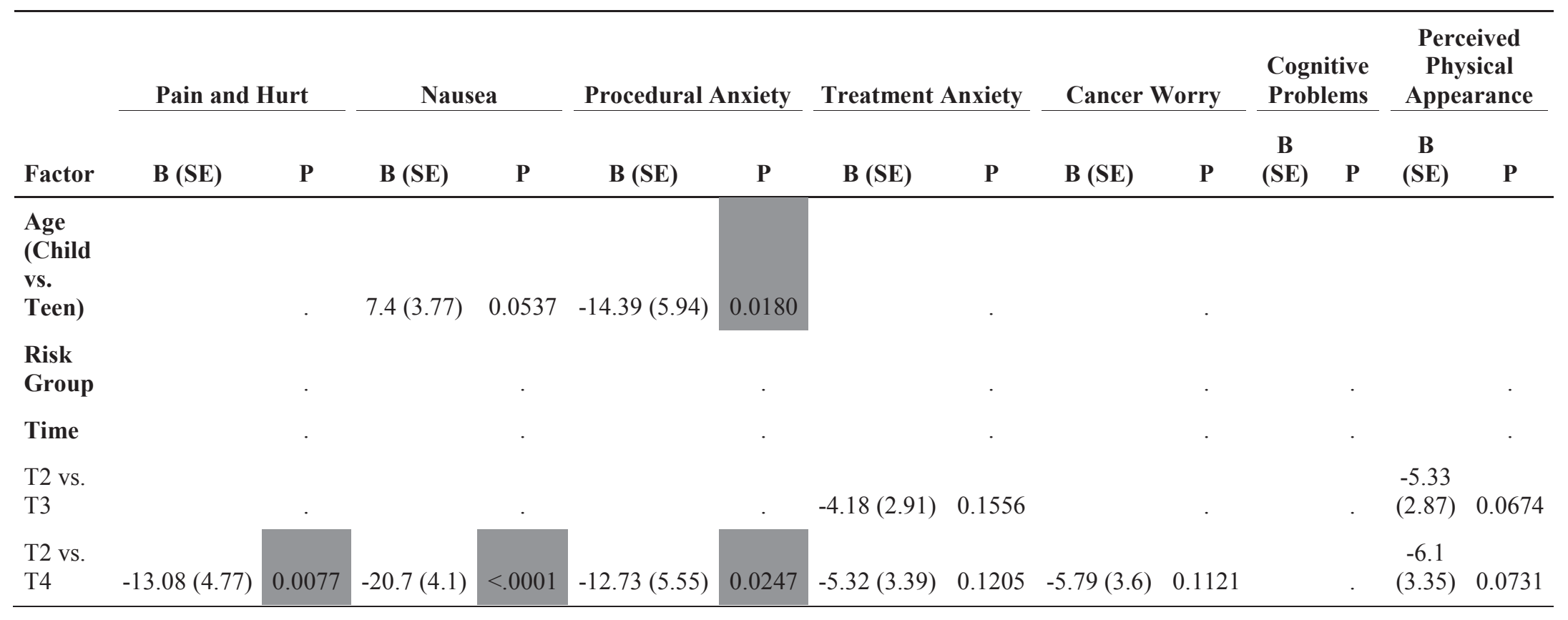




\section{Hodgkin Lymphoma}

A univariate model to identify predictors of the PedsQL-Generic domain scores identified gender, age, risk group, and time as significant factors is presented in

Table 4-33. Ethnicity and radiation dose were not significant predictors of HRQOL on the PedsQL-Generic scale. Table 4-34 presents the results of the multivariate analysis of PedsQL-Generic domain scores.

A multivariate analysis of the PedsQL-Generic domain scores which included the significant factors from the univariate analysis identified gender, risk, and time as significant predictors of HRQOL domains. On the PedsQL-Cancer module, age, gender, and time were significant predictors of HRQOL. As for cancer-related symptoms, age, gender, and time were significant predictors of HRQOL over time Table 4-35 presents the results of the univariate analysis. Table 4-36 presents the results of the multivariate analysis for the PedsQL-Cancer module.

In the HL group, gender was a significant predictor of HRQOL in children with HL. Gender was identified as a predictor of HRQOL in our univariate analysis on all domains of HRQOL except for the social functioning domain. Gender predicted physical $(p=.0021)$, emotional $(p=.0036)$, and total score $(p=.0019)$ on the multivariate model. It was also found to be a predictor of pain and hurt $(\mathrm{p}=.0054)$, procedural anxiety $(p=.0029)$, and perceived physical appearance $(p<.0001)$ from the cancer-related symptoms. On all these domains and symptoms, females consistently reported lower scores, indicating worse outcomes, in comparison to male children.

As for risk group, it was only a predictor of the physical functioning domain, with higher (unfavorable) risk groups reporting a significantly lower physical functioning score than the lower (favorable) risk group. The group with the highest physical functioning HRQOL domain was the favorable risk group, while the group with the lowest physical HRQOL was the unfavorable risk group. Risk, however, was not a predictor of any cancer-related symptoms in the HL group on the multivariate analysis.

Time was also a significant predictor of HRQOL in the HL when comparing the beginning of treatment (T1) in comparison to the end of treatment (T4). This significance was observed at all HRQOL domains. The significant differences in HRQOL cancerrelated symptoms, however, can be observed in comparing T2, the first time point for collecting PedsQL-Cancer score, to T4, where symptoms of pain and hurt $(\mathrm{p}<.0001)$, nausea $(\mathrm{p}<.0001)$, procedural anxiety $(\mathrm{p}<.0001)$, cancer worry $(\mathrm{p}=.0138)$, cognitive problems $(\mathrm{p}=.0129)$, perceived physical appearance $(\mathrm{p}<.0110)$ and communication $(p<.0001)$ were found to be significantly higher at T4 in comparison to T2.Ethnicity was not correlated with any HRQOL domain or cancer-related symptom in our sample of children with HL across all time points in treatment. 
Table 4-33. Univariate model results investigating predictors of PedsQL-Generic domain scores in HL

\begin{tabular}{|c|c|c|c|c|c|c|c|c|c|c|}
\hline \multirow[b]{2}{*}{ Factor } & \multicolumn{2}{|c|}{ Physical Functioning } & \multicolumn{2}{|c|}{ Emotional Functioning } & \multicolumn{2}{|c|}{ Social Functioning } & \multicolumn{2}{|c|}{ School Functioning } & \multicolumn{2}{|c|}{ Total Score } \\
\hline & B (SE) & $\mathbf{P}$ & B (SE) & $\mathbf{P}$ & B (SE) & $\mathbf{P}$ & B (SE) & $\mathbf{P}$ & B (SE) & $\mathbf{P}$ \\
\hline $\begin{array}{l}\text { Age (Child vs. } \\
\text { Teen) }\end{array}$ & $4.43(2.64)$ & 0.0942 & $2.44(2.57)$ & 0.3428 & $-3.01(1.74)$ & 0.0831 & $3.28(2.56)$ & 0.2013 & $1.83(2.05)$ & 0.3736 \\
\hline $\begin{array}{l}\text { Gender (Male } \\
\text { vs. Female) }\end{array}$ & $6.83(2.12)$ & 0.0014 & $5.67(2.07)$ & 0.0063 & $-0.11(1.43)$ & 0.9364 & $3.96(2.09)$ & 0.0591 & $4.81(1.66)$ & 0.0039 \\
\hline $\begin{array}{l}\text { Ethnicity } \\
\text { (Other vs. } \\
\text { White) }\end{array}$ & $0.19(2.57)$ & 0.9400 & $1.48(2.5)$ & 0.5531 & $1.01(1.69)$ & 0.5488 & $2.09(2.5)$ & 0.4020 & $1.42(2.01)$ & 0.4799 \\
\hline $\begin{array}{l}\text { Radiation (Yes } \\
\text { vs. No) }\end{array}$ & $-1.57(3.43)$ & 0.6473 & $1.91(3.32)$ & 0.5661 & $0.88(2.26)$ & 0.6968 & $-0.45(3.33)$ & 0.8928 & $0.05(2.65)$ & 0.9849 \\
\hline Risk Group & & 0.0364 & & 0.7998 & & 0.4530 & & 0.1695 & & 0.2314 \\
\hline $\begin{array}{l}\text { Favorable vs. } \\
\text { Intermediate }\end{array}$ & $3.26(2.99)$ & 0.2769 & $-1.51(2.93)$ & 0.6063 & $-1.47(1.99)$ & 0.4598 & $-1.06(2.94)$ & 0.7173 & $0.28(2.35)$ & 0.9039 \\
\hline $\begin{array}{l}\text { Favorable vs. } \\
\text { Unfavorable }\end{array}$ & $7.44(3.04)$ & 0.0148 & $-0.14(2.98)$ & 0.9626 & $0.46(2.02)$ & 0.8201 & $3.24(3)$ & 0.2798 & $3.15(2.39)$ & 0.1880 \\
\hline Time & & $<.0001$ & & $<.0001$ & & 0.0012 & & $<.0001$ & & $<.0001$ \\
\hline T1 vs. T2 & $7.33(1.42)$ & $<.0001$ & $-2.25(1.4)$ & 0.1081 & $0.62(1.03)$ & 0.5488 & $3.2(1.5)$ & 0.0333 & $3.01(1.04)$ & 0.0041 \\
\hline T1 vs. T3 & $6.01(1.45)$ & $<.0001$ & $-4.79(1.42)$ & 0.0008 & $0.71(1.04)$ & 0.4971 & $-0.05(1.53)$ & 0.9727 & $0.94(1.06)$ & 0.3784 \\
\hline T1 vs. T4 & $-5.79(1.51)$ & 0.0001 & $-11.18(1.49)$ & $<.0001$ & $-3.16(1.09)$ & 0.0040 & $-9.24(1.59)$ & $<.0001$ & $-6.92(1.1)$ & $<.0001$ \\
\hline
\end{tabular}


Table 4-34. Multivariable model results investigating predictors of PedsQL-Generic domain scores in HL

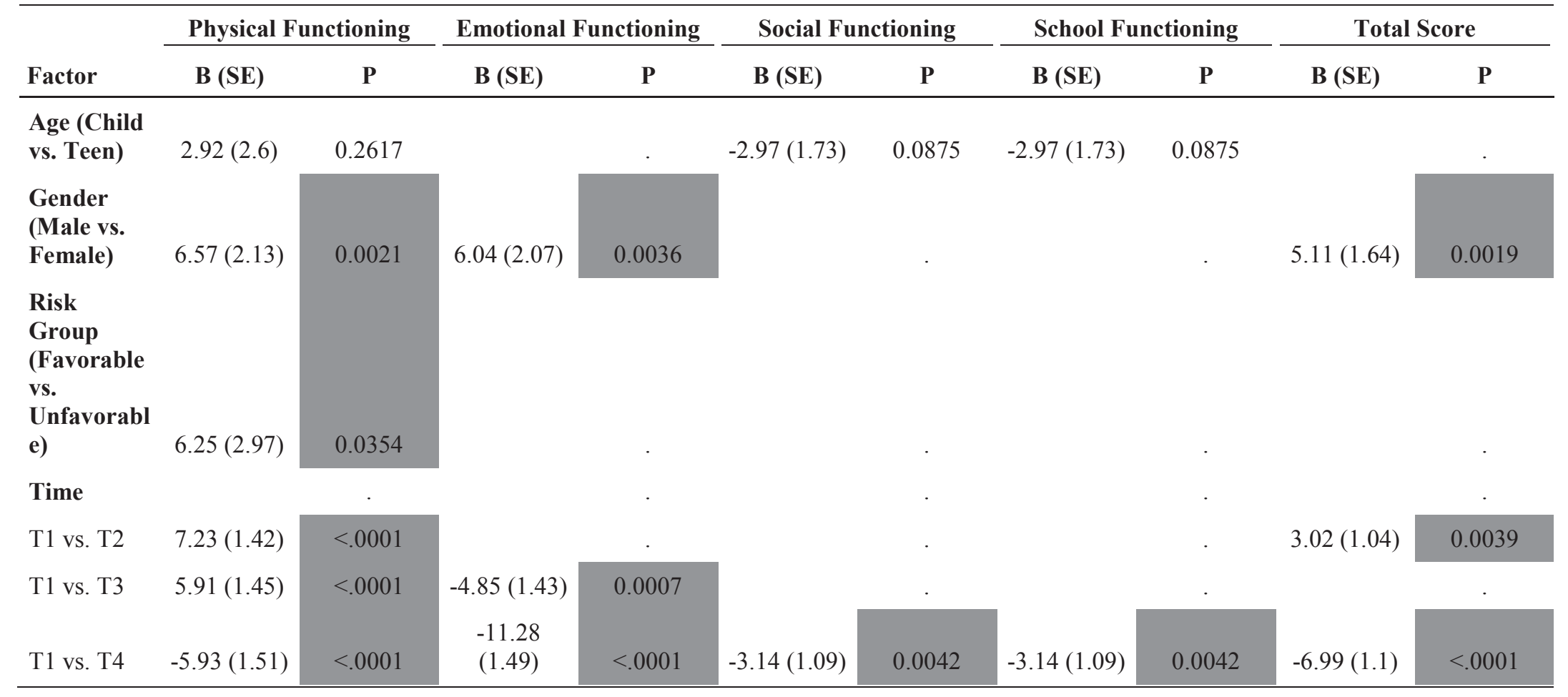


Table 4-35. Univariate model results investigating predictors of PedsQL-Cancer domain scores in HL

\begin{tabular}{|c|c|c|c|c|c|c|c|c|c|c|c|c|c|c|c|c|}
\hline Factor & \multicolumn{2}{|c|}{ Pain and Hurt } & \multicolumn{2}{|c|}{ Nausea } & \multicolumn{2}{|c|}{$\begin{array}{c}\text { Procedural } \\
\text { Anxiety }\end{array}$} & \multicolumn{2}{|c|}{$\begin{array}{c}\text { Treatment } \\
\text { Anxiety }\end{array}$} & \multicolumn{2}{|c|}{ Cancer Worry } & \multicolumn{2}{|c|}{$\begin{array}{l}\text { Cognitive } \\
\text { Problems }\end{array}$} & \multicolumn{2}{|c|}{$\begin{array}{c}\text { Perceived } \\
\text { Physical } \\
\text { Appearance } \\
\end{array}$} & \multicolumn{2}{|c|}{$\begin{array}{c}\text { Communica- } \\
\text { tion }\end{array}$} \\
\hline $\begin{array}{l}\text { Age } \\
\text { (Child vs. } \\
\text { Teen) }\end{array}$ & $\begin{array}{c}4.5 \\
(3.39)\end{array}$ & 0.1857 & $\begin{array}{c}3.26 \\
(3.34)\end{array}$ & 0.3293 & $\begin{array}{l}-19.19 \\
(3.95)\end{array}$ & $<.0001$ & $\begin{array}{l}-3.42 \\
(2.94)\end{array}$ & 0.2457 & $\begin{array}{c}7.42 \\
(3.72)\end{array}$ & 0.0469 & $\begin{array}{l}6.96 \\
(2.87)\end{array}$ & 0.0158 & $\begin{array}{c}4.52 \\
(3.38)\end{array}$ & 0.1826 & $\begin{array}{l}-0.08 \\
(2.85)\end{array}$ & $\begin{array}{c}0.97 \\
62\end{array}$ \\
\hline $\begin{array}{l}\text { Gender } \\
\text { (Male vs. } \\
\text { Female) }\end{array}$ & $\begin{array}{c}6.75 \\
(2.65)\end{array}$ & 0.0111 & $\begin{array}{l}-0.72 \\
(2.65)\end{array}$ & 0.7866 & $\begin{array}{c}6.66 \\
(3.25)\end{array}$ & 0.0412 & $\begin{array}{c}3.22 \\
(2.32)\end{array}$ & 0.1659 & $\begin{array}{c}4.98 \\
(2.96)\end{array}$ & 0.0940 & $\begin{array}{l}3.5 \\
(2.3)\end{array}$ & 0.1279 & $\begin{array}{l}12.59 \\
(2.56)\end{array}$ & $<.0001$ & $\begin{array}{l}1.98 \\
(2.24)\end{array}$ & $\begin{array}{c}0.37 \\
78\end{array}$ \\
\hline $\begin{array}{l}\text { Ethnicity } \\
\text { (Other } \\
\text { vs. } \\
\text { White) }\end{array}$ & $\begin{array}{c}0.16 \\
(3.17)\end{array}$ & 0.9607 & $\begin{array}{c}3.37 \\
(3.11)\end{array}$ & 0.2791 & $\begin{array}{c}3.46 \\
(3.86)\end{array}$ & 0.3704 & $\begin{array}{l}1.91 \\
(2.74)\end{array}$ & 0.4860 & $\begin{array}{c}5.27 \\
(3.49)\end{array}$ & 0.1321 & $\begin{array}{l}-1.08 \\
(2.72)\end{array}$ & 0.6904 & $\begin{array}{l}-5.84 \\
(3.14)\end{array}$ & 0.0642 & $\begin{array}{l}2.51 \\
(2.64)\end{array}$ & $\begin{array}{c}0.34 \\
14\end{array}$ \\
\hline $\begin{array}{l}\text { Risk } \\
\text { Group }\end{array}$ & & 0.7056 & & 0.8338 & & 0.9010 & & 0.7717 & & 0.5552 & & 0.7700 & & 0.7223 & & $\begin{array}{c}0.09 \\
38\end{array}$ \\
\hline $\begin{array}{l}\text { Favorable } \\
\text { vs. } \\
\text { Intermedi } \\
\text { ate }\end{array}$ & $\begin{array}{l}-2.96 \\
(3.94)\end{array}$ & 0.4530 & $\begin{array}{l}-2.17 \\
(3.88)\end{array}$ & 0.5768 & $\begin{array}{c}0.43 \\
(4.81)\end{array}$ & 0.9286 & $\begin{array}{l}-0.93 \\
(3.41)\end{array}$ & 0.7856 & $\begin{array}{l}-4.53 \\
(4.36)\end{array}$ & 0.2989 & $\begin{array}{l}-1.74 \\
(3.38)\end{array}$ & 0.6061 & $\begin{array}{l}-2.67 \\
(3.93)\end{array}$ & 0.4974 & $\begin{array}{c}-7.1 \\
(3.26)\end{array}$ & $\begin{array}{c}0.03 \\
03\end{array}$ \\
\hline $\begin{array}{l}\text { Favorable } \\
\text { vs. } \\
\text { Unfavora } \\
\text { ble }\end{array}$ & $\begin{array}{l}-1.19 \\
(4.01)\end{array}$ & 0.7661 & $\begin{array}{l}-2.22 \\
(3.94)\end{array}$ & 0.5738 & $\begin{array}{l}-1.18 \\
(4.88)\end{array}$ & 0.8084 & $\begin{array}{l}-2.27 \\
(3.47)\end{array}$ & 0.5127 & $\begin{array}{c}-2.4 \\
(4.42)\end{array}$ & 0.5876 & $\begin{array}{c}-0.1 \\
(3.43)\end{array}$ & 0.9775 & $\begin{array}{l}-3.16 \\
(3.99)\end{array}$ & 0.4284 & $\begin{array}{l}-5.66 \\
(3.31)\end{array}$ & $\begin{array}{c}0.08 \\
85\end{array}$ \\
\hline
\end{tabular}


Table 4-35. (Continued)

\begin{tabular}{|c|c|c|c|c|c|c|c|c|c|c|c|c|c|c|c|c|}
\hline \multirow[b]{2}{*}{ Factor } & \multicolumn{2}{|c|}{ Pain and Hurt } & \multicolumn{2}{|c|}{ Nausea } & \multicolumn{2}{|c|}{$\begin{array}{c}\text { Procedural } \\
\text { Anxiety }\end{array}$} & \multicolumn{2}{|c|}{$\begin{array}{c}\text { Treatment } \\
\text { Anxiety }\end{array}$} & \multicolumn{2}{|c|}{ Cancer Worry } & \multicolumn{2}{|c|}{$\begin{array}{l}\text { Cognitive } \\
\text { Problems } \\
\end{array}$} & \multicolumn{2}{|c|}{$\begin{array}{c}\text { Perceived } \\
\text { Physical } \\
\text { Appearance }\end{array}$} & \multicolumn{2}{|c|}{$\begin{array}{c}\text { Communica- } \\
\text { tion }\end{array}$} \\
\hline & B (SE) & $\mathbf{P}$ & B (SE) & $\mathbf{P}$ & B (SE) & $\mathbf{P}$ & B (SE) & $\mathbf{P}$ & B (SE) & $\mathbf{P}$ & $\begin{array}{c}\mathrm{B} \\
(\mathrm{SE})\end{array}$ & $\mathbf{P}$ & $\begin{array}{c}\text { B } \\
(\mathrm{SE})\end{array}$ & $\mathbf{P}$ & $\begin{array}{c}\mathrm{B} \\
(\mathrm{SE})\end{array}$ & $\mathbf{P}$ \\
\hline Time & & $<.0001$ & & $<.0001$ & & $<.0001$ & & 0.1528 & & $\begin{array}{c}0.039 \\
3\end{array}$ & & $\begin{array}{c}0.043 \\
4\end{array}$ & & $\begin{array}{c}0.048 \\
8\end{array}$ & & $\begin{array}{c}0.000 \\
1\end{array}$ \\
\hline $\mathrm{T} 2$ vs. T3 & $\begin{array}{l}-3.44 \\
(1.9)\end{array}$ & 0.0714 & $\begin{array}{l}1.08 \\
(1.7)\end{array}$ & 0.5261 & $\begin{array}{l}-1.96 \\
(1.75)\end{array}$ & 0.2622 & $\begin{array}{c}2.8 \\
(1.55)\end{array}$ & 0.0725 & $\begin{array}{l}-0.78 \\
(1.56)\end{array}$ & $\begin{array}{c}0.615 \\
6\end{array}$ & $\begin{array}{c}-1.54 \\
(1.37 \\
)\end{array}$ & $\begin{array}{c}0.262 \\
3\end{array}$ & $\begin{array}{c}-1.35 \\
(1.52 \\
)\end{array}$ & $\begin{array}{c}0.375 \\
2\end{array}$ & $\begin{array}{c}-2.4 \\
(1.42 \\
)\end{array}$ & $\begin{array}{c}0.092 \\
5\end{array}$ \\
\hline $\mathrm{T} 2$ vs. T4 & $\begin{array}{l}-18.55 \\
(1.98)\end{array}$ & $<.0001$ & $\begin{array}{l}-16.93 \\
(1.79)\end{array}$ & $<.0001$ & $\begin{array}{l}-8.33 \\
(1.83)\end{array}$ & $<.0001$ & $\begin{array}{c}0.29 \\
(1.62)\end{array}$ & 0.8591 & $\begin{array}{l}-4.05 \\
(1.64)\end{array}$ & $\begin{array}{c}0.014 \\
3\end{array}$ & $\begin{array}{c}-3.59 \\
(1.43 \\
)\end{array}$ & $\begin{array}{c}0.012 \\
3\end{array}$ & $\begin{array}{l}-3.92 \\
(1.6)\end{array}$ & $\begin{array}{c}0.014 \\
6\end{array}$ & $\begin{array}{c}-6.35 \\
(1.49 \\
)\end{array}$ & $\begin{array}{c}<.000 \\
1\end{array}$ \\
\hline
\end{tabular}


Table 4-36. Multivariate model results investigating predictors of PedsQL-Cancer domain scores in HL

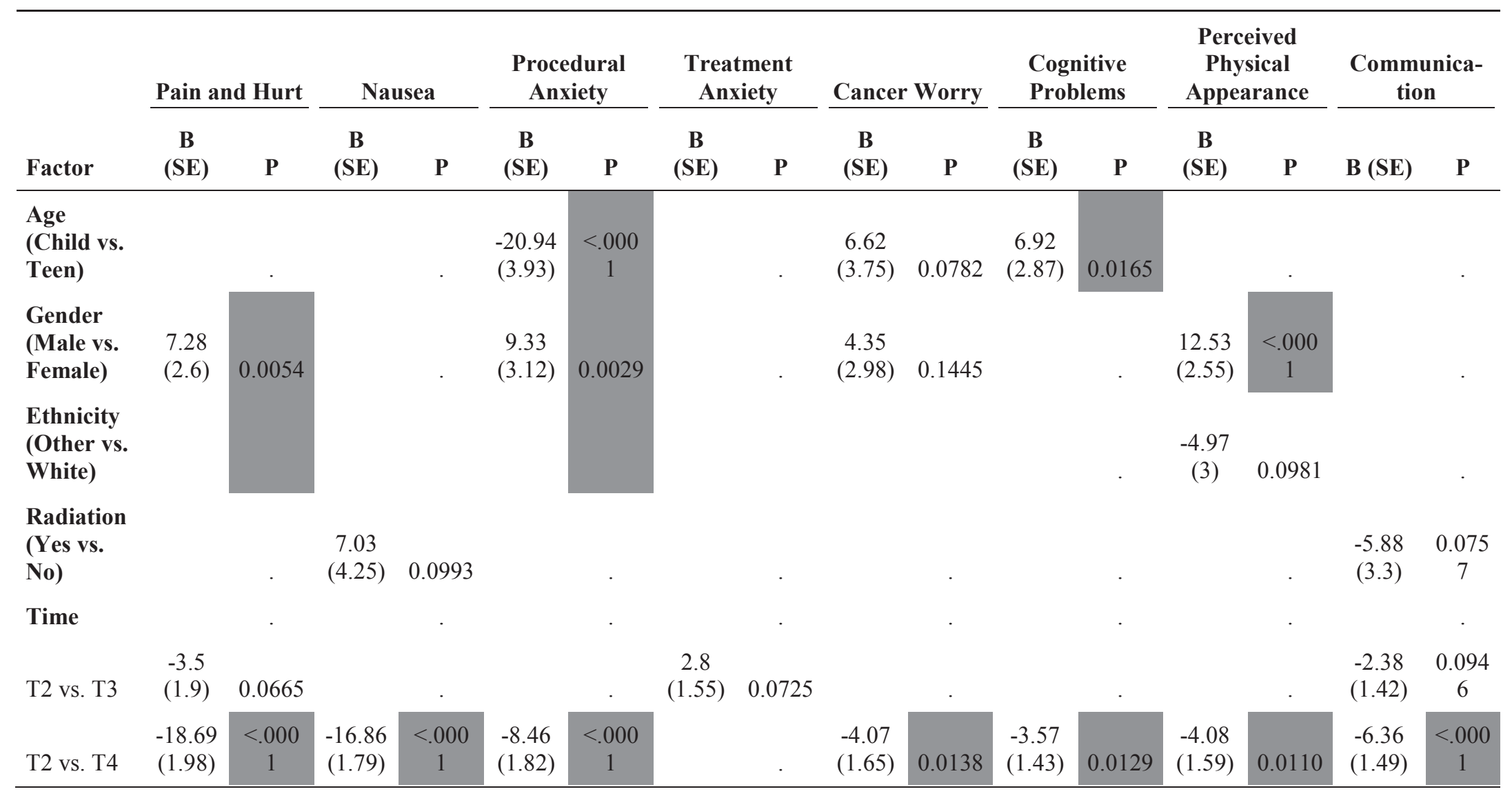




\section{Melanoma}

Only a univariate analysis was performed on the melanoma group considering the small sample size that did not support conducting a multivariate analysis. This analysis identified age, gender, race, and time as predictors of HRQOL domains in children with Melanoma. Females reported significantly lower physical HRQOL scores $(p=.0295)$, white children reported higher physical HRQOL scores $(p=.0498)$ than children from other races (Table 4-37).

On the PedsQL-cancer module symptoms, age, gender, and race were impacted different symptoms of cancer treatment. Adolescents reported higher social functioning scores than children $(\mathrm{p}=.0798)$. As for cancer-related symptoms, children reported a significantly lower procedural anxiety scores, indicating higher symptom burden $(p=.0171)$, while adolescents reported lower cancer worry score $(p=.0943)$.

Females reported significantly lower pain and hurt $(\mathrm{p}=.0082)$, nausea $(\mathrm{p}=.0065)$, and treatment anxiety $(\mathrm{p}=.0223$ scores, indicating higher symptom burden in females. Cancer-related symptoms including cognitive problems, perceived physical appearance, and communication had no predictors of HRQOL identified (Table 4-38).

\section{Osteosarcoma}

While children with OS reported the lowest HRQOL across all diagnostic groups. The analysis of factors that were significantly correlated with these low HRQOL scores resulted in few findings. A univariate model to identify predictors of the PedsQL-Generic domain scores identified time as the only significant predictor of HRQOL on the PedsQL-Generic scale in children with OS (Table 4-39).

A multivariate analysis reported the same significant effect $(p<.0001)$ of time (T1 vs. T4) on all HRQOL domains in children with OS (Table 4-40). T4 scores were significantly higher than T1 scores. Other factors considered in this analysis, including age, gender, and ethnicity, were not significantly correlated with HRQOL in children with OS.

On the PedsQL-Cancer module, age, race, type of surgery and time were significant predictors of HRQOL in children with OS on the univariate analysis (Table 4-41). However, on the multivariate analysis, time was the only significant predictor of cancer-related symptoms in children with OS (Table 4-42).

Children reported significantly higher cancer-symptom scores $(\mathrm{p}<0.05)$ on all cancer-related symptoms on the PedsQL-cancer scale at the end of treatment (T4) in comparison to the beginning of treatment (T1). All other factors included in this analysis were not correlated with cancer-related symptoms in children with OS. 
Table 4-37. Univariate model results investigating predictors of PedsQL-Generic domain scores for melanoma

\begin{tabular}{|c|c|c|c|c|c|c|c|c|c|c|}
\hline \multirow[b]{2}{*}{ Factor } & \multicolumn{2}{|c|}{ Physical Functioning } & \multicolumn{2}{|c|}{ Emotional Functioning } & \multicolumn{2}{|c|}{$\begin{array}{c}\text { Social } \\
\text { Functioning }\end{array}$} & \multicolumn{2}{|c|}{$\begin{array}{c}\text { School } \\
\text { Functioning }\end{array}$} & \multicolumn{2}{|c|}{ Total Score } \\
\hline & B (SE) & $\mathbf{P}$ & B (SE) & $\mathbf{P}$ & B (SE) & $\mathbf{P}$ & B (SE) & $\mathbf{P}$ & B (SE) & $\mathbf{P}$ \\
\hline $\begin{array}{l}\text { Age (Child } \\
\text { vs. Teen) }\end{array}$ & $7.37(5.36)$ & 0.1743 & $-0.74(6.38)$ & 0.9087 & $-15.66(8.78)$ & 0.0798 & $-3.95(9.97)$ & 0.6939 & $-1.78(5.86)$ & 0.7618 \\
\hline $\begin{array}{l}\text { Gender } \\
\text { (Male vs. } \\
\text { Female) }\end{array}$ & $10.82(4.84)$ & 0.0295 & $5.55(6.15)$ & 0.3710 & $4.18(9.16)$ & 0.6496 & $9.7(9.65)$ & 0.3200 & $8.55(5.45)$ & 0.1223 \\
\hline $\begin{array}{l}\text { Ethnicity } \\
\text { (Other vs. } \\
\text { White) }\end{array}$ & $-11.43(5.7)$ & 0.0498 & $1.17(6.94)$ & 0.8661 & $9.44(9.82)$ & 0.3402 & $2.65(11.1)$ & 0.8127 & $-2.21(6.32)$ & 0.7275 \\
\hline Time & & & & & & & & & & \\
\hline T1 vs. T2 & $2.2(4.51)$ & 0.6277 & $-9.73(4.87)$ & 0.0511 & $-0.43(3.3)$ & 0.8977 & $-1.37(5.74)$ & 0.8129 & $-2.43(3.27)$ & 0.4611 \\
\hline T1 vs. T4 & $-5.01(5.07)$ & 0.3278 & $-5.67(5.49)$ & 0.3064 & $-4.02(3.77)$ & 0.2919 & $-2.63(6.35)$ & 0.6807 & $-4.94(3.71)$ & 0.1888 \\
\hline
\end{tabular}


Table 4-38. Univariate model results investigating predictors of PedsQL-Cancer domain scores for melanoma

\begin{tabular}{|c|c|c|c|c|c|c|c|c|c|c|c|c|c|c|c|c|}
\hline Factor & \multicolumn{2}{|c|}{ Pain and Hurt } & \multicolumn{2}{|c|}{ Nausea } & \multicolumn{2}{|c|}{$\begin{array}{c}\text { Procedural } \\
\text { Anxiety }\end{array}$} & \multicolumn{2}{|c|}{$\begin{array}{c}\text { Treatment } \\
\text { Anxiety }\end{array}$} & \multicolumn{2}{|c|}{ Cancer Worry } & \multicolumn{2}{|c|}{$\begin{array}{l}\text { Cognitive } \\
\text { Problems } \\
\end{array}$} & \multicolumn{2}{|c|}{$\begin{array}{c}\text { Perceived } \\
\text { Physical } \\
\text { Appearance }\end{array}$} & \multicolumn{2}{|c|}{$\begin{array}{c}\text { Communica- } \\
\text { tion }\end{array}$} \\
\hline $\begin{array}{l}\text { Age } \\
\text { (Child } \\
\text { vs. } \\
\text { Teen) }\end{array}$ & $\begin{array}{l}5.43 \\
(8.45)\end{array}$ & 0.5251 & $\begin{array}{l}10.29 \\
(6.25)\end{array}$ & 0.1093 & $\begin{array}{c}-25.54 \\
(10.15 \\
)\end{array}$ & 0.0171 & $\begin{array}{c}3.51 \\
(5.38)\end{array}$ & 0.5184 & $\begin{array}{c}15.4 \\
(8.93)\end{array}$ & 0.0943 & $\begin{array}{l}9.78 \\
(9.01)\end{array}$ & 0.2861 & $\begin{array}{c}-1.91 \\
(11.87 \\
)\end{array}$ & 0.8735 & $\begin{array}{l}-3.06 \\
(9.75)\end{array}$ & $\begin{array}{c}0.75 \\
57\end{array}$ \\
\hline $\begin{array}{l}\text { Gender } \\
\text { (Male } \\
\text { vs. } \\
\text { Female) }\end{array}$ & $\begin{array}{l}19.75 \\
(6.97)\end{array}$ & 0.0082 & $\begin{array}{l}15.51 \\
(5.33)\end{array}$ & 0.0065 & $\begin{array}{c}12.19 \\
(11.18 \\
)\end{array}$ & 0.2836 & $\begin{array}{l}11.48 \\
(4.78)\end{array}$ & 0.0223 & $\begin{array}{l}11.44 \\
(8.83)\end{array}$ & 0.2043 & $\begin{array}{c}6.03 \\
(8.92)\end{array}$ & 0.5036 & $\begin{array}{c}4.33 \\
(11.57 \\
)\end{array}$ & 0.7109 & $\begin{array}{l}-5.85 \\
(9.47)\end{array}$ & $\begin{array}{c}0.54 \\
10\end{array}$ \\
\hline $\begin{array}{l}\text { Ethnicit } \\
\text { y (Other } \\
\text { vs. } \\
\text { White) }\end{array}$ & $\begin{array}{l}-22.47 \\
(7.99)\end{array}$ & 0.0086 & $\begin{array}{l}-12.44 \\
(7.17)\end{array}$ & 0.0923 & $\begin{array}{c}2.95 \\
(12.71 \\
)\end{array}$ & 0.8179 & $\begin{array}{l}-6.34 \\
(5.93)\end{array}$ & 0.2927 & $\begin{array}{c}-16.52 \\
(9.86)\end{array}$ & 0.1036 & $\begin{array}{l}-12.69 \\
(9.77)\end{array}$ & 0.2032 & $\begin{array}{c}-1.77 \\
(12.69 \\
)\end{array}$ & 0.8899 & $\begin{array}{c}7.28 \\
(10.38 \\
)\end{array}$ & $\begin{array}{c}0.48 \\
82\end{array}$ \\
\hline Time & & & & & & & & & & & & & & & & \\
\hline $\begin{array}{l}\text { T2 vs. } \\
\text { T3 }\end{array}$ & $\begin{array}{l}-3.48 \\
(4.21)\end{array}$ & 0.4154 & $\begin{array}{l}-8.91 \\
(5.53)\end{array}$ & 0.1180 & $\begin{array}{c}1.43 \\
(6.67)\end{array}$ & 0.8320 & $\begin{array}{c}1.8 \\
(4.16)\end{array}$ & 0.6685 & $\begin{array}{l}-1.78 \\
(5.86)\end{array}$ & 0.7635 & $\begin{array}{c}1.1 \\
(4.93)\end{array}$ & 0.8243 & $\begin{array}{l}2.01 \\
(3.4)\end{array}$ & 0.5588 & $\begin{array}{l}-2.91 \\
(4.5)\end{array}$ & $\begin{array}{c}0.52 \\
37\end{array}$ \\
\hline $\begin{array}{l}\text { T2 vs. } \\
\text { T4 }\end{array}$ & $\begin{array}{l}-3.76 \\
(4.42)\end{array}$ & 0.4032 & $\begin{array}{l}-15.12 \\
(5.53)\end{array}$ & 0.0104 & $\begin{array}{l}-2.03 \\
(6.67)\end{array}$ & 0.7634 & $\begin{array}{l}-2.36 \\
(4.16)\end{array}$ & 0.5752 & $\begin{array}{l}-0.41 \\
(5.86)\end{array}$ & 0.9452 & $\begin{array}{c}0.51 \\
(4.93)\end{array}$ & 0.9177 & $\begin{array}{l}4.44 \\
(3.4)\end{array}$ & 0.2008 & $\begin{array}{l}2.45 \\
(4.5)\end{array}$ & $\begin{array}{c}0.58 \\
99\end{array}$ \\
\hline
\end{tabular}


Table 4-39. Univariate model results investigating predictors of PedsQL-Generic domain scores in OS

\begin{tabular}{|c|c|c|c|c|c|c|c|c|c|c|}
\hline \multirow[b]{2}{*}{ Factor } & \multicolumn{2}{|c|}{ Physical Functioning } & \multicolumn{2}{|c|}{ Emotional Functioning } & \multicolumn{2}{|c|}{ Social Functioning } & \multicolumn{2}{|c|}{ School Functioning } & \multicolumn{2}{|c|}{ Total Score } \\
\hline & B (SE) & $\mathbf{P}$ & B (SE) & $\mathbf{P}$ & B (SE) & $\mathbf{P}$ & B (SE) & $\mathbf{P}$ & B (SE) & $\mathbf{P}$ \\
\hline $\begin{array}{l}\text { Age (Child vs. } \\
\text { Teen) }\end{array}$ & $5.22(3.45)$ & 0.1318 & $2.6(3.37)$ & 0.4416 & $-3.56(2.52)$ & 0.1590 & $-0.63(3.54)$ & 0.8588 & $2.16(2.62)$ & 0.4096 \\
\hline $\begin{array}{l}\text { Gender (Male } \\
\text { vs. Female) }\end{array}$ & $0.55(3.49)$ & 0.8754 & $3.77(3.35)$ & 0.2610 & $0.84(2.54)$ & 0.7405 & $-0.51(3.53)$ & 0.8861 & $1.15(2.62)$ & 0.6621 \\
\hline $\begin{array}{l}\text { Ethnicity (Other } \\
\text { vs. White) }\end{array}$ & $-4(3.66)$ & 0.2753 & $-4.13(3.54)$ & 0.2444 & $-4.27(2.65)$ & 0.1081 & $2.36(3.72)$ & 0.5260 & $-3(2.75)$ & 0.2764 \\
\hline $\begin{array}{l}\text { Surgery } \\
\text { (Amputation vs. } \\
\text { Limb Salvage) }\end{array}$ & $3.91(4.12)$ & 0.3432 & $-2.55(4)$ & 0.5240 & $2.84(3.02)$ & 0.3474 & $4.42(4.17)$ & 0.2907 & $2.29(3.12)$ & 0.4628 \\
\hline Time & & $<.0001$ & & $<.0001$ & & 0.1760 & & 0.0010 & & $<.0001$ \\
\hline T1 vs. T2 & $-5.05(2.76)$ & 0.0679 & $-6.65(2.16)$ & 0.0023 & $-2.12(1.87)$ & 0.2583 & $-5.53(2.62)$ & 0.0360 & $-4.39(1.73)$ & 0.0116 \\
\hline T1 vs. T3 & $-2.08(2.86)$ & 0.4672 & $-9.37(2.25)$ & $<.0001$ & $2.27(1.94)$ & 0.2427 & $-3.67(2.61)$ & 0.1622 & $-3.22(1.79)$ & 0.0735 \\
\hline T1 vs. T4 & $-16.09(2.92)$ & $<.0001$ & $-17.12(2.31)$ & $<.0001$ & 0.28 (1.99) & 0.8874 & $-10.64(2.64)$ & $<.0001$ & $-11.57(1.83)$ & $<.0001$ \\
\hline
\end{tabular}


Table 4-40. Multivariate model results investigating predictors of PedsQL-Generic domain scores in OS

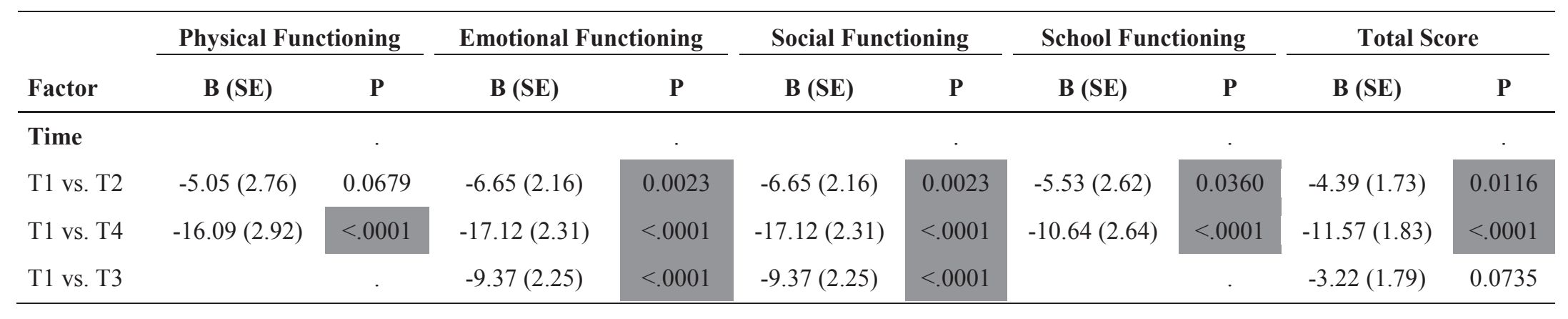


Table 4-41. Univariate model results investigating predictors of PedsQL-Cancer domain scores in OS

\begin{tabular}{|c|c|c|c|c|c|c|c|c|c|c|c|c|c|c|c|c|}
\hline \multirow[b]{2}{*}{ Factor } & \multicolumn{2}{|c|}{ Pain and Hurt } & \multicolumn{2}{|c|}{ Nausea } & \multicolumn{2}{|c|}{$\begin{array}{c}\text { Procedural } \\
\text { Anxiety }\end{array}$} & \multicolumn{2}{|c|}{$\begin{array}{c}\text { Treatment } \\
\text { Anxiety }\end{array}$} & \multicolumn{2}{|c|}{$\begin{array}{l}\text { Cancer } \\
\text { Worry }\end{array}$} & \multicolumn{2}{|c|}{$\begin{array}{l}\text { Cognitive } \\
\text { Problems }\end{array}$} & \multicolumn{2}{|c|}{$\begin{array}{c}\text { Perceived } \\
\text { Physical } \\
\text { Appearance }\end{array}$} & \multicolumn{2}{|c|}{$\begin{array}{c}\text { Communica- } \\
\text { tion }\end{array}$} \\
\hline & $\begin{array}{c}\text { B } \\
(\mathrm{SE})\end{array}$ & $\mathbf{P}$ & $\begin{array}{c}\text { B } \\
(\mathrm{SE})\end{array}$ & $\mathbf{P}$ & $\begin{array}{c}\text { B } \\
(\mathrm{SE})\end{array}$ & $\mathbf{P}$ & $\begin{array}{c}\text { B } \\
(\mathrm{SE})\end{array}$ & $\mathbf{P}$ & $\begin{array}{c}\text { B } \\
(\mathrm{SE})\end{array}$ & $\mathbf{P}$ & $\begin{array}{c}\text { B } \\
(\mathrm{SE})\end{array}$ & $\mathbf{P}$ & $\begin{array}{c}\text { B } \\
(\mathrm{SE})\end{array}$ & $\mathbf{P}$ & B (SE) & $\mathbf{P}$ \\
\hline $\begin{array}{l}\text { Age (Child } \\
\text { vs. Teen) }\end{array}$ & $\begin{array}{c}8.87 \\
(3.44)\end{array}$ & $\begin{array}{c}0.010 \\
4\end{array}$ & $\begin{array}{l}-1.08 \\
(3.22)\end{array}$ & $\begin{array}{c}0.736 \\
8\end{array}$ & $\begin{array}{l}-21.27 \\
(4.74)\end{array}$ & $\begin{array}{c}<.000 \\
1\end{array}$ & $\begin{array}{l}-2.01 \\
(2.99)\end{array}$ & $\begin{array}{c}0.502 \\
8\end{array}$ & $\begin{array}{c}9.95 \\
(4.67)\end{array}$ & $\begin{array}{c}0.034 \\
1\end{array}$ & $\begin{array}{l}-0.93 \\
(2.96)\end{array}$ & $\begin{array}{c}0.753 \\
2\end{array}$ & $\begin{array}{l}-2.03 \\
(3.42)\end{array}$ & $\begin{array}{c}0.552 \\
7\end{array}$ & $\begin{array}{l}-10.6 \\
(3.26)\end{array}$ & $\begin{array}{c}0.001 \\
3\end{array}$ \\
\hline $\begin{array}{l}\text { Gender } \\
\text { (Male vs. } \\
\text { Female) }\end{array}$ & $\begin{array}{c}3.35 \\
(3.51)\end{array}$ & $\begin{array}{c}0.341 \\
0\end{array}$ & $\begin{array}{l}2.69 \\
(3.2)\end{array}$ & $\begin{array}{c}0.402 \\
1\end{array}$ & $\begin{array}{c}7.92 \\
(5.07)\end{array}$ & $\begin{array}{c}0.119 \\
6\end{array}$ & $\begin{array}{c}1.49 \\
(2.98)\end{array}$ & $\begin{array}{c}0.617 \\
2\end{array}$ & $\begin{array}{c}2.85 \\
(4.76)\end{array}$ & $\begin{array}{c}0.549 \\
3\end{array}$ & $\begin{array}{c}0.19 \\
(2.96)\end{array}$ & $\begin{array}{c}0.949 \\
6\end{array}$ & $\begin{array}{c}5.71 \\
(3.37)\end{array}$ & $\begin{array}{c}0.090 \\
7\end{array}$ & $\begin{array}{c}1.28 \\
(3.41)\end{array}$ & $\begin{array}{c}0.706 \\
9\end{array}$ \\
\hline $\begin{array}{l}\text { Ethnicity } \\
\text { (Other vs. } \\
\text { White) }\end{array}$ & $\begin{array}{l}-5.26 \\
(3.68)\end{array}$ & $\begin{array}{c}0.154 \\
5\end{array}$ & $\begin{array}{l}-5.77 \\
(3.36)\end{array}$ & $\begin{array}{c}0.087 \\
0\end{array}$ & $\begin{array}{c}4.19 \\
(5.37)\end{array}$ & $\begin{array}{c}0.436 \\
0\end{array}$ & $\begin{array}{c}0.14 \\
(3.15)\end{array}$ & $\begin{array}{c}0.964 \\
4\end{array}$ & $1.5(5)$ & $\begin{array}{c}0.764 \\
3\end{array}$ & $\begin{array}{c}-1.3 \\
(3.11)\end{array}$ & $\begin{array}{c}0.675 \\
4\end{array}$ & $\begin{array}{l}-5.08 \\
(3.55)\end{array}$ & $\begin{array}{c}0.154 \\
2\end{array}$ & $\begin{array}{l}-4.44 \\
(3.56)\end{array}$ & $\begin{array}{c}0.213 \\
3\end{array}$ \\
\hline $\begin{array}{l}\text { Surgery } \\
\text { (Amputation } \\
\text { vs. Salvage) }\end{array}$ & $\begin{array}{c}6.23 \\
(4.18)\end{array}$ & $\begin{array}{c}0.137 \\
4\end{array}$ & $\begin{array}{c}7.22 \\
(3.78)\end{array}$ & $\begin{array}{c}0.057 \\
7\end{array}$ & $\begin{array}{c}-7.6 \\
(5.99)\end{array}$ & $\begin{array}{c}0.205 \\
4\end{array}$ & $\begin{array}{l}-7.07 \\
(3.53)\end{array}$ & $\begin{array}{c}0.046 \\
1\end{array}$ & $\begin{array}{l}-3.94 \\
(5.62)\end{array}$ & $\begin{array}{c}0.483 \\
7\end{array}$ & $\begin{array}{l}1.13 \\
(3.5)\end{array}$ & $\begin{array}{c}0.747 \\
7\end{array}$ & $\begin{array}{c}1.99 \\
(4.06)\end{array}$ & $\begin{array}{c}0.623 \\
9\end{array}$ & $\begin{array}{l}-3.22 \\
(4.01)\end{array}$ & $\begin{array}{c}0.423 \\
2\end{array}$ \\
\hline Time & & $\begin{array}{c}<.000 \\
1\end{array}$ & & $\begin{array}{c}<.000 \\
1\end{array}$ & & $\begin{array}{c}<.000 \\
1\end{array}$ & & $\begin{array}{c}<.000 \\
1\end{array}$ & & $\begin{array}{c}<.000 \\
1\end{array}$ & & $\begin{array}{c}0.019 \\
1\end{array}$ & & $\begin{array}{c}0.046 \\
9\end{array}$ & & $\begin{array}{c}0.000 \\
7\end{array}$ \\
\hline T1 vs. T2 & $\begin{array}{l}-24.08 \\
(2.99)\end{array}$ & $\begin{array}{c}<.000 \\
1\end{array}$ & $\begin{array}{l}16.44 \\
(2.86)\end{array}$ & $\begin{array}{c}<.000 \\
1\end{array}$ & $\begin{array}{c}-13.66 \\
(2.64)\end{array}$ & $\begin{array}{c}<.000 \\
1\end{array}$ & $\begin{array}{c}-12.37 \\
(2.6)\end{array}$ & $\begin{array}{c}<.000 \\
1\end{array}$ & $\begin{array}{l}-6.32 \\
(2.73)\end{array}$ & $\begin{array}{c}0.021 \\
2\end{array}$ & $\begin{array}{c}-2.3 \\
(1.87)\end{array}$ & $\begin{array}{c}0.218 \\
8\end{array}$ & $\begin{array}{l}-1.36 \\
(2.54)\end{array}$ & $\begin{array}{c}0.593 \\
3\end{array}$ & $\begin{array}{l}-3.85 \\
(2.52)\end{array}$ & $\begin{array}{c}0.126 \\
8\end{array}$ \\
\hline T1 vs. T3 & $\begin{array}{l}-20.3 \\
(3.12)\end{array}$ & $\begin{array}{c}<.000 \\
1\end{array}$ & $\begin{array}{l}18.06 \\
(2.98)\end{array}$ & $\begin{array}{c}<.000 \\
1\end{array}$ & $\begin{array}{l}-15.3 \\
(2.76)\end{array}$ & $\begin{array}{c}<.000 \\
1\end{array}$ & $\begin{array}{c}-14.93 \\
(2.71)\end{array}$ & $\begin{array}{c}<.000 \\
1\end{array}$ & $\begin{array}{r}-13.33 \\
(2.84)\end{array}$ & $\begin{array}{c}<.000 \\
1\end{array}$ & $\begin{array}{l}-3.91 \\
(1.95)\end{array}$ & $\begin{array}{c}0.046 \\
1\end{array}$ & $\begin{array}{c}-5.1 \\
(2.64)\end{array}$ & $\begin{array}{c}0.054 \\
5\end{array}$ & $\begin{array}{l}-7.99 \\
(2.61)\end{array}$ & $\begin{array}{c}0.002 \\
4\end{array}$ \\
\hline T1 vs. T4 & $\begin{array}{c}-18.91 \\
(3.2)\end{array}$ & $\begin{array}{c}<.000 \\
1\end{array}$ & $\begin{array}{c}-7.7 \\
(3.08)\end{array}$ & $\begin{array}{c}0.013 \\
1\end{array}$ & $\begin{array}{r}-19.34 \\
(2.85)\end{array}$ & $\begin{array}{c}<.000 \\
1\end{array}$ & $\begin{array}{l}-15.3 \\
(2.78)\end{array}$ & $\begin{array}{c}<.000 \\
1\end{array}$ & $\begin{array}{c}-19.48 \\
(2.92)\end{array}$ & $\begin{array}{c}<.000 \\
1\end{array}$ & $\begin{array}{c}-6.17 \\
(2)\end{array}$ & $\begin{array}{c}0.002 \\
3\end{array}$ & $\begin{array}{c}-6.74 \\
(2.71)\end{array}$ & $\begin{array}{c}0.013 \\
6\end{array}$ & $\begin{array}{l}-10.4 \\
(2.69)\end{array}$ & $\begin{array}{c}0.000 \\
1\end{array}$ \\
\hline
\end{tabular}


Table 4-42. Multivariate model results investigating predictors of PedsQL-Cancer domain scores in OS

\begin{tabular}{|c|c|c|c|c|c|c|c|c|c|c|c|c|c|c|c|c|}
\hline Factor & \multicolumn{2}{|c|}{ Pain and Hurt } & \multicolumn{2}{|c|}{ Nausea } & \multicolumn{2}{|c|}{$\begin{array}{c}\text { Procedural } \\
\text { Anxiety }\end{array}$} & \multicolumn{2}{|c|}{$\begin{array}{c}\text { Treatment } \\
\text { Anxiety }\end{array}$} & \multicolumn{2}{|c|}{ Cancer Worry } & \multicolumn{2}{|c|}{$\begin{array}{l}\text { Cognitive } \\
\text { Problems } \\
\end{array}$} & \multicolumn{2}{|c|}{$\begin{array}{c}\text { Perceived } \\
\text { Physical } \\
\text { Appearance }\end{array}$} & \multicolumn{2}{|c|}{$\begin{array}{c}\text { Communica- } \\
\text { tion }\end{array}$} \\
\hline Time & & . & & . & & . & & . & & . & & . & & . & & . \\
\hline $\begin{array}{l}\text { T1 vs. } \\
\text { T2 }\end{array}$ & $\begin{array}{l}-4.39 \\
(1.73)\end{array}$ & 0.0116 & $\begin{array}{l}16.31 \\
(2.86)\end{array}$ & $<.0001$ & $\begin{array}{l}-13.61 \\
(2.63)\end{array}$ & $<.0001$ & $\begin{array}{c}-12.31 \\
(2.6)\end{array}$ & $<.0001$ & $\begin{array}{l}-6.35 \\
(2.73)\end{array}$ & 0.0208 & & . & & . & $\begin{array}{l}-8.05 \\
(2.61)\end{array}$ & $\begin{array}{c}0.00 \\
22\end{array}$ \\
\hline $\begin{array}{l}\text { T1 vs. } \\
\text { T3 }\end{array}$ & $\begin{array}{l}-3.22 \\
(1.79)\end{array}$ & 0.0735 & $\begin{array}{l}17.86 \\
(2.98)\end{array}$ & $<.0001$ & $\begin{array}{l}-15.3 \\
(2.75)\end{array}$ & $<.0001$ & $\begin{array}{l}-14.8 \\
(2.72)\end{array}$ & $<.0001$ & $\begin{array}{l}-13.31 \\
(2.84)\end{array}$ & $<.0001$ & $\begin{array}{l}-3.91 \\
(1.95)\end{array}$ & 0.0461 & $\begin{array}{l}-5.13 \\
(2.64)\end{array}$ & $\begin{array}{c}0.052 \\
9\end{array}$ & $\begin{array}{l}-3.77 \\
(2.51)\end{array}$ & $\begin{array}{c}0.13 \\
49\end{array}$ \\
\hline $\begin{array}{l}\text { T1 vs. } \\
\text { T4 }\end{array}$ & $\begin{array}{l}-11.57 \\
(1.83)\end{array}$ & $<.0001$ & $\begin{array}{l}-7.92 \\
(3.08)\end{array}$ & 0.0107 & $\begin{array}{l}-19.38 \\
(2.84)\end{array}$ & $<.0001$ & $\begin{array}{r}-15.23 \\
(2.78)\end{array}$ & $<.0001$ & $\begin{array}{c}-19.42 \\
(2.92)\end{array}$ & $<.0001$ & $\begin{array}{c}-6.17 \\
(2)\end{array}$ & 0.0023 & $\begin{array}{l}-6.82 \\
(2.71)\end{array}$ & $\begin{array}{c}0.012 \\
5\end{array}$ & $\begin{array}{l}-10.47 \\
(2.69)\end{array}$ & $\begin{array}{c}0.00 \\
01\end{array}$ \\
\hline
\end{tabular}




\section{Total Sample}

A univariate model identified most variables as significant predictors of HRQOL on the PedsQL-Generic scale within the total sample across different HRQOL domains (Table 4-43). A multivariate analysis identified age, risk, diagnosis, and time in treatment as significant predictors $(\mathrm{p}<.05)$ of HRQOL domains in the total sample (Table 4-44). On the PedsQL-Cancer module, age, gender, race, risk, surgery, radiotherapy, diagnosis, and time were significant predictors of HRQOL in our total sample (Table 4-45). However, on the multivariate analysis, age, race, diagnosis, and time were significant $(\mathrm{p}<0.05)$ predictors of cancer-related symptoms (Table 4-46). Significantly higher cancersymptom scores $(\mathrm{p}<0.05)$ were reported on all cancer-related symptoms on the PedsQLCancer scale at the end of treatment (T4) in comparison to the beginning of treatment (T1).

- $\quad$ Research Question 3-2: What is the combined effect of cancer and treatment factors on the self-reported HRQOL of children undergoing curative cancer treatment in each diagnostic group?

To assess the combined effect of cancer and treatment factors on HRQOL, we attempted to look for the best model to fit the different variables on each HRQOL domain and cancer-related symptom in our analysis. Since we utilized a mixed linear model to identify predictors of HRQOL changes over time, the most feasible method to look for model fit is using the Akaike information criterion (AIC). To examine AIC values, lower values indicate better model fit. Table 4-47 represents the AIC values for the HRQOL domains, while Table 4-48 represents the AIC values for cancer-related symptoms.

The AIC values represent the best fit models for each separate HRQOL domain and for the total HRQOL as well. The best fit model for each domain was the following:

- $\quad$ Physical functioning: The AML diagnostic group (age*time).

- $\quad$ Emotional functioning: The AML group (risk*time).

- $\quad$ Social functioning: The AML group (risk*time).

- $\quad$ School functioning: The AML group (ethnicity*risk*time).

- $\quad$ Total HRQOL score: The AML group (risk*time).

As for cancer-related symptoms, the best fit model for each score was the following:

- $\quad$ Pain and hurt: The AML diagnostic group (time).

- $\quad$ Nausea: The AML diagnostic group (age*time).

- $\quad$ Procedural anxiety: The AML diagnostic group (age*risk*time).

- Treatment anxiety: The AML diagnostic group (risk*time).

- $\quad$ Cancer worry: The AML diagnostic group (risk*time).

- $\quad$ Cognitive problems: The AML diagnostic group (risk).

- $\quad$ Perceived risk appearance: The AML diagnostic group (time).

- $\quad$ Communication: The OS diagnostic group (age*time). 
Table 4-43. Univariate model results investigating predictors of PedsQL-Generic domain scores in the total sample

\begin{tabular}{|c|c|c|c|c|c|c|c|c|c|c|}
\hline \multirow[b]{2}{*}{ Factor } & \multicolumn{2}{|c|}{ Physical Functioning } & \multicolumn{2}{|c|}{ Emotional Functioning } & \multicolumn{2}{|c|}{ Social Functioning } & \multicolumn{2}{|c|}{ School Functioning } & \multicolumn{2}{|c|}{ Total Score } \\
\hline & B (SE) & $\mathbf{P}$ & B (SE) & $\mathbf{P}$ & B (SE) & $\mathbf{P}$ & B (SE) & $\mathbf{P}$ & B (SE) & $\mathbf{P}$ \\
\hline $\begin{array}{l}\text { Age (Child vs. } \\
\text { Teen) }\end{array}$ & $3.96(1.48)$ & 0.0076 & $1.02(1.24)$ & 0.4127 & $-6.09(1)$ & $<.0001$ & $0.41(1.3)$ & 0.7526 & $0.52(1.05)$ & 0.6171 \\
\hline $\begin{array}{l}\text { Gender (Male vs. } \\
\text { Female) }\end{array}$ & $3.84(1.5)$ & 0.0107 & $5.76(1.24)$ & $<.0001$ & $-0.13(1.04)$ & 0.9039 & $1.32(1.31)$ & 0.3122 & $2.91(1.06)$ & 0.0061 \\
\hline $\begin{array}{l}\text { Ethnicity (Other } \\
\text { vs. White) }\end{array}$ & $-2.25(1.74)$ & 0.1969 & $-0.83(1.45)$ & 0.5669 & $-0.9(1.2)$ & 0.4506 & $1.01(1.51)$ & 0.5044 & $-1.06(1.23)$ & 0.3893 \\
\hline Risk & & 0.0152 & & 0.0431 & & 0.4752 & & 0.1998 & & 0.0934 \\
\hline High vs. Low & $-5.68(2.09)$ & 0.0068 & $-4.14(1.85)$ & 0.0254 & $1.66(1.47)$ & 0.2597 & $-3.34(1.9)$ & 0.0796 & $-3.3(1.51)$ & 0.0296 \\
\hline $\begin{array}{l}\text { High vs. } \\
\text { Intermediate }\end{array}$ & $-1.51(1.9)$ & 0.4273 & $-3.79(1.68)$ & 0.0247 & $1.41(1.34)$ & 0.2947 & $-2.37(1.75)$ & 0.1745 & $-1.7(1.37)$ & 0.2167 \\
\hline $\begin{array}{l}\text { Radiotherapy } \\
\text { (Yes vs. No) }\end{array}$ & $10.4(1.55)$ & $<.0001$ & $1.41(1.33)$ & 0.2898 & $7.8(1.06)$ & $<.0001$ & $2.64(1.37)$ & 0.0549 & $6.25(1.1)$ & $<.0001$ \\
\hline Diagnosis & & $<.0001$ & & 0.0005 & & $<.0001$ & & 0.1017 & & $<.0001$ \\
\hline ALL vs. AML & $5(2.33)$ & 0.0318 & $4.76(2.13)$ & 0.0258 & $-5.47(1.68)$ & 0.0012 & $-3.62(2.27)$ & 0.1108 & $1.13(1.71)$ & 0.5077 \\
\hline ALL vs. HL & $-6.11(1.63)$ & 0.0002 & $0.85(1.5)$ & 0.5694 & $-8.45(1.18)$ & $<.0001$ & $-3.71(1.56)$ & 0.0180 & $-4.46(1.21)$ & 0.0002 \\
\hline ALL vs. MEL & $-10.35(3.84)$ & 0.0071 & $-5(3.52)$ & 0.1555 & $-5.11(2.77)$ & 0.0656 & $-4.01(3.73)$ & 0.2826 & $-6.5(2.84)$ & 0.0221 \\
\hline ALL vs. OS & $18.04(2.05)$ & $<.0001$ & $6.63(1.88)$ & 0.0004 & $2.88(1.48)$ & 0.0514 & $-0.29(1.97)$ & 0.8826 & $8.87(1.51)$ & $<.0001$ \\
\hline Time & & $<.0001$ & & $<.0001$ & & 0.0012 & & $<.0001$ & & $<.0001$ \\
\hline T1 vs. T2 & $-2.32(0.97)$ & 0.0165 & $-4.54(0.86)$ & $<.0001$ & $-0.48(0.73)$ & 0.5150 & $-0.37(1.04)$ & 0.7196 & $-2.02(0.66)$ & 0.0021 \\
\hline T1 vs. T3 & $-2.48(1.02)$ & 0.0150 & $-5.45(0.91)$ & $<.0001$ & $0.31(0.77)$ & 0.6822 & $-1.11(1.07)$ & 0.2995 & $-2.13(0.69)$ & 0.0020 \\
\hline
\end{tabular}


Table 4-44. Multivariate model results investigating predictors of PedsQL-Generic domain scores in the total sample

\begin{tabular}{|c|c|c|c|c|c|c|c|c|c|c|}
\hline \multirow[b]{2}{*}{ Factor } & \multicolumn{2}{|c|}{ Physical Functioning } & \multicolumn{2}{|c|}{ Emotional Functioning } & \multicolumn{2}{|c|}{ Social Functioning } & \multicolumn{2}{|c|}{ School Functioning } & \multicolumn{2}{|c|}{ Total Score } \\
\hline & B (SE) & $\mathbf{P}$ & B (SE) & $\mathbf{P}$ & B (SE) & $\mathbf{P}$ & B (SE) & $\mathbf{P}$ & B (SE) & $\mathbf{P}$ \\
\hline Age (Child vs. Teen) & $7.13(1.65)$ & $<.0001$ & & . & $-3.96(1.07)$ & 0.0002 & & . & & . \\
\hline High vs. Low & $-9.46(2.23)$ & $<.0001$ & $-3.69(1.96)$ & 0.0596 & & . & $-6.31(2.16)$ & 0.0036 & $-6.47(1.65)$ & $<.0001$ \\
\hline Diagnosis & & . & & . & & . & & . & & . \\
\hline ALL vs. AML & $0.79(2.31)$ & 0.7332 & $2.61(2.11)$ & 0.2171 & $-4.85(1.68)$ & 0.0041 & & . & & . \\
\hline ALL vs. HL & $-7.08(3.43)$ & 0.0394 & & . & $-5.1(2.51)$ & 0.0422 & $-3.59(3.19)$ & 0.2608 & $-3.24(2.48)$ & 0.1919 \\
\hline ALL vs. MEL & . (.) & . & & . & $-3.85(2.77)$ & 0.1643 & & . & . (.) & . \\
\hline ALL vs. OS & . (.) & . & . (.) & . & . (.) & . & & . &.$()$. & . \\
\hline Time & & . & & . & & . & & . & & . \\
\hline T1 vs. T2 & $-1.8(1.04)$ & 0.0833 & $-3.82(0.95)$ & $<.0001$ & & . & & . & $-1.41(0.72)$ & 0.0513 \\
\hline T1 vs. T3 & $-2.2(1.1)$ & 0.0450 & $-4.41(1)$ & $<.0001$ & & . & & . & $-1.55(0.76)$ & 0.0422 \\
\hline
\end{tabular}


Table 4-45. Univariate model results investigating predictors of PedsQL-Cancer in the total sample

\begin{tabular}{|c|c|c|c|c|c|c|c|c|c|c|c|c|c|c|c|c|}
\hline \multirow[b]{2}{*}{ Factor } & \multicolumn{2}{|c|}{ Pain and Hurt } & \multicolumn{2}{|c|}{ Nausea } & \multicolumn{2}{|c|}{$\begin{array}{c}\text { Procedural } \\
\text { Anxiety }\end{array}$} & \multicolumn{2}{|c|}{$\begin{array}{c}\text { Treatment } \\
\text { Anxiety }\end{array}$} & \multicolumn{2}{|c|}{ Cancer Worry } & \multicolumn{2}{|c|}{$\begin{array}{l}\text { Cognitive } \\
\text { Problems } \\
\end{array}$} & \multicolumn{2}{|c|}{$\begin{array}{c}\text { Perceived } \\
\text { Physical } \\
\text { Appearance } \\
\end{array}$} & \multicolumn{2}{|c|}{$\begin{array}{c}\text { Communica- } \\
\text { tion }\end{array}$} \\
\hline & $\begin{array}{c}\text { B } \\
(\mathrm{SE})\end{array}$ & $\mathbf{P}$ & $\begin{array}{c}\text { B } \\
(\mathrm{SE})\end{array}$ & $\mathbf{P}$ & $\begin{array}{c}\text { B } \\
(\mathrm{SE})\end{array}$ & $\mathbf{P}$ & $\begin{array}{c}\text { B } \\
(\mathrm{SE})\end{array}$ & $\mathbf{P}$ & $\begin{array}{c}\text { B } \\
(\mathrm{SE})\end{array}$ & $\mathbf{P}$ & $\begin{array}{c}\text { B } \\
(\mathrm{SE})\end{array}$ & $\mathbf{P}$ & $\begin{array}{c}\text { B } \\
(\mathrm{SE})\end{array}$ & $\mathbf{P}$ & $\begin{array}{c}\text { B } \\
(\mathrm{SE})\end{array}$ & $\mathbf{P}$ \\
\hline $\begin{array}{l}\text { Age (Child } \\
\text { vs. Teen) }\end{array}$ & $\begin{array}{c}6.8 \\
(1.52)\end{array}$ & $\begin{array}{c}<.000 \\
1\end{array}$ & $\begin{array}{c}3.74 \\
(1.35)\end{array}$ & 0.0057 & $\begin{array}{l}-17.61 \\
(1.84)\end{array}$ & $\begin{array}{c}<.000 \\
1\end{array}$ & $\begin{array}{l}-0.97 \\
(1.28)\end{array}$ & 0.4471 & $\begin{array}{c}8.21 \\
(1.68)\end{array}$ & $\begin{array}{c}<.000 \\
1\end{array}$ & $\begin{array}{c}2 \\
(1.31)\end{array}$ & 0.1259 & $\begin{array}{c}1.76 \\
(1.51)\end{array}$ & 0.2456 & $\begin{array}{l}-5.02 \\
(1.32)\end{array}$ & $\begin{array}{c}0.000 \\
1\end{array}$ \\
\hline $\begin{array}{l}\text { Gender } \\
\text { (Male vs. } \\
\text { Female) }\end{array}$ & $\begin{array}{c}4.79 \\
(1.53)\end{array}$ & 0.0018 & $\begin{array}{c}2.99 \\
(1.36)\end{array}$ & 0.0278 & $\begin{array}{c}6.77 \\
(1.95)\end{array}$ & 0.0005 & $\begin{array}{c}2.88 \\
(1.27)\end{array}$ & 0.0238 & $\begin{array}{l}7.21 \\
(1.7)\end{array}$ & $\begin{array}{c}<.000 \\
1\end{array}$ & $\begin{array}{c}0.76 \\
(1.31)\end{array}$ & 0.5625 & $\begin{array}{c}9.05 \\
(1.48)\end{array}$ & $\begin{array}{c}<.000 \\
1\end{array}$ & $\begin{array}{c}1.61 \\
(1.33)\end{array}$ & $\begin{array}{c}0.229 \\
0\end{array}$ \\
\hline $\begin{array}{l}\text { Ethnicity } \\
\text { (Other vs. } \\
\text { White) }\end{array}$ & $\begin{array}{l}-4.89 \\
(1.78)\end{array}$ & 0.0061 & $\begin{array}{l}-1.45 \\
(1.58)\end{array}$ & 0.3570 & $\begin{array}{c}1.84 \\
(2.26)\end{array}$ & 0.4164 & $\begin{array}{l}-1.43 \\
(1.48)\end{array}$ & 0.3343 & $\begin{array}{c}2.67 \\
(1.98)\end{array}$ & 0.1780 & $\begin{array}{l}-2.09 \\
(1.51)\end{array}$ & 0.1661 & $\begin{array}{l}-4.35 \\
(1.75)\end{array}$ & 0.0129 & $\begin{array}{l}-1.35 \\
(1.54)\end{array}$ & $\begin{array}{c}0.380 \\
5\end{array}$ \\
\hline Risk & & 0.1365 & & 0.3021 & & 0.5396 & & 0.3828 & & 0.0134 & & 0.0441 & & 0.6311 & & $\begin{array}{c}0.573 \\
2\end{array}$ \\
\hline $\begin{array}{l}\text { High vs. } \\
\text { Low }\end{array}$ & $\begin{array}{l}-3.27 \\
(2.44)\end{array}$ & 0.1810 & $\begin{array}{l}-2.99 \\
(2.1)\end{array}$ & 0.1552 & $\begin{array}{c}3.18 \\
(3.01)\end{array}$ & 0.2915 & $\begin{array}{l}-2.81 \\
(2.04)\end{array}$ & 0.1691 & $\begin{array}{l}-7.07 \\
(2.51)\end{array}$ & 0.0050 & $\begin{array}{l}-2.39 \\
(2.05)\end{array}$ & 0.2430 & $\begin{array}{l}-2.01 \\
(2.37)\end{array}$ & 0.3962 & $\begin{array}{c}0.8 \\
(2.04)\end{array}$ & $\begin{array}{c}0.696 \\
2\end{array}$ \\
\hline $\begin{array}{l}\text { High vs. } \\
\text { Intermediat } \\
\text { e }\end{array}$ & $\begin{array}{c}0.68 \\
(2.24)\end{array}$ & 0.7595 & $\begin{array}{l}-2.64 \\
(1.92)\end{array}$ & 0.1711 & $\begin{array}{l}1.06 \\
(2.75)\end{array}$ & 0.6998 & $\begin{array}{l}-1.36 \\
(1.87)\end{array}$ & 0.4672 & $\begin{array}{l}-5.55 \\
(2.29)\end{array}$ & 0.0155 & $\begin{array}{c}1.89 \\
(1.87)\end{array}$ & 0.3126 & $\begin{array}{l}-0.38 \\
(2.16)\end{array}$ & 0.8588 & $\begin{array}{c}-0.96 \\
(1.87)\end{array}$ & $\begin{array}{c}0.607 \\
4\end{array}$ \\
\hline $\begin{array}{l}\text { Surgery } \\
\text { (Yes vs. } \\
\text { No) }\end{array}$ & $\begin{array}{c}-4.9 \\
(1.99)\end{array}$ & 0.0138 & $\begin{array}{l}-7.01 \\
(1.73)\end{array}$ & $\begin{array}{c}<.000 \\
1\end{array}$ & $\begin{array}{c}0.88 \\
(2.57)\end{array}$ & 0.7307 & $\begin{array}{l}-1.79 \\
(1.66)\end{array}$ & 0.2799 & $\begin{array}{r}-10.07 \\
(2.21)\end{array}$ & $\begin{array}{c}<.000 \\
1\end{array}$ & $\begin{array}{c}-0.64 \\
(1.71)\end{array}$ & 0.7101 & $\begin{array}{c}-0.94 \\
(1.98)\end{array}$ & 0.6372 & $\begin{array}{l}-2.23 \\
(1.73)\end{array}$ & $\begin{array}{c}0.198 \\
0\end{array}$ \\
\hline $\begin{array}{l}\text { Radiothera } \\
\text { py (Yes vs. } \\
\text { No) }\end{array}$ & $\begin{array}{c}1.82 \\
(1.68)\end{array}$ & 0.2783 & $\begin{array}{c}-0.39 \\
(1.48)\end{array}$ & 0.7948 & $\begin{array}{c}7.03 \\
(2.11)\end{array}$ & 0.0009 & $\begin{array}{l}-1.37 \\
(1.39)\end{array}$ & 0.3219 & $\begin{array}{l}-2.72 \\
(1.85)\end{array}$ & 0.1432 & $\begin{array}{c}1.62 \\
(1.42)\end{array}$ & 0.2517 & $\begin{array}{c}0.39 \\
(1.64)\end{array}$ & 0.8109 & $\begin{array}{c}3.53 \\
(1.44)\end{array}$ & $\begin{array}{c}0.014 \\
6\end{array}$ \\
\hline
\end{tabular}


Table 4-45. (Continued)

\begin{tabular}{|c|c|c|c|c|c|c|c|c|c|c|c|c|c|c|c|c|}
\hline \multirow[b]{2}{*}{ Factor } & \multicolumn{2}{|c|}{ Pain and Hurt } & \multicolumn{2}{|c|}{ Nausea } & \multicolumn{2}{|c|}{$\begin{array}{c}\text { Procedural } \\
\text { Anxiety }\end{array}$} & \multicolumn{2}{|c|}{$\begin{array}{c}\text { Treatment } \\
\text { Anxiety }\end{array}$} & \multicolumn{2}{|c|}{ Cancer Worry } & \multicolumn{2}{|c|}{$\begin{array}{l}\text { Cognitive } \\
\text { Problems } \\
\end{array}$} & \multicolumn{2}{|c|}{$\begin{array}{c}\text { Perceived } \\
\text { Physical } \\
\text { Appearance }\end{array}$} & \multicolumn{2}{|c|}{$\begin{array}{c}\text { Communica- } \\
\text { tion }\end{array}$} \\
\hline & $\begin{array}{c}\text { B } \\
(\mathrm{SE})\end{array}$ & $\mathbf{P}$ & $\begin{array}{c}\text { B } \\
(\mathrm{SE})\end{array}$ & $\mathbf{P}$ & $\begin{array}{c}\text { B } \\
(\mathrm{SE})\end{array}$ & $\mathbf{P}$ & $\begin{array}{c}\text { B } \\
(\mathrm{SE})\end{array}$ & $\mathbf{P}$ & $\begin{array}{c}\text { B } \\
(\mathrm{SE})\end{array}$ & $\mathbf{P}$ & $\begin{array}{c}\text { B } \\
(\mathrm{SE})\end{array}$ & $\mathbf{P}$ & $\begin{array}{c}\text { B } \\
(\mathrm{SE})\end{array}$ & $\mathbf{P}$ & $\begin{array}{c}\text { B } \\
(\mathrm{SE})\end{array}$ & $\mathbf{P}$ \\
\hline Diagnosis & & 0.0330 & & $\begin{array}{c}<.000 \\
1\end{array}$ & & 0.0067 & & 0.1431 & & $\begin{array}{c}<.000 \\
1\end{array}$ & & 0.0805 & & 0.8796 & & 0.2209 \\
\hline $\begin{array}{l}\text { ALL vs. } \\
\text { AML }\end{array}$ & $\begin{array}{l}-0.86 \\
(2.81)\end{array}$ & 0.7586 & $\begin{array}{c}4.09 \\
(2.42)\end{array}$ & 0.0914 & $\begin{array}{c}2.73 \\
(3.47)\end{array}$ & 0.4318 & $\begin{array}{l}1.48 \\
(2.3)\end{array}$ & 0.5199 & $\begin{array}{c}5.68 \\
(2.96)\end{array}$ & 0.0553 & $\begin{array}{l}-4.52 \\
(2.32)\end{array}$ & 0.0515 & $\begin{array}{l}-2.54 \\
(2.71)\end{array}$ & 0.3497 & $\begin{array}{l}-1.43 \\
(2.41)\end{array}$ & 0.5529 \\
\hline $\begin{array}{l}\text { ALL vs. } \\
\text { HL }\end{array}$ & $\begin{array}{l}-1.23 \\
(1.84)\end{array}$ & 0.5031 & $\begin{array}{c}3.93 \\
(1.59)\end{array}$ & 0.0135 & $\begin{array}{l}-7.41 \\
(2.34)\end{array}$ & 0.0016 & $\begin{array}{c}3.09 \\
(1.53)\end{array}$ & 0.0432 & $\begin{array}{l}7.99 \\
(2)\end{array}$ & $\begin{array}{c}<.000 \\
1\end{array}$ & $\begin{array}{l}-3.62 \\
(1.57)\end{array}$ & 0.0210 & $\begin{array}{l}-0.19 \\
(1.82)\end{array}$ & 0.9179 & $\begin{array}{l}-3.1 \\
(1.6)\end{array}$ & 0.0528 \\
\hline $\begin{array}{l}\text { ALL vs. } \\
\text { MEL }\end{array}$ & $\begin{array}{l}-9.46 \\
(4.53)\end{array}$ & 0.0371 & $\begin{array}{l}-10.98 \\
(3.86)\end{array}$ & 0.0045 & $\begin{array}{l}-5.78 \\
(5.6)\end{array}$ & 0.3018 & $\begin{array}{l}-3.08 \\
(3.69)\end{array}$ & 0.4050 & $\begin{array}{l}-2.87 \\
(4.79)\end{array}$ & 0.5482 & $\begin{array}{c}-6.3 \\
(3.75)\end{array}$ & 0.0930 & $\begin{array}{c}0.51 \\
(4.38)\end{array}$ & 0.9067 & $\begin{array}{l}-3.59 \\
(3.86)\end{array}$ & 0.3519 \\
\hline Time & & $\begin{array}{c}<.000 \\
1\end{array}$ & & $\begin{array}{c}<.000 \\
1\end{array}$ & & $\begin{array}{c}<.000 \\
1\end{array}$ & & $\begin{array}{c}<.000 \\
1\end{array}$ & & $\begin{array}{c}<.000 \\
1\end{array}$ & & 0.0102 & & 0.0160 & & $\begin{array}{c}<.000 \\
1\end{array}$ \\
\hline T1 vs. T2 & $\begin{array}{l}-11.03 \\
(1.56)\end{array}$ & $\begin{array}{c}<.000 \\
1\end{array}$ & $\begin{array}{l}11.49 \\
(1.29)\end{array}$ & $\begin{array}{c}<.000 \\
1\end{array}$ & $\begin{array}{l}-12.12 \\
(1.45)\end{array}$ & $\begin{array}{c}<.000 \\
1\end{array}$ & $\begin{array}{l}-7.02 \\
(1.18)\end{array}$ & $\begin{array}{c}<.000 \\
1\end{array}$ & $\begin{array}{l}-2.76 \\
(1.3)\end{array}$ & 0.0341 & $\begin{array}{l}-1.33 \\
(1.07)\end{array}$ & 0.2131 & $\begin{array}{l}-0.42 \\
(1.27)\end{array}$ & 0.7406 & $\begin{array}{l}-2.48 \\
(1.25)\end{array}$ & 0.0483 \\
\hline T1 vs. T3 & $\begin{array}{l}-8.42 \\
(1.61)\end{array}$ & $\begin{array}{c}<.000 \\
1\end{array}$ & $\begin{array}{c}9.69 \\
(1.34)\end{array}$ & $\begin{array}{c}<.000 \\
1\end{array}$ & $\begin{array}{c}-16.35 \\
(1.5)\end{array}$ & $\begin{array}{c}<.000 \\
1\end{array}$ & $\begin{array}{l}-8.08 \\
(1.22)\end{array}$ & $\begin{array}{c}<.000 \\
1\end{array}$ & $\begin{array}{c}-5.42 \\
(1.34)\end{array}$ & $\begin{array}{c}<.000 \\
1\end{array}$ & $\begin{array}{r}-2.48 \\
(1.1)\end{array}$ & 0.0251 & $\begin{array}{c}-0.94 \\
(1.32)\end{array}$ & 0.4751 & $\begin{array}{l}-5.44 \\
(1.3)\end{array}$ & $\begin{array}{c}<.000 \\
1\end{array}$ \\
\hline T1 vs. T4 & $\begin{array}{c}-15.24 \\
(1.65)\end{array}$ & $\begin{array}{c}<.000 \\
1\end{array}$ & $\begin{array}{l}-3.94 \\
(1.37)\end{array}$ & 0.0040 & $\begin{array}{c}-21.84 \\
(1.53)\end{array}$ & $\begin{array}{c}<.000 \\
1\end{array}$ & $\begin{array}{l}-9.84 \\
(1.25)\end{array}$ & $\begin{array}{c}<.000 \\
1\end{array}$ & $\begin{array}{c}-10.16 \\
(1.37)\end{array}$ & $\begin{array}{c}<.000 \\
1\end{array}$ & $\begin{array}{l}-3.48 \\
(1.13)\end{array}$ & 0.0020 & $\begin{array}{l}-3.53 \\
(1.35)\end{array}$ & 0.0089 & $\begin{array}{l}-8.59 \\
(1.32)\end{array}$ & $\begin{array}{c}<.000 \\
1\end{array}$ \\
\hline
\end{tabular}


Table 4-46. Multivariate model results investigating predictors of PedsQL-Cancer scores in the total sample

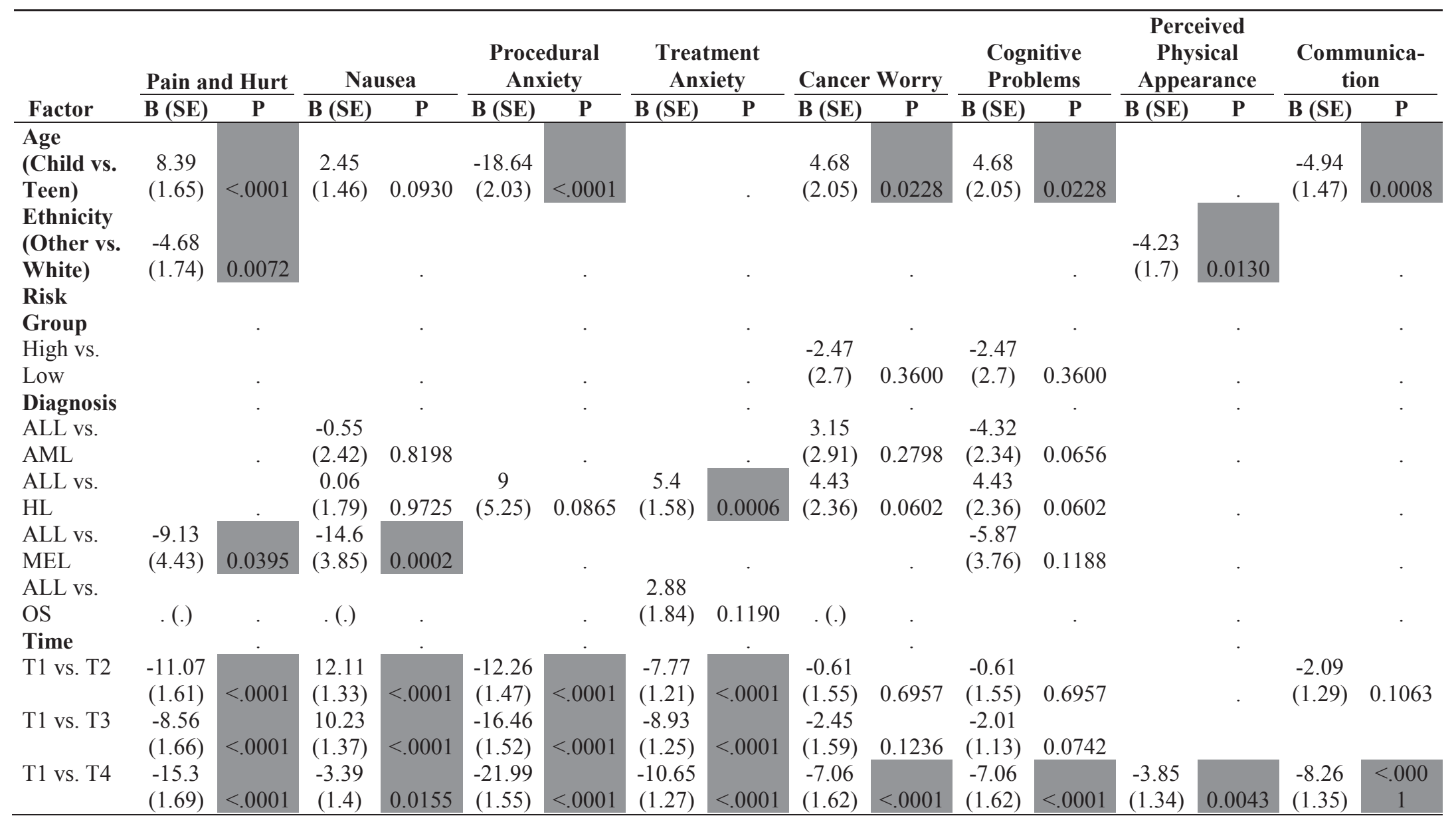


Table 4-47. Model fit AIC values for PedsQL-Generic HRQOL domain scores

\begin{tabular}{|c|c|c|c|c|c|c|c|c|}
\hline \multirow[b]{3}{*}{ Domain } & \multicolumn{8}{|c|}{ Diagnosis } \\
\hline & \multicolumn{2}{|l|}{ ALL } & \multicolumn{2}{|c|}{ AML } & \multicolumn{2}{|c|}{ HL } & \multicolumn{2}{|c|}{ OS } \\
\hline & Model & AIC & Model & AIC & Model & AIC & Model & AIC \\
\hline & age* gender*race* & & & & age* gender*risk* & & & \\
\hline Physical & risk*time & 6387.8 & age*time & 2010.6 & time & 6975.9 & time & 3472.6 \\
\hline Emotional & gender*risk*time & 6292.6 & risk*time & 1949.7 & gender*time & 6969.4 & time & 3316.3 \\
\hline Social & & & risk*time & 1769.3 & age*time & 6445.2 & & \\
\hline School & $\begin{array}{l}\text { age*risk } \\
\text { age*gender*race* }\end{array}$ & 5568 & race*risk*time & 1610.8 & gender*time & 6445.2 & time & 2874.5 \\
\hline Total & risk*time & 5962.2 & risk*time & 1808.3 & gender*time & 5832 & time & 3156.6 \\
\hline
\end{tabular}

ALL: acute lymphoblastic leukemia; AML: acute myeloid leukemia; HL: Hodgkin lymphoma; OS: osteosarcoma. 
Table 4-48. Model fit AIC values for PedsQL-Cancer symptoms

\begin{tabular}{|c|c|c|c|c|c|c|c|c|}
\hline \multirow[b]{3}{*}{ Domain } & \multicolumn{8}{|c|}{ Diagnosis } \\
\hline & \multicolumn{2}{|l|}{ ALL } & \multicolumn{2}{|c|}{ AML } & \multicolumn{2}{|l|}{ HL } & \multicolumn{2}{|l|}{ OS } \\
\hline & $\begin{array}{c}\text { Model } \\
\end{array}$ & AIC & Model & AIC & Model & AIC & Model & AIC \\
\hline Pain and Hurt & age*gender*race*risk*time & 6685.8 & time & 1369.5 & gender*time & 5282.7 & age*time & 3156.6 \\
\hline Nausea & age*gender*race*risk*time & 6685.8 & age*time & 1309.7 & radiation*time & 5161.6 & race*surgery*time & 3397.3 \\
\hline Procedural & & & & & & & & \\
\hline $\begin{array}{l}\text { Anxiety } \\
\text { Treatment }\end{array}$ & age*gender*time & 6716.4 & age*risk*time & 1388.7 & age*gender*time & 5267.6 & time & 5092.5 \\
\hline Anxiety & age*race*time & 6261.5 & risk*time & 1291.9 & time & 5092.5 & surgery*time & 3348.2 \\
\hline $\begin{array}{l}\text { Cancer Worry } \\
\text { Cognitive }\end{array}$ & gender*risk*time & 6427.1 & risk*time & 1308.2 & age*gender*time & 5143.3 & age*time & 3450.9 \\
\hline $\begin{array}{l}\text { Problems } \\
\text { Perceived } \\
\text { Physical }\end{array}$ & age*risk & 6278.1 & risk & 1230.4 & age*time & 4958.2 & time & 3187.8 \\
\hline Appearance & gender & 6586.7 & time & 1297.1 & gender*race*time & 5087.9 & gender*time & 3375.8 \\
\hline Communication & age*time & 6516.9 & & & risk*time & 4981.6 & age*time & 3332.9 \\
\hline
\end{tabular}

ALL: acute lymphoblastic leukemia; AML: acute myeloid leukemia; HL: Hodgkin lymphoma; OS: osteosarcoma. 


\title{
CHAPTER 5. DISCUSSION
}

Our review of the literature suggests that this study represents the largest longitudinal study of HRQOL in children with cancer. This study has also identified many longitudinal trends in HRQOL that were not previously reported and demonstrates the differences in HRQOL between children under curative treatment and childhood cancer survivors and highlights the need to separate and make this distinction in future HRQOL research. The study has also identified new sets of symptoms that are most concerning to children through their treatment. The findings in this study will further improve research by identifying symptoms that are of most concern to children with cancer.

The longitudinal trends of change in HRQOL have been poorly understood in many of the disease groups included in our study. Our study helps address some of the limitations that have been identified with longitudinal trends of HRQOL over time in children with cancer. Our study findings point to the dynamic nature of HRQOL in children with cancer as they go on through treatment. It also points to the need for specific interventions at certain times in treatment to achieve the highest impact on HRQOL of children with cancer. In addition, many factors that have been extensively measured in previous studies proved no effect, while other factors proved to be of high correlation to HRQOL in our sample.

Our findings also identify certain characteristics that define patients with likelihood of lower HRQOL in general. Patients who are non-white, female, younger in age, on a higher risk arm of treatment have higher risk of developing lower HRQOL. Also, patients who are new to treatment report the lowest HRQOL.

\begin{abstract}
$\operatorname{Aim} 1$
Aim 1 was to identify longitudinal trends in HRQOL change in diagnostic groups of children undergoing curative cancer treatment.

HRQOL varied across diagnostic groups and over time with a consistent trend of changing HRQOL over time in all diagnostic groups. Regardless of the diagnostic group, children reported poor HRQOL at the beginning of treatment (T1) followed by a decrease in HRQOL as children received cancer treatments (T2), improved HRQOL at later time points (T3) and a higher level in comparison to previous time points at the end of treatment (T4). Higher HRQOL scores on the PedsQL-Generic and PedsQL-Cancer indicated better outcomes and fewer problems with HRQOL domains, while lower HRQOL indicated more problems and worse HRQOL on these domains. While little information is provided by the available literature on the change in HRQOL over time in children undergoing active cancer treatment, our findings that demonstrate a dynamic change in HRQOL in response to time in treatment with improving HRQOL at the end of treatment are generally supported by previous literature. (13,46,48,49 $^{2}$
\end{abstract}


Another consistent finding across all diagnostic groups was the observation that social functioning remained the highest scoring domain throughout the entire treatment period. These results may be explained by the uniquely supportive environment and resources children being treated for cancer experience at SJCRH. Considering the nature of the hospital and the facilities that are not generally available at most treating hospitals, social functioning scores may not be as high in other institutions as was reported in our sample. Other factors may also support the high social functioning scores including the support children receive from their parents and family, and their community and school.

Our subgroup analysis found that children with ALL presented with among the lowest HRQOL at the beginning of treatment that continuously improved throughout treatment. Children with ALL also had the longest duration of treatment among all the diagnostic groups (120-146 weeks) with the first data collection occurring at day 40 of chemotherapy. This likely explains the particularly low HRQOL at T1 for children with ALL considering the side effects experienced by the time the first HRQOL scores were collected. It is also of note that of the cancer-related symptoms, children with ALL also reported low scores for procedural anxiety, which can be explained by the younger age of these children in compared to the other diagnostic groups.

Children with AML reported low emotional functioning, a trend that was observed in other diagnostic groups as well. However, emotional functioning scores improved steadily and rapidly throughout treatment, eventually reached high scores at the end of treatment that were comparable to HRQOL in normal populations. As for symptoms, nausea was the lowest scoring (most troublesome) symptom early in treatment; however, at the end of treatment, pain and hurt symptoms was the one most troublesome, followed by cancer worry. Children with AML have about a $15 \%$ percent chance of developing a refractory or recurrent AML. They also have a high risk of developing multiple complications, which may explain the burden of thinking about the recurrence reflected in the cancer worry scores.

Children with HL reported comparable trends as to those reported across all diagnostic groups with high social functioning scores and lower emotional functioning scores at the beginning of treatment that improved steadily throughout treatment. Similar to the children with AML, they also had low physical functioning scores during treatment and at the end of treatment. Nausea was the most troublesome cancer-related symptom that displayed abrupt improvement especially at the end of treatment. However, the most troublesome symptom at the end of treatment was cancer worry.

One understudied group of patients is children with melanoma. Our review did not identify any previous studies that measured HRQOL outcomes in children with melanoma. Melanoma is typically an adult onset disease, thus, little information exists on the HRQOL of life in children with melanoma. Children with melanoma also receive different treatments than other childhood cancer groups. The use of biological response modifiers like Interferon- $\alpha$ in melanoma have been reported to affect adults with melanoma. ${ }^{33}$ However, our small group of children with melanoma generally reported the highest HRQL outcomes across diagnostic groups at all time-points. These responses 
provide an insight into the general tolerance of melanoma treatment in adolescents with cancer (15 out of 23 participants in the melanoma group were adolescents). It can also be the result of different outcomes and symptoms of melanoma treatment (skin changes) that were not recorded or measured using our instruments.

The lowest HRQOL scores across all domains and symptoms were reported among children and adolescents with osteosarcoma (OS). While HRQOL improved abruptly over time in children with osteosarcoma, it remained well below the score of 80 which is considered to represent an average HRQOL score for a healthy child. The lower HRQOL score for children with osteosarcoma has been previously reported. ${ }^{48}$ Children with OS undergo considerable and extensive therapies including extensive surgery and chemotherapy. These treatments impact HRQOL during treatment and may explain the change in HRQOL over time in children with osteosarcoma. It is also of note that even at the end of treatment; the OS group reported lower HRQOL scores than the other groups included in this study. This trend of lower HRQOL may be explained to an extent by some of the moderating factors that were included in this study, most specifically surgical intervention in the form of limb amputation or limb-sparing procedures. These surgical interventions can be severe and result in multiple complications and may include permanent loss of limb and physical function that affect the child's physical and emotional functioning early in treatment and into survivorship. Previous studies have found children who underwent either limb sparing or amputation reported no significant differences between either procedures in terms of HRQOL outcomes. ${ }^{79}$ Our analysis of HRQOL in children with osteosarcoma found similar results, with no noted differences in HRQOL between children on the two surgical procedures. However, this outcome has been reported to change as children with osteosarcoma progress into survivorship, with evidence suggesting limb-sparing procedures offer higher HRQOL outcomes for

survivors of lower-limb osteosarcoma in comparison to survivors with amputations. ${ }^{80}$ The effect of surgery during osteosarcoma treatment can be especially significant in adolescents who have lower self-image secondary to these procedures. ${ }^{3,81,82}$

\begin{abstract}
$\operatorname{Aim} 2$
Aim 2 was to identify the differences in HRQOL among different diagnostic groups of children undergoing curative cancer treatment.

Across diagnostic groups and over time, multiple variations in self-reported HRQOL were observed. These variations were captured through the different domains that were measured using the PedsQL-Generic and PedsQL-Cancer scales. While some of the variations over time reflected a consistent trend of change across all diagnostic groups, other domain scores reflected specific issues with a particular diagnostic group in comparison to the other groups.

A noticeable low scoring domain across all diagnostic groups over time was the physical functioning domain. However, certain groups, children with osteosarcoma in particular, reported significantly lower physical functioning scores than other groups.
\end{abstract}


This could be inferred to be a result of the intensive therapies that children with osteosarcoma receive. However, physical functioning significantly increased by the end of treatment (for T4) for all diagnostic groups with the exception of melanoma. Improvement likely reflects the decreased effects of intensive treatments as children approach the end of their treatment. The importance of physical functioning as a domain of HRQOL has been extensively covered in literature, ${ }^{13,74,83,84}$ however, our study points to the considerably low physical functioning scores for children with osteosarcoma, in particular; a trend that relates to severe pain and limited mobility in children with osteosarcoma. $^{15,51}$ This trend also points to the need to assess and support interventions that may enhance physical activity, control pain, and improve physical functioning and mobility for these children. ${ }^{84}$

Emotional functioning was relatively higher than other domains throughout treatment. It was lowest in children with osteosarcoma and highest in children with melanoma at the beginning of treatment (T1). At the end of treatment (T4), children with AML reported the highest emotional functioning scores, while children with osteosarcoma reported the poorest emotional functioning score throughout treatment. However, in all diagnostic groups except for children with melanoma, emotional functioning improved significantly at the end of treatment in comparison to the beginning of treatment. Children with melanoma reported a non-significant decrease in their emotional functioning scores at the end of treatment (T4) in comparison to the previous time points in treatment (T2,T3). Across all diagnostic groups, children with AML achieve the highest score increase in emotional HRQOL, adding 19 points at the end of treatment (T4) in comparison to the beginning of treatment (T1). This significant increase may reflect the emotional burden that children with AML experience at the beginning of their treatments and the support they receive from their families and care professionals throughout their treatment. It could also be due to the attrition of children with higher risk disease who may have relapsed or progressed and thus taken off the study. HRQOL data on these children were not included in this study.

Social functioning domain scores were reported as the highest HRQOL domain scores over time and across all diagnostic groups. The lowest social functioning score at the beginning of treatment (T1) was for children with osteosarcoma, while the highest T1 score was for children with Hodgkin lymphoma. At the end of treatment (T4), children with osteosarcoma maintain the lowest social functioning score while children with AML report the highest scores. However, social functioning does not improve significantly over time in all diagnostic groups expect for children with Hodgkin lymphoma. This observation may reflect the consistent support from the family, community, and institute that children receive throughout their treatment.

In general, school functioning scores steadily increased over time across diagnostic groups. However, children with osteosarcoma reported the lowest school HRQOL scores across all diagnostic groups at T1 and T3. Only two groups, Hodgkin lymphoma and osteosarcoma, reported a significant increase in school functioning at the end of treatment (T4) in comparison to the beginning of treatment (T1). School functioning has been identified as a significant factor that affects HRQOL in children 
with cancer. School attendance was correlated with higher HRQOL in children undergoing cancer treatment. ${ }^{57}$ Children undergoing curative cancer treatment, however, may find it difficult to maintain a regular attendance at school, which may explain the low school functioning scores. Hospital-based schooling programs may offer help for children to keep pace with their healthy peers at home, but such programs can be argued to support the social functioning domain rather than school functioning considering the wording of school functioning items on the PedsQL-Generic scales. Items related to school functioning in this scale include statements as "I miss school because of not feeling well" and "I miss school to go to the doctor or hospital". Such items do not identify hospital-based schooling as a viable alternative to school and may thus lead to the lower school functioning scores as children do not identify their attendance at a hospital-based school program as a viable alternative to regular schooling.

Since cancer-related symptoms at the beginning of treatment were collected from only children with ALL and osteosarcoma, we should take care about drawing conclusions on the cancer-related symptom scores at the beginning of treatment.

However, because most diagnostic groups generally report similar trends of change in cancer-related symptoms over the remaining time points, it is possible to draw inferences from the information on the two groups in regard to symptom scores. In general, the children in all diagnostic groups reported gradually increasing scores for cancer-related symptoms, with varying degrees of improvement at the end of treatment in comparison to the beginning of treatment for different diagnostic groups. This observation implies HRQOL trends at the beginning of treatment (T1) in the groups that did not report symptoms at T1 (i.e., Hodgkin lymphoma, AML, melanoma) that are relatively similar to the groups that did report symptoms (i.e., ALL, osteosarcoma).

Pain and hurt was one of the most problematic cancer-related symptoms at the beginning of treatment and only three disease groups (AML, Hodgkin lymphoma, and osteosarcoma) reported significant improvement in pain and hurt scores. Children with melanoma and ALL reported no significant changes in pain and hurt scores at the end of treatment (T4) in comparison to the beginning of treatment. Children with ALL reported consistently low (poorer) pain and hurt scores that did not improve through their treatment, which also indicates substantial pain that is not relieved in children with ALL. The osteosarcoma group experienced the most significant improvement on pain and hurt scores following $\mathrm{T} 1$ before surgery, experienced a worsening in pain and hurt following surgery at $\mathrm{T} 3$, then improved at $\mathrm{T} 4$. This is likely a result of the improvement in pain and hurt following recovery from surgery after T3. However, even at the end of treatment (T4), children with osteosarcoma reported the second to lowest pain and hurt scores, indicating that while there was a substantial improvement, children with osteosarcoma experienced substantial pain even at the end of treatment (T4). Pain and hurt symptoms are widely reported and measured in children with cancer. ${ }^{82,85-87}$ The correlation of pain and HRQOL in children with cancer have also been identified previously. ${ }^{85}$ This study, however, adds new understanding to the variation in pain and hurt symptoms across different diagnostic groups and helps to identify groups with more severe pain symptoms, namely children with osteosarcoma and children with ALL. It also identifies other groups 
that may experience less pain symptoms, allowing researchers to identify target diagnostic groups for future intervention research.

The lowest symptom scores reported over time and across diagnostic groups were related to nausea. Nausea was also a symptom that significantly improved at the end of treatment (T4) in comparison to the beginning of treatment (T1) in all diagnostic groups except for children with ALL. In children with ALL, nausea decreases significantly at T2 but did not recover to the baseline score at $\mathrm{T} 1$ even at the end of treatment (T4). While the experience of nausea and vomiting early in treatment is directly related to chemotherapy, the complaint of nausea even at the end of treatment in children with ALL and osteosarcoma can be explained by the experience of anticipatory nausea and vomiting. Anticipatory nausea and vomiting is a commonly studied phenomenon in adult cancers. ${ }^{88,89}$ Recently, more attention to this phenomenon in the field of pediatric oncology led to a set of guidelines to the management of anticipatory nausea and vomiting in children with cancer. ${ }^{90}$ However, little information is available on the prevalence and significance of this issue in children with cancer. Our study helps to identify a potential target population of children with ALL to measure this phenomenon and to design and implement future interventions to control anticipatory nausea and vomiting in children with cancer.

Procedural anxiety continuously improved over time in all diagnostic groups except for children with melanoma. In addition, all diagnostic groups except for children with melanoma reported a significant improvement (fewer problems) in their procedural anxiety scores at the end of treatment (T4) in comparison to the beginning of treatment (T1). Children with melanoma presented with a different trend than the other diagnostic groups included in this study. They reported a non-significant worsening (decreased scores) in their procedural anxiety scores at the end of treatment (T4) in comparison to the first time reported (T2). Children with melanoma also report more procedural anxiety at the end of treatment (T4) across all diagnostic groups. This particular trend in children with melanoma may require further examination into aspects of their treatment that may result in more procedural anxiety even towards the end of their treatment.

Treatment anxiety on the PedsQL-Cancer module was a reflection of three items: 'I get scared when I'm waiting to see the doctor', 'I get scared when I have to go to the doctor', and 'I get scared when I have to go to the hospital'. In general, children across all groups reported high scores (fewer problems) on this symptom. However, only 2 groups reported a significant improvement in treatment anxiety at the end of treatment (T4) in comparison to the beginning of treatment, namely children with ALL and children with osteosarcoma. However, this significance may be due to the availability of an additional time-point at the beginning of treatment for these two groups while other groups had no report on these symptoms at the same time-point. Additionally, across all diagnostic groups and all time points, children with osteosarcoma reported the lowest treatment anxiety scores, indicating more problems, at the beginning of treatment (T1). This observation may again be related to the significant effects of surgery on children with osteosarcoma early in treatment. Treatment anxiety has been previously reported as a factor affecting HRQOL in children with cancer, ${ }^{91}$ especially in adolescents. ${ }^{92}$ This 
relationship of treatment anxiety with the adolescent age groups may explain the low treatment anxiety scores in children with osteosarcoma and Hodgkin lymphoma, two groups that tend to have a higher percentage of adolescents.

Cancer worry scores were lowest, indicating higher symptom burden, across diagnostic groups and over time in children with osteosarcoma at the beginning of treatment (T1). However, cancer worry scores improved in all diagnostic groups overall and significantly at the end of treatment (T4) in children with ALL, Hodgkin lymphoma, and osteosarcoma. Furthermore, cancer worry scores in children with osteosarcoma improved significantly at $\mathrm{T} 2$ in comparison to $\mathrm{T} 1$, indicating that the decreased cancer worry score at the beginning of treatment (T1) may be also related to the acute surgical resection that children with osteosarcoma undergo early in treatment.

Cognitive problems were stable over time except in children with Hodgkin lymphoma and osteosarcoma, where these outcomes improved significantly. The significant improvement in cognitive problems in children with Hodgkin lymphoma can be attributed to the effects of radiotherapy early in treatment. However, in all diagnostic groups, changes in cognitive problem scores were limited to a range of 5 points, a relatively narrow range in comparison to other symptoms measured in this study. This finding may be related to the long term nature of treatment effects on cognition and impact on children undergoing curative cancer treatment. It also may be a reflection of the continuous hospitalization of children that may lead to delayed assessment and recognition of cognitive problems outside of a school setting.

Perceived physical appearance was also a relatively stable domain that reflected continuous improvement over time, with the exception of children with melanoma who reported a non-significant decrease (worse symptoms) in these scores at the end of treatment (T4). This particular observation in children with melanoma may reflect a significant impact of treatments that may encompass issues beyond the domain of perceived physical appearance. It also calls for more research into this important trend in this group. Body image and perceived physical appearance have been previously identified as areas of concern in children with cancer, specifically in adolescents. ${ }^{93,94}$ Our study identified similar patterns of lower perceived physical appearance scores in adolescents and females. It also identifies children with melanoma, mainly composed of adolescents, as a group that may require further intervention and research into the perceived body image and physical appearance during and following treatment. We found no previous studies that attempted to measure and identify issues related to HRQOL or physical appearance in children with melanoma. This trend can be also related to the lower sample size which may result in inconsistent patterns of HRQOL change in children with melanoma.

Communication was also a relatively high and generally stable domain over time and across diagnostic groups. A significant increase in communication scores at the end of treatment (T4) in comparison to the beginning of treatment was found in children with ALL, Hodgkin lymphoma, and osteosarcoma. As was the case with other domains, the poorest communication scores across diagnostic groups and over time was for children 
with osteosarcoma at the beginning of treatment (T1). This consistent trend of poorer scores for children with osteosarcoma at T1 may reflect the significant impact that a major surgical procedure has on HRQOL aspects and domains that extend beyond the physical functioning domain.

\begin{abstract}
$\operatorname{Aim} 3$
Aim 3 was to identify correlates with HRQOL of children undergoing curative cancer treatment over time within each diagnostic group.

Consistent with our theoretical framework, multiple factors were identified as affecting the HRQOL in children across diagnostic groups and over time in treatment. These factors included time, diagnosis, age, gender, race, risk group, and surgery. Our study identified children who are females, non-white, older, on higher risk treatment, and early in treatment as the most vulnerable for lower HRQOL during treatment. The identification of vulnerable groups who are at most risk for poor HRQOL can help guide development of interventions targeting these population groups at an ideal time in treatment to achieve the highest potential benefit.
\end{abstract}

\title{
Cancer Factors
}

Factors associated with HRQOL were most often related to cancer diagnosis and cancer treatment. However, our review of literature found half the studies that measured cancer diagnoses found no effect on HRQOL, while the remaining studies varied widely in identifying specific diagnostic groups correlated with lower HRQOL. Some studies identified children with ALL as having a lower HRQOL while others linked solid tumors $^{13}$ and osteosarcoma with the lowest HRQOL. ${ }^{15}$ This variation among studies is most likely attributed to lower sample sizes and different collection times in these studies. Our study specifically identified children in the osteosarcoma diagnostic group as reporting lower HRQOL.

Cancer risk group or disease stage has been previously explored to identify treatment groups' lower HRQOL. ${ }^{13}$ Patients assigned to higher risk groups have been associated with higher intensity treatments and poorer outcomes, which correlates with a lower HRQOL. Thus, cancer risk group is a known factor that affects HRQOL in children with cancer. This study identified diagnostic groups in which assigned higher risk groups were correlated with lower HRQOL, namely, children with ALL and HL. While our study found risk group to be an important determinant of HRQOL in children with cancer, our review found only one study that identified a significantly negative effect of risk on HRQOL. ${ }^{50}$ 


\section{Treatment Factors}

Type of Treatment. No differences were found in HRQOL for surgical versus radiotherapy treatment. These findings are likely related to the small number of patients within our sample who received these treatments. Only children treated for OS had a surgical procedure and only children with HL received radiotherapy. In our review, the majority of studies that assessed the effect of treatment type measured HRQOL in a single diagnostic group, making it difficult to draw comparisons of the effect of treatment type on a heterogeneous sample of children with cancer. In general, radiotherapy was found to be the most common treatment affecting HRQOL in children ${ }^{7,53,95}$ and was exclusively measured in children with brain tumors. However, in our sample of children with HL there was no difference in HRQOL reported by those who received radiotherapy compared to those who did not. Radiotherapy for children with HL is widely varied based on the location and extent of disease. This variation in radiotherapy dose and location may result in less than definitive findings on the effect of radiotherapy on HRQOL in our sample. While our univariate analysis found children who received surgery reported lower HRQOL than children who did not receive any surgery, this finding did not hold up in the multivariate analysis and is further complicated by the fact that only the OS diagnostic group received surgical treatment.

Time in Treatment. Time is perhaps one of the least understood factors affecting HRQOL in children undergoing curative cancer treatment. Most studies in our review assessed HRQOL in a cross-sectional manner at varying time points, making it difficult to draw conclusions on the change in HRQOL over time. ${ }^{39,40,50}$ For example, some researchers measured HRQOL at the time of diagnosis ${ }^{15,16}$ whereas others chose a time point that was important for the particular diagnostic group under study. ${ }^{46,50,56}$ The variability in treatment modality, intensity, and timing among diagnostic groups also makes it difficult to draw comparisons or make assumptions regarding HRQOL across diagnoses. Our findings point to the importance of time in treatment as a significant variable affecting HRQOL in children undergoing curative cancer treatment and to the dynamic nature of HRQOL, calling for the need to likewise monitor HRQOL in a dynamic fashion whether in clinical settings or research trials. The results of our study further emphasize the need for future research that targets the most vulnerable populations at the time of their lowest HRQOL; which as our study found, differs for HRQOL domains, cancer-related symptoms, and by diagnostic group. The identification of these time-points may allow researcher to implement interventions at ideal time-points to achieve the highest potential benefit.

While we believe a large degree of the variation in HRQOL over time can be explained by the symptom experience of children, other factors should be considered and evaluated in future studies. These factors include the qualitative experiences of children throughout their cancer experience, including domains that address the meaning of illness and cancer worry. These domains may prove to have a significant effect on the HRQOL in children later in treatment as they, their families, and their clinical care providers learn how to manage their symptoms and develop different perspectives of the cancer experience based on their unique experiences and the growth they underwent during this 
experience. ${ }^{96}$ These domains form a framework that can help researchers understand the changing trajectory of HRQOL in children with cancer which would also benefit from the use of qualitative approaches that would enable deeper exploration of the children's views of themselves and their lives in the context of the cancer illness experience.

\section{Symptoms}

Symptoms of cancer and cancer treatment have been recognized as driving the cancer treatment experience. ${ }^{97,98}$ This association was also reported in our study. Symptoms captured through the PedsQL-Cancer module demonstrate the degree to which children's HRQOL experience is influenced throughout their cancer treatment. Nausea, pain, and painful procedures (procedural anxiety) were the most problematic symptoms across most diagnostic groups. These symptom experiences are generally related to the physical aspects of cancer treatment. These experiences were also reflected on the PedsQL-Generic module, where the physical domain was the worst domain of HRQOL.

Nausea has been constantly reported as an important factor affecting the wellbeing and HRQOL in children under cancer treatment for more than 2 decades of research on cancer symptoms in children. ${ }^{88,97}$ Nausea was specifically a troubling symptom for our study. In most diagnostic groups in our study, nausea symptom scores decreased significantly, indicating worse symptoms, during treatment and in some diagnostic groups did not recover to baseline scores at the end of treatment. This particularly troubling symptom for children undergoing cancer treatment may require innovative and timely interventions that extend beyond the scope of pharmaceutical interventions. ${ }^{90}$ Explanations of this finding include anticipatory nausea and vomiting, and non-compliance with nausea and vomiting treatment regimens. However, this particular symptom requires more attention from clinicians and researchers to identify possible cause and interventions to alleviate this experience in children undergoing curative cancer treatment.

\section{Child Factors}

Age was identified as a significant factor affecting HRQOL in our study. This finding is in contrast to many HRQOL studies that were identified in our literature review. Of the 16 studies that analyzed age in our review, 5 found lower HRQOL in adolescents (ages 13-18) compared to children (ages 5-12), an observation that was supported in our study. However, our study found variability in patient reported HRQOL across domains and symptoms according to age. Adolescents reported significantly lower HRQOL scores, except for social functioning and procedural anxiety, while children (ages 5-12) reported significantly lower scores on those domains. The variable effect age has on HRQOL makes it imperative that that this important factor be considered in studies examining HRQL in children undergoing cancer treatment. 
Our study also identified significant differences between gender and patient reported HRQOL. Females reported significantly lower HRQOL than males across all diagnostic groups. While gender was a strong predictor of HRQOL in our study and is widely reported in HRQOL literature, only one quarter of studies in our review that measured gender identified this variable as a determinant of HRQOL in children with cancer.

Ethnicity was significant in the ALL and OS diagnostic groups and only in the univariate analysis for the emotional and social domains. These findings should take into consideration the high ratio of white patients in comparison to other ethnic groups in our study. This trend seems to be consistent with our review of studies on HRQOL in children under curative cancer treatment; ${ }^{7,39,45}$ of which only one identified race as a significant factor affecting HRQOL in children with cancer. ${ }^{45}$ Figure 5-1 presents a modified theoretical framework that incorporates the results of our findings. In this framework, race was the only factor that was not supported by our study findings.

\section{Recommendations and Implications}

The findings from our study pose practical, theoretical, policy, and research implications on the field of HRQOL research in children with cancer.

\section{Research Implications}

This study provided evidence on the dynamic nature of HRQOL change in children undergoing curative cancer treatment. However, further research is needed into the impact of particular treatment modalities that were not supported by our study. While radiation therapy has been identified as an important factor affecting HRQOL in children with cancer, our study did not find a significant impact of radiation on the HRQOL of our sample. This may have been due to methodological and sample size considerations. The findings from this study also justify the need to devise and implement effective interventions to control and manage troublesome symptoms in children with cancer.

\section{Practice Implications}

A significant finding from our study was the identification of nausea as the most troublesome symptom in children undergoing curative treatment for cancer. This stands in contrast to clinical perceptions of nausea control using anti-emetic medications. Our study suggests that the subjective experience of nausea is not controlled despite the rigorous use of anti-emetics in pediatric oncology, or that protocols to address nausea and vomiting in children with cancer are not effectively implemented or followed. It also suggests that anti-emetic drugs are more effective in controlling the objective experience of vomiting, while playing a lesser role in controlling the subjective experience of nausea. This gap between clinicians' perceptions of nausea control using anti-emetics and 


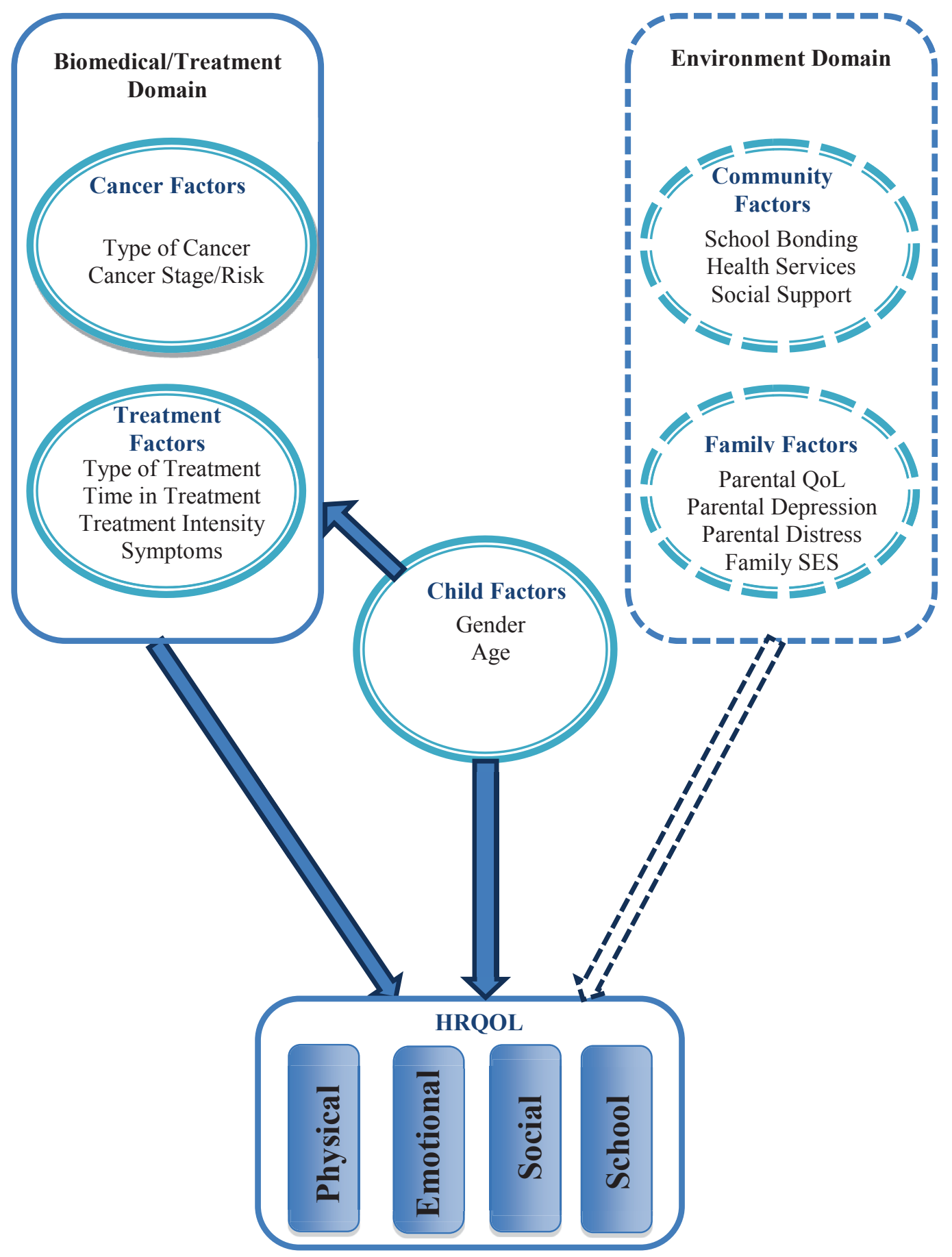

Figure 5-1. Modified conceptual model of HRQOL in children with cancer 
children's perception of continuous nausea symptoms require an effort from researchers to identify effective interventions to control nausea. It also calls for educating clinicians on the need to use integrative therapies that can effectively control nausea in children in addition to the routine use of anti-emetics. Our review criteria for interventions to improve HRQOL did not identify interventions that may help alleviate nausea in children with cancer. However, older studies and literature from adult oncology have identified possible interventions to help alleviate nausea that may be applicable for children with cancer. These interventions include behavioral, non-pharmacologic, and other supportive measures intended to decrease the effect of nausea on children with cancer. ${ }^{99-103}$

The findings of this study also support the need for a dynamic collection process of HRQOL in children undergoing curative cancer treatments. Our study identified the longitudinal nature of HRQOL outcomes over time in children with cancer. This finding supports the need for a dynamic process of HRQOL data collection that ensures prompt action from clinicians in response to HRQOL problems that may arise in children while undergoing cancer treatments. Many issues still impede a dynamic process of collecting, and promptly managing HRQOL issues and symptoms in children with cancer. These issues include the practicality and feasibility of collecting data during or prior to patients visits, the identification of significantly low HRQOL scores, and the integration of HRQOL outcomes into the medical record of patients. The current design of most HRQOL instruments in children with cancer requires researchers to go through multiple steps to generate a score for a child. These steps include reverse scoring the items and generating an average score for each domain separately in addition to a total average, and finally comparing the collected HRQOL scores to previous HRQOL reports to identify significant changes. Such lengthy process is time-prohibitive for clinicians, and poses a barrier to wider use of HRQOL outcomes in clinical decision making. Multiple steps have been proposed and implemented in order to address the prompt collection and reporting of HRQOL data. These steps include the use of electronic data collection methods (tablets, smart phones, computer portals). The use of such electronic data collection methods allow for the prompt collection of HRQOL, the comparison of HRQOL data collected to previous data reported by the same patient, and the prompt notification of any significant changes in HRQOL to the clinician before meeting the patient. This would allow for prompt interventions by clinicians to address problems in HRQOL.

Pain and hurt is another important symptom that was correlated with lower HRQOL and an important factor to be controlled for in these children. Related to the experience of pain was the experience of procedural anxiety. Many interventions can be introduced to alleviate the effects of painful procedures and as a result lead to better HRQOL for children undergoing cancer treatment. Such interventions include creative imagery, relaxation, and cognitive behavioral training. ${ }^{97,100,104}$ This study helps identify critical times in children's treatment trajectory, early at the beginning of treatment and during periods of intensified treatments, where such interventions may prove to be helpful and effective in controlling cancer pain. 
This study also identified low scores (more problems) of procedural anxiety in children (ages 5-12) with cancer. This finding calls for clinicians to take a more active role in better management and communication regarding painful and intensive procedures not just with the family, but also with children themselves.

Future interventions by clinicians and researchers may be crucial to improve HRQOL outcomes in children with cancer. The identification of the persistent nausea and pain and hurt, in addition to procedural anxiety in children (ages 5-12) provide further evidence to support the need for more extensive and targeted interventions to address these symptoms in clinical settings and to communicate with patients regarding the expectations from these experiences. It can also help guide development of specific interventions to improve HRQOL at specific time points during treatment for specific diagnostic groups. Such targeted interventions would yield the highest impact on HRQOL for each respective diagnostic group.

\section{Theoretical Implications}

Our conceptual framework was sufficient to identify the factors that are important for HRQOL in children with cancer. In this study, we have presented child factors as a separate domain of HRQOL in children with cancer, including gender and age. The findings from our study support the notion of designating child factors as a separate domain that affects HRQOL in a moderating capacity. The findings from this study also support the future use of our conceptual model in HRQOL research in children with cancer and possibly other chronic conditions as well.

\section{Policy Implications}

This study also presents the need for institutional policies to collect HRQOL outcomes as an important measure of the illness experience of children undergoing curative cancer treatment, and the need for a dynamic data collection policies that ensures children report their HRQOL consistently over time throughout their treatment, and that these outcomes are considered in the clinical decision making process.

These policies can be achieved through institutional commitment and with the help of modern technological advances to collect HRQOL data and other patient-reported outcomes during routine clinic visits. It also may include policies to encourage clinicians to discuss HRQOL outcomes during clinic visits and devise plans to control these outcomes. Furthermore, effective institutional policies to manage and control subjective experiences like nausea, pain and hurt, and procedural anxiety are needed to improve children's HRQOL. 


\section{Limitations}

Results of our study should be considered in the context of several factors that may limit their validity. These limitations include methodological, measurement, and conceptual aspects surrounding the conduct of the study.

\section{Methodological Limitations}

An important limitation was related to the utilization of multiple treatment modalities and intensities used to treat diagnostic groups and even within the same diagnostic groups for different risk stages. The wide variation of treatments and intensities may have affected the comparisons between diagnostic groups in this study. In addition, the variations in durations of treatment regimens across diagnostic groups, ranging from few months to few years, may have affected studying findings. The combination of varying treatments and duration of treatments presented a significant impediment to quantifying and comparing the change in HRQOL over time within and across diagnostic groups as well as the trajectories of HRQOL over time. As a result, it may be difficult, within the boundaries of our study, to distinguish between the effects of treatment factors, and the effect of diagnosis on HRQOL.

Additional methodological issues including the attrition of subjects as they progressed through treatment, or as they were lost to follow-up may also have affected our understanding of the change in HRQOL during the trajectory of treatment. ${ }^{24,105}$ Based on our experience, a considerable fraction of this attrition is due to disease relapse or progression. Thus, the results of HRQOL data at the end of treatment may best reflect the experience of healthier and better responding patients who were able to successfully complete treatment on their primary regimen.

"Response shift" or the changing standard for HRQOL that is believed to often occur when individuals are faced with life-threatening conditions is another factor that may have influenced our study findings. Although design and statistical approaches exist to control for this issue, ${ }^{106}$ these approaches would have been beyond the scope of the current study.

Response set by the child may have also affected our results, meaning that young children tend to respond in a consistent way, regardless of the question. ${ }^{107}$ This can include responding with the intent to please the interviewer, or answering questions they do not understand in order to appear competent. Some children also show a tendency to provide repetitive responses, or to report extreme responses to questionnaires, especially in measurement scales that use the same scaling system for all items. ${ }^{108}$ This study involved previously collected data, which did not allow us to address these address these methodological issues. However, the data were originally collected by experienced research nurses trained to recognize common child response sets and guide the child and parent to carefully examine their responses to avoid such patterns. 
A final confounding methodological issue was related to the optional participation in this study. This could have resulted in loss of patients who were experiencing lower HRQOL than their peers who agreed to participate. However, data indicated that most patients who were eligible to participate in the study did in fact consent and participate. The study did not include any invasive measures and posed no potential harm to the patients.

\section{Measurement Limitations}

HRQOL instruments are categorized as generic, disease-specific, or modular. Generic measures allow for comparisons between different groups of children, such as between children with cancer and children in the general population. Usually, population norms are available to facilitate the interpretation of results. These measures are generalizable, but may not adequately address symptoms important to patients with cancer, and may not be responsive to disease-specific interventions. In contrast, diseasespecific tools are more likely to be responsive to disease-related changes in HRQOL but do not facilitate comparisons between children with and without cancer. Several instruments have been developed and proposed for assessing HRQOL in children with cancer. $^{66,71,72,109,110}$ Our study utilized the most frequently used generic and cancerspecific instrument in childhood cancer studies. However, these instruments as with all other HRQOL instruments fail to measure many domains that affect HRQOL in particular diagnostic groups or for particular types of treatments. ${ }^{111,112}$ While we tried to achieve a better measurement of HRQOL in our sample by using both generic and cancer-specific modules, the variation in disease status and treatment modalities makes it difficult to draw conclusions on the differences between diagnostic groups of childhood cancer, or between children with cancer and the normal population of children. ${ }^{105,113}$ Additionally, there is a lack of consistency and number of domains included in different instruments. ${ }^{24,66,114}$ These limitations can lead to questioning the relevancy of the final outcome measures to the actual HRQOL of patients; ${ }^{115}$ thus, presenting a challenge to our interpretations of the data and comparisons between disease groups. This limitation may be of importance to one particular group in our study, children with melanoma. Children with melanoma are treated with novel treatments that result in symptoms of skin scarring and malformation, which may have attributed to their decreasing perceived physical appearance scores over time. Children with cancer commonly experience symptoms that are not assessed by the HRQOL measures used in this research. This may have resulted in an incomplete picture of symptoms, symptom burden, and other aspects of the cancer experience that can affect HRQOL in children with cancer.

\section{Conceptual Limitations}

An important limitation to our understanding of HRQOL lies in the lack of a consensus on a conceptual framework to guide the understanding and study. ${ }^{24}$ This is an issue that can explain the wide variation in items and domains that are included in HRQOL scales. This lack of conceptual clarity which may have affected the validity of 
findings could be explained in part by the differences in defining HRQOL, as an expression of functional abilities and performance, ${ }^{116}$ or as a measure of values and preferences, ${ }^{22,112,117}$ with more studies in the field of childhood cancer approaching it as a

function of perception. ${ }^{66}$ While many models have been proposed for HRQOL in the adult oncology population, a literature search provided no evidence of a HRQOL model in the childhood cancer population. This study has attempted to design and utilize a conceptual model that adapts adult and pediatric frameworks while maintaining the emphasis on the perception of the child as a force that largely affects the final outcome of HRQOL in children with cancer. This conceptual framework was built to be compatible with the instruments that have been used in to monitor HRQOL in this clinical population. We believe that our revised conceptual framework was successful in identifying relevant factors of HRQOL in children with cancer and should be incorporated by researchers to address the conceptual and theoretical limitations of HRQOL research.

\section{Conclusion}

HRQOL is a dynamic phenomenon that requires close attention by the research and the clinical care community. Close, long-term follow-up and longitudinal research are needed to monitor the trends and changes that new treatment modalities and regimens offer to the general illness experience of children with cancer. This will allow clinicians and researchers to provide timely and effective interventions to address and improve HRQOL issues and symptoms in children undergoing curative cancer treatment. 


\section{LIST OF REFERENCES}

1. Hinds PS. Advances in defining, conceptualizing, and measuring quality of life in pediatric patients with cancer. Oncology Nursing Forum. 2006;33:23-29.

2. Bradlyn AS, Ritchey AK, Harris CV, et al. Quality of life research in pediatric oncology: Research methods and barriers. Cancer. 1996;78(6):1333-1339.

3. Hinds P. Quality of life in children and adolescents with cancer. Seminars in Oncology Nursing. 1990;6(4):285-291.

4. Moons P, Budts W, De Geest S. Critique on the conceptualisation of quality of life: A review and evaluation of different conceptual approaches. International Journal of Nursing Studies. 2006;43(7):891-901.

5. Wilson IB, Cleary PD. Linking clinical variables with health-related quality of life: A conceptual model of patient outcomes. JAMA: The Journal of the American Medical Association. 1995;273(1):59-65.

6. Ferrans CE, Zerwic JJ, Wilbur JE, Larson JL. Conceptual model of health-related quality of life. Journal of Nursing Scholarship. 2005;37(4):336-342.

7. Kuhlthau KA, Pulsifer MB, Yeap BY, et al. Prospective study of health-related quality of life for children with brain tumors treated with proton radiotherapy. Journal of Clinical Oncology. 2012;30(17):2079-2086.

8. Landolt MA, Vollrath M, Niggli FK, Gnehm HE, Sennhauser FH. Health-related quality of life in children with newly diagnosed cancer: A one year follow-up study. Health and Quality of Life Outcomes. 2006;4(1):63.

9. Sitaresmi MN, Mostert S, Gundy CM, Sutaryo, Veerman AJ. Health-related quality of life assessment in Indonesian childhood acute lymphoblastic leukemia. Health \& Quality of Life Outcomes. 2008;6:96.

10. Zeltzer LK, Lu Q, Leisenring W, et al. Psychosocial outcomes and health-related quality of life in adult childhood cancer survivors: A report from the childhood cancer survivor study. Cancer Epidemioligy Biomarkers Prevention. 2008;17(2):435-446.

11. American Cancer Society. Cancer facts \& figures 2012. Atlanta, GA: American Cancer Society; 2012. 
12. Oeffinger KC, Mertens AC, Sklar CA, et al. Chronic health conditions in adult survivors of childhood cancer. New England Journal of Medicine. 2006;355(15):1572-1582.

13. Sung L, Klaassen RJ, Dix D, et al. Identification of paediatric cancer patients with poor quality of life. British Journal of Cancer. 2009;100(1):82-88.

14. Klassen A, Anthony S, Khan A, Sung L, Klaassen R. Identifying determinants of quality of life of children with cancer and childhood cancer survivors: A systematic review. Supportive Care in Cancer. 2011;19(9):1275-1287

15. Hinds PS, Billups CA, Cao X, et al. Health-related quality of life in adolescents at the time of diagnosis with osteosarcoma or acute myeloid leukemia. European Journal of Oncology Nursing. 2009;13(3):156-163

16. Eiser C, Eiser JR, Stride CB. Quality of life in children newly diagnosed with cancer and their mothers. Health \& Quality of Life Outcomes. 2005;3:29.

17. Halyard MY, Ferrans CE. Quality-of-life assessment for routine oncology clinical practice. Journal of Supportive Oncology. 2008;6(5):221-229, 233.

18. Varricchio CG, Ferrans CE. Quality of life assessments in clinical practice. Seminars in Oncology Nursing. 2010;26(1):12-17.

19. Montazeri A, Milroy R, Hole D, McEwen J, Gillis CR. Quality of life in lung cancer patients: As an important prognostic factor. Lung Cancer. 2001;31(2):233-240.

20. Trask PC, Hsu M-A, McQuellon R. Other paradigms: Health-related quality of life as a measure in cancer treatment. The Cancer Journal. 2009;15(5):435-440.

21. Geest SD, Moons P. The patient's appraisal of side-effects: The blind spot in quality-of-life assessments in transplant recipients. Nephrology Dialysis Transplantation. 2000;15(4):457-459.

22. Cantrell M. Health-related quality of life in childhood cancer: State of the science. Oncology Nursing Forum. 2007;34(1):103-111.

23. Testa MA, Simonson DC. Assessment of quality-of-life outcomes. New England Journal of Medicine. 1996;334(13):835-840.

24. Hinds PS. Progress in quality of life in children and adolescents with cancer. Seminars in Oncology Nursing. 2010;26(1):18-25.

25. Parsons S, Fairclough D, Wang J, Hinds P. Comparing longitudinal assessments of quality of life by patient and parent in newly diagnosed children with cancer: The value of both raters' perspectives. Quality of Life Research . 2012;21(5):915-923. 
26. Kazak AE, DeRosa BW, Schwartz LA, et al. Psychological outcomes and health beliefs in adolescent and young adult survivors of childhood cancer and controls. Journal of Clinical Oncology. 2010;28(12):2002-2007.

27. Eiser C, Morse R. The measurement of quality of life in children: Past and future perspectives. Journal of Developmental \& Behavioral Pediatrics. 2001;22(4).

28. Inaba H, Greaves M, Mullighan CG. Acute lymphoblastic leukaemia. The Lancet. 1;381(9881):1943-1955.

29. Pui C-H. Acute Lymphoblastic Leukemia. In: Schwab M, ed. Encyclopedia of Cancer. Vol Springer Berlin Heidelberg; 2012:23-26.

30. Rubnitz JE, Gibson B, Smith FO. Acute myeloid leukemia. Hematology/Oncology Clinics of North America. 2010;24(1):35-63.

31. Wong JR, Harris JK, Rodriguez-Galindo C, Johnson KJ. Incidence of childhood and adolescent melanoma in the United States: 1973-2009. Pediatrics. 2013;131(5):846-854.

32. Jen M, Murphy M, Grant-Kels JM. Childhood melanoma. Clinics in Dermatology. 2009;27(6):529-536.

33. Paradela S, Fonseca E, Pita-Fernández S, et al. Prognostic factors for melanoma in children and adolescents. Cancer. 2010;116(18):4334-4344.

34. Ottaviani G, Jaffe N. The epidemiology of osteosarcoma. In: Jaffe N, Bruland OS, Bielack S, eds. Pediatric and Adolescent Osteosarcoma. Vol Cancer Treatment and Research. Springer US; 2010:3-13.

35. Ottaviani G, Jaffe N. The etiology of osteosarcoma. In: Jaffe N, Bruland OS, Bielack S, eds. Pediatric and Adolescent Osteosarcoma. Vol Cancer Treatment and Research. Springer US; 2010:15-32.

36. Yasko AW. Surgical Management of Primary Osteosarcoma. In: Jaffe N, Bruland OS, Bielack S, eds. Pediatric and Adolescent Osteosarcoma. Vol Cancer Treatment and Research. Springer US; 2010:125-145.

37. Jaffe N. Adjuvant chemotherapy in osteosarcoma. In: Jaffe N, Bruland OS, Bielack S, eds. Pediatric and Adolescent Osteosarcoma. Vol Cancer Treatment and Research. Springer US; 2010:219-237. 
38. Schwarz R, Bruland O, Cassoni A, Schomberg P, Bielack S. The role of radiotherapy in oseosarcoma. In: Jaffe N, Bruland OS, Bielack S, eds. Pediatric and Adolescent Osteosarcoma. Vol Cancer Treatment and Research. Springer US; 2010:147-164.

39. Baggott CR, Dodd M, Kennedy C, et al. An evaluation of the factors that affect the health-related quality of life of children following myelosuppressive chemotherapy. Support Care Cancer. 2011;19(3):353-361.

40. Barakat LP, Marmer PL, Schwartz LA. Quality of life of adolescents with cancer: Family risks and resources. Health and Quality of Life Outcomes. 2010;8:63.

41. Erickson JM, Beck SL, Christian BR, et al. Fatigue, sleep-wake disturbances, and quality of life in adolescents receiving chemotherapy. Journal of Pediatric Hematology/Oncology. 2011;33(1):e17-e25.

42. Hullmann S, Wolfe-Christensen C, Meyer W, McNall-Knapp R, Mullins L. The relationship between parental overprotection and health-related quality of life in pediatric cancer: The mediating role of perceived child vulnerability. Quality of Life Research. 2010;19(9):1373-1380.

43. Pek JH, Chan YH, Yeoh AE, Quah TC, Tan PL, Aung L. Health-related quality of life in children with cancer undergoing treatment: A first look at the Singapore experience. Annals of the Academy of Medicine Singapore. 2010;39(1):43-48.

44. Sandeberg M af, Johansson EM, Hagell P, Wettergren L. Psychometric properties of the DISABKIDS Chronic Generic Module (DCGM-37) when used in children undergoing treatment for cancer. Health and Quality of Life Outcomes. 2010;8:109.

45. Shankar S, Robison L, Jenney MEM, et al. Health-related quality of life in young survivors of childhood cancer using the minneapolis-manchester quality of lifeyouth form. Pediatrics. 2005;115(2):435-442.

46. Tremolada M, Bonichini S, Altoè G, Pillon M, Carli M, Weisner T. Parental perceptions of health-related quality of life in children with leukemia in the second week after the diagnosis: A quantitative model. Supportive Care in Cancer. 2011;19(5):591-598.

47. Zareifar S, Farahmandfar MR, Cohan N, Modarresnia F, Haghpanah S. Evaluation of health related quality of life in 6-18 years old patients with acute leukemia during chemotherapy. Indian Journal of Pediatrics. 2012;79(2):177-182

48. Hinds PS, Gattuso JS, Billups CA, et al. Aggressive treatment of non-metastatic osteosarcoma improves health-related quality of life in children and adolescents. European Journal of Cancer. 2009;45(11):2007-2014. 
49. Penn A, Lowis SP, Hunt LP, et al. Health related quality of life in the first year after diagnosis in children with brain tumours compared with matched healthy controls: A prospective longitudinal study. European Journal of Cancer. 2008;44(9):12431252.

50. de Vries MA, van Litsenburg RR, Huisman J, et al. Effect of dexamethasone on quality of life in children with acute lymphoblastic leukaemia: A prospective observational study. Health and Quality of Life Outcomes. 2008;6:103.

51. Akahane T, Shimizu T, Isobe K, Yoshimura Y, Fujioka F, Kato H. Evaluation of postoperative general quality of life for patients with osteosarcoma around the knee joint. Journal of Pediatric Orthopaedics B July 2007. 2007;16(4):269-272.

52. Frances JM, Morris CD, Arkader A, Nikolic ZG, Healey JH. What is quality of life in children with bone sarcoma? Clinicial Orthopedic Research. 2007;459:34-39.

53. Houtrow AJ, Yock TI, Delahaye J, Kuhlthau K. The family impacts of proton radiation therapy for children with brain tumors. Journal of Pediatric Oncology Nursing. 2012;29(3):171-179.

54. Hamidah A, Wong C-Y, Tamil AM, Zarina LA, Zulkifli ZS, Jamal R. Healthrelated quality of life (HRQOL) among pediatric leukemia patients in Malaysia. Pediatric Blood \& Cancer. 2011;57(1):105-109. doi:10.1002/pbc.23125.

55. Peeters J, Meitert J, Paulides M, et al. Health-related quality of life (HRQL) in allpatients treated with chemotherapy only: A report from the late effects surveillance system in Germany. Klinische Pädiatrie. 2009;221(3):156-161.

56. Madden JR, Mowry P, Gao D, Cullen PM, Foreman NK. Creative arts therapy improves quality of life for pediatric brain tumor patients receiving outpatient chemotherapy. Journal of Pediatric Oncology Nursing. 2010;27(3):133-145.

57. Sandeberg M af, Johansson E, Björk O, Wettergren L. Health-related quality of life relates to school attendance in children on treatment for cancer. Journal of Pediatric Oncology Nursing. 2008;25(5):265-274. doi:10.1177/1043454208321119.

58. Erickson P. A health outcomes framework for assessing health status and quality of life: Enhanced data for decision making. Journal of the National Cancer Institute Monographs. 2004;2004(33):168-177.

59. Speyer E, Herbinet A, Vuillemin A, Chastagner P, Briançon S. Agreement between children with cancer and their parents in reporting the child's health-related quality of life during a stay at the hospital and at home. Child: Care, Health and Development. 2009;35(4):489-495. 
60. Stevens B, Croxford R, McKeever P, et al. Hospital and home chemotherapy for children with leukemia: A randomized cross-over study. Pediatric Blood \& Cancer. 2006;47(3):285-292.

61. Varni JW, Seid M, Knight TS, Uzark K, Szer IS. The PedsQLTM 4.0 generic core scales: Sensitivity, responsiveness, and impact on clinical decision-making. Journal of Behavioral Medicine. 2002;25(2):175-193.

62. Ewing J, King M, Smith N. Validation of modified forms of the PedsQL generic core scales and cancer module scales for adolescents and young adults (AYA) with cancer or a blood disorder. Quality of Life Research. 2009;18(2):231-244.

63. Palmer SN, Meeske KA, Katz ER, Burwinkle TM, Varni JW. The PedsQL ${ }^{\mathrm{TM}}$ brain tumor module: Initial reliability and validity. Pediatric Blood \& Cancer. 2007;49(3):287-293.

64. Eiser C, Morse R. A review of measures of quality of life for children with chronic illness. Archives of Disease in Childhood. 2001;84(3):205-211.

65. Eiser C, Jenney M. Measuring quality of life. Archives of Disease in Childhood. 2007;92(4):348-350..

66. Klassen A, Strohm S, Maurice-Stam H, Grootenhuis M. Quality of life questionnaires for children with cancer and childhood cancer survivors: A review of the development of available measures. Supportive Care in Cancer. 2010;18(9):1207-1217.

67. Penn A, Lowis SP, Stevens MCG, et al. Family, demographic and illness-related determinants of HRQL in children with brain tumours in the first year after diagnosis. Pediatric Blood \& Cancer. 2009;53(6):1092-1099..

68. Lansky SB, List MA, Lansky LL, Ritter-Sterr C, Miller DR. The measurement of performance in childhood cancer patients. Cancer. 1987;60(7):1651-1656.

69. Smith J, McSherry W. Spirituality and child development: A concept analysis. Journal of Advanced Nursing. 2004;45(3):307-315.

70. Weaver AJ, Flannelly KJ. The role of religion/spirituality for cancer patients and their caregivers. Southern Medical Journal. 2004;97(12).

71. Varni JW, Seid M, Kurtin PS. PedsQL(TM) 4.0: Reliability and validity of the pediatric quality of life inventory version 4.0 generic core scales in healthy and patient populations. Medical Care. 2001;39(8):800-812. 
72. Varni JW, Burwinkle TM, Katz ER, Meeske K, Dickinson P. The PedsQL in pediatric cancer. Cancer. 2002;94(7):2090-2106.

73. Varni JW, Burwinkle TM, Seid M. The PedsQL as a pediatric patient-reported outcome: Reliability and validity of the PedsQL measurement model in 25,000 children. Expert Review of Pharmacoeconomics \& Outcomes Research. 2005;5(6):705-719.

74. Varni JW, Limbers CA. The pediatric quality of life inventory: Measuring pediatric health-related quality of life from the perspective of children and their parents. Pediatric Clinics of North America. 2009;56(4):843-863.

75. Varni JW. Scaling and Scoring of The Pediatric Quality of Life Inventory PedsQL. Mapi Research Trust; 2008. http://www.pedsql.org/PedsQL-Scoring.pdf.

76. Chang P-C, Yeh C-H. Agreement between child self-report and parent proxy-report to evaluate quality of life in children with cancer. Psycho-Oncology. 2005;14(2):125-134.

77. Hulley SB, Cummings SR, Browner WS, Grady DG, Newman TB. Designing Clinical Research. Vol Third. Philadelphia: Lippincott, Williams, and Wilkins; 2007.

78. Polit DF, Hungler BP. Nursing Research: Principles and Methods. Vol sixth. Philadelphia: Lippincott, Williams, and Wilkins; 1999.

79. Stokke J, Sung L, Gupta A, Lindberg A, Rosenberg AR. Systematic review and meta-analysis of objective and subjective quality of life among pediatric, adolescent, and young adult bone tumor survivors. Pediatric Blood \& Cancer. March 2015:n/a n/a. doi:10.1002/pbc.25514.

80. Mason GE, Aung L, Gall S, et al. Quality of life following amputation or limb preservation in patients with lower extremity bone sarcoma. Frontiers in Oncology. $2013 ; 3(210)$.

81. Chandylen L. Nightingale, Gwendolyn P. Quinn, Elizabeth A. Shenkman, et al. Health-related quality of life of young adult survivors of childhood cancer: A review of qualitative studies. Journal of Adolescent and Young Adult Oncology. 2011;1(2):124-132.

82. Hedström M, Haglund K, Skolin I, Essen L von. Distressing events for children and adolescents with cancer: Child, parent, an nurse perceptions. Journal of Pediatric Oncology Nursing. 2003;20(3):120-132. 
83. Smith AW, Bellizzi KM, Keegan THM, et al. Health-related quality of life of adolescent and young adult patients with cancer in the United States: The adolescent and young adult health outcomes and patient experience study. Journal of Clinical Oncology. 2013;31(17):2136-2145.

84. Paxton RJ, Jones LW, Rosoff PM, Bonner M, Ater JL, Demark-Wahnefried W. Associations between leisure-time physical activity and health-related quality of life among adolescent and adult survivors of childhood cancers. Psycho-Oncology. 2010;19(9):997-1003.

85. Calissendorff-Selder M, Ljungman G. Quality of life varies with pain during treatment in adolescents with cancer. Upsala Journal of Medical Sciences. 2006;111(1):109-116.

86. van de Wiel H, Geerts E, Hoekstra-Weebers J. Explaining inconsistent results in cancer quality of life studies: The role of the stress-response system. PsychoOncology. 2008;17(2):174-181.

87. Wolfe J, Dussel V, Neville B, et al. Longitudinal assessment of symptom distress in children with advanced cancer: Report of the first 20 weeks in the pediatric qualityof-life evaluation of symptoms technology (PediQUEST) study. Journal of Pain and Symptom Management. 2011;41(1):187.

88. Morrow GR, Dobkin PL. Anticipatory nausea and vomiting in cancer patients undergoing chemotherapy treatment: Prevalence, etiology, and behavioral interventions. Clinical Psychology Review. 1988;8(5):517-556.

89. Roscoe JA, Morrow GR, Aapro MS, Molassiotis A, Olver I. Anticipatory nausea and vomiting. Supportive Care in Cancer. 2011;19(10):1533-1538.

90. Dupuis LL, Robinson PD, Boodhan S, et al. Guideline for the prevention and treatment of anticipatory nausea and vomiting due to chemotherapy in pediatric cancer patients. Pediatr Blood \& Cancer. 2014;61(8):1506-1512.

91. Fortier MA, Batista MLP, Wahi A, Kain A, Strom S, Sender LS. Illness uncertainty and quality of life in children with cancer. Journal of Pediatric Hematology. doi:10.1097/MPH.0b013e318290cfdb.

92. Larsson G, Mattsson E, Essen L von. Aspects of quality of life, anxiety, and depression among persons diagnosed with cancer during adolescence: A long-term follow-up study. European Journal of Cancer. 2010;46(6):1062-1068.

93. Williamson H, Harcourt D, Halliwell E, Frith H, Wallace M. Adolescents' and parents' experiences of managing the impact of appearance change during cancer treatment. Journal of Pediatric Oncology Nursing. 2010;27(3):168-175. 
94. Jones DC, Vigfusdottir TH, Lee Y. Body image and the appearance culture among adolescent girls and boys: An examination of friend conversations, peer criticism, appearance magazines, and the internalization of appearance ideals. Journal of Adolescent Research. 2004;19(3):323-339.

95. Upton P, Lawford J, Eiser C. Parent-child agreement across child health-related quality of life instruments: A review of the literature. Quality of Life Research. 2008;17(6):895-913.

96. Momani TG, Mandrell BN, Gattuso JS, West NK, Taylor SL, Hinds PS. Children's perspective on health-related quality of life during active treatment for acute lymphoblastic leukemia: An advanced content analysis approach. Cancer Nursing. 2015;38(1):50-59.

97. Hockenberry M. Symptom management research in children with cancer. Journal of Pediatric Oncology Nursing. 2004;21(3):132-136.

98. Tyc VL, Mulhern RK, Jayawardene D, Fairclough D. Chemotherapy-induced nausea and emesis in pediatric cancer patients: An analysis of coping strategies. Journal of Pain and Symptom Management. 1995;10(5):338-347.

99. Geiger F, Wolfgram L. Overshadowing as prevention of anticipatory nausea and vomiting in pediatric cancer patients: Study protocol for a randomized controlled trial. Trials. 2013;14(1):103.

100. Grealish LRN, Lomasney ARN, Whiteman BRN. Foot massage: A nursing intervention to modify the distressing symptoms of pain and nausea in patients hospitalized with cancer. Cancer Nursing. 2000;23(3):237-243.

101. Kelly KM. Complementary and alternative medical therapies for children with cancer. European Journal of Cancer. 2004;40(14):2041-2046.

102. Mustian KM, Devine K, Ryan JL, et al. Treatment of nausea and vomiting during chemotherapy. US Oncology Hematology. 2011;7(2):91-97.

103. Rodgers C, Norville R, Taylor O, et al. Children's coping strategies for chemotherapy-induced nausea and vomiting. Oncology Nursing Forum. 2012;39(2):202-209.

104. Syrjala KL, Donaldson GW, Davis MW, Kippes ME, Carr JE. Relaxation and imagery and cognitive-behavioral training reduce pain during cancer treatment: A controlled clinical trial. Pain. 1995;63(2):189-198. 
105. Nathan PC, Furlong W, Barr RD. Challenges to the measurement of health-related quality of life in children receiving cancer therapy. Pediatric Blood \& Cancer. 2004;43(3):215-223. doi:10.1002/pbc.20096.

106. Schwartz CE, Sprangers MA. Methodological approaches for assessing response shift in longitudinal health-related quality-of-life research. Social Science \& Medicine. 1999;48(11):1531-1548.

107. Matza LS, Swensen AR, Flood EM, Secnik K, Leidy NK. Assessment of healthrelated quality of life in children: A review of conceptual, methodological, and regulatory issues. Value in Health. 2004;7(1):79-92.

108. Eiser C, Mohay H, Morse R. The measurement of quality of life in young children. Child: Care, Health and Development. 2000;26(5):401-414.

109. Furlong WJ, Feeny DH, Torrance GW, Barr RD. The Health Utilities Index (HUI®) system for assessing health-related quality of life in clinical studies. Annals of Medicine. 2001;33(5):375-384.

110. Hinds PS, Nuss SL, Ruccione KS, et al. PROMIS pediatric measures in pediatric oncology: Valid and clinically feasible indicators of patient-reported outcomes. Pediatric Blood \& Cancer. 2013; 60(3):402-408.

111. Cantrell M. A narrative review summarizing the state of the evidence on the healthrelated quality of life among childhood cancer survivors. Journal of Pediatric Oncology Nursing. 2011;28(2):75-82.

112. Haas BK. Clarification and integration of similar quality of life concepts. Journal of Nursing Scholarship. 1999;31(3):215-220.

113. Sprangers MAG. Quality-of-life assessment in oncology. Acta Oncologica. 2002;41(3):229-237.

114. Bradlyn AS. Health-related quality of life in pediatric oncology: Current status and future challenges. Journal of Pediatric Oncology Nursing. 2004;21(3):137-140.

115. Hinds PS, Gattuso JS, Fletcher A, et al. Quality of life as conveyed by pediatric patients with cancer. Quality of Life Research. 2004;13(4):761-772.

116. Furlong W, Rae C, Feeny D, et al. Health-related quality of life among children with acute lymphoblastic leukemia. Pediatric Blood \& Cancer. 2012; 59(4):717-724.

117. Huang I-C, Quinn G, Krull K, et al. Head-to-head comparisons of quality of life instruments for young adult survivors of childhood cancer. Supportive Care in Cancer. 2011:1-11. 


\section{APPENDIX A. PEDSQL MODULES AND SCORING}

- $\quad$ The PedsQL-Generic Core Scale age-specific modules are available on the following link:

http://www.proqolid.org/content/download/11861/176794/version/1/file/RC Peds QL-4.0-Core-All AU4.0 eng-USori.pdf

- $\quad$ The PedsQL-Cancer Scale age-specific modules are available on the following link:

http://www.proqolid.org/content/download/11814/176655/version/1/file/RC Peds QL-3.0-Cancer-All_AU3.0_eng-USori.pdf

- $\quad$ The scoring manual for the PedsQL-Generic and PedsQL-Cancer scales is available on the following link:

http://www.pedsql.org/PedsQL-Scoring.pdf 


\section{APPENDIX B. IRB APPROVALS}

\begin{tabular}{lr}
\hline THE UNIVERSITY OF TENNESSEE \\
Health Science Center & Institutional Review Board \\
\hline & 910 Madison Avenue, Suite 600 \\
& Memphis, TN 38163 \\
& Tel: (901) 448-4824
\end{tabular}

August 12, 2013

Tha'er G Almomani

UTHSC - CON - Nursing- Academic Programs

St. Jude Children's Research Hospital

262 Danny Thomas Place

Memphis, TN 38105

Re: 13-02593-XM STJUDE

Study Title: Quality of Life in Children with Cancer / St. Jude \#NR13-077

Dear Mr. Almomani:

The Administrative Section of the UTHSC Institutional Review Board (IRB) reviewed the above referenced IRB application which includes human subjects and/or tissue for investigative purposes. It determined that your application is eligible for expedited review under the Memorandum of Agreement (Cooperative Agreement) between St. Jude Children's Research Hospital and the University of Tennessee, dated November 22,2003. This application was approved as complying with proper consideration of the rights and welfare of human subjects, the risk involved, and the potential benefits of the study.

This study may not be initiated until you receive approval from the institution(s) where the research is being conducted.

St. Jude Children' s Research Hospital Institutional Review Board (SJCRH IRB) will be the primary IRB for this project. In this capacity the SJCRH IRB will have full responsibility for the oversight of the research. It is your responsibility to comply with all Federal and SJCRH IRB regulations concerning the conduct of the study. Under the cooperative agreement mentioned above, the SJCRH IRB will maintain correspondence with the UTHSC IRB in regard to the performance of the research

Sincerely,

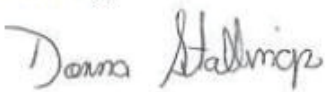

Signature applied by Donna L Stallings on 08/12/2013 07:39:58 AM CDT

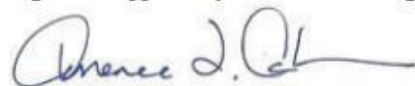

Signature applied by Terrence F Ackerman on 08/12/2013 08:10:01 AM CDT

Donna Stallings, CIM

IRB Administrat or

UTHSC $\mathbb{R B}$
Terrence F. Ackerman, $\mathrm{Ph} D$.

Chairman

UTHSC IRB 


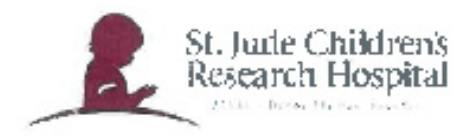

Instiluliurla. Review Bcand \#29

FWACOCO47\%

Bi11/2C13

Thaer Almomar $\mathrm{i}$

NURSING-IRCGLARCU

RE: NR13.077 O.lallty of Li:c in Ch kden with Cancer

Leg' k'r A.rrrurr:ıai.

This is to certify that, on Gir14:2013, the

Non-humąn detemination

submitrod to tra Inst tuticา日 Revien Boa:d ior considerator: was ieviswad $\mathbf{b}_{j}$ an IRB memoer using expedited

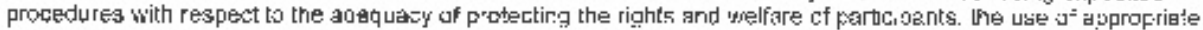
metrocs $0^{x}$ securing informed acnaent, the meastres to be lakw' lo minirrize risk and the cegree of risk relajve :o the palential beleft's of the poposod resuarco'.

iRB Review Stat.ds:

The actlylty has been determined to not involve human subjects, as deflned in 45CFRA6. 102 (f):

Humas subject means a lly|ng Indlyldual about whom an investigator (whether profess lonal or student) conductlong research obtains (1) Dafa through interyentlon or Interactlon with the individual, or (2) Identifiable private irmormation.

This determlnation also ls based an the Office far Human Research Protsctions' (QHRP) Guidance Document dated 10-16-200B, on Resagrch involving Coded Private Informatian or Biodogicel Specimens, found at the following Web link; http:Niwww.hhs gowiohrpipollcyfedebiol.html

Pleas keep thig letter in your files.

Far further essisance, please contect tho Clliwa of Hurrar Subjects Drotextinn at 901-595-4357 or email hsp-1@stjude.org.

(Suorrission Link: Pro00003947)

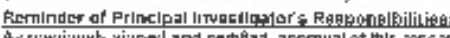

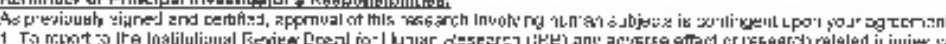

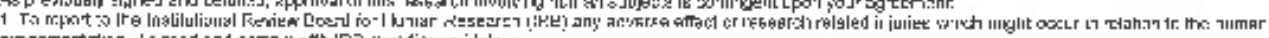

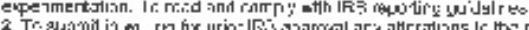

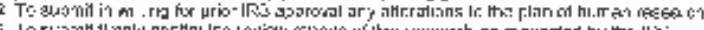

parlspiars

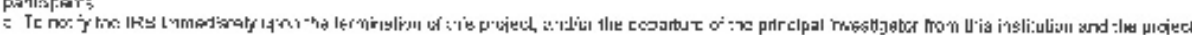


APPENDIX C. PEDSQL USER-AGREEMENT

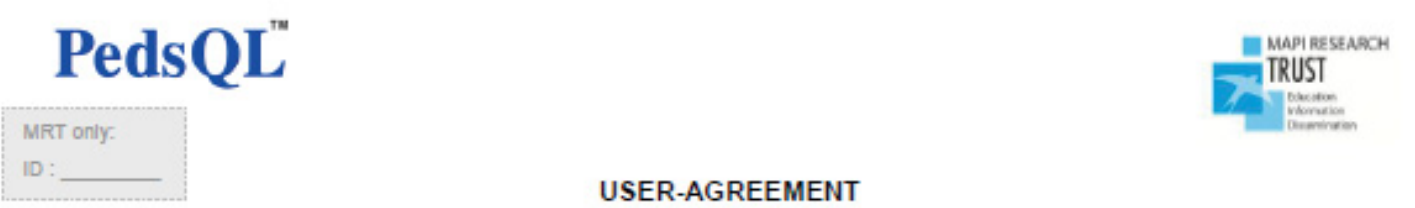

Use of the PedsQLn 4.0 Generic Core Scales, Modules and Translations

Date : !_2_!_2_!!0_!_5_! !_1_!_3_!

day month year

PART 1. LICENSEE'S DETAILS

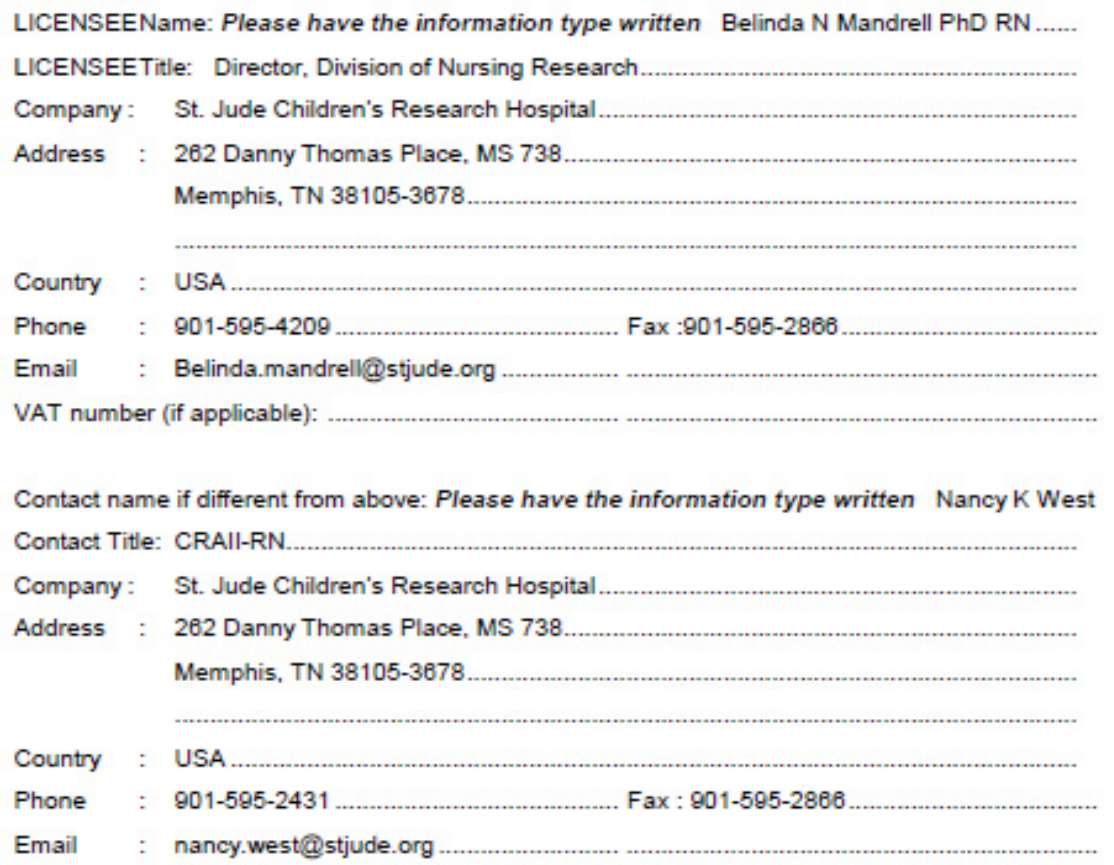




\section{PedsQL'}

3. Research study $\times \square$

- Title: Quality of Life in Children with Cancer

- Disease or disorder:_Acute Lymphoblastic Leukemia, Acute Myeloid Leukemia, Hodgkin Lymphoma, Melanoma, Osteosarcoma

- Type of research:

口 xclinical trial - Phase II $\square$ / Phase III $x \square$

口 epidemiologiclobservational

a other:

- PedsQL used as primary end point: yes $\square$ no $\quad x \square$

- Number of expected patients (total):

- Number of administrations of the questionnaire per patient:

- Length of the follow-up (if any) for each patient:

- Planned study date:

start $\quad 06 / 2003$ monturese

end $\frac{72}{\frac{700}{06 / 2010}}$




\section{PedsQL}

- Not tunded academic research

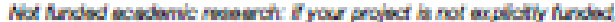

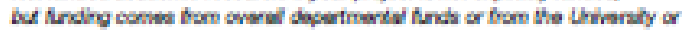
indivitiol Lrods Bhen loes aro maivel.

- Funded academic research

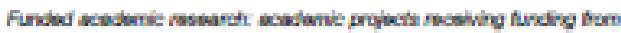

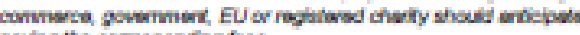
paping the comasponding fast

Note: Funded academie research aponsored by induaty fits ccommerciel study" categony

- Large non-commerclal organizaton Research and Evaluaton (pei-study licarse)

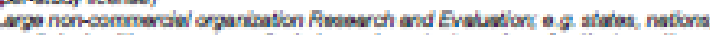

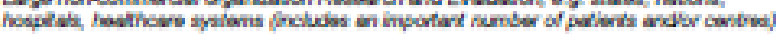

- Large non-commerclal organizaton Unilmited Research and Evaluation and clinical use (arnual licersea unimited use)

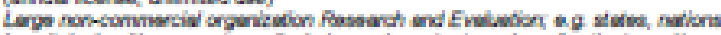

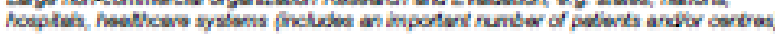

Please specify number of centres

- Commerclal study

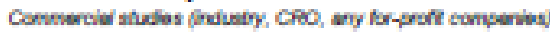

Please speclify number of centres--.--

Granuing / Sponsoning from (1f any) (name of the govemmentalfoundationlcompany or other

tunding/sponsorting source): 
4. REQUESTED PEDSQL ${ }^{\text {nu }}$ SCALES (please tick the aporoprlate box(es))

\begin{tabular}{|c|c|c|c|c|c|c|c|c|c|c|}
\hline \multicolumn{4}{|c|}{ PedaQL $\mathrm{L}^{\mathrm{n}}$ Generic Core Scales } & \multicolumn{7}{|c|}{ Plesese apecily: Standard $\square$ Actute $\square$ Both $\square$} \\
\hline \multicolumn{2}{|c|}{$\begin{array}{c}\text { Adulk } \\
\text { (over 26) }\end{array}$} & \multicolumn{2}{|c|}{$\begin{array}{c}\text { Young Adult } \\
\text { (18-25) }\end{array}$} & \multicolumn{2}{|c|}{$\begin{array}{l}\text { Adolesesnt } \\
\text { (13-18) }\end{array}$} & \multicolumn{2}{|c|}{$\begin{array}{l}\text { Colld } \\
(3-12)\end{array}$} & \multicolumn{2}{|c|}{$\begin{array}{c}\text { Young celld } \\
(5-7)\end{array}$} & \multirow{2}{*}{ 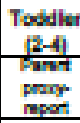 } \\
\hline Ball-apont & $\begin{array}{l}\text { Prawe } \\
\text { pros } \\
\text { nopot }\end{array}$ & Des: & $\begin{array}{l}\text { Pawn } \\
\text { prowy } \\
\text { nopert }\end{array}$ & $\begin{array}{l}\text { Chld went } \\
\text { nepent }\end{array}$ & $\begin{array}{l}\text { panet } \\
\text { prow } \\
\text { most }\end{array}$ & $\begin{array}{l}\text { Chid weit } \\
\text { nopon }\end{array}$ & $\begin{array}{l}\text { Pawer } \\
\text { grour } \\
\text { mogent }\end{array}$ & $\begin{array}{c}\text { Chald ant- } \\
\text { mport }\end{array}$ & 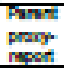 & \\
\hline 口 & $\square$ & $\square$ & $\square$ & 口 & 口: & 口 & 口 & 口 & $\square$ & 口 \\
\hline
\end{tabular}

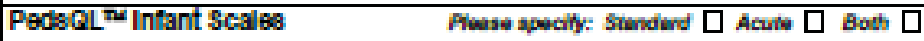

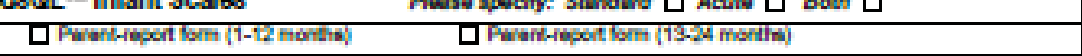

\begin{tabular}{|c|c|c|c|c|c|c|}
\hline \multicolumn{7}{|c|}{ PedsCL ${ }^{\text {nu }}$ Short Form 15 Generic Core Scales } \\
\hline \multicolumn{2}{|c|}{ Adolescent (12-18) } & \multicolumn{2}{|c|}{ Chid (a-12) } & \multicolumn{2}{|c|}{ Yoong Child $(5-7)$} & Toddier $(2-4)$ \\
\hline Onle mellonporn & Pawnt pragr-rooot & Onle nellonpent & Frent prosr mpont & Onle whopent & Drut prosor mpot & Favent presy-reoot \\
\hline 更 & 更 & 口 & 更 & 口 & a & प \\
\hline
\end{tabular}

\begin{tabular}{|c|c|c|c|c|c|c|}
\hline \multicolumn{7}{|c|}{ PedsCLL Arthrftls Module } \\
\hline Adoles: & $\operatorname{sen}(12-15)$ & Ch & ब(ब्व-12) & Yo. & child $(5-1)$ & Tosdier $(2-4)$ \\
\hline Conemphod & 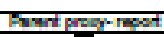 & Ontemingen & Prenprar mpot & Ontewhor & portprers mport & 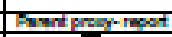 \\
\hline 口 & प & 口 & 口 & $\square$ & प & $\square$ \\
\hline
\end{tabular}

\begin{tabular}{|c|c|c|c|c|c|c|}
\hline \multicolumn{7}{|c|}{ PedsCl. ${ }^{n}$ Asthma Module } \\
\hline Adolesc & $\operatorname{sent}(13-18)$ & $\overline{\mathrm{Ch}}$ & $d(a-12)$ & Yoong & Child (S-7) & Toddier $(2-4)$ \\
\hline Onk allonpen & Pawnt pragr-reoot & Onknallopent & Prent prapr mpot & Onk sollapon & Prot presp mpot & Pawent pras-reopt \\
\hline
\end{tabular}

PodsCiL Short Form 22 Asthma Module

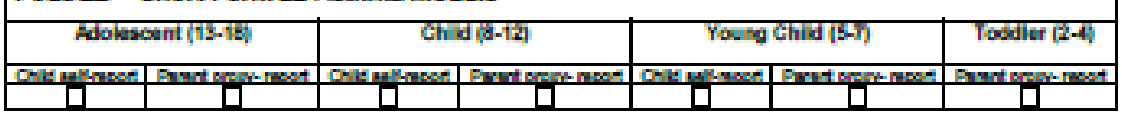

PødsCL ${ }^{\text {nu }}$ Braln Tumor Module

\begin{tabular}{|c|c|c|c|c|c|c|}
\hline Adoles: & gent (13-18) & $\mathrm{Ch}$ & $d(a-12)$ & Yooteg & Child (s-7) & Toddier $(2-4)$ \\
\hline Onemingern & 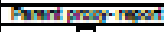 & 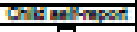 & Preriprar wpor & One werast & Powtpras mpon & 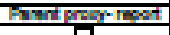 \\
\hline 口 & 口 & 口 & 口 & 口 & प & 口 \\
\hline
\end{tabular}

PedsQL ${ }^{\text {nu }}$ Cardlac Module

\begin{tabular}{|c|c|c|c|c|c|c|}
\hline \multicolumn{2}{|c|}{ Adolescent(19-1E) } & \multicolumn{2}{|c|}{ Chida (8-12) } & \multicolumn{2}{|c|}{ Young Ch d (5-T) } & Todelér $(2-4)$ \\
\hline Conde mathpor & 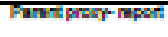 & 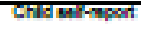 & Paren prow & 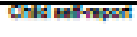 & Pawnipray & Tanespor mpor \\
\hline 口 & $\square$ & 口 & 口 & प & 0 & $\square$ \\
\hline
\end{tabular}

\begin{tabular}{|c|c|c|c|c|c|c|c|c|c|}
\hline \multicolumn{3}{|c|}{ PedsQL" Cancer Module } & \multicolumn{7}{|c|}{ Flevae apecify: Standard $\square$ Acxite $\square$ Both $\square$} \\
\hline$\underset{\text { Adulk }}{\text { Aduet 26) }}$ & \multicolumn{2}{|c|}{$\begin{array}{c}\text { Young Adult } \\
\text { (18-2.2) }\end{array}$} & \multicolumn{2}{|c|}{$\begin{array}{l}\text { Adoleseent } \\
\text { (13-18) }\end{array}$} & \multicolumn{2}{|c|}{$\begin{array}{l}\text { Colld } \\
(8-12)\end{array}$} & \multicolumn{2}{|c|}{$\begin{array}{c}\text { Young Colld } \\
{[5-7]}\end{array}$} & \multirow{2}{*}{$\begin{array}{c}\begin{array}{c}\text { Toddler } \\
\text { [2-4] }\end{array} \\
\begin{array}{c}\text { Danth } \\
\text { praxy: } \\
\text { nopor: }\end{array} \\
\end{array}$} \\
\hline Self-mport & seost & $\begin{array}{l}\text { Pawn } \\
\text { prowt } \\
\text { moget }\end{array}$ & $\begin{array}{l}\text { Chald wart } \\
\text { nesoen }\end{array}$ & $\begin{array}{l}\text { Panent } \\
\text { prow } \\
\text { mogot }\end{array}$ & $\begin{array}{l}\text { Chid wask } \\
\text { nopon }\end{array}$ & $\begin{array}{l}\text { Panert } \\
\text { prow } \\
\text { mogrt }\end{array}$ & $\begin{array}{c}\text { Chald ant- } \\
\text { mpon: }\end{array}$ & $\begin{array}{l}\text { Pannt: } \\
\text { praxy } \\
\text { nsogen }\end{array}$ & \\
\hline$\square$ & $\square$ & $\square$ & $x$ & $x$ & 口 & 口 & $\times \square$ & 口 & $x$ \\
\hline
\end{tabular}

\begin{tabular}{|c|c|c|c|c|c|c|}
\hline \multicolumn{7}{|c|}{ PedsQL" Cerebral Palay Module } \\
\hline \multicolumn{2}{|c|}{ Adolescent (13-18) } & \multicolumn{2}{|c|}{ Cald [8-12) } & \multicolumn{2}{|c|}{ Young Child $(5-n)$} & Toddiler $(2-4)$ \\
\hline Ondatsmapent & 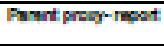 & Onle aullorepon & 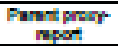 & Ond whowoot & 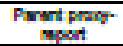 & Prent prasp mpot \\
\hline I & I & I & (1 & ] & D & 口 \\
\hline
\end{tabular}




\section{PedsQL"}

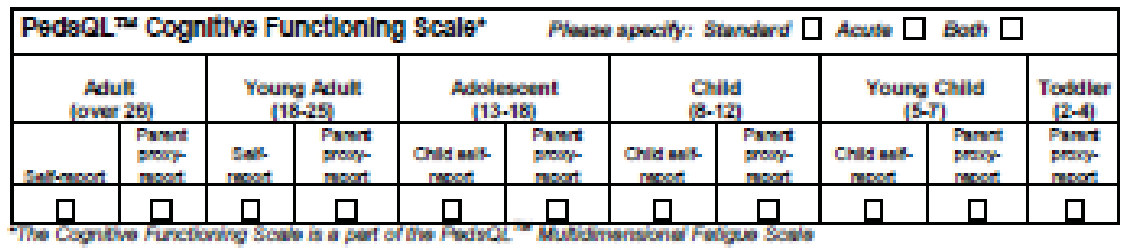

\begin{tabular}{|c|c|c|c|c|c|c|}
\hline \multicolumn{4}{|c|}{ PedsQL" Dlabetes Module 3.0 version } & Plouse specilf: & Standard $\square$ Acuse $\square$ & Boต $\square$ \\
\hline Adsiesc: & $\operatorname{sen}(13-18)$ & Chi & व[5-12] & Young & GChld $(5-7)$ & Tosdaler $(2-4)$ \\
\hline Inld matrogest & 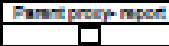 & Chlid whengent & Pentitger moont & Ond wifreost & \begin{tabular}{l|l} 
Pant proy-noot \\
\end{tabular} & Panent prograpot \\
\hline
\end{tabular}

\begin{tabular}{|c|c|c|c|c|c|c|c|}
\hline \multicolumn{3}{|c|}{ PedsQL ${ }^{n-1}$ Dlabetes Module 3.2 version } & \multicolumn{4}{|c|}{ Flasese specily: Standard $\square$} & Asure $\square$ \\
\hline Adult (18-45) & Adotes: & (13-18) & cal & & Young & $d(5-7)$ & Todale $(2-4)$ \\
\hline \multirow{2}{*}{ solngoot } & $\begin{array}{l}\text { Onlt nest. } \\
\text { mpot }\end{array}$ & 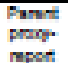 & $\begin{array}{c}\text { Chlld nal- } \\
\text { rwoot }\end{array}$ & $\begin{array}{l}\text { Prowt } \\
\text { promer } \\
\text { post }\end{array}$ & onid wat: & 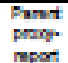 & $\begin{array}{c}\text { Pavert praxy } \\
\text { mpoet }\end{array}$ \\
\hline & a & $\square$ & $\square$ & प & 口 & प & D \\
\hline
\end{tabular}

\begin{tabular}{|c|c|c|c|c|c|}
\hline \multicolumn{6}{|c|}{ PedsoL $\approx$ Duchenne Muscular Dystrophy Module } \\
\hline \multicolumn{2}{|c|}{ Adolescent (13-15) } & \multicolumn{2}{|c|}{ C्यार (8-12) } & Young calle $(5-7)$ & Tि्daler $(2-\pi)$ \\
\hline Ond nestropot & Panert propormpont & 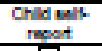 & Panert prag- raoont & Pawnt proy-mot & No Tosdlier \\
\hline प & प & $\square$ & & & \\
\hline
\end{tabular}

\begin{tabular}{|c|c|c|c|c|c|c|}
\hline \multicolumn{7}{|c|}{ PedicLL $\approx$ End Stage Renal Module } \\
\hline \multicolumn{2}{|c|}{ DSolescent (13-18) } & \multicolumn{2}{|c|}{ Child (5-12) } & \multicolumn{2}{|c|}{ Young calla $(5-7)$} & Toddeler (2-4) \\
\hline Ohld wilmopont & Fwerepromp mpen & $\begin{array}{l}\text { Ohid nats } \\
\text { negent }\end{array}$ & 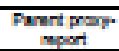 & Onle ant: & $\begin{array}{l}\text { Pront pmaxy } \\
\text { noost }\end{array}$ & 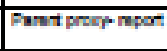 \\
\hline$\square$ & I & 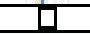 & प & 口 & प & 마 \\
\hline
\end{tabular}

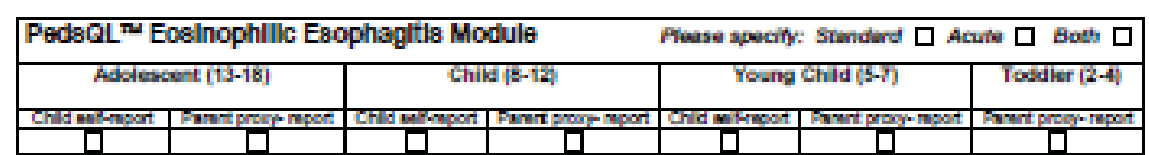

\begin{tabular}{|c|c|c|c|c|c|}
\hline \multicolumn{6}{|c|}{ 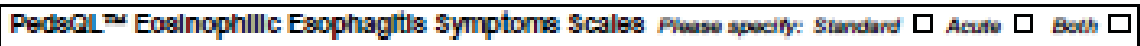 } \\
\hline \multicolumn{2}{|c|}{ Adotescent $(13-18)$} & \multicolumn{2}{|c|}{ Chid (8-12) } & Young Child (5-n) & Tosdilet $(2-4)$ \\
\hline Chlid wilkepont & Fawnt prest. & Chlid warmpont & Pantpron & 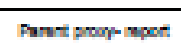 & Frent prest mpon \\
\hline D & a & G & nest & 口 & T \\
\hline
\end{tabular}

\begin{tabular}{|c|c|c|c|c|c|c|c|}
\hline & & & & & & \multicolumn{2}{|c|}{ PedsoL "Tw General Well-Being Scale } \\
\hline \multicolumn{2}{|c|}{ Yousg Ad_alt (18-25) } & \multicolumn{2}{|c|}{ Adolescent (13-18) } & \multicolumn{2}{|c|}{ cald (a-12) } & Yousg Child (5-7) & Toddlet $(2-4)$ \\
\hline $\begin{array}{c}\text { One nask } \\
\text { nopont }\end{array}$ & 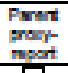 & Ondent. & 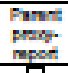 & $\begin{array}{l}\text { Chlid on:- } \\
\text { reont }\end{array}$ & $\begin{array}{l}\text { Prown } \\
\text { pmort } \\
\text { novent }\end{array}$ & $\begin{array}{l}\text { No Young Caild } \\
\text { version }\end{array}$ & $\begin{array}{l}\text { No Toddlet } \\
\text { version }\end{array}$ \\
\hline प & $\square$ & 口 & ב & $\square$ & प & & \\
\hline
\end{tabular}

\begin{tabular}{|c|c|c|c|c|c|c|c|c|c|}
\hline \multicolumn{5}{|c|}{ PedsQL" ${ }^{n}$ Multidlmensional Fatigue Scale } & \multicolumn{5}{|c|}{ Plaase specily: Standard $\square$ Aculs $\square$ Both } \\
\hline $\begin{array}{c}\text { Adidit } \\
\text { (over 2f) }\end{array}$ & Youne & |utat (18- & Adoleso & $(13-18)$ & Chile & $-12)$ & Yosang & iled $(5-T)$ & Todder $(2-4)$ \\
\hline Salkmpont & काद & prent & $\begin{array}{c}\text { Chld an: } \\
\text { mpen }\end{array}$ & $\begin{array}{l}\text { Paner } \\
\text { pmat: }\end{array}$ & $\begin{array}{l}\text { Chid wor. } \\
\text { mpot }\end{array}$ & $\begin{array}{l}\text { Prower } \\
\text { port }\end{array}$ & ChIS & 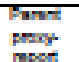 & $\begin{array}{c}\text { Pawnt praxy } \\
\text { mport }\end{array}$ \\
\hline ב & ב & (1) & प्रत & 要 & 므 & प्र & 뭉 & 至口 & 므 \\
\hline
\end{tabular}




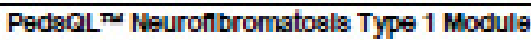
पAdall (over 2E) selliapon

\begin{tabular}{|c|c|c|c|c|c|}
\hline \multicolumn{6}{|c|}{ PedsCL ${ }^{2}$ Neuromuscular Module } \\
\hline Adoles & oent (13-15) & Child [\&-12] & Young & Chied (S-T) & Todder $(2-4)$ \\
\hline 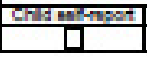 & 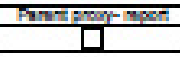 & 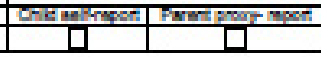 & 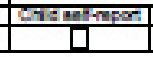 & 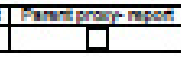 & 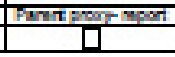 \\
\hline \multicolumn{6}{|c|}{ PedsCL $\approx$ Oral Health Scale } \\
\hline \multicolumn{2}{|c|}{ Adoleseent (13-15) } & Cild (8-12) & \multicolumn{2}{|c|}{ Young Child (5-7) } & Toddler $(2-4)$ \\
\hline & 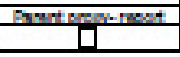 & 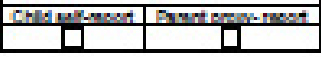 & & & 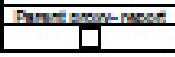 \\
\hline
\end{tabular}

\begin{tabular}{|c|c|c|c|c|c|}
\hline \multicolumn{6}{|c|}{ PedsQL ${ }^{\text {Iu }}$ Pedlatric Pain Coping Inventory } \\
\hline Adolesc & ent (13-.15) & CकाI & ब(5-12) & \multirow{2}{*}{$\begin{array}{l}\text { Young clild wersion } \\
\text { is Includod in Ele } \\
\text { child version }\end{array}$} & \multirow{2}{*}{ No Toddlet versicn } \\
\hline 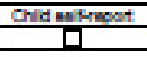 & 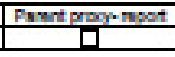 & 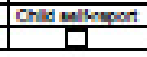 & 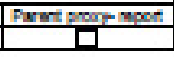 & & \\
\hline
\end{tabular}

\begin{tabular}{|c|c|c|c|c|c|c|}
\hline \multicolumn{7}{|c|}{ 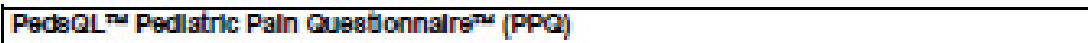 } \\
\hline Addoles: & $\operatorname{xent}(13-18)$ & & $\operatorname{ld}(8-12)$ & Yosing & gChive(5-n) & \multirow{2}{*}{$\begin{array}{l}\text { No Toddle } \\
\text { version }\end{array}$} \\
\hline$\frac{\text { Oaremanpen }}{\square}$ & 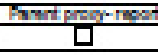 & $\frac{\text { OAlambanpen }}{\square}$ & 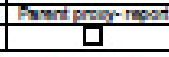 & 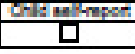 & 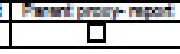 & \\
\hline
\end{tabular}

PedsQL ${ }^{\text {ma }}$ Present Functioning Visual Analogue Scales

\begin{tabular}{|c|c|}
\hline PedsQL ${ }^{n}$ Present Fu & e Scale8 \\
\hline & $(5-15)$ \\
\hline पChisfinon form & 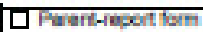 \\
\hline
\end{tabular}

\begin{tabular}{|c|c|c|c|c|c|c|}
\hline \multicolumn{7}{|c|}{ PedicLL Fheumatology Module } \\
\hline Adolese & ent $(13-18)$ & & Id (8-12) & Young & Child $(5-7)$ & Toddiet $(2-4)$ \\
\hline 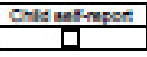 & 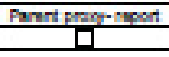 & 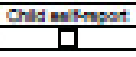 & 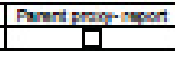 & 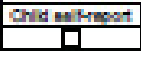 & 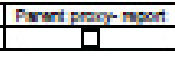 & 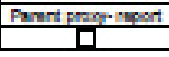 \\
\hline \multicolumn{4}{|c|}{ PedeCL $\approx$ Sickle Cell Dlsease Module } & \multicolumn{3}{|c|}{ Fleeses specty: Standard $\square$ Aeute $\square$ Both $\square$} \\
\hline \multicolumn{2}{|c|}{ Adolescent (13-18) } & \multicolumn{2}{|c|}{ Cilld (8-12) } & Young & Child (5-r) & Todder $(2-4)$ \\
\hline 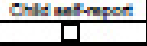 & 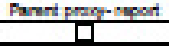 & $\frac{\text { Onld enthopot }}{\square}$ & 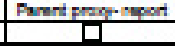 & 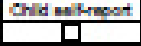 & 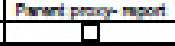 & 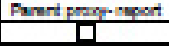 \\
\hline
\end{tabular}

\begin{tabular}{|c|c|c|c|}
\hline \multicolumn{4}{|l|}{ PedsCLL Transplant Module } \\
\hline Addiescent (19-18) & C्याa (3-12) & Ycung Chld $(5-r)$ & Todaler $(2-A)$ \\
\hline 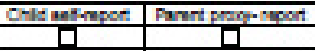 & 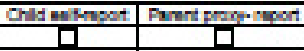 & 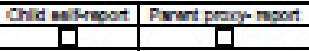 & Penritponorapont \\
\hline \multicolumn{4}{|c|}{ PedsQL ${ }^{n \alpha}$ Famlly information Form } \\
\hline प Parenthepent form & & & \\
\hline
\end{tabular}

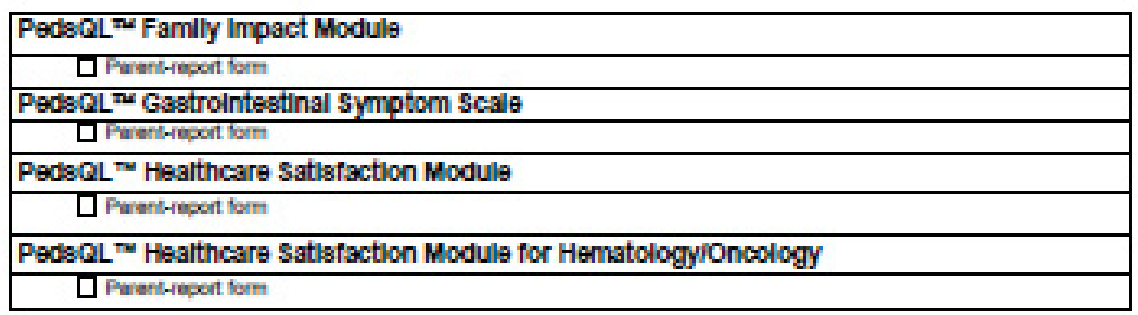




\section{PedsQL"}

\section{TRANSLATIONS}

Please indlcate In which language(s) and for which country(les) the above requested Peds $\mathrm{CL}$ scale(s) Is/are needed:

\begin{tabular}{|c|c|c|c|c|c|}
\hline Langunge: & $\begin{array}{l}\text { For use in the } \\
\text { following country }\end{array}$ & Languege: & $\begin{array}{l}\text { For use in the } \\
\text { following country }\end{array}$ & Language: & $\begin{array}{l}\text { For uas in the } \\
\text { following country }\end{array}$ \\
\hline ag Englist & USA & Englsh & USA & & \\
\hline e.g. Sparist & USA & & & & \\
\hline & & & & & \\
\hline & & & & & \\
\hline & & & & & \\
\hline & & & & & \\
\hline & & & & & \\
\hline & & & & & \\
\hline & & & & & \\
\hline & & & & & \\
\hline & & & & & \\
\hline
\end{tabular}

The PedsQL ${ }^{\text {n }}$ transiation(s) may not be avallable in the country required. Plesse check avallabllity of transiations with MAPI Research TRUST or consult the PedsCL webalte at: muwepdaqlorg section "Translations".

If not avallable in the language(s) required, a Ungulstic Valldation must be undergone. 


\section{PedsQL}

\section{USER AGREEMENT}

This agreement is between MAPI RESEARCH TRUST and Belinds N Mandrell, FhD, RN

["user").

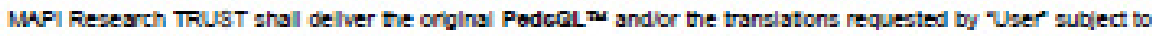
the following conditions:

- The transiations requested are avaliabie, and

- The present contract le duly completed and slgned by "User"

The uce of the PodcaL ${ }^{x}$ In the above mentloned context ic cubjeot to the following oonditionc:

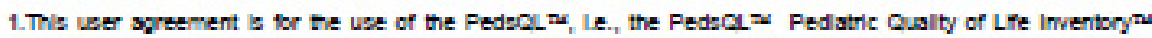
report forma, reglatered copyrights in the PedeCL= (e.9., U.8. copyright reglatration No. TXu 956-101) and reiated teasy, convention and common law rights pertaining thereto, with all riphts reserved to Dr. James W. Vaml, Icensor and author of the PedeCLn.

2. Fees:

The ues of the PedeCL $w$ for untunded academic research purpose is free.

The ves of the PedaCL= for funded academic research pupoes la subject to a datrtution fse payable to MAPI Reserch Truat (piesse reler to the 'PedaCL Cost structure').

The use of the FedaCLw for large non-commerclal organization research and evaluation (eq., states, Nations, Hosplals, Heahcare Systems) or commerclal purpose and lape non-commercia organizasion urlimited researchlevaluationiclinical use $\mathrm{la}$ subject to Dr. James W. Vam's royaty fee plus MAPI Research Truets detribution fee. These fees are paysbie to MAPI Research Trust (please refer to the "PedaCL Cost atructure").

The questionnaire and requeated tranalatona shal only be delvered to User upon ether receipt of payment or proot of payment (in the form of a copy of the check or wire tranefer debla) of all due fees.

3. "User" shal not modry, abridge, condense, transiate, adopt, recast or tranafom the PedoCLne questionnaires in any manner or form, including but not limlited to any minor or significant change in wordings or organisation in PedeCLa questionnaires, without the prior written agreoment of Dr. Jamec W. Varnl. If permisalon is granted any Improvements, modications, or enhancementa to the PedeCLax which myy be concelved or developed including transiatons and modules, shal become the property of Dr. James W. Vaml.

4. "User" shal not reproduce the PedoOL $w$ questornalres except for the Imted purpose of generating suffcient. copies for use in the above mentioned clinical investigations and shall in no event datribute copies of the PedeQLis questionnaires to third parties by saie, rental, lease, lending, or any others meana.

5. In case of publication, 'User' shall cle the following PedsoLw publication(s) in the reference section of the publication. It is requested that a copy of al publlahed papers and abstracte uaing the PedaCL ${ }^{2}$ be provided to Dr. James W. Varrl.

- Generie Core Scales: Varnl JW, ex al. The PedeCL" Measurement Model for the Pedatric Gualty of uite Inventory. Medical Care, 1999; 37/2)126-139

Vaml, J.W., et a. The PedeQLn 4.0: Relabilty and valdity of the Pedlatric Qusity of Lie Inventoryne Verzlon 4.0 Generic Core Scaies in heathy and patient popuations. Medcal Care, 2001; 39(8): 800-812.

Vaml, J.W., et al, (2002). The PedeQL= 40 Generic Core scaiez: Sercitulty, responalveness, and impact on clinical declalon-making. Joumal of Behovioral lediche, 25, 175-193.

Vaml, J.W., et al. (2003). The PedeCLI 4.0 as a pedlatric population health measure: Feasbilly, relablity. and valdity. Ambulutory Pediatrics, 3, 329-341.

Chan, K.8., Manglone-8mith, R., BurwinkJe, T.M. Fosen, M, s Vaml, J.W. (2005). The FedzCLI: Relabilty and valdity of the short-Form Generic Core Scales and Aathma Module. Medical Care, 43, 256-265.

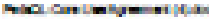




\section{PedsQL"}

Vam), J.W., s Lmbers, C.A. (2009). The PedsCLn 4.0 Generic Core Scaies Young Adult Version: Feaslbity, relability and validty in a univeralty student population. Joumal of Heseh Psychology, 14, 611-622

- Asthme Module: Vaml, JW., Burwnkie, TM, Rapoti, MA, Kampa, JL, a Olaon, N. The PedaCLI in pedaric asthma: Reliabilty and valdty of the Pedaric Qualty of Ufe Inventoryne Generic Core Scaies and Aethma Module. Journal of Behavioral Medicine, 2004; 27:297-318.

Chan, K.8. Manglone-Smith, R, Eurwinkle, T.M. Rosen, M., B. Vaml, J.W. (2005). The PedaCLa: Relabilty and validty of the Short-Form Ceneric Core Scales and Anthma Module. Medical Care, 43, 255-255.

- Brain Tumor Module: Palmer, 8.N., Meeske, K.A, Kaz, ER., Burwinke, T.M., B Vaml, J.W. (2007). The FedeOL Brain Tumor Module: initai relablity and valdity. Fediatric Blood and Cancer, 49, 287-293.

- Cancer Module Vaml, J.W., Eurwinkie, TM, Katz, E.R., Meeske, K., a Dickineon, P. The FedeQLII in pedaric cancer. Relisbilty and valdity of the Pedlatric Quality of Life Inventory=u Generic Core Scaies. Mulfdimensional Fatigue Scale, and Cancer Module. Cancer, 2002,84: 2090-2105.

Robert R8, Paxton RJ, Palla SL, Yang G, Askina MA, Joy 8E, Ater JL. Feaslbilly, relabilty, and validity of the pedaric qusilty of life invertory generic core scales, cancer modve, and multidmeralonal fatgue gcale in iong-term adult survivors of pedatric cancer. Pedlatr Blood Cancer 2012 59:703-707.

- Cerabral Paisy Module Vaml JW, BurWinkie TM, Berrin 8J, Sherman 8A, Artarla K, Malcarte VL Chamber: HO (2005). The PedeQL IN in Pedatic Cerebral Pasy. Relability, Vald scales and Cerebral Palsy Module. Developmental Mledclne and Child Neurology, 48: 442-449.

- Cardlac Module: Uzark, K. Jones, K., Eurwikie, T.M, B Vaml, J.W. The Pedatric Gualty of Ufe inventory in chlidren with heart doese. Progress in Pedutric Cardlology, 2003;18:141-148.

Uzark, K. Jones, K., Slusher, J., Limbers, C.A, Burwinkie, T.M., a Vaml, J.W. (2008). Quslity of IRe in children with heart dsease as perceived by children and parent. Pealatrics, 121 , e1050-1067.

- Cognitive Funetioning Seale: McCarthy, ML. MacKenzie, E.J., Durtin, D.R, Atken, ME, Jafte, K.M. Faidas, C.N. et a. (2005). The Pedatric Qualty of Lfe inventory. An evaluation of ite rellabllity and validity for chlldren with traumatic brain injury. Archives of Physicar Medicine and Rehabutation, 85, 1901-1909.

Vaml, J.W., Eunwinkie, TM., Katz, E.R., Meeske, K., s Dickineon, P. (2002). The PedaCLn in pedaric cancer: Relability and valdity of the Pedatic Qusily of Lite Inventory ${ }^{\text {Th }}$ Generic Core Scales, Mutidmenclonal Fafgue Scale, and Cancer Module. Cancer, 94, 2090-2105.

Vaml, J.W., Umberz, C.A., Soreneen, LG., Nelghbors, K, Martz, K., Bucuvalas, J.C, s. Nonso, E.M. (2011). PedeCL ${ }^{m}$ Cognitive Functioning Scale in pediatric liver transplant reciplent: Feasblity, relabily and validty. Qualty of Life Resesurch, 20, $913-921$

- Dlabotes Module. Varn, J.W., Curtis, B.H., Abecz, L.N. Lasch, K.E., Paul, E.C., a Zeytoonlan, A.A (In preas). Content valdity of the FedeCL $=3.2$ Dlabetes Module in newly dagnoed pasents with Type Dibetes Melltus apes 8-45. Qualty of Lle Research.

Vaml, J.W., Burwinkie, TM, Jacobs, JR, Gotachalk, M., Kautman, F, s Jones, KL. The PodaCL ${ }^{2}$ in Type 1 and Type 2 dabetes: Relabily and validity of the Pedatric Qualty of Life Invertoryar Generic Core Scales and Type 1 Diabetes Module. Dlabetes Care, 2003;25: 631-637.

Nansel, T.R. Weigberg-Benchell, J., Wyeocki, T. La"el, L. s Andergon, B. (2008). Quality of life in chlidren with Type 1 dabetes: A comparison of genera and disesee-apecific messures and support for a unitary dsectes qualty of life construct. Diabetic Medicine, 25, 1316-1323.

Naughton, M.J., Ruggero, AM, Laarence, J.M., Imperatore, G., Kingenamith, G.J. Watzelder, B. MeKeown, RE., Standiford, D.A. Uese, A. ., a Loota, B. (2008). Heath-related qualty of Ife of children and sdolescents with type 1 or type 2 diabetes mellus: SEARCH for Diabetes in Youth Studty. Archlves of Pedatics and Adolescent Mledicline, 152, 649-657.

- Duchenne Muscular Dystrophy Module: Uzark, K., Kng, E, Cripe, L, Spicer, R., Sage, J., KInnelt, K. Wong, E., Pratt, J., s Varnl, J.W. (2012). Health-related quality of life in chliden and adolescents with Ducherne Muecular Dyetrophy. Pedlatrics, 130, e1559-e1566.

- End Stage Renal Disease Module: Goldstein, 8.L. Graham, N. Warady, B.A, Selkaly, M., McDonsid, R. Burwinkle, T.M. Limbers, C.A. a Vaml, J.W. (2008). Measuring healthreatad qualty of life in chlidren wits ESFD: Performance of the Genertic and ESRD-Specific Inatrument of the Pedlatric Qualty of Life invertory ${ }^{m}$ (PedeQL ${ }^{2}$ ). Amertcan Joumal of Kloney Diseases, 51 , 285-297. 


\section{PedsQL"}

- Eosinophilic Esophagiv's: Frandoel, J.P., Hommel, K.A, Bendo, C.E., Kng. E.C., Collna, M.H., Evy, MD. Marsolo, K., Abonla, J.F., von Tiehl, K.F., Futnam, P.E, Greenier, A.J, Greenberg. A.B., Bryson, R.A, Davis C.M., Olve, A.P. Gupta, S.K., Erwin, E.A. Klnnert, M.D. Sperget, J.M, Denham, JM, Funta, Q.T. Rothenberg. ME, s Vaml, J.W. (2012). PedeCL "w Eosinophlilc Esophagtts Module: Feasbilty, reliablity and valdity. Monuacript submitsed for publlcation.

Franciosl, J.P., Homme, K.A, Greenberg, A.B., Debrosse, C.W. Greenler, A.J, Aborla, J.P., Rothenberg. ME., a Vami, J.W. (in preas). Development of the Fedatric Qualty of Ufe Inventoryn Eosinophilic Eeophaglts Module teme: Qualtative methods. BuC Gastoenterology.

Franclosl J.P., Hommel, KA., Debrosse, C.W., Greenberg, A.B., Greenier, A.J., Abonla, J.P., Rothenberg. ME., s Vaml, J.W. (2012). Gualty of life in psedatric eozinophlic oesophsgitis: What is important to patienta? Child: Care, Heath and Development, $38,477-483$.

- Family impact Module: Vaml, J.W., Sherman, 8.A, Burwinkie, T.M, Dickineon, P.E, B. Diron, P. ( 2004)

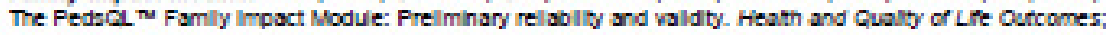
$\underline{2}(55), 1-5$.

- Gastrointestinal Symptom Seale: Vaml, J.W., Lane, M.M. Eurwinkie, T.M. Fortaine, EN., Yougoe, N.N. Schwimmer, J.B. Fardet, PE., Pohl, J.F., a Easley, D.J. (2006). Hearhrelated qua ity of ife in pedistric patents with Imtabie bowel syndrome: A comparative anatysis. Joumal of Developmental and Behavioral Pedatics, $27,451-458$.

- General Woll-Boing Scale: Varnl, JW., Seld, M, a Kurtin, P.8. (1999). Ped atric heath-related qualty of ife measurement technology: A gulde for hesith care decialon makes. Joumal of Cinlcal Outcomes lonogement, 5 , $33-40$.

Haletrand, T.8., Curts, J.R., Atken, M.L, s Sullvan, 8.D. (2003). Quality of ifte in adoiescents with mild atrma. Pedlatic Ruimonology, 35, 536-543.

- Healtheare Satsfaction Generie Module: Vaml, J.W., Burwinkie, T.M., Dickingon, P., Sheman, 8.A, Duon, P., Envice, JA, Leyden, P.A \& Sadler, B.L (2004). Evalustion of the bult environment at a Chldren's

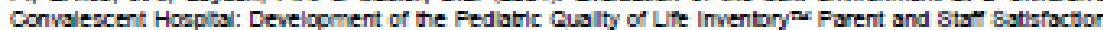
Measures for pedatric heaith care foclities. Joumal of Develogmental and Behovioral Pedlatrics, 2004. 25:10-25.

- Health Care Satisfaction Module specifie for HomatologylOncology Vaml, J.W., Quggina, D.JL, B. Avala, G.X (2000). Development of the Fedlaric Hematologyioncology Parent Satifaction survey. Childen's healtr Care, 29, 243-255.

- Intant Scales: Vaml, J.W., Umberz, C.A, Neighborz, K, Schulz, K., LeU, JE.C., Hewer, R.W., Turzinkiewicz K., Manglone-Smith, R., Zimmeman, J.J., 3 Alonso, E.M. (In press). The FedeCL $n$ infant Scalez: Feastblity, Intemal consiatency relablity and validity in heathy and II infante. Quaity of Life Research.

- Mutidimentional Fatigue Scalec Varrl, J.W. Burwinkie, TM, Katz ER, Meeske, K, B Dickingon, P. The PedaCL= in pedatic cancer. Rellabllty and valdty of the Pedatric Qualty of Lie inventory ${ }^{2}$ Generic Core Scalez, Mutidmenalonal Fabgue Scale, and Cancer Module. Cancer, 2002;94: 2090-2106.

Vaml, J.W., Burwirkie, T.M. \& 8zer, I.8. ( 2004). The PedaCL $w$ Multidmenalonal Fatigue Scale in pediatric reumatology. Relability and valdity. Joumal of Rheumutology, 31, 2494-2500.

Vam), J.W., a LImbers, C.A. (2008). The PedaQLa Multidmeneional Fatgue Scale in young adule: Feasibility, relability and validity in a univeralty student poculason. Qualty of Life Research, 17 105-114.

- Newrenbromafosis Type 1 Module: Nutakkj, K. Hingtgen, C.M, Monahan, P., Vaml, J.W. a Swlponckl, N.L. (2013). Deveiopment of the aduit PedaCLn Neurofbromatosis Type 1 Module: initisi feasibility, relisilly and valdty. Heath and Cualty of Lfe Cutcomes, 11:21, 1-9

- Newromuscular Module: Iarnaccone, 8.T., Hynan, L8, Morton, A, Euchanan, R., Umbers, C.A, a Vaml. J.W. (2009). The PedeCL $n$ in pedlatric patiente wh Spinal Muscular Atrophy. Feasbilty, relability, and valdity of the Pedatric Qualty of Lfe inventory ${ }^{m}$ Generic Core Scales and Neuromugcular Module. Nieuromuscular Disorders, 19, 805-812.

Davis, S.E., Hunan, LS., Umbers, C.A., Andersen, C.M. Greene, M.C., Varnl, J.W. s lannaccone, 8.T. (2010). The PedsCL $w$ in pedlatic pastents with Ducherne Muecular Dyetrophy. Feasblity, rellability, and valdty of the Pediatric Cualty of Le Inventory ${ }^{n}$ Neuromuscular Module and Generic Core Scalez. Joumal of Cankal Neuromuscular Disesse, 11, $97-109$. 


\section{PedsQL"}

- Oral Heath Seale steeie, MM., Steele, R.G., s Varnl, J.W. (2009). Relabily and validty of the PedeQLn Oral Health Scale: Measuring the relationahip between chlid oral health and heath-related qualty of ife. Childen's Heath Care, 35, 228-224

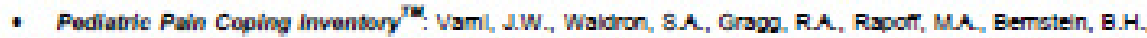
Lindzley, C.B., \& Newcomb, M.D (1996). Development of the WaldronWami Pedlaric Pain Coping Inventory. Pain, 57, 141-150.

- Pediatric Pain Questionnaire: Varnl, J.W., Thompeon, KL, a Hanson, V. (1997). The VamiThompson Pedatric Pain Questionnaire: L. Crronic muscuicekeietal pain in juvenlie rheumatold artirtis. Pah, 28, 27-38.

- Present Functioning Visual Analogue Scales: Sheman, 8.A., Elsen, 8, Burwinkie, T.M., s Vaml, J.W.

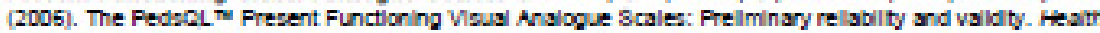
and Qualty of Lle Outcomes, 4:75, 1-10.

- Sickle Cell Disease Module: Panepinto, JA, Torres, 8., Bendo, C.B., McCavt, T., Dinu, B., Sherman-Blen, 8., Bemrich-Stok, C, a Vaml, J.W (2012). PedeOL m Sickie Cell Desese Module: Feasblity, relabilty and vald ty. Manuscript submited for publication.

Panepinto, JA, Torres, 8, a Vaml. J.W. (2012). Development of the FedeQL $n$ sickle Cell Desease Module itema: Qualtastve methoda. Qualty of Life Research, 21, 341-357.

- Rhoumafology Module: Varnl, J.W., Seid, M, Knight, T.8, Burwinile, TM, Erown, J., s. 8zer, 18. (2002) The PedeCL $=$ in pediatric reumatology. Rellablity, validity, and responelveness of the Pedlatric Qualty of Ule Inventory Ceneric Core Scales and Rheumatology Module. Arthrtis and Rheumatism, 2002; 46: 714725.

5. The author of the PedeOL $=$ requeste to be acknowledged in any communicaton including publicaton in which the questornaire ib ueed, as follows: The Qualty of Life study described in this paper was carried out using the PedeCL $=\mathbf{\alpha}$, develooed by Dr. James W. Vamr'.

7. All data, resulte and reports obtained by, or prepared in connection with, the asthorized use of the PedaQLa shall remain the "Users" property.

B. Eectronic use:

Al screera related to the PedaCLas of the above mentioned e-applicason ahal include the appropriate copyright and trademark infomaton.

Lat verzion of the screena related to the PedeoLn as it wil be preserted in the applcation ahal be reviewed and approved by Dr James W. Vaml before being given permibsion to use.

User may incorporate the PedoCL $\mathrm{n}$ questonnaires in ta above mentioned electronic asplication.

9. Confidentisity.

MAPI Research TRUST and 'Urer' acknowiedge that exch party in connection wth the terma of this agreement will obtain certain information, which is confdental andior property to the other party in the course of its use of the PedeCLI

All and any informaton related to the PedeCLa inciuding but not Imted to the following: information conceming clinical inveatigationa, creatona, syeteme, materias, sotware, data and know-how, tranalationa, Improvements ideas, specifcationa, documents, recorde, notebooks, drawings, and any repostories or representation of such information, whether oral or in writng or software stored, are herein referred to as confidentis information.

in consideraton of the declosure of any such confidertial informasion to the other, each party agrees to hold such conflidential information in confidence and not divuge it, in whoie or in part, to ary third party except for the purpose apecifled in this sgreement.

10. If, at any tme during the term of this agreement, either party hereto learns of any intingement by a third party of any intelectusl Property Rights in connection wh ary of the PedscLat, the party frat leaming of such infringement shal promptty notfy the other. MAPI Research TrusT shal have the right, but shal have no

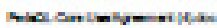




\section{PedsQL"}

obllgation, to inathute proceedings againat the Intringing party. The "Uger" shal asalat MAFI Rezearch TRUST in any such procesedings, if so requegted by MAPI Research TrusT.

In the event of tobl or partial bresch by MAPI Research TRUST of any of lts obllgationa hereunder, MAFI Research TRUST's Iabity shal be Imited to the direct loas or damspe (excluding loes of proft and operating losses) suffered by "User" as a result of such breach and shall not include any other damages and particular consequental damsges.

11. This agreement holds for the above mentoned atudy only. The use of the PedsoL $=$ in any additonal study of the "User" wil require a separate sgresment.

12. Under no circumatances may Dr. James W. Vaml or MAPI Research TrusT be held lable for direct or consequential damsge resuling from the use of the PedaCL $=$.

13. This Agreement shal be effective as the date of It signsture by USER and shall continue untl expiry of the term of the studyiproject referred to in PART 2 (CONTEXT OF PEDSQL USE) of the present Agreement. Elther party may terminate this Agreement immedlately upon providing wrtten notice to the other party in the event of (a) the other part/z unexcused falure to furll any of Its material obllgationa under this Agreement or (b) upon the insolvency or bankruptcy of, or the filing of a petion in bankruptcy or almllyr arrangement by the other party. Upon termination, User" shal cesse al use of the services of the FedsoLw. As soon as execution of this agreement. MRPI Research TRUST shal promptly provide "User" with a definitve invoice, and "User" ahall pay zuch invoice within thirty (30) days of the date of the involice. Upon expiration or termination of this Agreement MAPI Research TRUST may retain in I possession confidential Informaton it acquired from FedsCLw whlle under contract.

In the event of temination or non-renewal of this Agreement by MAPI Research TRUST for any cause or falure by MAPI Research TRUST to conclude a new sgreement wth "User" upon the exply of this Agreement, MAPI Research TRUST will have no labilty for payment of any damspes andlor indemnlty to "User".

14. MAPI Research Trust ahal not daciose, whether to the public press or otherwise, the name of "Company name', to any third party to tis agreement except to the asthor of the PedoCLa. This Agreement and any of the nghts and obllgationa of "User" are personal to the "User" and cannot be asalgned or tranaterred by "User" to any tird party or by operation of law, except wth the written consent of MAPI Research TRUST notifled to "User.

15. The entre agreement between the partes hereto is contained herein and this Agreement cancels and superzedes al prior agreementa, oral or written, between the parties hereto wth the reapect to the aubject matter hereto. This Agreement or any of lte terms may not be changed or amended except in writing and the falure by ether party hereb to enforce any or al of the provision(s) of this Agreement shal not be deemed a walver or an amendment of the asme and shall not prevent future enforcement thereof.

it any one or more of the provisiona or clauses of this Agreement are adudged by a court to be invald or unenforcesble, this ahall in no way prejudice or affect the binding nature of this Agresment as a whole, or the valdity or enforceabilty of each/and every other provision of this Agreement.

16. This Aortement is made in and shal be govemed by and interpreted in accordance with the aubetartive iswa of France, wthout regard to conflicte of lawe.

17. Ary controversy ariaing under thle Agreement ir IIjated, shal be adjulicated in the court of the competent Juriediction in Lyon, France, notwithetanding the pluraity of defendants or claim in warranty, even in the event of 


\section{PedsQL"}

emergency procedures or protective procedures, and the partes hereby submit to the exclusive jurlsdiction of such court.

18. This agreement may not be attered, amended or modfied except by written document slaned by all parties.

N WITNESS WHEREOF, the partes hereb have cayesd this agreement to be executed by their duly authorlesd representatves as of the date trst above written.

AGREED

Uaer's signature:

CompanyiOroanication stamp (lif appllosbiok:

The: Director Nurzing Regearch

CompanyiOrganlsation: st. Jude Chldren's Research

Hosplal, 252 Darny Thomas Flace, MS 738, Memphis, TN 38105-3678 USA

Date: May 22, 2013 


\section{VITA}

Tha'er Ghandi Almomani, born in 1984 in Ajloun, Jordan, earned the Doctor of Philosophy from the University of Tennessee Health Science Center in May, 2015. His dissertation research investigated longitudinal trends of health-related quality of life in children undergoing treatment for cancer.

While a doctoral student at the University of Tennessee Health Science Center, Tha'er was a research assistant at St. Jude Children's Research Hospital. Through his assistantship, Tha'er authored one peer-reviewed publication and conducted and contributed to multiple professional presentations on the topic of health-related quality of life in children under treatment for cancer. He was lead author on five poster presentations that described some of his projects at St. Jude Children's Research Hospital. He has also collected, entered, and analyzed data from several studies conducted by researchers with St. Jude Children's Research Hospital.

Tha'er earned a Bachelor of Science in Nursing in 2006, and a Master of Science in Public Health in 2008 from the University of Jordan. 